August 2001 • NREL/ TP-500-29491

\title{
Unsteady Aerodynamics Experiment Phase V: Test Configuration and Available Data Campaigns
}

\author{
M.M. Hand \\ D.A. Simms \\ L.J. Fingersh \\ D.W. Jager \\ J.R. Cotrell
}

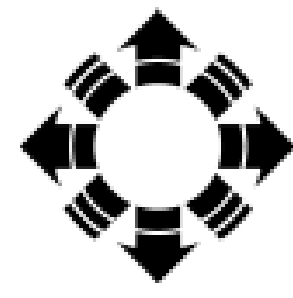

National Renewable Energy Laboratory

1617 Cole Boulevard

Golden, Colorado 80401-3393

NREL is a U.S. Department of Energy Laboratory

Operated by Midwest Research Institute $\bullet$ Battelle $\bullet$ Bechtel

Contract No. DE-AC36-99-G010337 


\title{
Unsteady Aerodynamics Experiment Phase V: Test Configuration and Available Data Campaigns
}

\author{
M.M. Hand \\ D.A. Simms \\ L.J. Fingersh \\ D.W. Jager \\ J.R. Cotrell
}

Prepared under Task No. WER1.1110

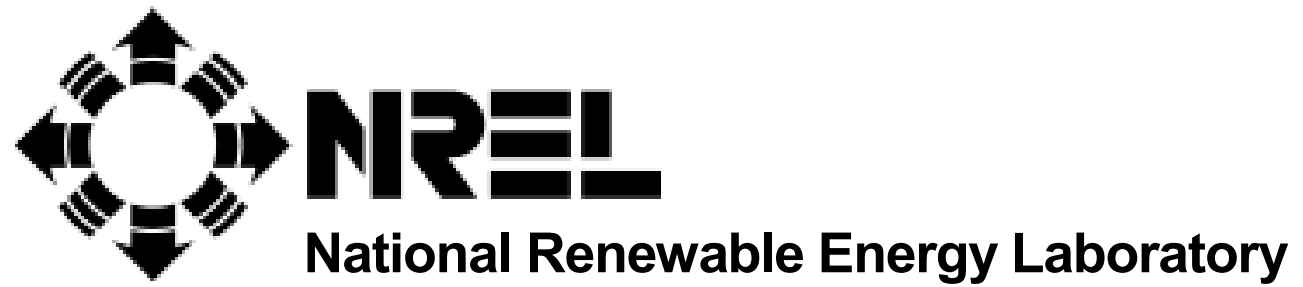

1617 Cole Boulevard

Golden, Colorado 80401-3393

NREL is a U.S. Department of Energy Laboratory

Operated by Midwest Research Institute • Battelle • Bechtel

Contract No. DE-AC36-99-G010337 


\section{NOTICE}

This report was prepared as an account of work sponsored by an agency of the United States government. Neither the United States government nor any agency thereof, nor any of their employees, makes any warranty, express or implied, or assumes any legal liability or responsibility for the accuracy, completeness, or usefulness of any information, apparatus, product, or process disclosed, or represents that its use would not infringe privately owned rights. Reference herein to any specific commercial product, process, or service by trade name, trademark, manufacturer, or otherwise does not necessarily constitute or imply its endorsement, recommendation, or favoring by the United States government or any agency thereof. The views and opinions of authors expressed herein do not necessarily state or reflect those of the United States government or any agency thereof.

Available electronically at http://www.doe.gov/bridge

Available for a processing fee to U.S. Department of Energy

and its contractors, in paper, from:

U.S. Department of Energy

Office of Scientific and Technical Information

P.O. Box 62

Oak Ridge, TN 37831-0062

phone: 865.576.8401

fax: 865.576.5728

email: reports@adonis.osti.gov

Available for sale to the public, in paper, from:

U.S. Department of Commerce

National Technical Information Service

5285 Port Royal Road

Springfield, VA 22161

phone: 800.553.6847

fax: 703.605.6900

email: orders@ntis.fedworld.gov

online ordering: http://www.ntis.gov/ordering.htm

Printed on paper containing at least $50 \%$ wastepaper, including $20 \%$ postconsumer waste 


\section{Table of Contents}

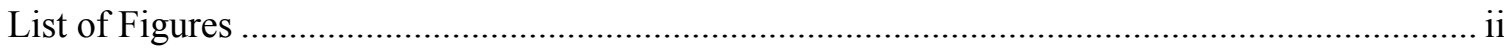

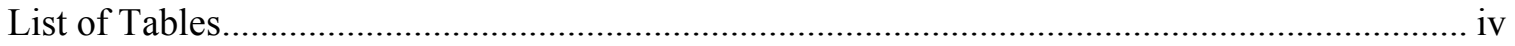

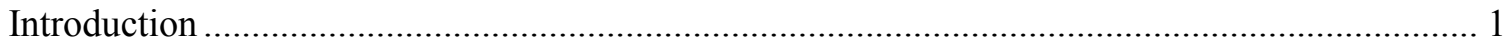

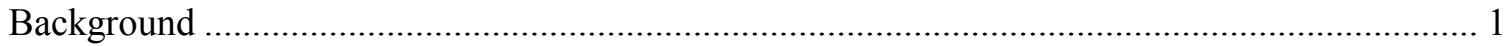

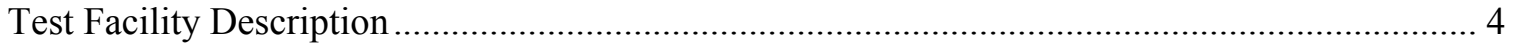

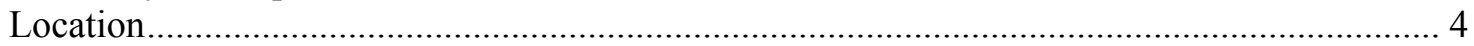

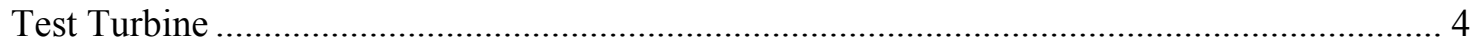

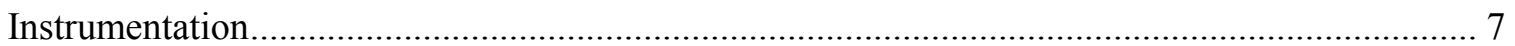

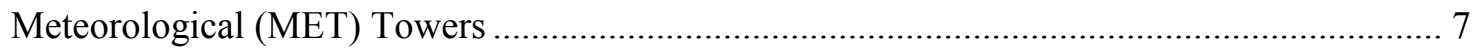

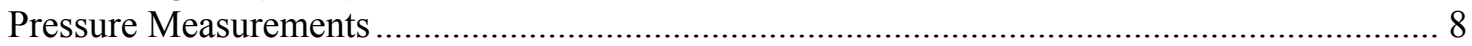

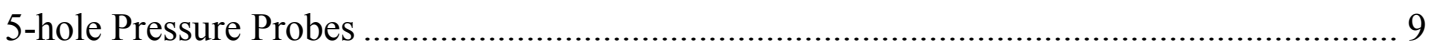

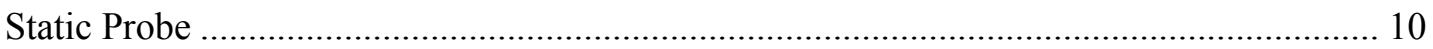

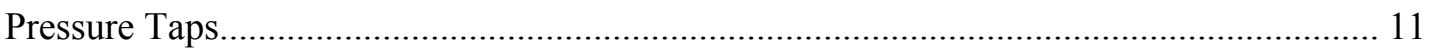

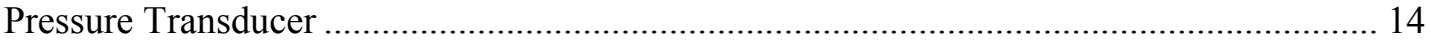

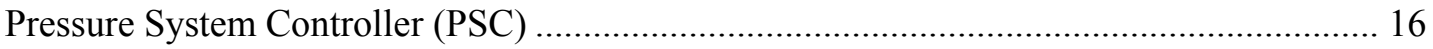

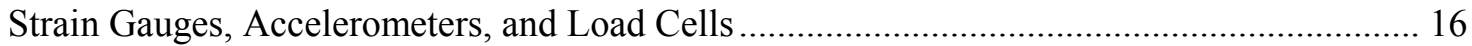

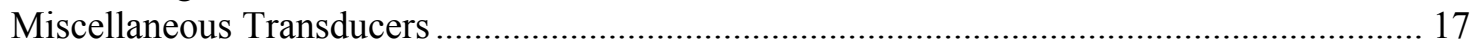

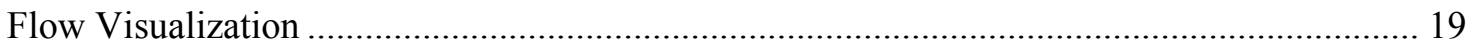

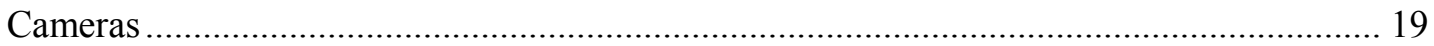

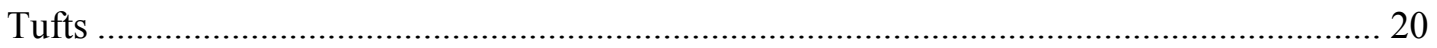

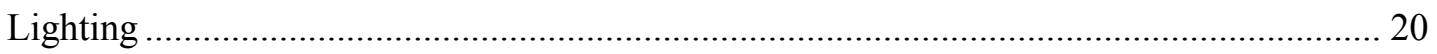

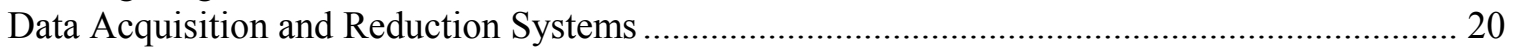

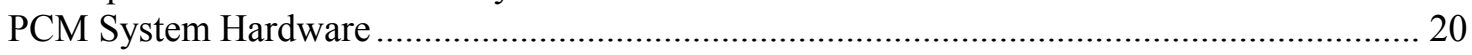

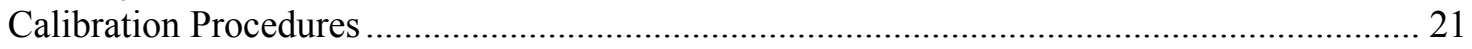

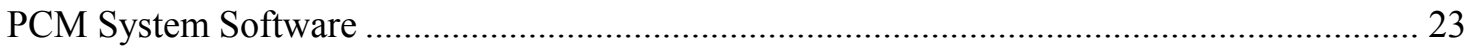

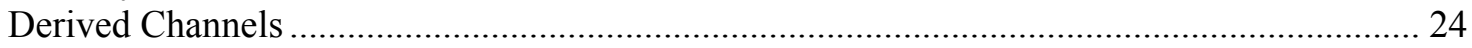

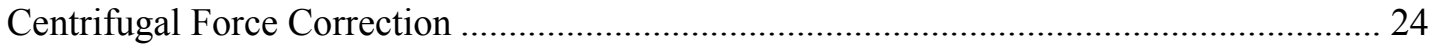

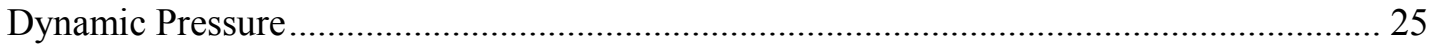

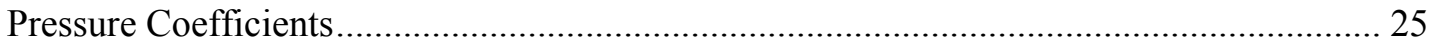

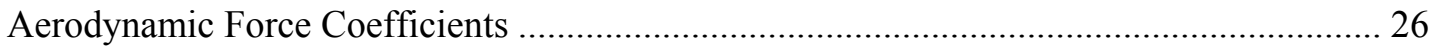

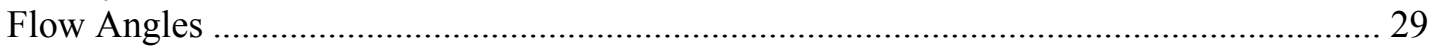

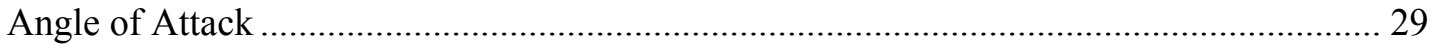

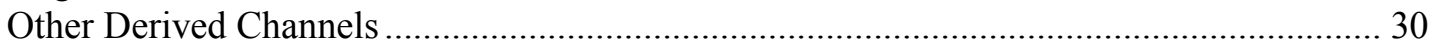

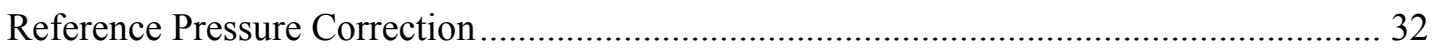

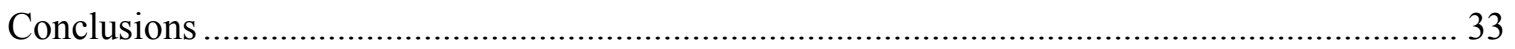

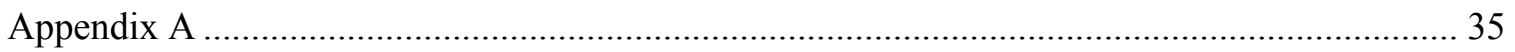

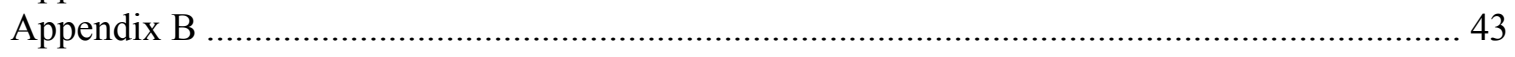

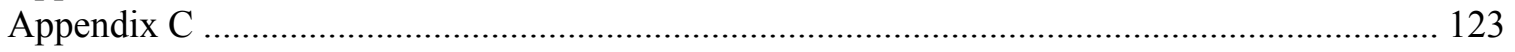

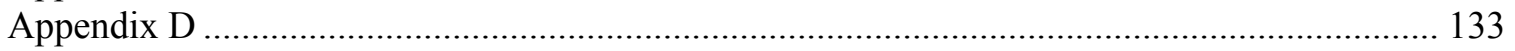

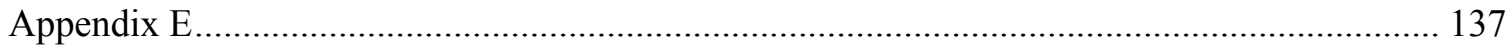

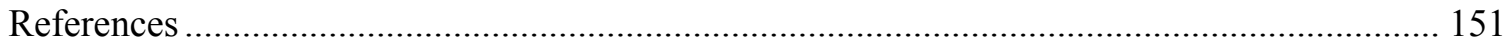

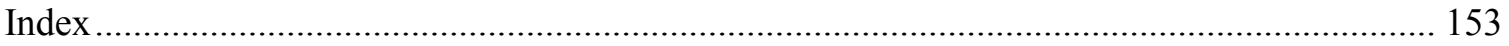




\section{List of Figures}

Figure 1. Phase V test configuration .................................................................................. 4

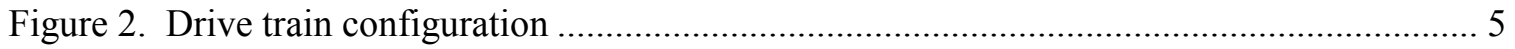

Figure 3. Twisted-blade planform .................................................................................... 6

Figure 4. Blade twist distribution at the pitch setting used most frequently during experiment

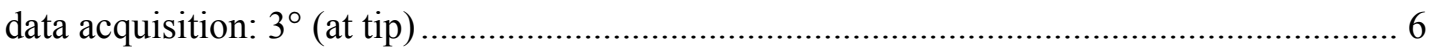

Figure 5. Phase $\mathrm{V}$ meteorological instrumentation. Elevation view looking downwind toward

$112^{\circ}$. Meteorological instruments are $1.5 \mathrm{D}(15 \mathrm{~m})$ upwind of the turbine tower................. 7

Figure 6. Blade-mounted 5-hole probe.......................................................................... 9

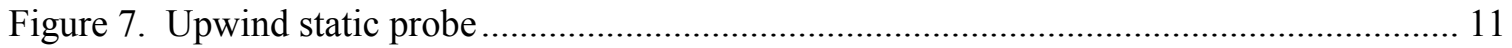

Figure 8. Pressure instrumentation................................................................................ 12

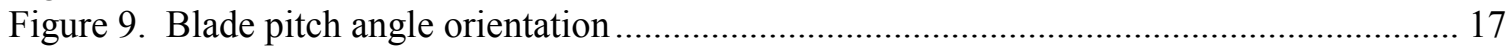

Figure 10. Blade azimuth angle convention............................................... 18

Figure 11. Yaw angle convention.................................................................................... 18

Figure 12. Blade flap angle convention ........................................................................... 19

Figure 13. Aerodynamic force coefficient conventions ......................................................... 28

Figure 14. Local flow angle flag assembly ................................................................... 30

Figure 15. Yaw error angle convention.............................................................................. 31

Figure 16. Blade root surface depiction (dimensions in meters) ……………………………..... 38

Figure 17. Hub-mounted instrumentation boxes, boom, and camera............................................ 40

Figure 18. Cup anemometer wiring diagram..................................................................... 46

Figure 19. Bi-vane anemometor wiring diagram.............................................................. 52

Figure 20. Sonic anemometer wiring diagram ………………………………………………. 55

Figure 21. Temperature, delta temperature, and dew-point wiring diagram................................ 60

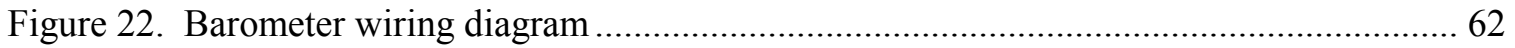

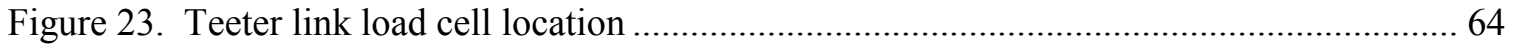

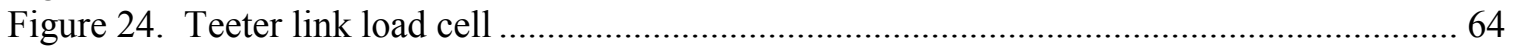

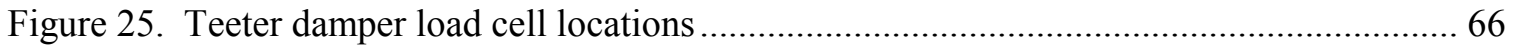

Figure 26. Teeter damper load cell cross-sectional view............................................................. 66

Figure 27. Hub-shaft strain gauge orientation..................................................................... 70

Figure 28. Planview of hub shaft strain gauges ………………………………………..... 70

Figure 29. Root-bending gauges, side view .................................................................... 71

Figure 30. Root-bending strain gauge configuration.......................................................... 72

Figure 31. Low-speed shaft strain gauge positions .............................................................. 74

Figure 32. Low-speed shaft strain gauge configuration ............................................................ 74

Figure 33. Low-speed shaft strain gauge location within nacelle ……………………………..... 75

Figure 34. Yaw moment strain gauge configuration ............................................................. 76

Figure 35. Nacelle accelerometer configuration ................................................................... 78

Figure 36. Blade tip accelerometer configuration............................................................... 79

Figure 37. Blade pitch angle orientation ……………………….................................... 82

Figure 38. Azimuth angle encoder photograph and orientation.............................................. 83

Figure 39. Yaw angle encoder photograph and orientation ………………………………..... 83

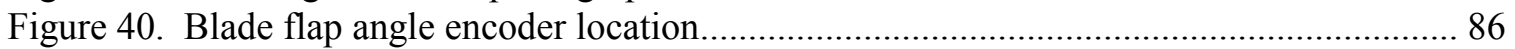

Figure 41. Blade flap angle close-up view......................................................................... 86

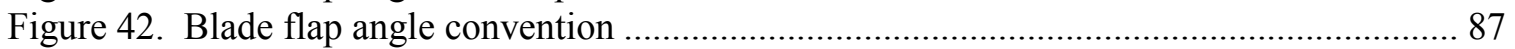

Figure 43. Pneumatic layout for spring 1998 data collection. ..................................................... 92

Figure 44. Pneumatic layout for fall 1998 data collection....................................................... 93

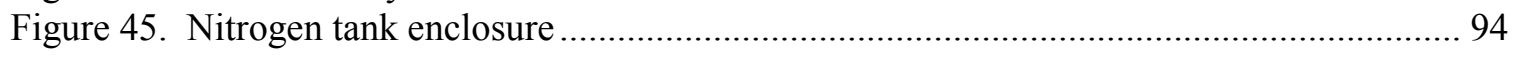




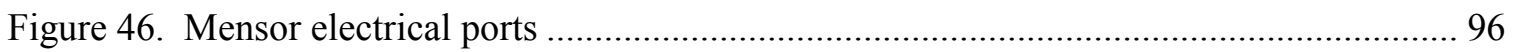

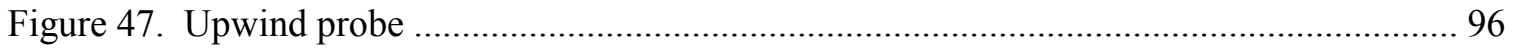

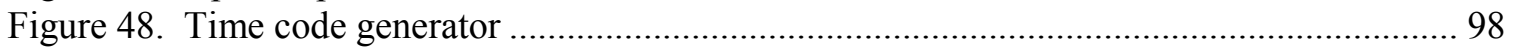

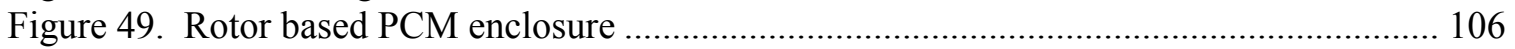

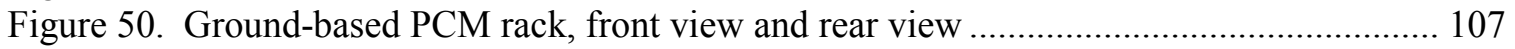

Figure 51. Signal path from PCM streams to useable data ........................................................ 109

Figure 52. Production of calibration and header files (calibration procedures are summarized on

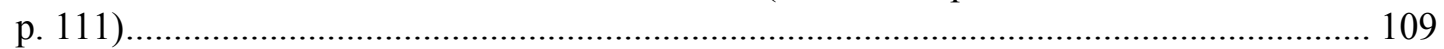

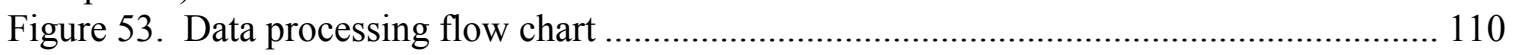

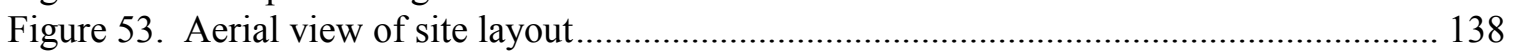

Figure 54. Plan view of site showing location of meteorological instruments relative to turbine

Figure 55. Rotor instrumentation block diagram

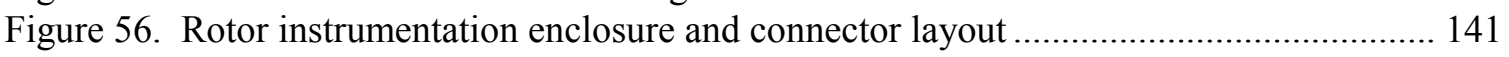

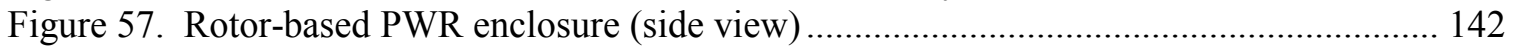

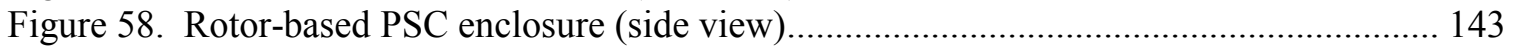

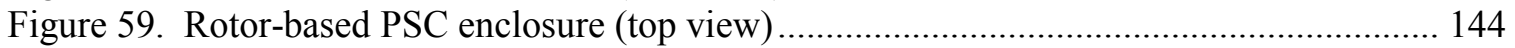

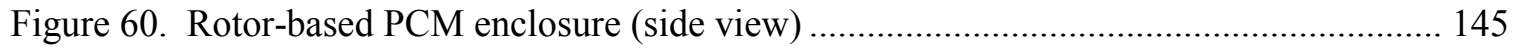

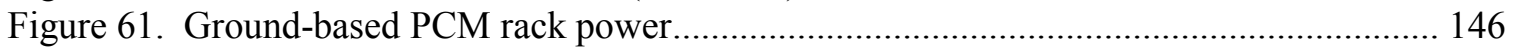

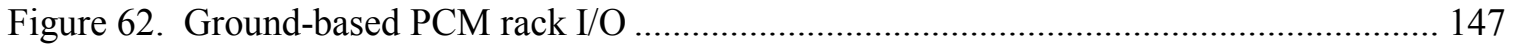

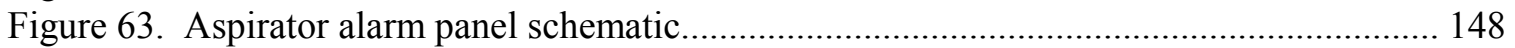

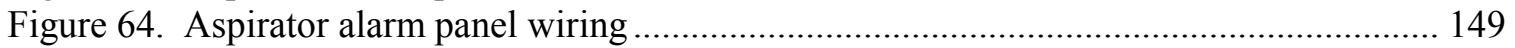

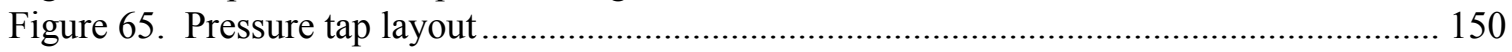




\section{List of Tables}

Table 1. Unsteady Aerodynamics Experiment Configuration Differences................................... 3

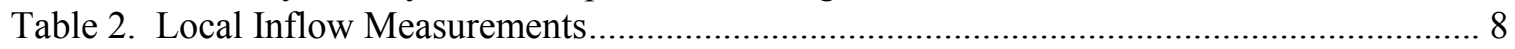

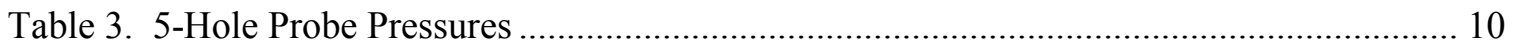

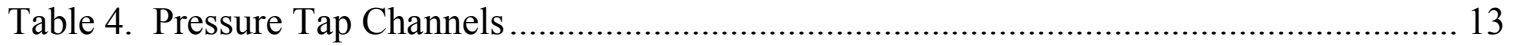

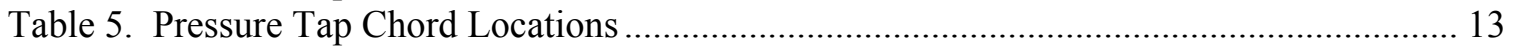

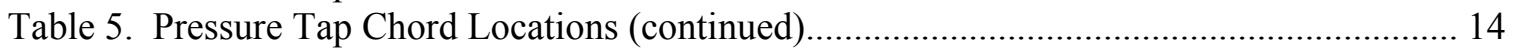

Table 6. Nominal, Full-scale, Pressure Transducer Measurement Ranges................................... 14

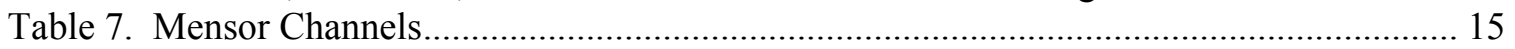

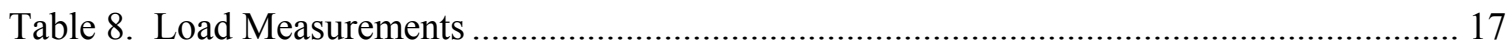

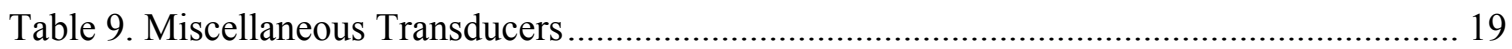

Table 10. Phase II PCM Decoder Board Specifications ........................................................... 21

Table 11. Uncertainty Analysis Results for Selected Phase II Measured Channels ................... 23

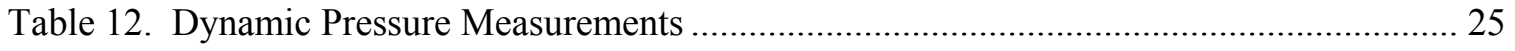

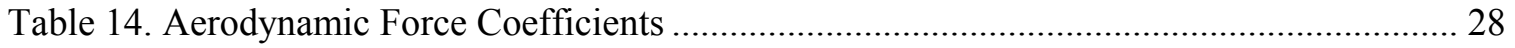

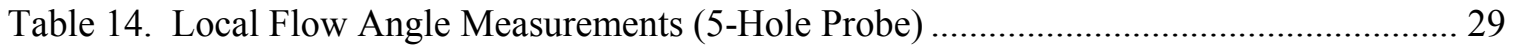

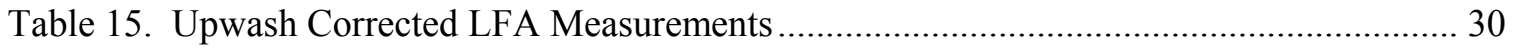

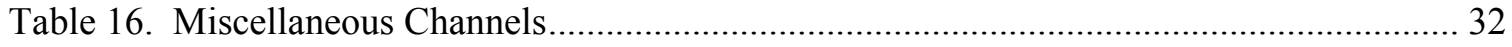

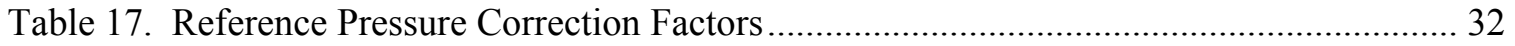

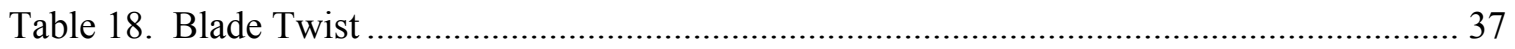

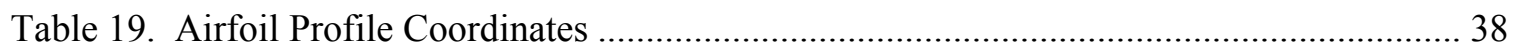

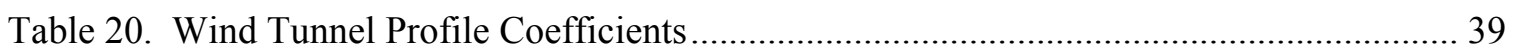

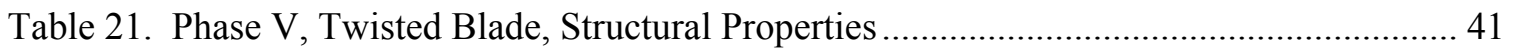

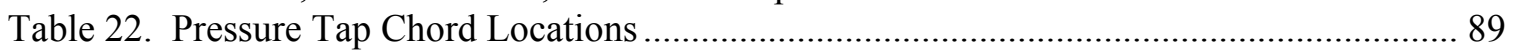

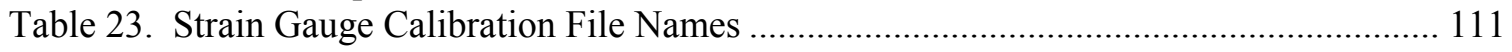

Table 24. Electronic Path Calibration File Names and Voltage Ranges .................................. 112

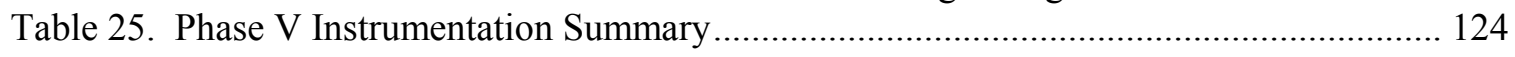

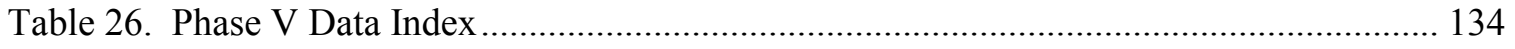




\section{Introduction}

The main objective of the Unsteady Aerodynamics Experiment is to provide information needed to quantify the full-scale, three-dimensional, unsteady aerodynamic behavior of horizontal-axis wind turbines (HAWTs). To accomplish this, an experimental wind turbine configured to meet specific research objectives was assembled and operated at the National Renewable Energy Laboratory (NREL). The turbine was instrumented to characterize rotating-blade aerodynamic performance, machine structural responses, and atmospheric inflow conditions. Comprehensive tests were conducted with the turbine operating in an outdoor field environment under diverse conditions. Resulting data are used to validate aerodynamic and structural dynamics models, which are an important part of wind turbine design and engineering codes. Improvements in these models are needed to better characterize aerodynamic response in both the steady-state post-stall and dynamic- stall regimes.

Much of the effort in the first phase of the Unsteady Aerodynamics Experiment focused on developing required data acquisition systems. Complex instrumentation and equipment was needed to meet stringent data requirements while operating under the harsh environmental conditions of a wind turbine rotor. Once the data systems were developed, subsequent phases of experiments were then conducted to collect data for use in answering specific research questions. A description of the experiment configuration used during Phase V of the experiment is contained in this report.

\section{Background}

Test results from previous phases of the Unsteady Aerodynamics Experiment have shown that wind turbines undergo complex aerodynamic reactions when operating in typical atmospheric conditions. All wind turbine design codes are based on aerodynamic forces derived from steady two-dimensional (2-D) wind tunnel airfoil test results. Blade designs are developed assuming steady loading optimization principles. Although these design codes produce accurate predictions on average, instantaneous loads and peak power predictions are often incorrect. For HAWTs, these principles are accurate for low to moderate wind speeds, provided that the inflow remains constant. In reality, the inflow conditions exhibit an extremely complex and dynamic nature. Factors such as atmospheric turbulence, shear across the rotor plane, yawed operation, and blade passage through the tower wake all contribute to constantly changing aerodynamic forces that do not obey steady principles. Resulting unsteady aerodynamic forces can be significantly greater than steady forces. These increased fluctuating forces lead to greater dynamic turbine structural responses and high fatigue stresses. With the trend toward lightweight flexible turbines, unsteady aerodynamic loading has become an even more important consideration in predicting dynamic turbine responses.

In order to bridge this gap between the three-dimensional (3-D), unsteady operating environment and the 2-D, steady design environment, NREL implemented the Unsteady Aerodynamics Experiment measurement program designed to obtain experimental data from the 3-D field environment. Measurements needed to quantify the 3-D effects of field operation include meteorological data, loads, local flow angles, and blade surface pressures. Meteorological instrumentation was configured to obtain wind speed, wind direction, and atmospheric stability measurements upwind of the turbine. Loads, such as power production, teeter impact, low-speed shaft bending and torque, blade root bending, and tower motion, were obtained using various 
power transducers, load cells, accelerometers, and strain gauges. Two devices have been used to obtain local flow characteristics in front of one of the two blades. A flag assembly measured local flow angles during the earlier phases of the experiment, and 5-hole differential pressure probes were implemented in the latter phases of the experiment to improve the dynamic response of the local flow angle measurement. Lastly, blade surface pressures were first measured at one blade span location, but the measurements were extended to five span locations as the experiment progressed. In addition to various measurement capabilities, two blade designs were tested. A constant-chord zero-twist blade set was used in Phase I and Phase II tests. A constantchord, optimally twisted blade set was used in Phases III and IV. Future tests are planned for a tapered and twisted blade set. The turbine configuration originally consisted of a three-bladed, rigid hub. The current phase, Phase $\mathrm{V}$, introduced a two-bladed, teetered-hub configuration using the constant-chord, optimally twisted blades.

The Unsteady Aerodynamics Experiment was begun in 1987 (it was initially called the "Combined Experiment") and has been implemented in five phases to date. Phase I planning began in 1987 and produced valuable knowledge and experience with these types of measurements (Butterfield, Musial, and Simms 1992). The instrumentation configuration that resulted in Phase I was used to obtain the Phase II data in the spring of 1989. Untwisted blades were used again in Phase II, and the pressure instrumentation was expanded from one to four span locations. Optimally twisted blades were designed for Phase III of the project, which began in 1993 and resulted in data sets in early 1995. The fourth phase, initiated in late 1995, also used the twisted blades; the flow angle measurements, however, were improved. The instrumentation differences between the Phase II, Phase III, and Phase IV configurations were described by Simms et al. (1999). This report contains information regarding Phase V, which was conducted during 1998. However, the major differences between the various phases of data collection are summarized in Table 1.

This report provides the reader with information related to Phase V data collection. For information regarding Phases II-IV, the reader is referred to Butterfield, Musial, and Simms (1992) and Simms et al. (1999). The tables in the body of this report that describe the channels collected by the data system are based upon the header files that accompany each data campaign. Appendix A provides details of the turbine configuration that could be used to develop models. Detailed descriptions and figures of each component of instrumentation are included in Appendix B. Flow charts illustrate the complete signal path from the measurement source to the resulting data file. Calibration procedures are presented for each instrument. Data processing procedures and the associated input files are described in Appendix B as well. Appendix C contains manufacturer specifications for the instrumentation components summarized in one table. General atmospheric and turbine conditions, instrumentation failures, and observations made during data collection are summarized in Appendix D. 
Table 1. Unsteady Aerodynamics Experiment Configuration Differences

\begin{tabular}{|c|c|c|c|c|}
\hline & Phase II & Phase III & Phase IV & Phase V \\
\hline Dates for data collection & $4 / 25 / 89-7 / 25 / 92$ & $4 / 7 / 95-6 / 6 / 95$ & $\begin{array}{l}4 / 3 / 96-5 / 18 / 96 \text { and } \\
4 / 29 / 97-5 / 7 / 97\end{array}$ & $\begin{array}{l}\text { 6/11/98-6/18/98 and } \\
10 / 28 / 98-11 / 18 / 98\end{array}$ \\
\hline Blades / hub & Untwisted / rigid & Twisted / rigid & Twisted / rigid & Twisted / teeter \\
\hline Number of blades & s. & 3 & 3 & 2 \\
\hline Local flow angle (LFA) measurement device & Flag & $\begin{array}{l}\text { Flag, 5-Hole Probe } \\
\text { (test) }\end{array}$ & 5-Hole Probe & 5-Hole Probe \\
\hline Span locations instrumented with LFA sensors & 4 & 5 & 5 & 5 \\
\hline Span locations instrumented with full-chord pressure taps & 4 & 5 & 5 & 5 \\
\hline Span locations instrumented with pairs of pressure taps & 6 & 10 & 10 & 10 \\
\hline Azimuth angle measurements and rotor speed calculation & Poor & Good & Good & Good \\
\hline Meteorological instrumentation & $\begin{array}{l}\text { Vertical Plane } \\
\text { Array }\end{array}$ & $\begin{array}{l}\text { Horizontal and } \\
\text { Vertical Shear } \\
\end{array}$ & $\begin{array}{l}\text { Horizontal and } \\
\text { Vertical Shear } \\
\end{array}$ & $\begin{array}{l}\text { Horizontal and } \\
\text { Vertical Shear }\end{array}$ \\
\hline Blade strain gauges / blade root strain gauges & Yes / yes & Yes / yes & No / yes & No / yes \\
\hline Blade tip and nacelle accelerometers & No & Yes & Yes & Yes \\
\hline Selections of data during which yaw brake engaged & Yes & No & Yes & Yes \\
\hline Campaign duration & 5 minutes & 10 minutes & 10 minutes & 10 minutes \\
\hline $\begin{array}{l}\text { Boom extension and camera mounted on hub; tufts on } \\
\text { suction side of instrumented blade }\end{array}$ & Yes & No & Yes & Yes \\
\hline Video & Yes & No & Yes & Yes \\
\hline Pitch angles (blade tip) & $12^{\circ}$ & $3^{\circ},-3^{\circ}, 8^{\circ}$ & $3^{\circ},-3^{\circ}, 8^{\circ}, 12^{\circ},-9^{\circ}$ & $3^{\circ},-3^{\circ}, 8^{\circ}, 12^{\circ},-9^{\circ}$ \\
\hline $\begin{array}{l}\text { File naming conventions: } \\
\text { - parked\#, d4pb\#\#, and d5pb\#\#\#: Rotor brake engaged } \\
\text { with instrumented blade at either } 0^{\circ} \text { or } 180^{\circ} \text { azimuth } \\
\text { - } \quad \text { slwrot\# and d4sr\#\#: Blades feathered with rotor } \\
\text { slowly rotating } \\
\text { - d5y3\#\#\#: yaw brake engaged throughout campaign, } \\
\text { pitch angle of } 3^{\circ} \\
\text { d4pp\#\#, and d5pp\#\#: 'pp' indicates pitch angle, 'm' } \\
\text { indicates negative value } \\
\text { - \# indicates numerical order in which data collected }\end{array}$ & $\begin{array}{l}\text { d6511, d6512, } \\
\text { d6521, d6522, } \\
\text { d6611,..,d7521, } \\
\text { d7522 }\end{array}$ & $\begin{array}{l}\text { data1-data19 } \\
\text { parked1, parked2, } \\
\text { slwrot1, slwrot2 } \\
\\
\text { (parked1 and } \\
\text { parked2 are } 60 \\
\text { second duration) }\end{array}$ & $\begin{array}{l}\text { data20-data112, } \\
\text { slwrot4, slwrot5 } \\
\text { d403001-d403039, } \\
\text { d408001-d408012, } \\
\text { d4m3001-d4m3012, } \\
\text { d4pb001-d4pb009, } \\
\text { d4sr001, d412001, } \\
\text { d4m9001 }\end{array}$ & $\begin{array}{l}\text { d503003-d503014, } \\
\text { d503017-d503040, } \\
\text { d5m3001-d5m3004, } \\
\text { d5m3008-d5m3014, } \\
\text { d508007-d508012, } \\
\text { d512001, } \\
\text { d5m9001-d5m9006, } \\
\text { d5y3001-d5y3002, } \\
\text { d5pb012-d5pb022 }\end{array}$ \\
\hline Number of campaigns & 58 & 23 & 170 & 73 \\
\hline
\end{tabular}




\section{Test Facility Description}

\section{Location}

All atmospheric testing was conducted at NREL's National Wind Technology Center (NWTC), which is located 10 miles north of Golden, Colorado. Winter winds are dominant at this site from a prevailing direction of $292^{\circ}$ from true north. Although the local terrain is flat with grassy vegetation extending over 0.8 kilometers $(\mathrm{km})$ upwind, the site is situated about $5 \mathrm{~km}$ from the base of the Rocky Mountains, which are located directly upwind. The wind turbine site was unobstructed by other wind turbines or structures.

\section{Test Turbine}

The Phase V Unsteady Aerodynamics Experiment test turbine is a modified Grumman Wind Stream 33 shown in Figure 1. It is a 10-m-diameter, two-bladed, downwind, free-yaw turbine equipped with full-span pitch capability that can be manually controlled during the testing to provide fixed-pitch (stall-controlled) operation at any pitch angle desired. The turbine is supported on a guyed-pole tower ( $0.4064 \mathrm{~m}$ in diameter) that is equipped with a hinged base and gin pole to allow it to be tilted down easily. An electric winch is used to lower and raise the system during installation. A manually operated yaw brake was added to allow fixed-yaw operation at arbitrary yaw positions. This yaw-retention system has a strain-gauged link that measured yaw moments when the yaw brake was applied. A mechanical caliper rotor brake system was operated manually from the control shed. This feature also was used to obtain data with the instrumented blade parked at the top of the rotational cycle $\left(0^{\circ}\right)$. A complete listing of turbine specifications may be found in Appendix A.

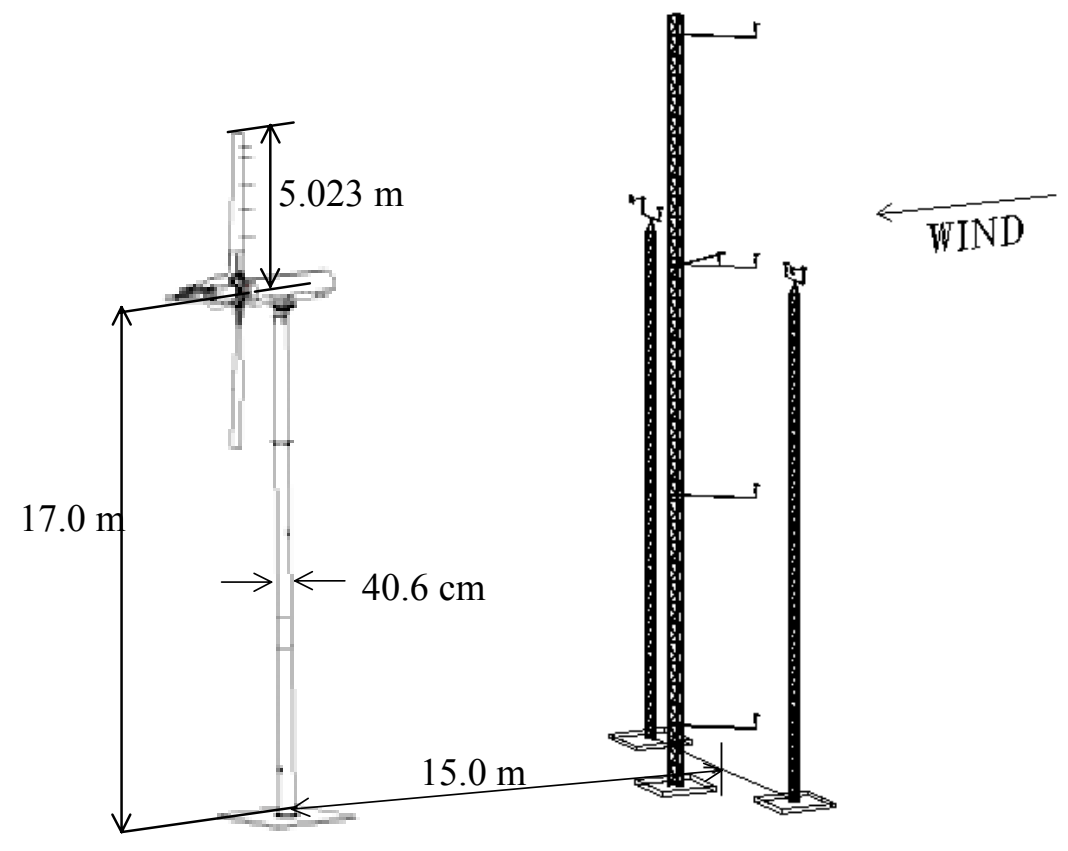

Figure 1. Phase $\mathrm{V}$ test configuration 
The drive train, pictured in Figure 2, is similar to the original Grumman configuration. The rotor operates at a nominal 72 RPM. Low-speed shaft torque is transferred through a 25.1:1 gearbox ratio to the high-speed shaft which is connected to the 20-kilowatt $(\mathrm{kW})$ induction generator. The drive train (low-speed shaft, gearbox, and high-speed shaft) inertia was determined during Phase IV testing using startup and pendulum tests. An estimate of drive train stiffness was also obtained from this test. Data collected during operation of the instrumented turbine provided measurements of the generator slip and total efficiency of the drive train. The machine description in Appendix A lists all of these results.

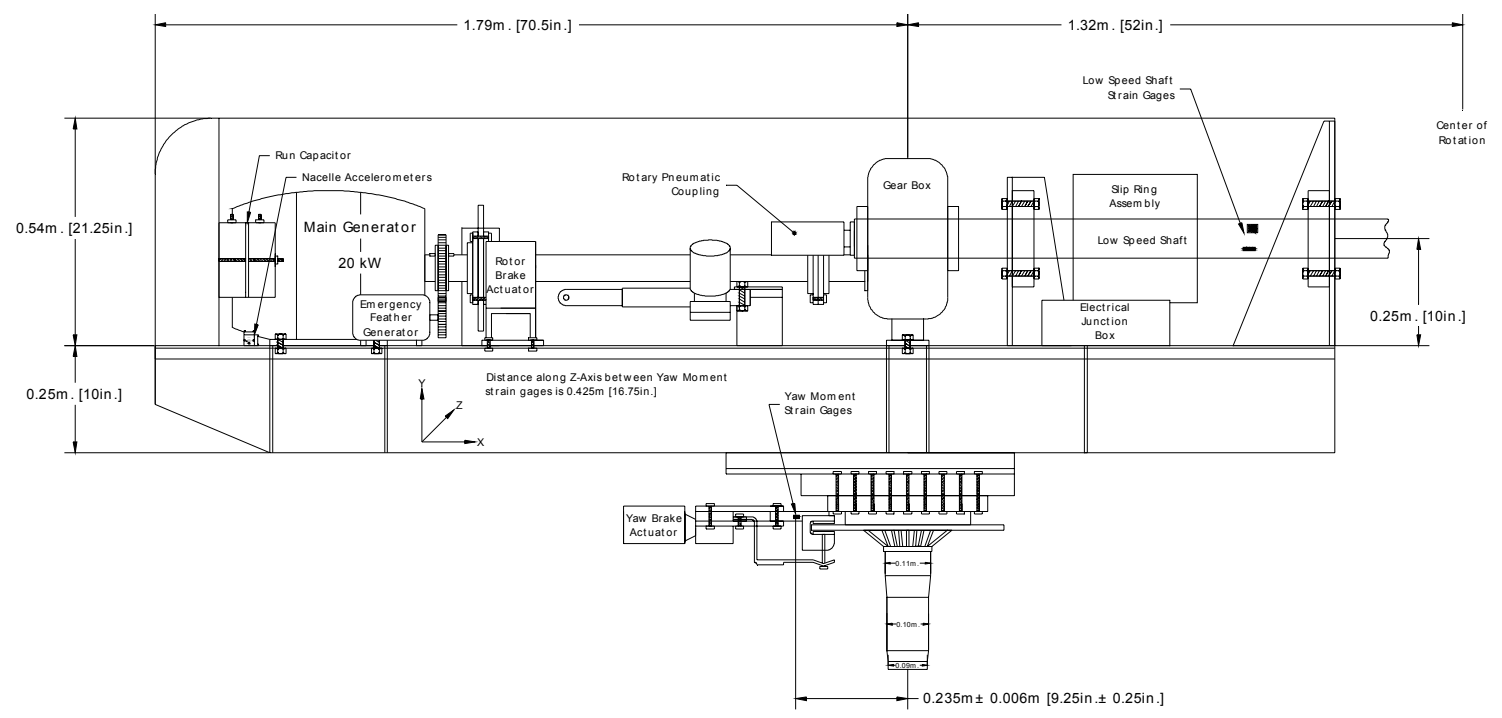

Figure 2. Drive train configuration

The two-bladed, teetered hub was designed specifically for this application (Cotrell 1999).

During Phase V, the teeter configuration was maintained, but the hub was designed to be rigid or permit independent blade flap motion. A rigid link between the blades was instrumented with a load cell, and load cells were placed inside the teeter guides to record teeter impact forces. The collective blade pitch system from the original turbine was replaced with servo motors on each blade. The blades can pitch independently or collectively, and the servo motors hold the blades at the specified pitch angle within $\pm 0.1^{\circ}$. Blade pitch control is achieved through software running on a computer in the data shed. Although the turbine has only two blades, the instrumented blade name from previous phases, Blade 3, was maintained for this test.

Another significant configuration change to the original Grumman turbine was the blade design. The NREL S809 airfoil replaced the original Grumman airfoil. The S809 airfoil was developed by Airfoils, Inc., under contract to NREL (Somers 1997). It was optimized to improve wind energy power production and is insensitive to leading-edge roughness. The S809 airfoil has a well-documented wind tunnel database that includes pressure distributions, separation boundary locations, drag data, and flow-visualization data (Somers 1997, Butterfield, Musial, and Simms 1992).

The twisted blades had a constant $0.457-\mathrm{m}$ chord; a planform view of the blades is shown in Figure 3. The intent in the design of the twisted blades was to maintain a constant angle of attack along the span of the blade at a wind speed of $8 \mathrm{~m} / \mathrm{s}$ (Simms, Fingersh, and Butterfield 
1995). The twist distribution is listed in Appendix A and shown in Figure 4. The spar enlargement at the root of the blade extends to $25 \%$ span. The blades were fiberglass/epoxy composite, and the spar in the twisted blades was carbon fiber. The blades were designed to be stiff to mitigate aeroelastic blade responses. The dynamic characteristics of the blades were tailored to avoid coalescence of rotor harmonics with flap-wise, edge-wise, and torsional natural frequencies. To minimize the possibility of aeroelastic instabilities, the mass and elastic axes were aligned with the aerodynamic axis. The instrumented blade was painted black to contrast with the white tufts that were used for flow visualization. The pitch shaft on which the blades are mounted is less stiff than the inboard sections of the blade, and most of the flap deflection occurs in this region. For this reason, the pitch shaft must be included in a blade or hub model and is included with the estimated blade mass and stiffness distributions in Appendix A.

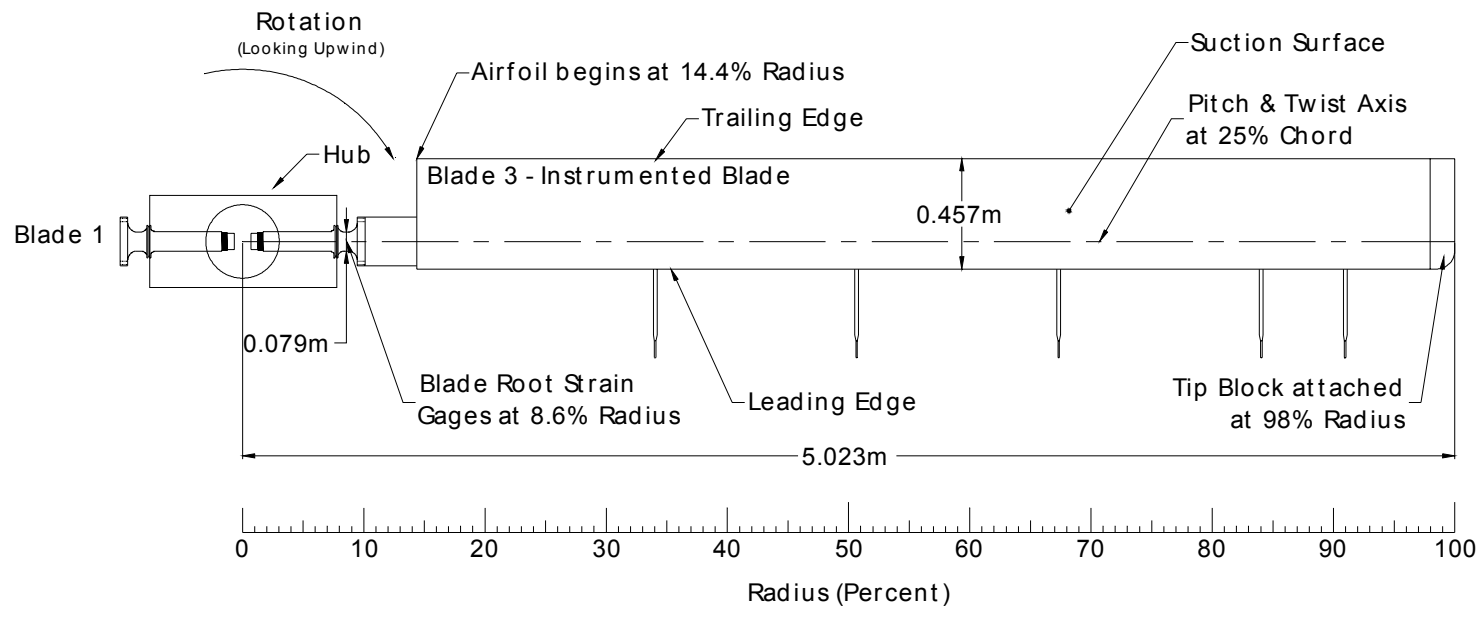

Figure 3. Twisted-blade planform

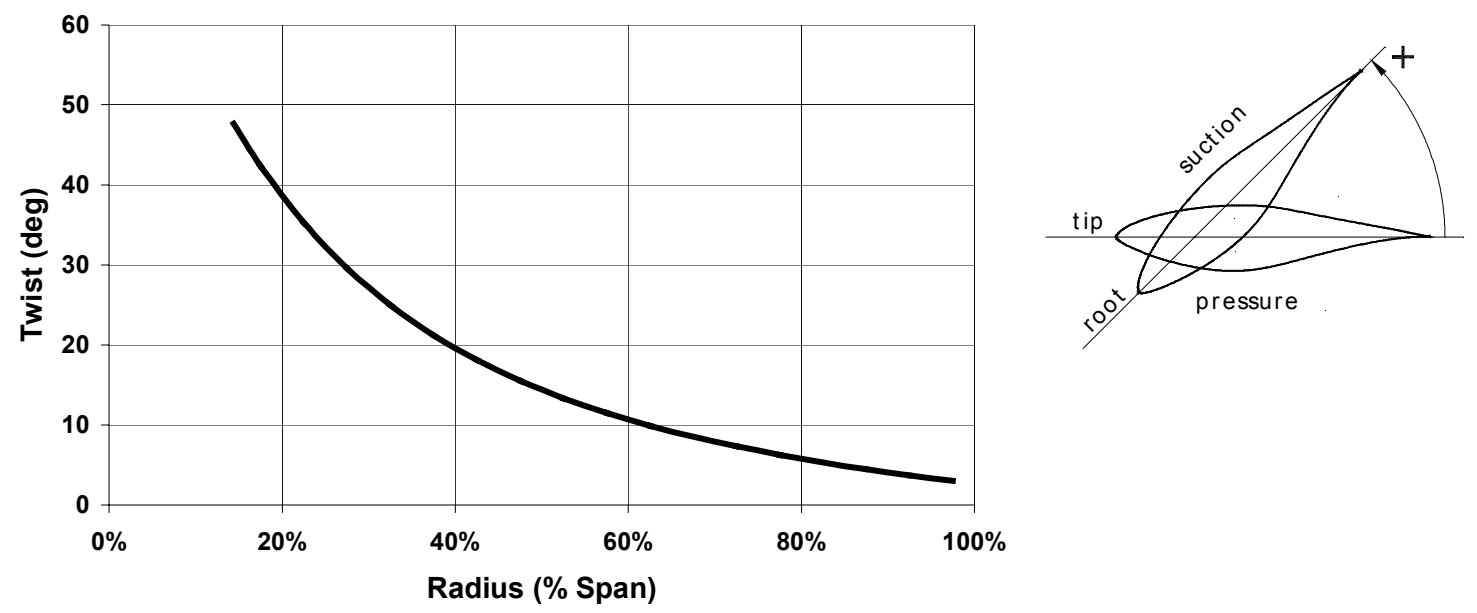

Figure 4. Blade twist distribution at the pitch setting used most frequently during experiment data acquisition: $3^{\circ}$ (at tip) 


\section{Instrumentation}

\section{Meteorological (MET) Towers}

Inflow conditions such as shear and stability were measured directly upwind of the turbine.

Three MET towers placed 1.5 D (15 m) upwind of the turbine supported multiple cup anemometers, bi-vane anemometers, and one sonic anemometer. Temperature and barometric pressure measurements were also made. Figure 5 shows the three, instrumented, MET towers. Phase V meteorological channel descriptions are shown in Table 2, and detailed instrumentation and wiring information is presented in Appendix B.

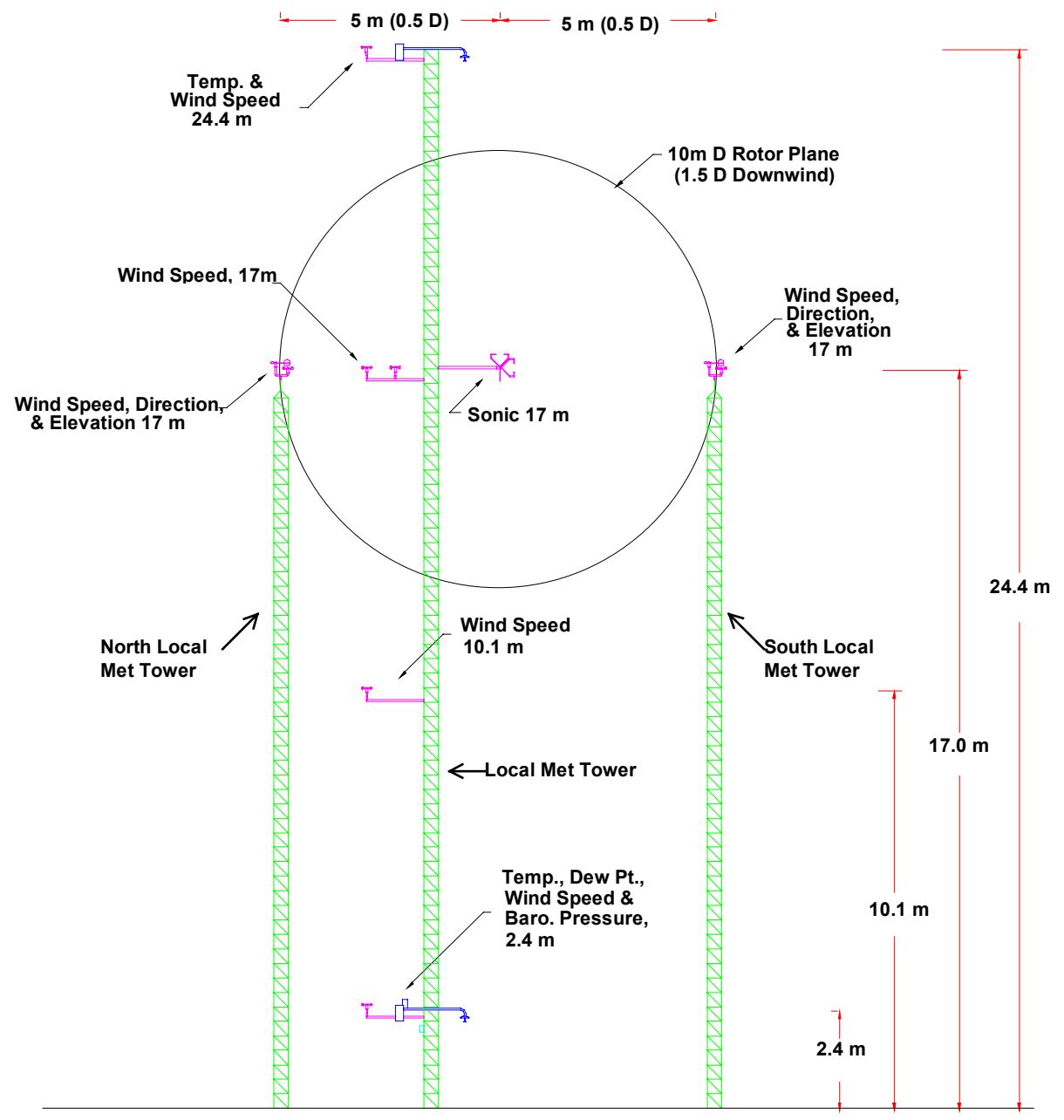

Figure 5. Phase $\mathbf{V}$ meteorological instrumentation. Elevation view looking downwind toward $112^{\circ}$. Meteorological instruments are 1.5 D $(15 \mathrm{~m})$ upwind of the turbine tower. 
Table 2. Local Inflow Measurements

\begin{tabular}{|c|c|l|c|}
\hline Channel & Channel ID & Description & Units \\
\hline 300 & LMWS24M & Local Met Wind Speed 24.38 m & $\mathrm{m} / \mathrm{s}$ \\
\hline 302 & LMWS17M & Local Met Wind Speed 17.02 m (hub height) & $\mathrm{m} / \mathrm{s}$ \\
\hline 304 & LMWS10M & Local Met Wind Speed 10.06 m & $\mathrm{m} / \mathrm{s}$ \\
\hline 306 & LMWS2M & Local Met Wind Speed 2.4 m & $\mathrm{m} / \mathrm{s}$ \\
\hline 308 & NLMWS17M & N local Met Wind Speed 17.02 m (hub height) & $\mathrm{m} / \mathrm{s}$ \\
\hline 310 & NLMWD17M & N local Met Wind Direction 17.02 m (hub height) & $\mathrm{deg}$ \\
\hline 312 & NLMWE17M & N local Met Wind Elevation $17.02 \mathrm{~m}$ (hub height) & $\mathrm{deg}$ \\
\hline 314 & SLMWS17M & S local Met Wind Speed 17.02 m (hub height) & $\mathrm{m} / \mathrm{s}$ \\
\hline 316 & SLMWD17M & S local Met Wind Direction 17.02 m (hub height) & $\mathrm{deg}$ \\
\hline 318 & SLMWE17M & S local Met Wind Elevation $17.02 \mathrm{~m}$ (hub height) & $\mathrm{deg}$ \\
\hline 320 & LMT2M & Local Met Temperature 2.4 m & $\mathrm{degC}$ \\
\hline 322 & LMDT & Local Met Delta Temperature & $\mathrm{degC}$ \\
\hline 324 & LMDP2M & Local Met Dewpoint 2.4m & $\mathrm{degC}$ \\
\hline 326 & LMSU17M & Local Met Sonic Channel U 17.02 m & $\mathrm{m} / \mathrm{s}$ \\
\hline 328 & LMSV17M & Local Met Sonic Channel V 17.02 m & $\mathrm{m} / \mathrm{s}$ \\
\hline 330 & LMSW17M & Local Met Sonic Channel W $17.02 \mathrm{~m}$ & $\mathrm{~m} / \mathrm{s}$ \\
\hline 334 & BARO & Barometric Pressure & Pascal \\
\hline
\end{tabular}

\section{Pressure Measurements}

A variety of pressure measurements yield aerodynamic information. The turbine had one blade (Blade 3) instrumented with pressure taps and 5-hole probes to measure the blade surface pressures and impinging flow angles. The pressure transducers within the blade were all referenced to the pressure inside one of the rotating instrumentation boxes. A digital differential pressure transducer was used to measure the difference between the pressure in this instrumentation box and the static pressure port of a probe upwind of the turbine. In previous phases of the experiment, it was assumed that the pressure inside the rotating instrumentation box was free-stream static pressure. This would permit direct measurement of dynamic pressures. Comparison of the free-stream dynamic pressure obtained through wind speed measurements upwind of the turbine with the dynamic pressures measured on the wind turbine blade showed a consistent offset indicating that the pressure measurements were not referenced to free-stream static pressure. The static pressure probe was then mounted upwind of the turbine in order to measure the difference between the free-stream static pressure and the instrumentation box pressure. This measurement confirmed that the reference pressure inside the instrumentation box was not free-stream static pressure. However, the pressure difference between the upwind static probe and the instrumentation box was not the required magnitude to eliminate the offset between the wind-speed dynamic pressure and the measured dynamic pressure. It was concluded that the upwind probe was influenced by the flow field around the rotor. An empirical correction was derived using the wind-speed estimated dynamic pressure and the measured pressures. Application of this reference pressure correction results in pressure measurements referenced to free-stream static pressure such that the dynamic pressure measurements truly are of the correct magnitude. This correction is explained in the Reference Pressure Correction section of this report, but it was not applied to the stored data. The user is responsible for application of this correction. 


\section{5-hole Pressure Probes}

The 5-hole probe shown in Figure 6 provided dynamic pressure, local flow angle, and spanwise flow angle measurements $0.37 \mathrm{~m}$ ahead of the leading edge of the blade. The 5-hole probes were mounted at $34 \%, 51 \%, 67 \%, 84 \%$, and $91 \%$ span. The probes were positioned at an angle nominally $20^{\circ}$ below the chord line to align the probe with the flow under normal operating conditions. The pressure channels associated with each of the five holes are listed in Table 3. Stainless steel tubes with an outer diameter of $1.6 \mathrm{~mm}(0.063$ ") $(0.7874 \mathrm{~mm}(0.031$ ") inner diameter), carried the probe pressures to the pressure transducer. A short piece of plastic tubing $(1.6 \mathrm{~mm}(0.063$ ") inner diameter) joined the tubes to the transducers which were mounted inside the blade near the full-chord pressure tap stations.

Each probe was calibrated in a wind tunnel with a $0.914 \times 0.914 \mathrm{~m}(3 \times 3 \mathrm{ft})$ cross section. The probe was mounted in the center of the test section, and pressure data were acquired for angles of attack from $-40^{\circ}$ to $40^{\circ}$. The probe was then rotated $15^{\circ}$ about the probe axis and tested for the same angle of attack range. This was done for roll angles of $0^{\circ}, 15^{\circ}, 30^{\circ}, 45^{\circ}, 60^{\circ}, 90^{\circ}, 120^{\circ}$, $135^{\circ}$, and $150^{\circ}$. The difference between the inboard and outboard pressures was normalized with the tunnel dynamic pressure to correspond with the span-wise flow angle. The difference in pressure between the upper (towards the upper surface of the airfoil) and lower port measurements was normalized with the tunnel dynamic pressure in order to calibrate the local flow angle. The center port pressure normalized with the tunnel dynamic pressure provided the total pressure. These wind tunnel data were input to a neural network model to create surfaces for each of the three probe measurements for all five probes (Fingersh and Robinson 1997). The surfaces were implemented as look-up tables in the post-processing code. The span-wise flow angle and local flow angle channels appear in Table 14 and the dynamic pressure measurements appear in Table 12.

The probe that was mounted at $51 \%$ span was not rotated to the appropriate roll angle for one of the runs during the wind tunnel calibration. Data obtained from a different probe at the appropriate roll angle was substituted for the erroneous data prior to use of the neural network. New surfaces for the $51 \%$ span probe were generated using the data obtained from another probe at that particular roll angle. These new surfaces were implemented in the processing of all Phase V data.

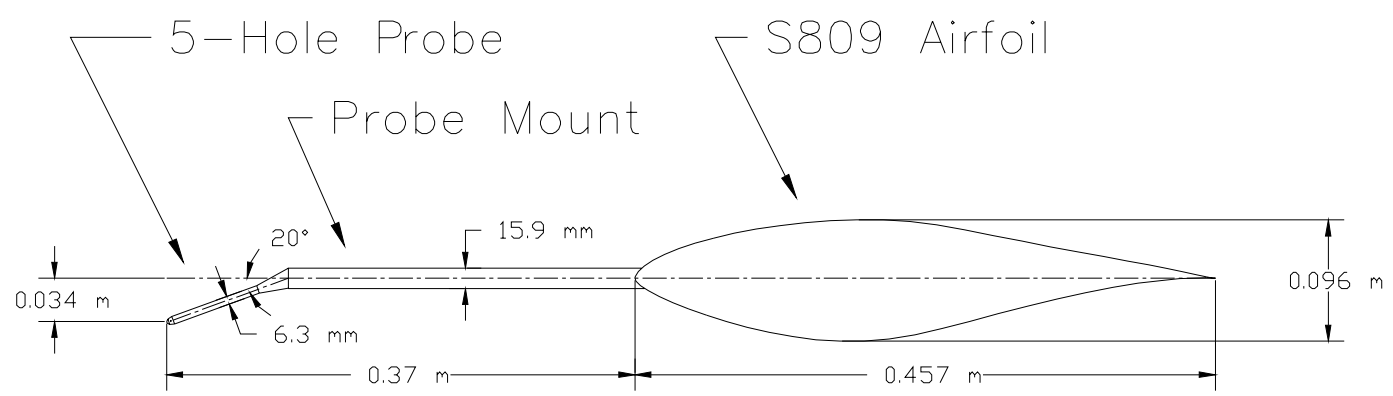

Figure 6. Blade-mounted 5-hole probe 
Table 3. 5-Hole Probe Pressures

\begin{tabular}{|c|c|c|c|}
\hline Channel & Channel ID & Description & Units \\
\hline $\begin{array}{l}052,053 \\
152,153 \\
252\end{array}$ & $\begin{array}{l}\text { 5HC34, 5HC51, } \\
\text { 5HC67, 5HC } 84, \\
5 \mathrm{HC} 91\end{array}$ & $\begin{array}{l}5 \text {-hole Center Port } 1(34 \%, 51 \%, 67 \%, 84 \% \text {, and } \\
91 \% \text { span })\end{array}$ & $\mathrm{Pa}$ \\
\hline $\begin{array}{l}054,055 \\
154,155 \\
254\end{array}$ & $\begin{array}{l}\text { 5HL34, 5HL51, } \\
\text { 5HL67, 5HL84, } \\
\text { 5HL91 }\end{array}$ & $\begin{array}{l}\text { 5-hole Lower Port } 2(34 \%, 51 \%, 67 \%, 84 \% \text {, and } \\
91 \% \text { span) }\end{array}$ & $\mathrm{Pa}$ \\
\hline $\begin{array}{l}056,057, \\
156,157, \\
256\end{array}$ & $\begin{array}{l}\text { 5HU34, 5HU51, } \\
\text { 5HU67, 5HU84, } \\
\text { 5HU91 }\end{array}$ & $\begin{array}{l}\text { 5-hole Upper Port } 3(34 \%, 51 \%, 67 \%, 84 \% \text {, and } \\
91 \% \text { span) }\end{array}$ & $\mathrm{Pa}$ \\
\hline $\begin{array}{l}058,059 \\
158,159 \\
258\end{array}$ & $\begin{array}{l}\text { 5HO34, 5HO51, } \\
5 \mathrm{HO} 67,5 \mathrm{HO} 84, \\
5 \mathrm{HO} 91\end{array}$ & $\begin{array}{l}5 \text {-hole Outboard Port } 4(34 \%, 51 \%, 67 \%, 84 \% \text {, and } \\
91 \% \text { span) }\end{array}$ & $\mathrm{Pa}$ \\
\hline $\begin{array}{l}060,061 \\
160,161 \\
260\end{array}$ & $\begin{array}{l}\text { 5HI34, 5HI51, } \\
\text { 5HI67, 5HI84, } \\
\text { 5HI91 }\end{array}$ & $\begin{array}{l}5 \text {-hole Inboard Port } 5(34 \%, 51 \%, 67 \%, 84 \% \text {, and } \\
91 \% \text { span) }\end{array}$ & $\mathrm{Pa}$ \\
\hline
\end{tabular}

\section{Static Probe}

During field testing, the static port of a Dwyer 160-U pitot static probe was used to determine the differential between the atmospheric flow field and the instrumentation enclosure to which all blade pressures were referenced. This probe was mounted $2.3 \mathrm{~m}$ upwind of the nacelle at hub height when the turbine was operating in a downwind condition. The probe was attached to a vane that aligned itself with the wind as shown in Figure 7. Pressure tubing 1.6-mm (0.063") inner diameter connected the static probe to a rotary pneumatic coupling on the low-speed shaft. The other end of the coupling transferred this pressure to the Mensor digital differential pressure transducer that was open to the rotating instrumentation box (The Mensor output is included in Table 16). 


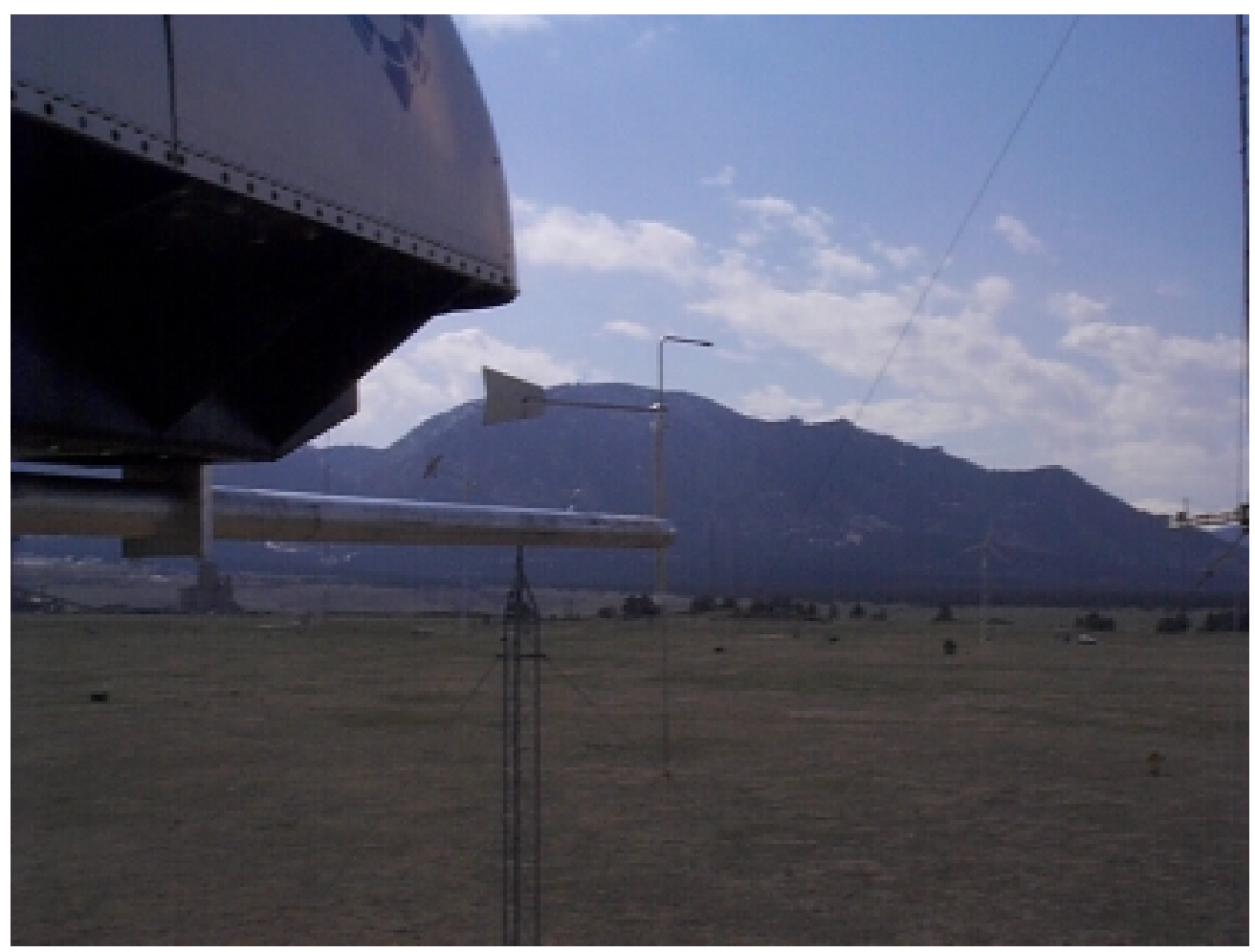

Figure 7. Upwind static probe

\section{Pressure Taps}

The most important, yet most difficult, measurements were the blade surface tap pressures. The quality of the aerodynamic performance coefficients depends on the accuracy of individual pressure tap measurements. Aerodynamic coefficients for a particular radial station resulted from the integrated value of the measured pressure distribution. The measurement approach was to install small pressure taps in the surface of the blade skin. Each opening was mounted flush to the airfoil surface. The flush profile was necessary to prevent the taps themselves from disturbing the flow. Stainless-steel tubes with an outer diameter of $1.6 \mathrm{~mm}(0.7874 \mathrm{~mm}$ inner diameter), were installed inside the blade's skin during manufacturing to carry surface pressures to the pressure transducer. A short piece of plastic tubing (1.6 $\mathrm{mm}$ inner diameter) joined the tubes to the transducers. To mitigate potential dynamic effects, total tubing length was kept less than $0.45 \mathrm{~m}$ (18 in.) by mounting the pressure transducers inside the blade near the pressure tap locations. The taps were aligned along the chord (instead of being staggered) so that span-wise variations in pressure distributions would not distort measured chordwise distributions. As illustrated in Figure 8, the taps were concentrated toward the leading edge to achieve increased resolution in the more active regions of the pressure distributions. 


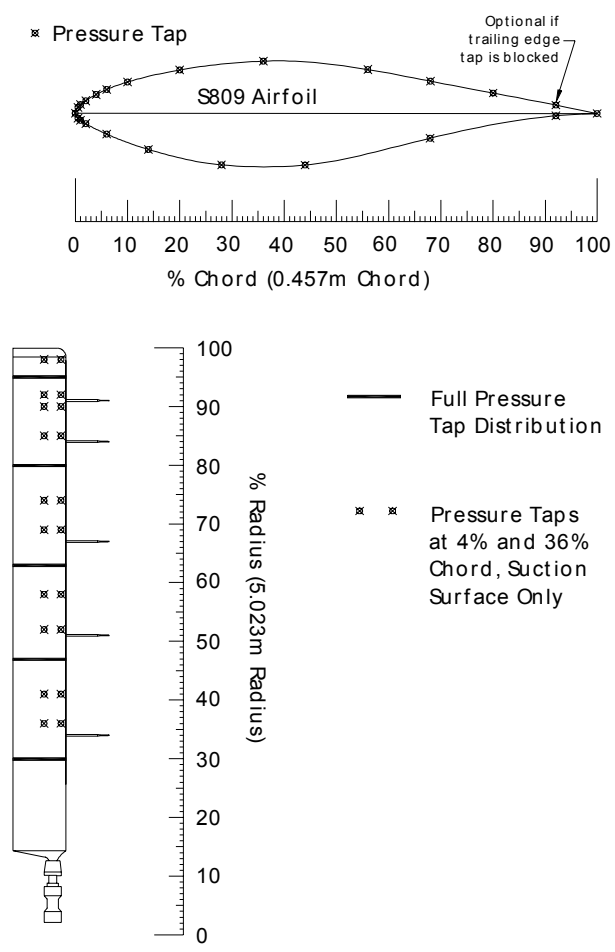

Figure 8. Pressure instrumentation

Twenty two taps were instrumented at five primary span-wise locations: $30 \%$ span, $46.6 \%$ span, $63.3 \%$ span, $80 \%$ span, and $95 \%$ span. Pairs of taps at $4 \%$ chord and $36 \%$ chord were installed at various other intermediate span locations $(36 \%, 41 \%, 52 \%, 58 \%, 69 \%, 74 \%, 85 \%, 90 \%, 92 \%$, and $98 \%$ ) on the suction surface. These channels are listed in Table 4 . The correlation between pressure tap number and airfoil chord location is shown in Table 5. At $63 \%$ and $95 \%$ span, the trailing edge tap was blocked so the tap at $92 \%$ chord on the upper surface (P026392U and P029592U) was instrumented instead. Extrapolation provided an estimate of the trailing edge tap pressure as described in the Derived Channels section. The pressure tap channels contain normalized pressure coefficients as described in the Derived Channels section rather than measured pressures. 
Table 4. Pressure Tap Channels

\begin{tabular}{|c|c|l|c|}
\hline $\begin{array}{c}\text { Channel } \\
\text { Channel ID }\end{array}$ & Description & Units \\
\hline $\begin{array}{c}000-042 \\
\text { (even) }\end{array}$ & Ptt30ccc & $\begin{array}{l}\text { Surface Pressure Coefficients at 30\% Span } \\
\mathrm{tt}=\text { Pressure Tap Number }(1,4,6,8,11,13,15, \\
17,18,19,20,21,22,23,24,25,27,31,32,34,36,\end{array}$ & $\mathrm{Cp}$ \\
\hline $\begin{array}{c}001-043 \\
\text { (odd) }\end{array}$ & Ptt47ccc & $\begin{array}{l}\text { Surface Pressure Coefficients at 47\% Span } \\
\mathrm{tt}=\text { Pressure Tap Number }(1,4,6,8,11,13,15,\end{array}$ & $\mathrm{Cp}$ \\
$17,18,19,20,21,22,23,24,25,27,31,32,34,36$, & \\
\hline $\begin{array}{c}100-142 \\
\text { (even) }\end{array}$ & Ptt63ccc & $\begin{array}{l}\text { Surface Pressure Coefficients at 63\% Span } \\
\mathrm{tt}=\text { Pressure Tap Number }(2,4,6,8,11,13,15,\end{array}$ & $\mathrm{Cp}$ \\
$17,18,19,20,21,22,23,24,25,27,30,32,34,36$, & \\
\hline $\begin{array}{c}101-143 \\
\text { (odd) }\end{array}$ & Ptt80ccc & $\begin{array}{l}\text { Surface Pressure Coefficients at 80\% Span } \\
\mathrm{tt}=\text { Pressure Tap Number }(1,4,6,8,11,13,15,\end{array}$ & $\mathrm{Cp}$ \\
$17,18,19,20,21,22,23,24,25,27,30,32,35,36$, & \\
\hline $\begin{array}{c}200-250 \\
\text { (even) }\end{array}$ & Ptt95ccc & $\begin{array}{l}\text { Surface Pressure Coefficients at 95\% Span } \\
\mathrm{tt}=\text { Pressure Tap Number }(2,4,6,8,11,13,15,\end{array}$ & $\mathrm{Cp}$ \\
$17,18,19,20,21,22,23,24,25,27,30,32,34,36$, & \\
\hline $\begin{array}{c}44-51, \\
144-151, \\
244-250 \\
\text { (even) }\end{array}$ & P18ss04U & $\begin{array}{l}\text { Intermediate Surface Pressure Coefficients at 36\%, } \\
41 \%, 52 \%, 58 \%, 69 \%, 74 \%, 85 \%, 90 \%, 92 \%, \text { and }\end{array}$ & $\mathrm{Cp}$ \\
& & $\begin{array}{l}98 \% \text { Span } \\
\text { Pressure Tap Number }(11,18) \\
\mathrm{P} 118536 \mathrm{U} \text { was inoperable. }\end{array}$ & \\
\hline
\end{tabular}

Table 5. Pressure Tap Chord Locations

\begin{tabular}{|ccccc|}
\hline $\begin{array}{c}\text { Pressure } \\
\text { Tap Number }\end{array}$ & \% chord & Surface & tt $^{*}$ & ccc $^{*}$ \\
\hline 1 & $100 \%$ & Trailing edge & 01 & 100 \\
2 & $92 \%$ & Upper & 02 & $92 \mathrm{U}$ \\
4 & $80 \%$ & Upper & 04 & $80 \mathrm{U}$ \\
6 & $68 \%$ & Upper & 06 & $68 \mathrm{U}$ \\
8 & $56 \%$ & Upper & 08 & $56 \mathrm{U}$ \\
10 & $44 \%$ & Upper & 10 & $44 \mathrm{U}$ \\
11 & $36 \%$ & Upper & 11 & $36 \mathrm{U}$ \\
12 & $28 \%$ & Upper & 12 & $28 \mathrm{U}$ \\
13 & $20 \%$ & Upper & 13 & $20 \mathrm{U}$ \\
14 & $14 \%$ & Upper & 14 & $14 \mathrm{U}$ \\
15 & $10 \%$ & Upper & 15 & $10 \mathrm{U}$ \\
16 & $8 \%$ & Upper & 16 & $08 \mathrm{U}$ \\
17 & $6 \%$ & Upper & 17 & $06 \mathrm{U}$ \\
18 & $4 \%$ & Upper & 18 & $04 \mathrm{U}$ \\
19 & $2 \%$ & Upper & 19 & $02 \mathrm{U}$ \\
20 & $1 \%$ & Upper & 20 & $01 \mathrm{U}$ \\
21 & $0.5 \%$ & Upper & 21 & $.5 \mathrm{U}$ \\
22 & $0 \%$ & Leading edge & 22 & 000 \\
23 & $0.5 \%$ & Lower & 23 & $.5 \mathrm{~L}$ \\
24 & $1 \%$ & Lower & 24 & $01 \mathrm{~L}$ \\
25 & $2 \%$ & Lower & 25 & $02 \mathrm{~L}$ \\
26 & $4 \%$ & Lower & 26 & $04 \mathrm{~L}$ \\
\hline
\end{tabular}


Table 5. Pressure Tap Chord Locations (continued)

\begin{tabular}{|cclll|}
\hline $\begin{array}{c}\text { Pressure } \\
\text { Tap Number }\end{array}$ & \% chord & Surface & $\mathbf{t t}^{*}$ & ccc $^{*}$ \\
\hline 27 & $6 \%$ & Lower & 27 & $06 \mathrm{~L}$ \\
28 & $8 \%$ & Lower & 28 & $08 \mathrm{~L}$ \\
30 & $14 \%$ & Lower & 30 & $14 \mathrm{~L}$ \\
31 & $20 \%$ & Lower & 31 & $20 \mathrm{~L}$ \\
32 & $28 \%$ & Lower & 32 & $28 \mathrm{~L}$ \\
34 & $44 \%$ & Lower & 34 & $44 \mathrm{~L}$ \\
36 & $68 \%$ & Lower & 36 & $68 \mathrm{~L}$ \\
38 & $92 \%$ & Lower & 38 & $92 \mathrm{~L}$ \\
\hline
\end{tabular}

* See Table 4 .

Based on tests performed in Phase I of the experiment, corrections to compensate for dynamic effects on pressure measurements caused by the pressure tap tubing were not applied to measured data sets (Butterfield, Musial, and Simms 1992). Effort was made to mitigate needed corrections by minimizing tubing diameter and keeping tubing length as short as possible. Gain amplifications and phase effects that occur as a function of tube size and length were measured. Results indicated that these effects were not significant up to a frequency of $50 \mathrm{Hertz}(\mathrm{Hz})$, and the measured pressure spectra of a typical data set showed no appreciable information above 50 Hz. Depending on data requirements, it would be possible to process data to remove the dynamic tubing effects. This may become necessary if, for example, a study of high-rate aerodynamic events were to be undertaken.

\section{Pressure Transducer}

The dynamic pressure varied significantly along the span of the blade because of rotational effects, so transducers with different measurement ranges were used. The nominal transducer ranges are listed in Table 6. The transducers, Pressure Systems Inc. (PSI) model ESP-32, scanned electronically port to port at $16,666 \mathrm{~Hz}$ and completed a scan of all pressure taps at $520.83 \mathrm{~Hz}$. One transducer was used at each primary span location to measure up to 32 differential pressures at the blade surface pressure taps and each of the five ports of a 5-hole probe. These measurements were referenced to the pressure in one of the hub-mounted instrumentation boxes. Corrections were applied to account for the centrifugal force acting on the air column in the pressure tubing as described in the Derived Channel section of the report. Each transducer was installed inside the blade as close to the pressure taps as possible. These electronic scanner-type transducers provided remote calibration capability through a pneumatically operated valve. The capacity to purge all of the pressure taps with dry nitrogen was used periodically to prevent moisture or small particles from affecting the pressure measurements.

Table 6. Nominal, Full-scale, Pressure Transducer Measurement Ranges

\begin{tabular}{|l|l|}
\hline 30\% Span & $\pm 2488 \mathrm{~Pa}\left( \pm 10 ” \mathrm{H}_{2} \mathrm{O}\right)$ \\
\hline $\mathbf{4 7 \%}$ Span & $\pm 2488 \mathrm{~Pa}\left( \pm 10 ” \mathrm{H}_{2} \mathrm{O}\right)$ \\
\hline $\mathbf{6 3 \%}$ Span & $\pm 4977 \mathrm{~Pa}\left( \pm 20 ” \mathrm{H}_{2} \mathrm{O}\right)$ \\
\hline $\mathbf{8 0 \%}$ Span & $\begin{array}{l} \pm 10,342 \mathrm{~Pa}( \pm 1.5 \mathrm{psi}) \text { during } \\
\text { spring } 1998 ; \pm 6894 \mathrm{~Pa}( \pm 1 \mathrm{psi}) \\
\text { during fall } 1998\end{array}$ \\
\hline $\mathbf{9 5 \%}$ Span & $\pm 10,342 \mathrm{~Pa}( \pm 1.5 \mathrm{psi})$ \\
\hline
\end{tabular}


Differential pressures between the blade surface pressure and the hub reference pressure were measured by the ESP-32 pressure transducers. For all blade surface pressure measurements as well as probe pressure measurements, the common reference pressure was the pressure inside one of the rotating instrumentation boxes on the hub, which was assumed to be free stream static pressure. Each transducer located in the blade was connected to the reference via a plastic 0.6731 $\mathrm{mm}$ inner diameter tube between the hub and the transducer. The hub-mounted instrumentation box was vented to the atmosphere through an orifice on the upwind side of the box. This resulted in a time constant of about 5-10 seconds and provided a relatively stable pressure reference.

Because of the rotation of the pressure tubing, centrifugal forces acting on the column of air contained in the tube change the pressure along the radius of the blade. Each pressure tap measurement was corrected for centrifugal force effects and normalized with the blade stagnation pressure as described in the Derived Channels section that follows. No correction for hydrostatic pressure variation has been applied, although one was proposed by Corten (1998).

A Mensor digital differential pressure transducer was used for two purposes. During pressure calibrations, the Mensor read the pressure difference between the stable, rotating reference pressure (inside the instrumentation box) and the calibration pressure applied by a motorized syringe. During standard operation, the Mensor read the pressure difference between the stable, rotating pressure reference (inside the instrumentation box) and the static pressure port of a pitot static probe mounted upwind of the turbine. Comparison of blade dynamic pressure measurements corrected with this offset and the wind speed estimated dynamic pressure indicate that the probe is not far enough upstream of the turbine to be outside the influence of the rotor. However, this measurement did confirm that the reference pressure for all pressure measurements is not free-stream static pressure as was originally assumed. Table 7 shows the channels corresponding to the digital signal from the Mensor. These are converted into one pressure measurement during post-processing. Two channels are required because the Mensor output is 16 bits, and the data acquisition system is a 12-bit system.

Table 7. Mensor Channels

\begin{tabular}{|c|c|l|c|}
\hline Channel & Channel ID & Description & Units \\
\hline 259 & VBL176 & Digital First 12 bits from D pressure & $\mathrm{Pa}$ \\
\hline 261 & VBL178 & Digital Last 12 bits from D pressure & $\mathrm{Pa}$ \\
\hline
\end{tabular}

Comparison of measured blade dynamic pressure versus wind speed estimated dynamic pressure has shown that the reference pressure in the box during Phase II was slightly higher than free stream static pressure. However, similar comparisons in the Phase III, IV, and V data showed that the box reference pressure varied significantly from static pressure. Subsequent direct measurement by the Mensor and the upwind static probe confirmed the result. Therefore, all pressure measurements should be corrected for this reference pressure offset. This proposed correction is described in the "Reference Pressure Correction" section, but it was not applied to the data during post-processing.

During the spring 1998 portion of Phase V, the tubing from the rotary pneumatic coupling to the Mensor was connected to a tee that joined the calibration syringe and the calibration volume chamber $\left(8 \mathrm{in}^{3}\right)$ to the Mensor. This resulted in a very slow response for the static pressure measurement. A valve at this junction was added prior to the fall 1998 portion of Phase V to 
eliminate the additional volume associated with the calibration volume chamber while the turbine was in operation. The static pressure measurement then had a much faster response. The valve was open to the volume chamber and syringe during calibration before and after each campaign.

\section{Pressure System Controller (PSC)}

Remote control of ESP-32 pressure transducer calibration, scanner addressing, and demultiplexing of the analog multiplexed signals were performed by the PSC, a hub-mounted microprocessor control unit designed by NREL (Butterfield, Musial, and Simms 1992). The PSC was completely redesigned in subsequent phases to improve the accuracy and the user interface. Currently, up to 155 pressure channels may be processed simultaneously. All pressure ports were scanned at $520.83 \mathrm{~Hz}$. The objective was to provide $100-\mathrm{Hz}$ bandwidth frequency response to enable study of dynamic stall behavior on the rotating wind turbine blade.

Once the PSC scanned the pressure transducers, the samples were digitized, synchronized, and passed to the pulse code modulation (PCM) encoder. The PCM system multiplexed 62 channels of data into one digital data stream, which was conducted through a single coaxial cable. Rotor data were encoded into three PCM streams, which were passed over slip rings to the control building and were recorded on optical disk for subsequent processing.

The PSC pneumatic control valves and ramp calibration sequence is discussed in the Phase I report (Butterfield, Musial, and Simms 1992) and summarized in Appendix B. The only changes between Phase II and later phases were that a more accurate calibration reference pressure was used, and calibrations were automated by a computer-controlled processing system.

\section{Strain Gauges, Accelerometers, and Load Cells}

Strain gauges, accelerometers, and load cells were used to measure bending moments, accelerations, and forces in both the rotating and non-rotating environments. Blade flap- and edge-bending moments were recorded from strain gauges mounted at the root $(8.6 \%$ span) of each blade. Strain gauges on the hub shaft and the low-speed shaft measured bending about two axes and torque. Strain gauges were used to measure yaw moment when the yaw brake was applied. A relatively constant yaw angle and non-zero, fluctuating, yaw moment indicate the yaw brake was engaged during data acquisition. Accelerometers were placed in the nacelle to determine yaw, pitch, and fore-aft motion. Accelerometers were also used in the tips of each blade to measure acceleration in the flap and edge directions. Load cells placed inside the teeter

dampers recorded the forces applied during teeter impact. A tension/compression load cell in the link between the blades measured the force between the blades. These measurements are listed in Table 8, and a description of the instrumentation is presented in Appendix B.

The strain gauges measuring root flap and edge loads were applied to the steel pitch shaft adjacent to the blade attachment location. The pitch shaft was reduced to a uniform, cylindrical, 80 -mm diameter at $8.6 \%$ span, the location where the strain gauges were applied. The uniform, cylindrical region eliminates geometry effects to facilitate accurate measurement of flap- and edge-bending moments. This cylindrical section of the blade root is illustrated in Figure 3 as well as in Appendix B. 
Table 8. Load Measurements

\begin{tabular}{|c|c|l|c|}
\hline Channel & Channel ID & Description & Units \\
\hline 201 & B1ACFL & Accelerometer Blade 1-Flap & $\mathrm{m} / \mathrm{s}^{2}$ \\
\hline 203 & B1ACED & Accelerometer Blade 1-Edge & $\mathrm{m} / \mathrm{s}^{2}$ \\
\hline 209 & B3ACFL & Accelerometer Blade 3-Flap & $\mathrm{m} / \mathrm{s}^{2}$ \\
\hline 211 & B3ACED & Accelerometer Blade 3-Edge & $\mathrm{m} / \mathrm{s}^{2}$ \\
\hline 215 & HSXXB & Strain Hub Shaft XX Bending & $\mathrm{N}-\mathrm{m}$ \\
\hline 217 & HSYYB & Strain Hub Shaft YY Bending & $\mathrm{N}-\mathrm{m}$ \\
\hline 219 & HSTQ1 & Strain Hub Shaft Torque 1 & $\mathrm{N}-\mathrm{m}$ \\
\hline 221 & HSTQ2 & Strain Hub Shaft Torque 2 & $\mathrm{N}-\mathrm{m}$ \\
\hline 223 & TLINKF & Strain Teeter Link Force & $\mathrm{N}$ \\
\hline 225 & B1RFB & Strain Blade 1 Root Flap Bending & $\mathrm{N}-\mathrm{m}$ \\
\hline 227 & B1REB & Strain Blade 1 Root Edge Bending & $\mathrm{N}-\mathrm{m}$ \\
\hline 229 & B1TDAMPF & Strain Blade 1 Teeter Damper Force & $\mathrm{N}$ \\
\hline 231 & B3TDAMPF & Strain Blade 3 Teeter Damper Force & $\mathrm{N}$ \\
\hline 233 & B3RFB & Strain Blade 3 Root Flap Bending & $\mathrm{N}-\mathrm{m}$ \\
\hline 235 & B3REB & Strain Blade 3 Root Edge Bending & $\mathrm{N}-\mathrm{m}$ \\
\hline 237 & LSSXXB & Strain X-X LSS Bending & $\mathrm{N}-\mathrm{m}$ \\
\hline 239 & LSSYYB & Strain Y-Y LSS Bending & $\mathrm{N}-\mathrm{m}^{*}$ \\
\hline 241 & LSSTQ & Strain LSS Torque & $\mathrm{N}-\mathrm{m}$ \\
\hline 336 & NAACYW & Nacelle Accelerometer Yaw & $\mathrm{m} / \mathrm{s}^{2}$ \\
\hline 338 & NAACFA & Nacelle Accelerometer Fore-Aft & $\mathrm{m} / \mathrm{s}^{2}$ \\
\hline 340 & NAACPI & Nacelle Accelerometer Pitch & $\mathrm{m} / \mathrm{s}^{2}$ \\
\hline 342 & NAYM & Nacelle Yaw Moment & $\mathrm{N}-\mathrm{m}$ \\
\hline
\end{tabular}

* This channel was not operable during the spring 1998 data campaigns.

\section{Miscellaneous Transducers}

Gear-driven, BEI model R-25 and RAS-25 optical absolute-position encoders were used to measure yaw position, pitch angle, blade teeter angle, and rotor azimuth position. The yaw position encoder was located near the yaw brake. The rotor azimuth encoder was located in the nacelle on the low-speed shaft. Each blade was provided with an encoder for pitch angle measurement. Figures 9-11 illustrate the measurement conventions.

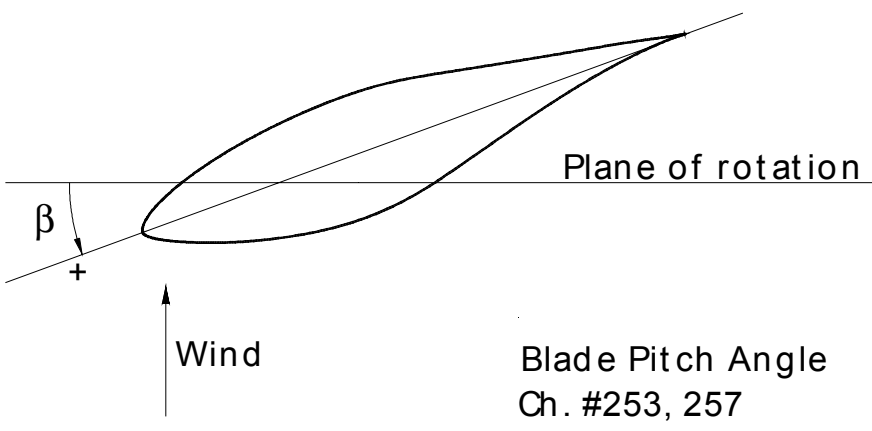

Figure 9. Blade pitch angle orientation 


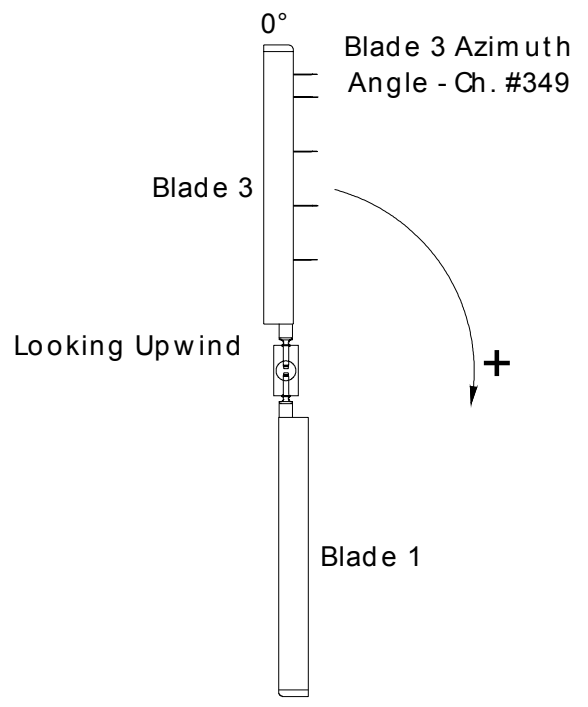

Figure 10. Blade azimuth angle convention

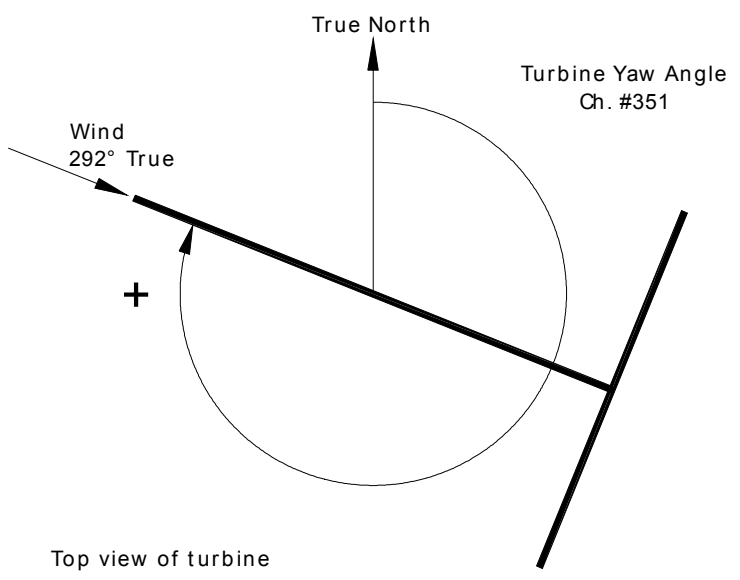

Figure 11. Yaw angle convention

Individual blade flap angles were obtained with an encoder on either side of the teeter pin with an 8:1 gear ratio to improve the accuracy of the small angle measurements. Although the blade cone angle was set at $3.4^{\circ}$ downwind, flexibility in the linkage permits slight fluctuation in this angle. Figure 12 illustrates the measurement conventions used. The flap angle encoders permit calculation of the true cone angle as follows:

$$
\text { cone }=\frac{\phi_{3}+\phi_{1}}{2}
$$

where $\phi_{3}$, and $\phi_{1}$ are the respective blade flap angles. The teeter angle can obtained from the flap angle measurements as follows:

$$
\text { teeter }=\frac{\phi_{3}-\phi_{1}}{2}
$$




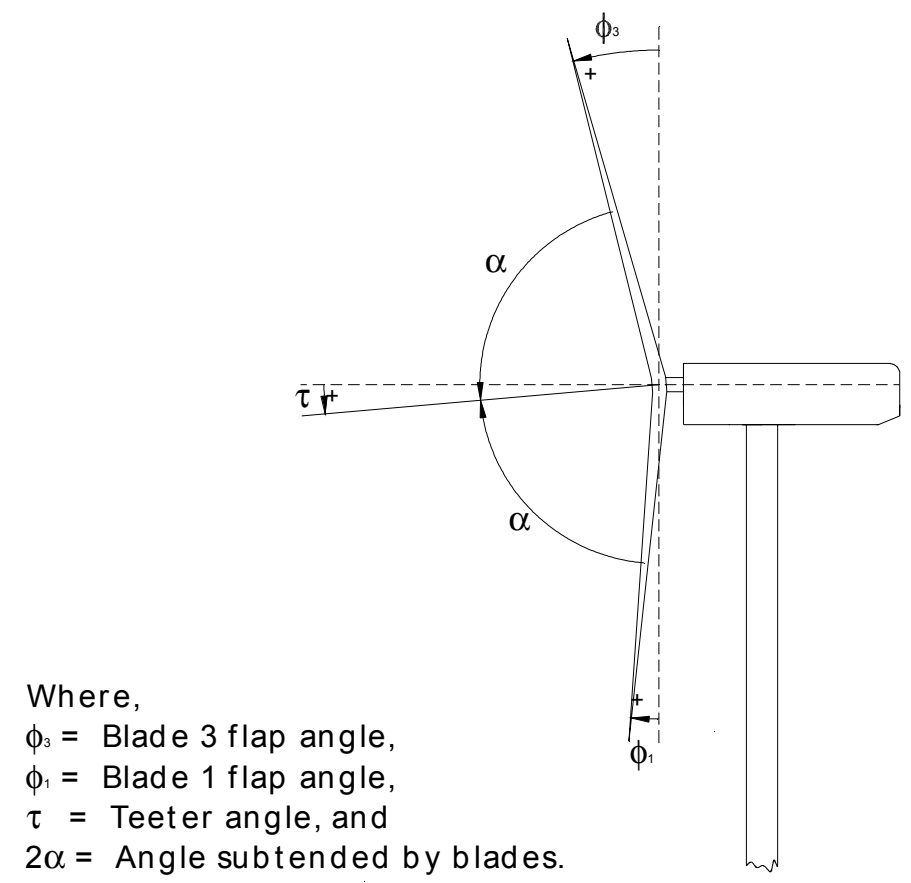

Figure 12. Blade flap angle convention

Generator power was monitored using an Ohio Semitronics, Inc. (OSI), power watt transducer during all phases of testing. A time code generator provided a signal to which all of the PCM streams were synchronized. These miscellaneous channels are listed in Table 9 below and fully described in Appendix B.

Table 9. Miscellaneous Transducers

\begin{tabular}{|c|c|l|c|}
\hline Channel & Channel ID & Description & Units \\
\hline 251 & B1FLAP & Digital Blade 1 Teeter Angle & $\mathrm{deg}$ \\
\hline 253 & B1PITCH & Digital Blade 1 Pitch & $\mathrm{deg}$ \\
\hline 255 & B3FLAP & Digital Blade 3 Teeter Angle & $\mathrm{deg}$ \\
\hline 257 & B3PITCH & Digital Blade 3 Pitch & $\mathrm{deg}$ \\
\hline 332 & GENPOW & Generator Power & $\mathrm{kW}$ \\
\hline 349 & B3AZI & Blade 3 Azimuth Angle & $\mathrm{deg}$ \\
\hline 351 & YAW & Yaw Angle & deg \\
\hline 353 & DAY & Clock - Day & day \\
\hline 355 & HOUR & llock - Hour & hour \\
\hline 357 & MINUTE & Clock - Minute & minute \\
\hline 359 & SECOND & llock - Second & second \\
\hline 361 & MILLISEC & Clock - Millisecond & msec \\
\hline
\end{tabular}

\section{Flow Visualization}

\section{Cameras}

Two high-shutter-speed cameras were mounted in the rotating frame. A Panasonic camera with a Rainbow $^{\mathrm{TM}}$ zoom lens and remote control iris and focus adjustments was mounted on the end of a lightweight, 3-m boom, which was attached to the hub. The boom was designed to be stiff with a 
system fundamental frequency exceeding 10 cycles per revolution $(10 \mathrm{P})$, and the axes of the boom and camera were mass balanced about the axis of rotation. The camera angle was remotely adjustable to display various span locations on the blade. An additional high-shutter-speed video camera was mounted at the root of the instrumented blade to provide a view of the blade span. This camera pitched with the blade to provide a full-span picture of all the tufts at one time. The mass of this camera was included in the mass of the blades listed in Appendix A. Additional equipment, such as the data acquisition system, the PSC, and lighting for night testing, was also mounted on the hub.

\section{Tufts}

Flow visualization was achieved through the use of tufts attached to the surface of the blade. The tufts were made of thin, white, polyester thread measuring about $0.25 \mathrm{~mm}$ in diameter and $45 \mathrm{~mm}$ in length. A small drop of fast-drying glue held each of the tufts to the downwind (suction) side of the instrumented blade. The tufts extended from the leading edge to the trailing edge in 50.8- $\mathrm{mm}$ increments. The tufts were also spaced $50.8 \mathrm{~mm}$ in the span-wise direction. However, if the 50.8-mm radius of a tuft would interfere with any pressure tap, the tuft was omitted. Thus, the tip of a tuft could be as close as $6 \mathrm{~mm}$ to a tap or as far away as $50.8 \mathrm{~mm}$. The diameter of the tufts was chosen to minimize the effects on the boundary layer yet maintain good visibility for the video camera. If the tufts were large relative to the boundary layer thickness, they could cause transition or premature separation. This effect is discussed in more detail by Rae and Pope (1984).

\section{Lighting}

Daylight tended to produce glare and reflections that interfered with video images. Thus, night testing was preferred. In order to collect data at night, four 100-W Halogen-IR ${ }^{\mathrm{TM}}$ bulbs and two 250-W Halogen-IR ${ }^{\mathrm{TM}}$ bulbs were mounted on the boom and were used for some campaigns. These bulbs operate at a color temperature of $2900 \mathrm{~K}$ and produce 2000 and 3370 lumens, respectively.

\section{Data Acquisition and Reduction Systems}

\section{PCM System Hardware}

In order to increase accuracy, simplify instrumentation, and reduce noise, digital and analog data signals are sampled and encoded into PCM streams as close to the transducer as possible. For this reason, three PCM streams originate in the instrumentation boxes mounted on the hub, and one PCM stream originates in the data shed at the base of the turbine. The rotor streams are conducted through slip rings and cables to the data shed, where all four streams are then decommutated and stored on optical disk.

A customized digital PCM-based hardware system for data acquisition was developed and tested throughout Phase I of the Unsteady Aerodynamic Experiment (Butterfield, Musial, and Simms 1992). The same hardware was used during Phase II, but upgrades were made for subsequent phases. The number of measured channels increased from 185 in Phase II to 207 in Phase V. All of the channels were sampled at $520.83 \mathrm{~Hz}$ and stored directly to optical disk. Copies of the optical disks and the processed engineering-unit files were recorded on compact discs for dissemination. 
The PCM encoders convert conditioned analog input voltages into digital counts. The digital signals are also encoded into PCM streams. The digital conversion code limits the overall accuracy to 12-bit resolution for count values ranging from 0 to 4095 . Therefore, quantizing errors are limited to $0.024 \%$ of full scale, and the peak signal-to-noise ratio $(\mathrm{S} / \mathrm{N})$ is $83 \mathrm{~dB}$. Signal conditioning of the analog signals prior to PCM encoding allows the channels to use as much of the quantizing range as possible. Also, filtering the analog signals prior to PCM encoding reduces the potential for aliasing. The pressure signals were not filtered due to the filtering effect of the long pressure tap tubes. Also, it is extremely difficult to filter analogmultiplex signals.

The decoder boards are printed circuit boards mounted inside the chassis of a PC. The specifications are listed in Table 10, which is taken from Butterfield, Musial, and Simms (1992). Software that controls the decoder boards was written in C for DOS. Upon receiving a capture command, a direct memory access (DMA) controller moves decoded data from the PCM board to computer memory in variable buffer sizes from 0-64 kilobytes. Each word is tagged with its corresponding PCM board number, and custom software was developed to facilitate conversion of the PCM data to binary files.

Table 10. Phase II PCM Decoder Board Specifications

\begin{tabular}{|ll|}
\hline Bit Rate & $1-800$ Kbits/second \\
Input Streams & 4 (only one processed at a time) \\
Input Polarity & Negative or positive \\
Input Resistance & $>10$ Kohms \\
Codes & Bi-phase L, NRZ \\
Bit Sync Type & Phase-locked loop (PLL) \\
Input Data Format & $8-12$ bits/word, most significant bit (MSB) first \\
Words Per Frame & 2-64 (including sync) \\
Sync Words Per Frame & $1-3$ (maximum 32 bits) \\
\hline
\end{tabular}

\section{Calibration Procedures}

The most desirable form of calibration is to apply a known load and measure the response with the instrumentation system, i.e., a full-path calibration. Several points provide data for linear interpolation, and the slope and offset values of a linear transducer can then be determined. This form of calibration is used for the pressure transducers, the strain gauges, and the load cells. However, it is not feasible for a number of instruments because manufacturer calibrations are required, as in the case of anemometers. In this situation, calibration coefficients are obtained through the manufacturer. The analog instruments output values in units of volts, but the data acquisition system converts all measurements into digital counts. The electronic path from the instrument output through the data acquisition system must be calibrated to convert manufacturer-specified calibration coefficients in units of volts to units of counts. Lastly, the digital position encoders must be oriented with a known position to obtain the offset while the slope is prescribed by the instrument. Detailed descriptions of the calibration procedures for each channel are included in Appendix B.

Calibrations of the pressure channels were performed in the manner described in Simms and Butterfield (1991) by using a motorized syringe to apply positive and negative pressure to all scanning transducers simultaneously over their full measurement range. This was done before and after each 10-minute campaign by remote control while the turbine was operating. Calibration coefficients were derived by performing a least-squares linear regression on each of 
the pressure channels referenced to the precision digital pressure transducer signal. In order to verify lack of zero-drift in the pressure transducers, comparisons between pre- and postcalibrations were made.

The strain gauges were also calibrated by applying a known load. A jig was attached to each blade to isolate loads in both flap and edge directions. Weights were used to apply a moment, which was measured by the strain gauges. A least-squares regression analysis provided slope calibration coefficients. The zero offsets were determined by positioning each blade in zero-load locations of the rotational cycle. This calibration was performed prior to each series of data collection, which lasted less than 1 month.

A custom jig was built to apply loads to load cells in series. One of the load cells is considered the calibration load cell, and the others are the teeter link load cell or the button force sensors used to measure teeter impact. The jig is loosened or tightened over the range of the load cell being calibrated. The calibration load cell provides the known load. Linear regression provides slope and offset coefficients. Prior to the spring 1998 collection, the load cells were calibrated on the ground prior to installing the hub on the turbine. The data acquisition system was used to obtain the load measurements, and only the length of cable from the load cell to the system differed from field application. Prior to the fall 1998 campaigns, the teeter damper force load cells were zeroed by teetering the rotor into zero-load positions and recording count values. The slope values for all load cells were maintained throughout Phase V.

For the other channels, it was impossible to perform full-path calibrations in situ. For example, the cup anemometers required a known wind velocity and were thus calibrated by the manufacturer in a wind tunnel. Manufacturer calibrations generally provide both slope and offset values. In some cases, for example the optical-position encoders, the offset was determined by placing the transducer in a known position and noting the associated count value. For analog transducers, once the slope and offset calibration coefficients were obtained from manufacturer specifications, an electronic path calibration was performed. Known reference voltages were inserted in place of the transducer signal in order to separately calibrate the system electronic path. These values were used to convert the manufacturer-supplied calibration coefficients to units of counts.

A database of resulting calibration coefficients was maintained and applied to raw data values to produce engineering unit data files. Because all of the measured channels were linear, only slope and offset calibration coefficients were applied.

These calibration procedures were established to ensure that all recorded data values were within the stated error limits. Uncertainty analysis results for selected measured channels used during Phase II are presented in Table 11. Total estimated uncertainty values listed in the table are expressed in engineering units, and represent random and bias error components. The uncertainty is also expressed in terms of percent full-scale error. Error analysis and calibration procedures specific to wind turbine field testing are described in McNiff and Simms (1992). 
Table 11. Uncertainty Analysis Results for Selected Phase II Measured Channels

\begin{tabular}{|lcccc|}
\hline \multicolumn{1}{|c}{ Measurement } & Units & $\begin{array}{c}\text { Measurement } \\
\text { Range }\end{array}$ & $\begin{array}{c}\text { Total } \\
\text { Estimated } \\
\text { Uncertainty }\end{array}$ & $\begin{array}{c}\text { \% Full- } \\
\text { Scale } \\
\text { Error }\end{array}$ \\
\hline Pressures at 30\% span & $\mathrm{Pa}$ & \pm 2970 & \pm 12 & 0.2 \\
Pressures at 47\% span & $\mathrm{Pa}$ & \pm 2970 & \pm 18 & 0.3 \\
Pressures at 63\% span & $\mathrm{Pa}$ & \pm 8274 & \pm 33 & 0.2 \\
Pressures at 80\% span & $\mathrm{Pa}$ & \pm 8274 & \pm 50 & 0.3 \\
Angle of Attack & $\mathrm{deg}$ & -22 to 40 & \pm 1.0 & 1.6 \\
Wind Velocity & $\mathrm{m} / \mathrm{s}$ & 0 to 37 & \pm 0.5 & 1.4 \\
Blade Pitch Angle & $\mathrm{deg}$ & -10 to 71 & \pm 1.0 & 1.2 \\
Blade Azimuth Angle & $\mathrm{deg}$ & 0 to 360 & \pm 1.0 & 2.8 \\
\hline
\end{tabular}

\section{PCM System Software}

A diagram of the signal path from PCM streams to useable data, along with the possible viewing options is shown in Appendix B (Figure 51). It was possible to view a bar graph showing all channels within each of the four PCM streams. The count value of a user-selected channel was noted on the bottom of the screen. The most powerful real-time viewing program displayed nearly all measured channels on one screen. Each of the five pressure distributions, angles of attack, and dynamic pressures were displayed graphically in real time. Inflow conditions such as wind speed, vertical and horizontal wind shear, azimuth angle, yaw angle, and wind direction were displayed as well. A bar graph tracked power, root flap bending moment, damper load cells, and low-speed shaft torque. Other parameters such as time, pitch angles, Richardson number, and rotational speed appeared as text. This program could also be used to review recorded data at adjustable speeds. Time histories of user-selected channels could be displayed by selecting an averaging value. Each point average was updated graphically in real time. This software provided a means of determining inoperable channels quickly and easily. A variation of this program was used to combine video camera images with superimposed graphical and text data. The resulting integrated video and data image archives are stored on video tape.

The flowcharts presented in Appendix B (Figures 52 and 53) illustrate the process of creating the engineering-unit files which are stored on compact disc. Pressure calibrations were initiated with psc.exe, which controls the syringe in the PSC package. The resulting measurements were fit to a linear curve with the corresponding slope and offset values entered in the prescal.hdr file. A similar process was performed using the gencal.exe program to determine slope and offset values for the strain gauges, load cells, and electronic-path calibrations. All of the other calibration coefficients for anemometers, accelerometers, optical absolute position encoders, and the power transducer were determined using manufacturer specifications and/or single-point offset determination which were entered in the spreadsheet calconst.xls. The buildhdr.exe program converted the manufacturer-supplied calibration coefficients in units of volts to engineering units created by the electronic-path calibrations. Production of the master.hdr file resulted in one file containing all slope and offset values for each measured channel. This file, together with the recorded data file, $(*$.dat), was input to the main processing program called munch.exe. This program requires additional input files that explain the pressure profiles (cexp.prf), the blade shape (cexp.bsh), the record format (cexp.rft), and the ID codes for the data channels (chanid.txt).

Three files were created by the munch.exe program: the updated header file, the engineering-unit file, and an archive file. The header file contained a description of each channel, calibration 
coefficients, and statistics for the 10-minute campaign (mean, standard deviation, maximum, record location of maximum, minimum, record location of minimum, and number of errors). An example of the header file is attached in Appendix B, p. 121. The engineering-unit file contained the time series of each channel converted from PCM code to engineering units. Additionally the time series of several derived channels such as normal and tangential force coefficients were included. An example of the format of the engineering-unit file appears in Appendix B, p. 122. The archive file consisted of a copy of the data file in the event of corruption or destruction. All of these files were stored on compact disc along with the calibration files and munch.exe input files.

While creating the engineering-unit file, a byte is attached to each record to indicate whether channels exceeded the measurement ranges. This "error byte" contains 8 bits representing each of the five span locations, the $4 \%$ chord and $36 \%$ chord span-wise distributed taps, and one bit for all other channels. If the bit is turned on, the maximum value of the transducer was exceeded for at least one of the channels associated with that bit. For instance, if the pressure at any tap at $30 \%$ span exceeds the transducer measurement range, the error bit representing the $30 \%$ span station is incremented.

In addition to the original high-rate $(520.83 \mathrm{~Hz})$ engineering-unit data files, various slower-rate averaged or filtered data files were subsequently produced. For example, once an engineeringunit file was created for each campaign, all of the channels were averaged over one complete rotation, or cycle, of the instrumented blade. A database of statistical values for each of these cycles for every channel was created. This process was performed for all campaigns and stored on compact disc. This database provided a means of identifying baseline performance and dynamic-stall occurrences. Additional post-processing software is described in Appendix B.

\section{Derived Channels}

\section{Centrifugal Force Correction}

The differential pressures between the blade surface pressure and the hub reference pressure were reduced by the centrifugal force acting on the column of air in the pressure tubing caused by rotation of the blade. This force was added to each measured pressure data value per Equations (3) and (4). Each of the probe pressures was also corrected in this manner.

$$
\begin{gathered}
P_{c o r}=P_{\text {meas }}+P_{\text {cent }}, \\
P_{\text {cent }}=\frac{1}{2} \rho(r \omega)^{2}, \text { and } \\
\rho=0.0034838 * \frac{P_{a t m}}{T} \text { (Smithsonian Institution 1949); }
\end{gathered}
$$

where

$\mathrm{P}_{\text {cor }}=$ differential pressure corrected for centrifugal force $(\mathrm{Pa})$,

$\mathrm{P}_{\text {meas }}=$ pressure differential measured at blade-mounted transducer $(\mathrm{Pa})$,

$\mathrm{P}_{\text {cent }}=$ centrifugal force correction $(\mathrm{Pa})$,

$\rho=$ air density $\left(\mathrm{kg} / \mathrm{m}^{3}\right)$,

$\mathrm{r}=$ radial distance to surface pressure tap $(\mathrm{m})$,

$\omega=$ rotor speed $(\mathrm{rad} / \mathrm{s})$,

$\mathrm{P}=$ atmospheric pressure $(\mathrm{Pa})$, and

$\mathrm{T}=$ air temperature $(\mathrm{K})$. 


\section{Dynamic Pressure}

Assuming that the reference pressure is free stream static pressure, two measurements of dynamic pressure were obtained: probe dynamic pressure and stagnation point dynamic pressure. Note, however, that without application of the reference pressure correction, these values are offset from the dynamic pressure because the reference pressure for the pressure transducer was not free-stream static pressure.

The pressure measured with the 5 -hole probes and corrected for centrifugal effects was one measure of dynamic pressure, and these channels are listed in Table 12. The difference between the inboard and outboard ports was normalized with the center port pressure after the centrifugal force correction was applied. The difference between the upper and lower ports was normalized similarly. The probe dynamic pressure was then extracted from the lookup table using these two numbers. An algorithm using a spherical coordinate system was developed to obtain the probe dynamic pressure measurement from the look-up table (Freeman and Robinson 1998).

The dynamic pressure was also estimated from the stagnation point pressure at each of the fullchord pressure tap locations as shown in Table 12. The pressure tap at each primary span location where the static pressure attains a maximum was considered to be the stagnation point, and the corresponding pressure at that location was used as the stagnation pressure. The resolution of the pressure taps on the lower surface was assumed to be sufficient to extract the maximum positive surface pressure, especially at lower angles of attack. According to Shipley et al. (1995), the stagnation point method is the preferred method of estimating dynamic pressure on the blade. This measurement of dynamic pressure was used to normalize each of the blade surface pressures and is thus referred to as the normalization pressure.

Table 12. Dynamic Pressure Measurements

\begin{tabular}{|c|c|l|c|}
\hline Channel & Channel ID & Description & Units \\
\hline 822 & QNORM30 & Normalization Factor at 30\% Span & $\mathrm{Pa}$ \\
\hline 828 & QNORM47 & Normalization Factor at 47\% Span & $\mathrm{Pa}$ \\
\hline 834 & QNORM63 & Normalization Factor at 63\% Span & $\mathrm{Pa}$ \\
\hline 840 & QNORM80 & Normalization Factor at 80\% Span & $\mathrm{Pa}$ \\
\hline 846 & QNORM95 & Normalization Factor at 95\% Span & $\mathrm{Pa}$ \\
\hline 852 & 5HP34P & 5-hole 34\% Pressure & $\mathrm{Pa}$ \\
\hline 855 & 5HP51P & 5-hole 51\% Pressure & $\mathrm{Pa}$ \\
\hline 858 & 5HP67P & 5-hole 67\% Pressure & $\mathrm{Pa}$ \\
\hline 861 & 5HP84P & 5-hole 84\% Pressure & $\mathrm{Pa}$ \\
\hline 864 & 5HP91P & 5-hole 91\% Pressure & $\mathrm{Pa}$ \\
\hline
\end{tabular}

\section{Pressure Coefficients}

Each of the corrected blade surface pressure values was normalized by the stagnation pressure at the corresponding span location as shown in Equation 6. These values were recorded in the engineering-unit files for each pressure tap.

$$
C_{p}=\frac{P_{c o r}}{Q_{\text {stag }}} ;
$$

where

$\mathrm{C}_{\mathrm{p}}=$ pressure coefficient, dimensionless, 
$\mathrm{P}_{\text {cor }}=$ differential pressure corrected for centrifugal force $(\mathrm{Pa})$, and

$\mathrm{Q}_{\text {stag }}=$ stagnation point dynamic pressure (corrected for centrifugal force) $(\mathrm{Pa})$.

If a pressure tube was damaged, the nearest working tap was instrumented. Using this additional measurement, a value for the damaged tap was determined through either interpolation or extrapolation, depending on the location of the tap. These channels were noted as ' $\mathrm{P}($ deriv)' in the header files to indicate derivation instead of actual measurement. The trailing edge taps at $63 \%$ span (P0163100) and 95\% span (P0195100) were both damaged so the tap at $92 \%$ chord (P026392U, P029592U) on the upper surface was instrumented to provide an extrapolated value of the trailing edge tap. The intermediate tap pressure at $85 \%$ span, $36 \%$ chord (P118536U) was derived by interpolation of span-wise adjacent tap measurements.

\section{Aerodynamic Force Coefficients}

The pressure distributions for rotating-blade data were integrated to compute normal force coefficients $\left(\mathrm{C}_{\mathrm{N}}\right)$ and tangent force coefficients $\left(\mathrm{C}_{\mathrm{T}}\right)$, which represent the forces acting perpendicular and parallel to the airfoil chord, respectively. The average pressure between two adjacent taps was first projected onto the chord line, integrated to determine the $\mathrm{C}_{\mathrm{N}}$ values, and then projected onto an axis orthogonal to the chord and integrated to compute $\mathrm{C}_{\mathrm{T}}$ values. This procedure is described in detail by Rae and Pope (1984). Equations 7 and 8 give the integration procedure used to determine $\mathrm{C}_{\mathrm{N}}$ and $\mathrm{C}_{\mathrm{T}}$. The $\mathrm{x}$ and $\mathrm{y}$ values begin at the trailing edge $(\mathrm{x}=1)$, proceed forward over the upper surface of the blade, and then aft along the bottom surface, ending at the starting point, the trailing edge.

$$
\begin{aligned}
C_{N} & =\sum_{i=1}^{\text {\#oftaps }}\left(\frac{C_{p_{i}}+C_{p_{i+1}}}{2}\right)\left(x_{i+1}-x_{i}\right), \text { and } \\
C_{T} & =\sum_{i=1}^{\text {\#oftaps }}\left(\frac{C_{p_{i}}+C_{p_{i+1}}}{2}\right)\left(y_{i+1}-y_{i}\right) ;
\end{aligned}
$$

where,

$\mathrm{C}_{\mathrm{p}}=$ normalized pressure coefficient

$\mathrm{x}_{\mathrm{i}}=$ normalized distance along chord line from leading edge to $\mathrm{i}^{\text {th }}$ pressure tap

$\mathrm{y}_{\mathrm{i}}=$ normalized distance from chord line along axis orthogonal to chord to $\mathrm{i}^{\text {th }}$ pressure tap.

In a similar integral procedure, pitching moment coefficients $\left(\mathrm{C}_{M}\right)$ were determined. The pitching moment represents the total moment about the pitch axis ( $1 / 4$ chord $)$ due to the normal and tangential forces at a pressure tap with the vertical or horizontal distance from the pitch axis as the moment arm. This equation follows:

$$
C_{M}=-\sum_{i=1}^{\# \text { oftaps }}\left[\left(\frac{C_{p_{i}}+C_{p_{i+1}}}{2}\right)\left[\left(x_{i+1}-x_{i}\right)\left(\frac{x_{i+1}-x_{i}}{2}+x_{i}-0.25\right)+\left(y_{i+1}-y_{i}\right)\left(\frac{y_{i+1}-y_{i}}{2}+y_{i}\right)\right]\right] \text {. }
$$

All other airfoil performance coefficients, such as lift $\left(\mathrm{C}_{\mathrm{L}}\right)$, pressure drag $\left(\mathrm{C}_{\mathrm{Dp}}\right)$, torque $\left(\mathrm{C}_{\text {torque }}\right)$, and thrust $\left(\mathrm{C}_{\text {thrust }}\right)$, were computed using the $\mathrm{C}_{\mathrm{N}}$ and $\mathrm{C}_{\mathrm{T}}$ values together with their reference angles. Torque and thrust coefficients were calculated as a function of blade pitch angle $(\beta)$ and local twist angle $(\phi)$, both of which were easily measured. Lift and pressure drag coefficients, on the other hand, rely upon the angle of attack $(\alpha)$, which is not as easily acquired. For this reason, only torque and thrust coefficients were included in the recorded data, but the equations used to determine lift and pressure drag coefficients are shown below. 


$$
\begin{gathered}
C_{\text {Torque }}=C_{N} \sin (\phi+\beta)+C_{T} \cos (\phi+\beta), \\
C_{\text {Thrust }}=C_{N} \cos (\phi+\beta)-C_{T} \sin (\phi+\beta), \\
C_{L}=C_{N} \cos (\alpha)+C_{T} \sin (\alpha), \text { and } \\
C_{D p}=-\left(C_{N} \sin (\alpha)-C_{T} \cos (\alpha)\right) .
\end{gathered}
$$

Torque and thrust coefficients were integrated along the span of the blade and multiplied by the number of blades (2) to provide a rough estimate of the total aerodynamic thrust and torque applied to the entire rotor. This integration divided the blade into panels that extend halfway between full-chord pressure tap locations. It was assumed that the pressure at the pressure tap location was applied evenly over the corresponding panel. The panel at the root began at $14.4 \%$ span and extended to halfway between the $30 \%$ and $47 \%$ span stations. The panel at the tip began halfway between the $80 \%$ and $95 \%$ stations and extended to the tip. There is no tip loss model applied. In highly yawed conditions, the assumption that each blade is enduring the same load is problematic. These estimates are provided primarily for the purpose of rough measurement cross-checking and estimating general trends in uniform flow conditions. Thrust is positive downwind and torque is positive in the direction of rotation. These derived channels appear in Table 13, and the equations follow:

$$
\begin{aligned}
& \text { EAEROTH }=2 * \sum_{n=1}^{5} C_{T H n} * \text { QNORM }_{n} * \text { area }_{n} \\
& \text { EAEROTQ }=2 * \sum_{n=1}^{5} C_{T Q_{n}} * \text { QNORM }_{n} * \text { area }_{n} * r_{n}
\end{aligned}
$$

where,

$\mathrm{n}=$ index for each panel,

QNORM = blade stagnation pressure at full-chord pressure tap location, $\mathrm{Pa}$, area $=$ area of each trapezoidal panel, $\mathrm{m}^{2}$,

$\mathrm{r}=$ radial location to full-chord pressure tap location along the blade span, $\mathrm{m}$. 
Table 13. Aerodynamic Force Coefficients

\begin{tabular}{|c|c|l|c|}
\hline Channel & Channel ID & Description & Units \\
\hline 813 & EAEROTH & Estimated aerodynamic thrust & N \\
\hline 814 & EAEROTQ & Estimated aerodynamic torque & $\mathrm{Nm}$ \\
\hline 817 & CN30 & Normal Force at 30\% Span & $\mathrm{Cn}$ \\
\hline 818 & CT30 & Tangent Force at 30\% Span & $\mathrm{Ct}$ \\
\hline 819 & CTH30 & Thrust Coeff at 30\% Span & Cth \\
\hline 820 & CTQ30 & Torque Coeff at 30\% Span & Ctq \\
\hline 821 & CM30 & Pitch Moment Coeff at 30\% Span & Cm \\
\hline 823 & CN47 & Normal Force at 47\% Span & Cn \\
\hline 824 & CT47 & Tangent Force at 47\% Span & Ct \\
\hline 825 & CTH47 & Thrust Coeff at 47\% Span & Cth \\
\hline 826 & CTQ47 & Torque Coeff at 47\% Span & Ctq \\
\hline 827 & CM47 & Pitch Moment Coeff at 47\% Span & Cm \\
\hline 829 & CN63 & Normal Force at 63\% Span & Cn \\
\hline 830 & CT63 & Tangent Force at 63\% Span & Ct \\
\hline 831 & CTH63 & Thrust Coeff at 63\% Span & Cth \\
\hline 832 & CTQ63 & Torque Coeff at 63\% Span & Ctq \\
\hline 833 & CM63 & Pitch Moment Coeff at 63\% Span & Cm \\
\hline 835 & CN80 & Normal Force at 80\% Span & Cn \\
\hline 836 & CT80 & Tangent Force at 80\% Span & $\mathrm{Ct}$ \\
\hline 837 & CTH80 & Thrust Coeff at 80\% Span & Cth \\
\hline 838 & CTQ80 & Torque Coeff at 80\% Span & Ctq \\
\hline 839 & CM80 & Pitch Moment Coeff at 80\% Span & Cm \\
\hline 841 & CN95 & Normal Force at 95\% Span & Cn \\
\hline 842 & CT95 & Tangent Force at 95\% Span & Ct \\
\hline 843 & CTH95 & Thrust Coeff at 95\% Span & Cth \\
\hline 844 & CTQ95 & Torque Coeff at 95\% Span & Ctq \\
\hline 845 & CM95 & Pitch Moment Coeff at 95\% Span & Cm \\
\hline
\end{tabular}

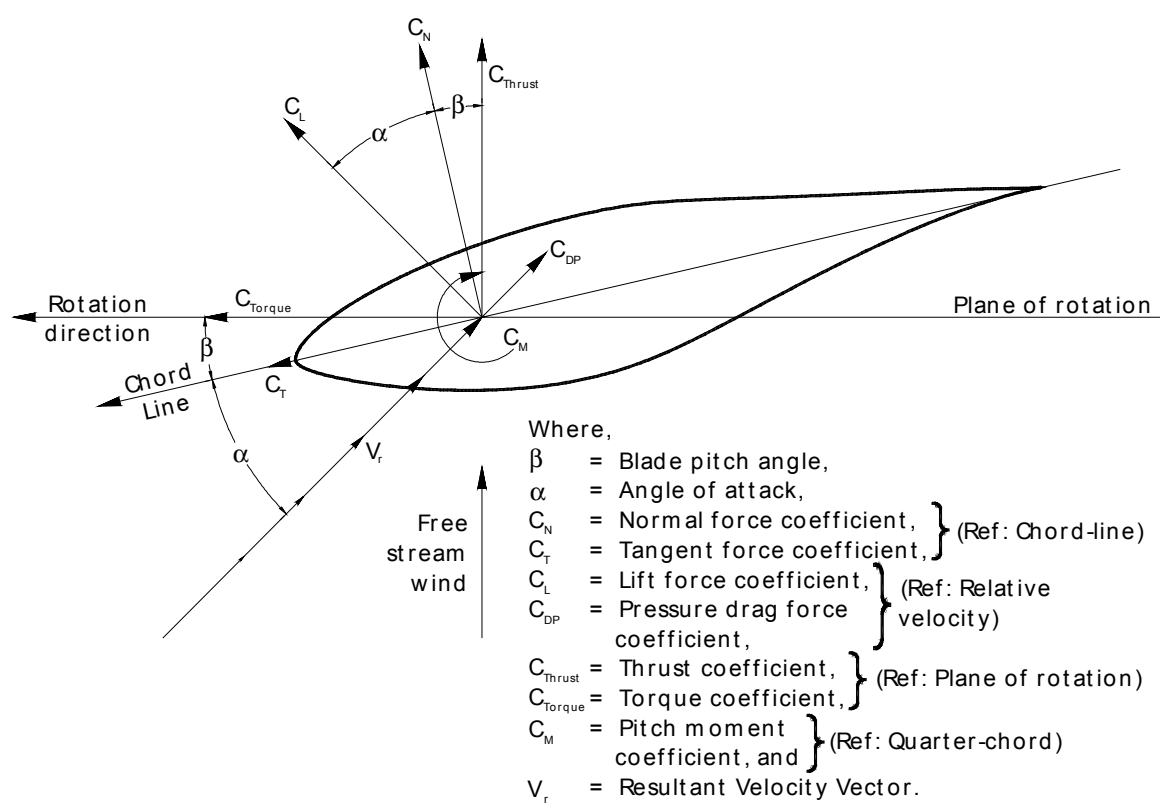

Figure 13. Aerodynamic force coefficient conventions 


\section{Flow Angles}

The 5-hole probes measure the local flow angle and the spanwise flow angle as listed in Table 14. The angular values are extracted from tables based upon the neural network surfaces. The normalized difference between opposing ports in each 5-hole probe is used together with bilinear interpolation to locate the resulting angle in each table. Tables exist for each probe for both the local flow angle and the spanwise flow angle.

The probe stalks were designed to be aligned with the chord and perpendicular with the pitch and twist axis. The probes were then attached to the stalk at a nominal $20^{\circ}$ angle to place the probe in better alignment with the flow when the turbine is operating. The actual angle between the chord and the probe was measured at each span location. Table 14 contains these measured angles between each probe and the chord. The local flow angle measurement from the probe is not aligned with the full-chord pressure measurements introducing blade twist and rotational effects for which no correction is applied. The local flow angle recorded in these channels is relative to the chord of the blade at the radial location where the probe is mounted. In other words, the offset shown in Table 14 was added to the angle measured by each probe. The spanwise flow angle is positive outboard, and it is measured in the plane of the probe not the blade chord. No corrections for the $20^{\circ}$ angle were made.

Table 14. Local Flow Angle Measurements (5-Hole Probe)

\begin{tabular}{|c|c|l|c|c|}
\hline Channel & Channel ID & Description & Offset Angle & Units \\
\hline 853 & 5HP34A & 5Hole 34\% Local Flow Angle (Angle of Attack) & 18.7 & deg \\
\hline 856 & 5HP51A & 5Hole 51\% Local Flow Angle (Angle of Attack) & 19.3 & deg \\
\hline 859 & 5HP67A & 5Hole 67\% Local Flow Angle (Angle of Attack) & 20.8 & deg \\
\hline 862 & 5HP84A & 5Hole 84\% Local Flow Angle (Angle of Attack) & 18.4 & deg \\
\hline 865 & 5HP91A & 5Hole 91\% Local Flow Angle (Angle of Attack) & 19.2 & deg \\
\hline 854 & 5HP34F & 5Hole 34\% Spanwise Flow Angle & & deg \\
\hline 857 & 5HP51F & 5Hole 51\% Spanwise Flow Angle & & deg \\
\hline 860 & 5HP67F & 5Hole 67\% Spanwise Flow Angle & & deg \\
\hline 863 & 5HP84F & 5Hole 84\% Spanwise Flow Angle & & deg \\
\hline 866 & 5HP91F & 5Hole 91\% Spanwise Flow Angle & \\
\hline
\end{tabular}

\section{Angle of Attack}

During Phase II and Phase III tests, a flow-angle flag device was used to measure local flow angle. This assembly is shown in Figure 14. Wind tunnel tests were performed with the flag sensor mounted on a full-chord scale airfoil section in order to develop a correction for upwash and to determine the dynamic characteristics of the flag. The configuration and resulting data are explained in the Phase I report (Butterfield, Musial, and Simms 1992). The upwash correction derived from a polynomial fit of the wind tunnel test data was applied to the local flow angle measurements made with the 5-hole probes to arrive at the angle of attack. For measured local flow angles less than $-10^{\circ}$ and greater than $60^{\circ}$, linear relationships were used.

$$
\begin{gathered}
\alpha=0.58090 * \alpha_{m}-0.46470 \text { for } \alpha_{m}<-10^{\circ} \\
\alpha=-(5.427 E-5) * \alpha_{m}{ }^{3}+(6.713 E-3) * \alpha_{m}{ }^{2}+(0.617) * \alpha_{m}-0.8293 ; \\
\alpha=0.93421 * \alpha_{m}-7.4174 \text { for } \alpha_{m}>60^{\circ}
\end{gathered}
$$

where, 
$\alpha=$ angle of attack (deg) and

$\alpha_{\mathrm{m}}=$ local flow angle measurement (deg).

This upwash correction has proven satisfactory in determining aerodynamic performance (Simms et al. 1996) for measurements made with the flag sensor, but this application of the upwash correction to the 5-hole probe could be improved. The 5-hole probes measure a local flow angle $4 \%$ span outboard of the pressure tap locations ( $4 \%$ span inboard of the $95 \%$ pressure tap location) which are used to calculate aerodynamic force coefficients. Both the local flow angle measurement and the angle of attack were included in the engineering-unit files. Channels associated with angle of attack are listed in the table below.

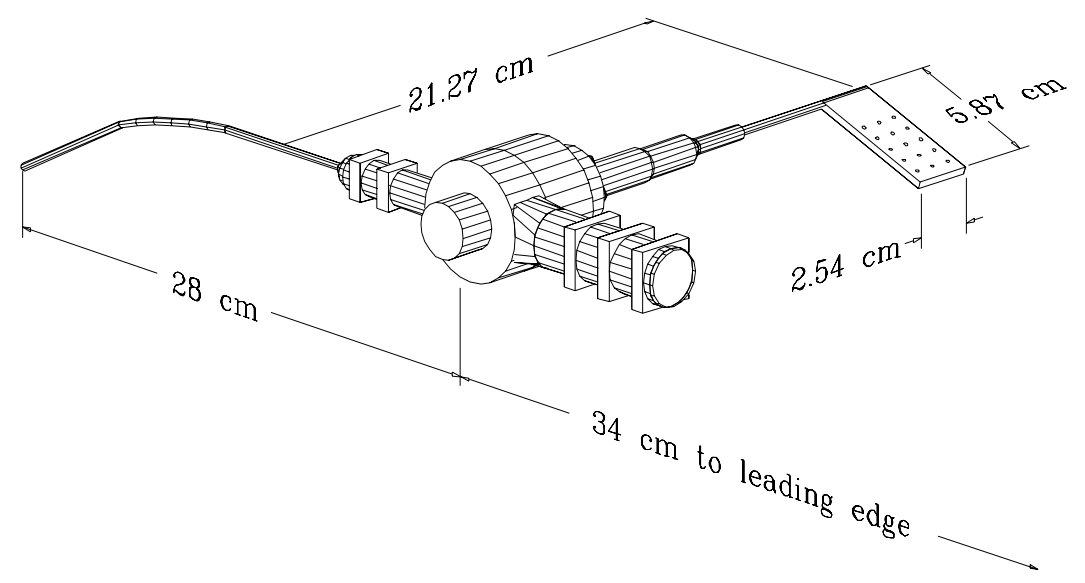

Figure 14. Local flow angle flag assembly.

Table 15. Upwash Corrected LFA Measurements

\begin{tabular}{|c|c|l|r|}
\hline Channel & Channel ID & Description & Units \\
\hline 867 & $345 \mathrm{HP}$ & 5HP 34\% Span - Upwash Corrected & deg \\
\hline 868 & $515 \mathrm{HP}$ & 5HP 51\% Span - Upwash Corrected & deg \\
\hline 869 & $675 \mathrm{HP}$ & 5HP 67\% Span - Upwash Corrected & deg \\
\hline 870 & $845 \mathrm{HP}$ & 5HP 84\% Span - Upwash Corrected & deg \\
\hline 871 & $915 \mathrm{HP}$ & 5HP 91\% Span - Upwash Corrected & deg \\
\hline
\end{tabular}

\section{Other Derived Channels}

Yaw error describes the misalignment of the turbine with the prevailing wind. The channel representing yaw error included in the engineering-unit files was calculated by finding the difference between the sonic measured wind direction (LMSWD1) and the turbine angle (YAW). This value is then restricted to $\pm 180^{\circ}$.

$$
\text { yawerr }=y a w-\text { wind direction }
$$




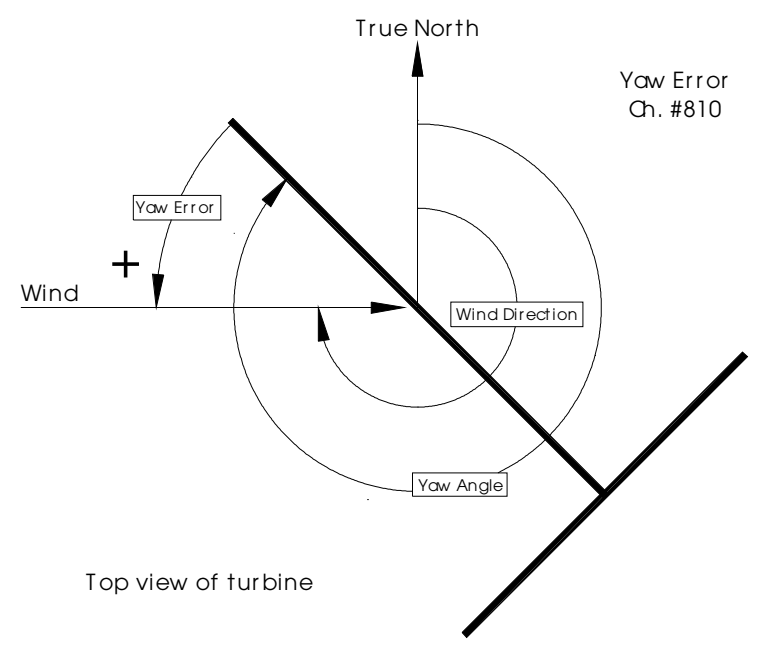

Figure 15. Yaw error angle convention.

The rotational speed of the rotor was determined as a running average. The blade azimuth position and the corresponding time for the record 150 steps prior to the current record are subtracted from the current blade azimuth and time. The output is in units of RPM.

Additionally, a cycle counting channel was incremented each time the instrumented blade completed a rotation.

The gradient Richardson number provides an indication of atmospheric stability based on temperature gradients and wind shear. This was calculated using the following equations on a sample-by-sample basis. This number is more appropriately calculated using time-averaged parameters. The data summary tables in Appendix D contain Richardson numbers calculated using 10-minute averaged wind speeds, temperature, and barometric pressure.

$$
R i=\frac{\left(\frac{9.8}{\Theta_{m}}\right)\left(\frac{\Delta \Theta}{\Delta Z}\right)}{{\overline{V_{\text {shear }}}}^{2}}, \Theta=T\left(\frac{100,000}{P}\right)^{0.286}, \bar{V}_{\text {shear }}=\frac{\sum_{n=1}^{N-1} \frac{W S_{n+1}-W S_{n}}{Z_{n+1}-Z_{n}}}{N-1} ;
$$

where,

$\mathrm{Ri}=$ Richardson Number (dimensionless),

$\Theta_{\mathrm{m}}=$ Average potential temperature between top of tower and bottom of tower $(\mathrm{K})$,

$\Delta \Theta=$ potential temperature difference between top of tower and bottom of tower $(\mathrm{K})$,

$\Delta \mathrm{Z}=$ elevation difference between temperature measurements $(\mathrm{m})$,

$\mathrm{V}_{\text {shear }}=$ Average vertical wind shear over $\Delta \mathrm{Z}(\mathrm{m} / \mathrm{s} / \mathrm{m})$,

$\Theta=$ potential temperature $(\mathrm{K})$,

$\mathrm{T}=$ measured, dry-bulb temperature $(\mathrm{K})$,

$\mathrm{P}=$ barometric pressure $(\mathrm{Pa})$,

$\mathrm{N}=$ number of wind speed measurements,

$\mathrm{WS}_{\mathrm{n}}=$ wind speed $(\mathrm{m} / \mathrm{s})$, and

$\mathrm{Z}_{\mathrm{n}}=$ elevation at $\mathrm{n}^{\text {th }}$ wind speed measurement (m).

A sonic anemometer was used to measure wind velocity and direction in the $\mathrm{u}, \mathrm{v}$, and $\mathrm{w}$ orthogonal component directions. These vector components were transformed into magnitude and direction during post-processing using vector relations. 
The 16-bit Mensor signal was stored as two data channels during data collection. The postprocessing software accommodated glitches that occurred with the channel containing the additional 4 bits. These two channels were converted into one engineering unit channel that provided the difference between the upwind free-stream static pressure and the reference pressure inside the instrumentation box.

Table 16. Miscellaneous Channels

\begin{tabular}{|c|c|l|c|}
\hline Channel & Channel ID & Description & Units \\
\hline 810 & YAWERR & Yaw Error & $\mathrm{deg}$ \\
\hline 811 & RPM & Current RPM & $\mathrm{rpm}$ \\
\hline 812 & CYCLECNT & Cycle Count & $\mathrm{rev}$ \\
\hline 815 & MENSOR & Mensor & $\mathrm{Pa}$ \\
\hline 816 & RICHN & Richardson Number & $(\mathrm{none})$ \\
\hline 850 & LMSWS1 & Sonic \#1 WS (horiz) & $\mathrm{m} / \mathrm{s}$ \\
\hline 851 & LMSWD1 & Sonic \#1 WD & $\mathrm{deg}$ \\
\hline
\end{tabular}

\section{Reference Pressure Correction}

Every pressure transducer was referenced to the pressure inside one of the instrumentation boxes. If this pressure is assumed to be free-stream static pressure, then the total pressure measurements made with the 5-hole probes are actually dynamic pressure measurements. For the same reason, the stagnation pressure on the blade is also a measurement of dynamic pressure. The dynamic pressure of the free stream can be estimated using the wind speed measurements from the cup anemometers and local air density derived from temperature and barometric pressure data. Comparison of the wind-speed-derived dynamic pressure and the pressure system measured dynamic pressures (neglecting the dynamic pressure due to rotational effects at each span location) showed a consistent offset. This offset has been attributed to the fact that the pressure inside the instrumentation box is not free-stream static pressure, as was assumed. Therefore, all of the pressure measurements must be corrected by subtracting the difference between the pressure in the box and the free stream static pressure.

The measured dynamic pressure on the blade that is stored in the data files includes the correction applied to account for the centrifugal force acting on the air in the reference pressure tube. By subtracting this amount, the result is the actual pressure measured by the transducer. This value was plotted versus the wind speed derived dynamic pressure for each of the five span locations. The data plotted were cycle-averaged values that were selected using limiting criteria on wind speed variation and yaw error angle variation over the cycle. All wind speed ranges and yaw error angle ranges were included. A linear fit was applied to the data representing each of the five span locations, and the slope values were averaged. The deviation from a slope of 1.0 provides a measure of the difference between the box pressure and the free stream static pressure. Table 17 lists the correction factors for parked-blade data and for rotating-blade data.

\section{Table 17. Reference Pressure Correction Factors}

\begin{tabular}{|c|c|}
\hline Phase V & Correction factor \\
\hline Parked blade & 0.24 \\
\hline Rotating blade & 0.32 \\
\hline
\end{tabular}

The correction must be applied to all of the data on either a cycle-averaged or time-step basis by users of the data. The magnitude of the correction is determined using the blade stagnation 
pressure at 30\% span and $47 \%$ span because these transducers have the highest resolution. First, the centrifugal force correction that was applied during post-processing is removed. Then the average measured dynamic pressure at the two span locations is calculated. The slope correction factor that was determined using data across all wind conditions is then applied, resulting in the magnitude of the pressure correction $(\mathrm{Pa})$ that must be subtracted from all measured pressures at all span locations.

$$
\text { correction }=\text { factor } * \frac{\left(Q_{\text {stag } 30 \%}-P_{\text {cent } 30 \%}+Q_{\text {stag } 47 \%}-P_{\text {cent } 47 \%}\right)}{2} ;
$$

where,

$\mathrm{Q}_{\text {stag }}=$ stagnation point pressure at the $30 \%$ or $47 \%$ station $(\mathrm{Pa})$,

$\mathrm{P}_{\text {cent }}=$ centrifugal force correction at the $30 \%$ or $47 \%$ station $(\mathrm{Pa})$, and

factor $=$ varies for rotating and non-rotating conditions.

An example of the calculation of the correction magnitude for rotating-blade data using the channel ID codes is shown below:

1. Remove centrifugal force correction from blade dynamic pressure at $30 \%$ span and $47 \%$ span.

$$
\begin{aligned}
& Q_{30}=\text { QNORM } 30-\frac{1}{2}\left(\frac{B A R O}{287.04 *(L M T 2 M+273.15)}\right)\left(0.3 * 5.023 * R P M * \frac{\pi}{30}\right)^{2} \\
& Q_{47}=\text { QNORM } 47-\frac{1}{2}\left(\frac{B A R O}{287.04 *(L M T 2 M+273.15)}\right)\left(0.47 * 5.023 * R P M * \frac{\pi}{30}\right)^{2}
\end{aligned}
$$

2. Average the measured dynamic pressures.

$$
Q_{\text {ave }}=\frac{Q_{30}+Q_{47}}{2}
$$

3. Apply correction factor.

$$
\text { correction }=0.32 * Q_{\text {ave }}
$$

4. Correct measured pressure coefficient at $30 \%$ span, leading edge.

$$
P 2230000_{\text {corrected }}=\frac{P 2230000 * Q N O R M 30-\text { correction }}{Q N O R M 30-\text { correction }}
$$

The pressure difference measured by the Mensor was intended to provide this correction. By subtracting the Mensor signal from the measured pressures prior to centrifugal force correction, a corrected dynamic pressure value similar to the correction above is obtained. However, this measured pressure difference does not provide a correlation of 1.0 between the measured dynamic pressures and the wind speed estimated dynamic pressure. Thus, the upwind probe is influenced by the rotor and is not positioned such that it can measure free-stream static pressure.

\section{Conclusions}

The two-bladed, teetered-rotor version of the Unsteady Aerodynamics Experiment has successfully provided data in the 3-D unsteady operating environment. Full-chord pressure tap distributions permit calculation of aerodynamic force coefficients and pressure distributions at five span locations. The use of 5-hole probes near each of the full-chord pressure tap stations provides local flow angle and spanwise flow angle measurements. Additional measurements 
provide inflow conditions, position information, and loads at the blade root, hub shaft, and lowspeed shaft. This report provides the reader with detailed information regarding the type of instrumentation used and the mathematical manipulations of the data. 
Appendix A

Phase V Turbine Parameters 


\section{Basic Machine Parameters}

- Number of blades: 2

- Rotor diameter: $10.046 \mathrm{~m}$

- Hub height: $17.03 \mathrm{~m}$

- Type of rotor: teetered

- Rotational speed: $71.63 \mathrm{rpm}$ synchronous speed

- Cut-in wind speed: $6 \mathrm{~m} / \mathrm{s}$ (tests were run at lower speeds)

- Power regulation: stall

- Rated power: $19.8 \mathrm{~kW}$

- Tilt: $1^{\circ}$ (positive tilt indicates boom tip higher than upwind side of low-speed shaft; blade pitch angle was calibrated assuming $1^{\circ}$ tilt)

- Cone angle: $3.4^{\circ}$

- Location of rotor: downwind

- Rotational direction: clockwise (viewed from downwind)

- Rotor overhang: $1.32 \mathrm{~m}$ (yaw-axis to apex of blade cone angle; teeter pin $0.074 \mathrm{~m}$ downwind of apex).

- No full-system modal test was performed on this turbine configuration.

\section{Rotor}

\section{Geometry}

- Blade cross section and planform: NREL S809 (constant chord, no taper, optimally twisted)

- Root extension: $0.723 \mathrm{~m}$

- Blade pitch angle (manually set by turbine operator): $-9^{\circ},-3^{\circ}, 3^{\circ}, 8^{\circ}$, and $12^{\circ}$ (see each data file).

- Blade profile: NREL S809

- Blade chord: $0.4572 \mathrm{~m}$ at all span stations

- Blade twist: see Table 18. 
Table 18. Blade Twist

\begin{tabular}{|cc|}
\hline $\begin{array}{c}\text { Radius } \\
\text { from Rotor } \\
\text { Center }(\mathbf{m})\end{array}$ & Twist $\mathbf{(}^{\circ}$ ) \\
\hline 0.724 & 44.67 \\
0.880 & 39.39 \\
1.132 & 32.29 \\
1.383 & 26.56 \\
1.634 & 21.95 \\
1.886 & 18.19 \\
2.137 & 15.10 \\
2.389 & 12.52 \\
2.640 & 10.35 \\
2.892 & 8.50 \\
3.143 & 6.91 \\
3.395 & 5.52 \\
3.646 & 4.32 \\
3.897 & 3.25 \\
4.149 & 2.30 \\
4.400 & 1.45 \\
4.652 & 0.69 \\
4.903 & 0.00 \\
\hline
\end{tabular}

- Blade thickness:

- At 14.4\% span: $\mathrm{t}=43.0 \%$ chord (span refers to rotor center)

- Between $14.4 \%$ and $25.0 \%$ span the thickness decreases linearly

- At $25.0 \%$ span: $\mathrm{t}=20.95 \%$ chord

- Outboard of $25.0 \%$ span: $\mathrm{t}=20.95 \%$ chord

- Airfoil distribution: Except for the root, the blade uses the S809 at all span locations. The airfoil coordinates are shown in Table 19. In the root sections the airfoil shape is altered by the enlarged spar. This enlargement is a virtually perfect circle (in cross section) at the root, which is centered at the quarter chord. The thickness of the spar area enlargement varies from this maximum at the root to a thickness that fits inside the airfoil profile at the $25 \%$ span (and outboard). In between the root and 25\% span the spar area enlargement is flattened into consecutively thinner and thinner elliptic shapes, but each ellipse has a perimeter equal to the circumference of the base circle. Figure 16 illustrates the blade surface in the root region. 
Table 19. Airfoil Profile Coordinates

\begin{tabular}{|c|c|c|c|}
\hline \multicolumn{2}{|c|}{ Upper Surface } & \multicolumn{2}{c|}{ Lower Surface } \\
\hline $\mathbf{x} / \mathbf{c}$ & $\mathbf{y} / \mathbf{c}$ & $\mathbf{x} / \mathbf{c}$ & $\mathbf{y} / \mathbf{c}$ \\
\hline 0.00037 & 0.00275 & 0.00140 & -0.00498 \\
\hline 0.00575 & 0.01166 & 0.00933 & -0.01272 \\
\hline 0.01626 & 0.02133 & 0.02321 & -0.02162 \\
\hline 0.03158 & 0.03136 & 0.04223 & -0.03144 \\
\hline 0.05147 & 0.04143 & 0.06579 & -0.04199 \\
\hline 0.07568 & 0.05132 & 0.09325 & -0.05301 \\
\hline 0.10390 & 0.06082 & 0.12397 & -0.06408 \\
\hline 0.13580 & 0.06972 & 0.15752 & -0.07467 \\
\hline 0.17103 & 0.07786 & 0.19362 & -0.08447 \\
\hline 0.20920 & 0.08505 & 0.23175 & -0.09326 \\
\hline 0.24987 & 0.09113 & 0.27129 & -0.10060 \\
\hline 0.29259 & 0.09594 & 0.31188 & -0.10589 \\
\hline 0.33689 & 0.09933 & 0.35328 & -0.10866 \\
\hline 0.38223 & 0.10109 & 0.39541 & -0.10842 \\
\hline 0.42809 & 0.10101 & 0.43832 & -0.10484 \\
\hline 0.47384 & 0.09843 & 0.48234 & -0.09756 \\
\hline 0.52005 & 0.09237 & 0.52837 & -0.08697 \\
\hline 0.56801 & 0.08356 & 0.57663 & -0.07442 \\
\hline 0.61747 & 0.07379 & 0.62649 & -0.06112 \\
\hline 0.66718 & 0.06403 & 0.67710 & -0.04792 \\
\hline 0.71606 & 0.05462 & 0.72752 & -0.03558 \\
\hline 0.76314 & 0.04578 & 0.77668 & -0.02466 \\
\hline 0.80756 & 0.03761 & 0.82348 & -0.01559 \\
\hline 0.84854 & 0.03017 & 0.86677 & -0.00859 \\
\hline 0.88537 & 0.02335 & 0.90545 & -0.00370 \\
\hline 0.91763 & 0.01694 & 0.93852 & -0.00075 \\
\hline 0.94523 & 0.01101 & 0.96509 & 0.00054 \\
\hline 0.96799 & 0.00600 & 0.98446 & 0.00065 \\
\hline 0.98528 & 0.00245 & 0.99612 & 0.00024 \\
\hline 0.99623 & 0.00054 & 1.00000 & 0.00000 \\
\hline 1.00000 & 0.00000 & 0.00000 & 0.00000 \\
\hline
\end{tabular}

(Butterfield, Musial, and Simms 1992)

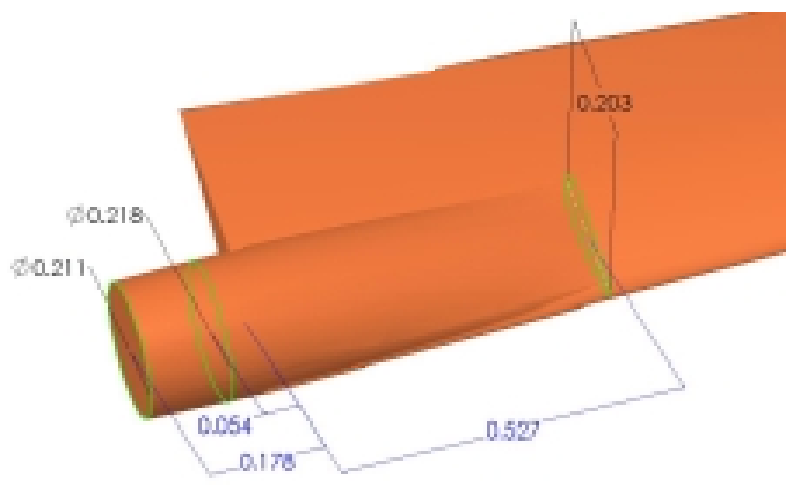

Figure 16. Blade root surface depiction (dimensions in meters) 


\section{Aerodynamics for S809 Airfoil}

- Performance coefficients ( $\alpha=$ angle of attack; $C_{1}=$ lift coefficient, $C_{d p}=$ pressure drag coefficient) obtained at the Colorado State University wind tunnel with a Reynolds number of 500,000 are shown in Table 20 (Butterfield, Musial, and Simms 1992; for additional wind tunnel measurements, see Somers 1997).

Table 20. Wind Tunnel Profile Coefficients

\begin{tabular}{|r|r|r|}
\hline \multicolumn{1}{|c|}{$\boldsymbol{\alpha}$} & \multicolumn{1}{c|}{$\mathbf{C}_{\text {l }}$} & $\mathbf{C}_{\text {dp }}$ \\
\hline-2.23 & $-6.00 \mathrm{E}-02$ & $6.00 \mathrm{E}-03$ \\
\hline$-1.61 \mathrm{E}-01$ & $1.56 \mathrm{E}-01$ & $4.00 \mathrm{E}-03$ \\
\hline 1.84 & $3.69 \mathrm{E}-01$ & $6.00 \mathrm{E}-03$ \\
\hline 3.88 & $5.71 \mathrm{E}-01$ & $8.00 \mathrm{E}-03$ \\
\hline 5.89 & $7.55 \mathrm{E}-01$ & $9.00 \mathrm{E}-03$ \\
\hline 7.89 & $8.60 \mathrm{E}-01$ & $1.70 \mathrm{E}-02$ \\
\hline 8.95 & $8.87 \mathrm{E}-01$ & $2.40 \mathrm{E}-02$ \\
\hline 9.91 & $8.69 \mathrm{E}-01$ & $3.50 \mathrm{E}-02$ \\
\hline 10.9 & $8.68 \mathrm{E}-01$ & $3.90 \mathrm{E}-02$ \\
\hline 12 & $8.94 \mathrm{E}-01$ & $4.80 \mathrm{E}-02$ \\
\hline 12.9 & $9.38 \mathrm{E}-01$ & $6.10 \mathrm{E}-02$ \\
\hline 14 & $9.29 \mathrm{E}-01$ & $7.40 \mathrm{E}-02$ \\
\hline 14.9 & $9.08 \mathrm{E}-01$ & $8.00 \mathrm{E}-02$ \\
\hline 16 & $9.12 \mathrm{E}-01$ & $1.06 \mathrm{E}-01$ \\
\hline 17 & $6.55 \mathrm{E}-01$ & $2.71 \mathrm{E}-01$ \\
\hline 18 & $5.88 \mathrm{E}-01$ & $2.65 \mathrm{E}-01$ \\
\hline 19 & $5.87 \mathrm{E}-01$ & $2.81 \mathrm{E}-01$ \\
\hline 20 & $5.97 \mathrm{E}-01$ & $2.99 \mathrm{E}-01$ \\
\hline 22 & $6.03 \mathrm{E}-01$ & $3.26 \mathrm{E}-01$ \\
\hline 24 & $6.47 \mathrm{E}-01$ & $3.75 \mathrm{E}-01$ \\
\hline 26 & $6.83 \mathrm{E}-01$ & $4.19 \mathrm{E}-01$ \\
\hline 28.1 & $7.45 \mathrm{E}-01$ & $4.82 \mathrm{E}-01$ \\
\hline 30 & $8.24 \mathrm{E}-01$ & $5.60 \mathrm{E}-01$ \\
\hline 35 & 1.05 & $8.17 \mathrm{E}-01$ \\
\hline 40 & 1.14 & 1.03 \\
\hline 45 & 1.2 & 1.26 \\
\hline 50 & 1.12 & 1.38 \\
\hline 55 & 1.17 & 1.7 \\
\hline 60 & 1.08 & 1.87 \\
\hline 65 & $9.40 \mathrm{E}-01$ & 1.98 \\
\hline 70 & $8.57 \mathrm{E}-01$ & 2.19 \\
\hline 74.9 & $6.66 \mathrm{E}-01$ & 2.17 \\
\hline 79.9 & $4.72 \mathrm{E}-01$ & 2.21 \\
\hline 84.8 & $3.56 \mathrm{E}-01$ & 2.32 \\
\hline 89.9 & $1.42 \mathrm{E}-01$ & 2.09 \\
\hline & & \\
\hline
\end{tabular}




\section{Structural Properties}

- Rotor mass: $606.4 \mathrm{~kg}$

- Pitch shaft, bull gear, instrumentation, bearings, nut, spacers: $38.6 \mathrm{~kg}$ (for one blade)

- Hub mass: $237.8 \mathrm{~kg}$

- Boom, instrumentation enclosures, lights, and camera mass: $152.2 \mathrm{~kg}$

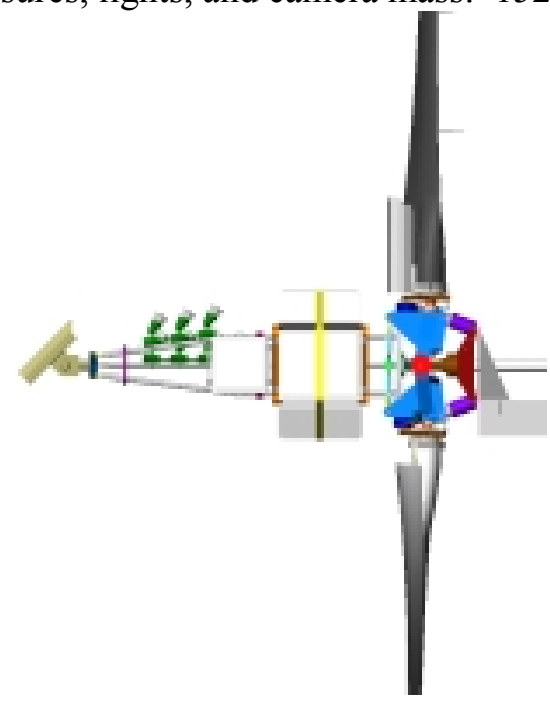

Figure 17. Hub-mounted instrumentation boxes, boom, and camera

- Blade material: Fiberglass/epoxy composite

- Blade mass (outside root; includes blade mounted camera):

- Blade 1: $69.6 \mathrm{~kg}$

- Blade 3: $69.6 \mathrm{~kg}$

- Blade center of gravity (from the center of rotation):

- Blade 1: $2.004 \mathrm{~m}$

- Blade 3: $1.994 \mathrm{~m}$

- Blade mass and stiffness distributions:

- Estimates of mass and stiffness distributions were made by the blade manufacturer (Composite Engineering 1994). The pressure instrumentation and counterweights were included, as well as the root-mounted camera. 
Table 21. Phase V, Twisted Blade, Structural Properties

\begin{tabular}{|c|c|c|c|}
\hline $\begin{array}{c}\text { Distance } \\
\text { from Rotor } \\
\text { Center }(\mathbf{m})\end{array}$ & $\begin{array}{c}\text { Mass } \\
\mathbf{( k g} / \mathbf{m})\end{array}$ & $\begin{array}{c}\text { Edgewise } \\
\text { Stiffness } \\
\mathbf{( N m}^{\mathbf{2}} \mathbf{)}\end{array}$ & $\begin{array}{c}\text { Flapwise } \\
\text { Stiffness } \\
\mathbf{( N m}^{\mathbf{2}} \mathbf{)}\end{array}$ \\
\hline 5.029 & 9.32 & 46,953 & 365,070 \\
\hline 4.526 & 9.25 & 46,953 & 387,600 \\
\hline 4.023 & 10.22 & 65,974 & 436,440 \\
\hline 3.520 & 11.19 & 84,468 & 512,420 \\
\hline 3.018 & 12.06 & 105,560 & 583,420 \\
\hline 2.515 & 12.95 & 123,480 & 650,900 \\
\hline 2.012 & 13.49 & 149,420 & 737,010 \\
\hline 1.509 & 16.92 & 232,180 & 997,640 \\
\hline 1.006 & 46.09 & 710,230 & $1,332,800$ \\
\hline 0.749 & 45.18 & $1,302,400$ & $1,556,800$ \\
\hline 0.508 & 30.14 & $2,320,700$ & $2,322,100$ \\
\hline 0.402 & & 473,517 & 473,517 \\
\hline
\end{tabular}

- First edge-wise eigenfrequency:

- Non-instrumented blade: $8.16 \mathrm{~Hz}, 0.84 \%$ damping

- Instrumented blade: $7.97 \mathrm{~Hz}, 0.69 \%$ damping.

- First flap-wise eigenfrequency:

- Non-instrumented blade: $4.94 \mathrm{~Hz}, 0.9 \%$ damping

- Instrumented blade: $4.79 \mathrm{~Hz}, 0.95 \%$ damping.

\section{Power Train}

\section{Layout}

- The power train consists of the rotor mounted on a low-speed shaft coupled to a high-speed shaft via a gearbox. The high-speed shaft couples directly to an induction generator. The mechanical brake is positioned on the high-speed shaft.

\section{Characteristics}

- Power train inertia (low-speed shaft, gearbox, high-speed shaft, generator): $179 \mathrm{~kg} \mathrm{~m}^{2}$

- Power train stiffness (low-speed shaft, gearbox, and high-speed shaft as a lumped parameter): $1.70 \cdot 10^{5} \mathrm{Nm} / \mathrm{rad}$.

- Drive train frequency: $5.77 \mathrm{~Hz}$

- Gearbox ratio: 25.13:1

- Gearbox inertia: Not available

- Gearbox stiffness: Not available

- Gearbox suspension stiffness: Not available

- Gearbox suspension damping: Not available

- High-speed shaft inertia: Not available

- High-speed shaft damping: $0.5 \%$ to $1.0 \%$

- High-speed shaft stiffness: Not available

- Generator inertia: $143 \mathrm{~kg} \mathrm{~m}^{2}$ w.r.t. low-speed shaft

- Generator slip: $1.59 \%$ at $20 \mathrm{~kW}$ 
- Generator time constant: $<0.025$ seconds (electro-mechanical time constant, for generator only)

- Power train efficiency:

- Gearbox: 97\% (from Grumman design documents)

- Windage, couplings, main shaft bearings: 98\% (from Grumman design documents)

- Generator: The efficiency curve (in \%) of the combined system (gearbox + generator) versus generator power $(\mathrm{kW})$ is as follows:

$$
\mathrm{Eff}=\mathrm{P}_{\mathrm{gen}} /\left(\left(4.533223 \cdot 10^{-3}\right) \cdot \mathrm{P}_{\mathrm{gen}}{ }^{2}+\left(1.115023 \cdot 10^{0}\right) \cdot \mathrm{P}_{\mathrm{gen}}+\left(1.500035 \cdot 10^{0}\right)\right) * 100 .
$$

Thus, the efficiency is fairly constant at about $78 \%$.

- Maximum brake torque: $115.24 \mathrm{Nm}$.

\section{Tower}

\section{Description}

- Basic description: two different diameter cylinders connected by a short conical section. The conical section base is $5.385 \mathrm{~m}$ above the ground. The conical section top is $6.300 \mathrm{~m}$ above the ground. The tower is further supported by four guy wires attached $11.91 \mathrm{~m}$ above the ground. The guy wires descend to the ground at an angle 44.3 degrees below horizontal. The ground anchors for the four wires are at the following compass directions from the tower axis: $90^{\circ}, 180^{\circ}, 270^{\circ}$, and $360^{\circ}$.

\section{Characteristics}

- Tower material: 9.525-mm Corten steel

- Tower height: $15.9 \mathrm{~m}$

- Tower diameter(base): $0.4572 \mathrm{~m}$

- Tower diameter(top): $0.4064 \mathrm{~m}$

- Tower mass: $1481 \mathrm{~kg}$

- Tower head mass: $1279 \mathrm{~kg}$ (hub and nacelle)

- Position of tower head c.g.: Not available

- Bending spring constant: $48,118 \mathrm{~N} / \mathrm{m}$

- Torsional stiffness: Not available

- Torsional damping: Not available

- Nacelle inertia: $1211 \mathrm{~kg} \mathrm{~m}^{2}$

- First tower bending eigenfrequency (x): $5.49 \mathrm{~Hz}, 1.22 \%$ damping

- First tower bending eigenfrequency (y): $5.71 \mathrm{~Hz}, 1.49 \%$ damping

- First tower torsion eigenfrequency: Not available

- First tower/nacelle eigenfrequency (x): $1.95 \mathrm{~Hz}, 1.87 \%$ damping

- First tower/nacelle eigenfrequency (y): $1.94 \mathrm{~Hz}, 2.10 \%$ damping. 
Appendix B

Instrumentation, Data Collection, and Data Processing for Phase V 


\section{Anemometers (Cup)}

\begin{tabular}{|c|c|c|c|c|c|}
\hline Channel & ID Code & \multicolumn{4}{|c|}{ Description } \\
\hline 300 & LMWS24M & \multicolumn{4}{|c|}{ Local met wind speed, $24.38 \mathrm{~m}$} \\
\hline 302 & LMWS17M & \multicolumn{4}{|c|}{ Local met wind speed, $17.02 \mathrm{~m}$ (hub height) } \\
\hline 304 & LMWS10M & \multicolumn{4}{|c|}{ Local met wind speed, $10.06 \mathrm{~m}$} \\
\hline 306 & LMWS2M & \multicolumn{4}{|c|}{ Local met wind speed, $2.4 \mathrm{~m}$} \\
\hline 308 & NLMWS17M & \multicolumn{4}{|c|}{ North local met wind speed, $17.02 \mathrm{~m}$ (hub height) } \\
\hline 314 & SLMWS17M & \multicolumn{4}{|c|}{ South local met wind speed, $17.02 \mathrm{~m}$ (hub height) } \\
\hline \multicolumn{2}{|l|}{ Location } & \multicolumn{4}{|c|}{ Met towers located 1.5D (15 m) upwind of turbine } \\
\hline \multicolumn{2}{|c|}{ Measurement type and units } & \multicolumn{4}{|c|}{ Wind speed, $\mathrm{m} / \mathrm{s}$} \\
\hline \multirow{7}{*}{\multicolumn{2}{|c|}{ Sensor description }} & \multicolumn{4}{|c|}{ Cup anemometer } \\
\hline & & \multicolumn{4}{|c|}{ DC pulse output, photo chopper type } \\
\hline & & \multicolumn{4}{|c|}{ Distance constant $=1.5 \mathrm{~m}$} \\
\hline & & \multicolumn{4}{|c|}{ Threshold $=0.45 \mathrm{~m} / \mathrm{s}$} \\
\hline & & \multicolumn{4}{|c|}{ Accuracy $= \pm 1 \%$ of true, certified at $6.70 \mathrm{~m} / \mathrm{s}$ and $25.03 \mathrm{~m} / \mathrm{s}$} \\
\hline & & \multirow{2}{*}{\multicolumn{4}{|c|}{$\begin{array}{l}\text { Met One Instruments } \\
\text { Model: 1564B (wind speed sensor), 170-41 (standard } \\
\text { plastic cup set) }\end{array}$}} \\
\hline & & & & & \\
\hline \multirow{2}{*}{$\begin{array}{l}\text { Cup } \\
\text { Anemometer }\end{array}$} & Wind Speed & \multirow{2}{*}{\begin{tabular}{|l} 
Butterworth \\
filter \\
p. 103
\end{tabular}} & Analog to & 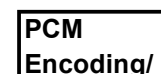 & \multirow{2}{*}{$\begin{array}{l}\text { PC Data Storage } \\
\text { and Processing } \\
\text { p. } 108\end{array}$} \\
\hline & $\begin{array}{l}\text { Processor } \\
\text { p. } 46\end{array}$ & & $\rightarrow \mid \begin{array}{l}\text { Digital } \\
\text { Conversion } \\
\text { p. } 104\end{array}$ & $\begin{array}{l}\text { Decoding } \\
\text { p. } 105\end{array}$ & \\
\hline
\end{tabular}




\section{Wind Speed Processor}

$\begin{array}{ll}\text { Location } & \text { Met rack in data shed } \\ \text { Range } & 0 \text { to } 50 \mathrm{~m} / \mathrm{s}=0 \text { to } 5 \text { volts (Established with the following } \\ & \text { switch settings: } \mathrm{S} 2=1,4,7 ; \mathrm{S} 3=5) \\ \text { Resolution } & 10 \mathrm{~m} / \mathrm{s} / \text { volt } \\ \text { Output level } & 0-5 \mathrm{Vdc} \\ \text { Nonlinearity } & \pm 0.25 \% \text { max } \\ \text { Calibration method } & \text { Manufacturer specifications (M1) and electronic path } \\ & \text { calibration (E1) } \\ \text { Description } & \text { Wind speed processor } \\ & \text { Met One Instruments } \\ & \text { Model: 49.03A (rack mount), } 21.11 \text { (processor), 48.11B } \\ & \text { (power supply) } \\ \end{array}$

\section{Calibration Procedure}

\section{Manufacturer specifications - (M1)}

1. A wind tunnel calibration was performed by Met One Instruments before installation of each anemometer. The correlation between the serial numbers of the cup assembly and the anemometer paired for calibration was maintained when installed in the field.

2. The wind speed processor is adjusted as follows:

a. With mode switch set to $\mathrm{LO}$, adjust voltage to $0 \mathrm{~V} \pm 1 \mathrm{mV}$.

b. With mode switch set to HI, adjust voltage to $3.810 \mathrm{~V} \pm 1 \mathrm{mV}$ (This value was specified by the manufacturer for a range of $0 \mathrm{~m} / \mathrm{s}$ to $50 \mathrm{~m} / \mathrm{s}$.).

c. Set mode switch to OP for normal operation.

3. Enter the slope $(50 \mathrm{~m} / \mathrm{s} / 5 \mathrm{~V})$ and the single-point offset $(0 \mathrm{~m} / \mathrm{s} / 0 \mathrm{~V})$ in the appropriate columns of calconst.xls (see p. 119).

\section{Electronic path calibration - (E1)}

1. Modify vbl.lst so that the wind speed channels are listed at the top of the file. Set NV (number of variables) in the first line to the number of channels to be calibrated, and ensure that the correct PCM stream is specified in gencal.cap (all meteorological measurements are on PCM stream 3).

2. Connect the precision voltage generator to the processor output.

3. Run the gc.bat batch file which invokes both gencal.exe and genfit.exe. Collect samples for voltages ranging from 0 to $4.5 \mathrm{~V}$ in $0.5 \mathrm{~V}$ increments with two repetitions at each voltage level. The recorded input and output values are stored in the *.cao input file. Genfit.exe computes slopes and offsets of the electronic path from the processor output to the computer in units of $\mathrm{V} /$ count and $\mathrm{V}$, respectively. These values are stored in a temporary header file, *.hdr. These slope and offset values are combined with the manufacturer-provided slope and offset stored in calconst.xls during the buildhdr.bat process to obtain units of engineering unit/count and counts, respectively. 


\section{Calibration frequency}

The anemometers were calibrated prior to each series of data collection or upon replacement due to cup damage. Processors were adjusted prior to each series of data collection which lasted 1 month at most. On occasion, the processors were adjusted during a series of data collection.
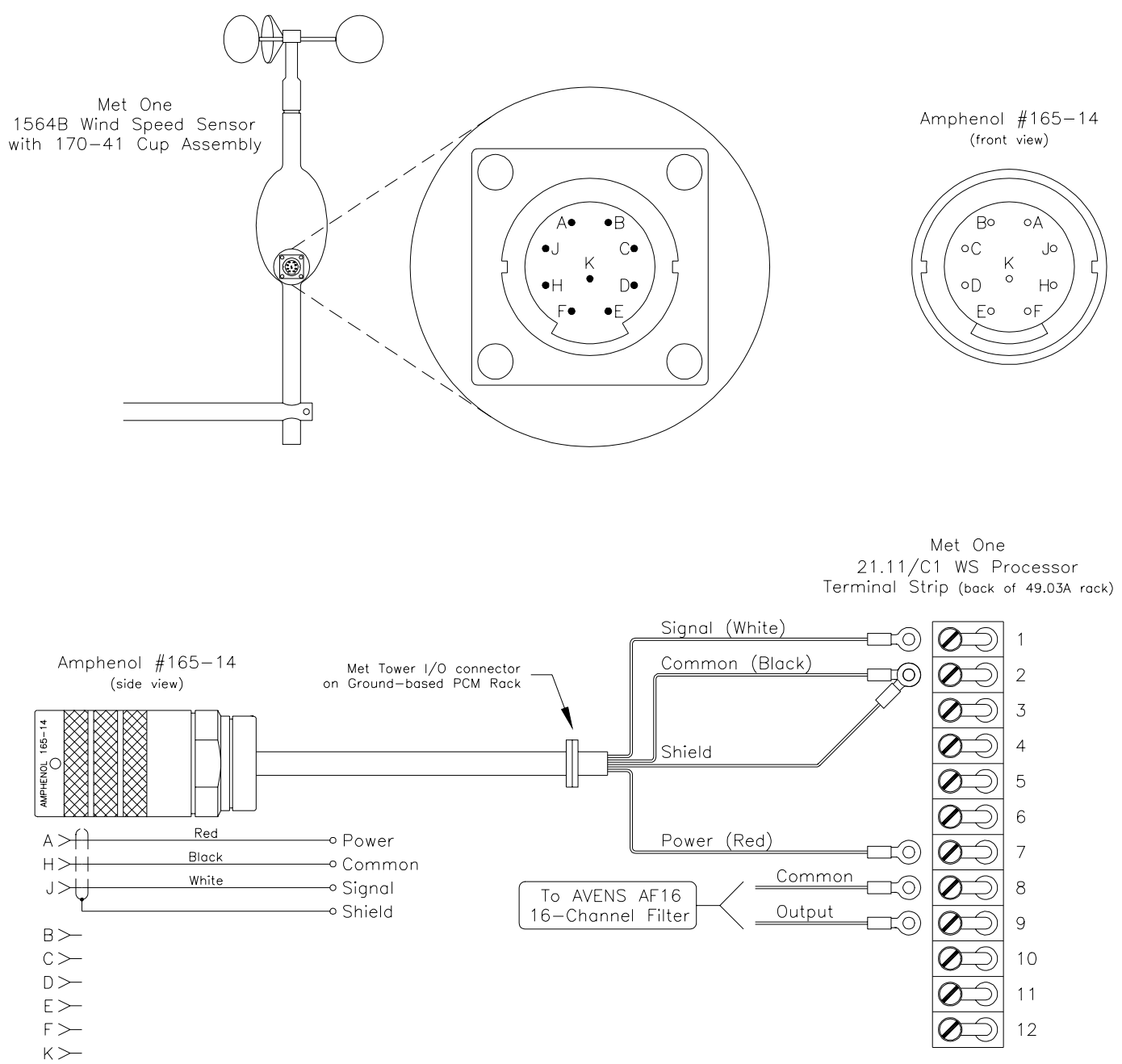

Figure 18. Cup anemometer wiring diagram 


\section{Anemometers (Bi-Vane)}

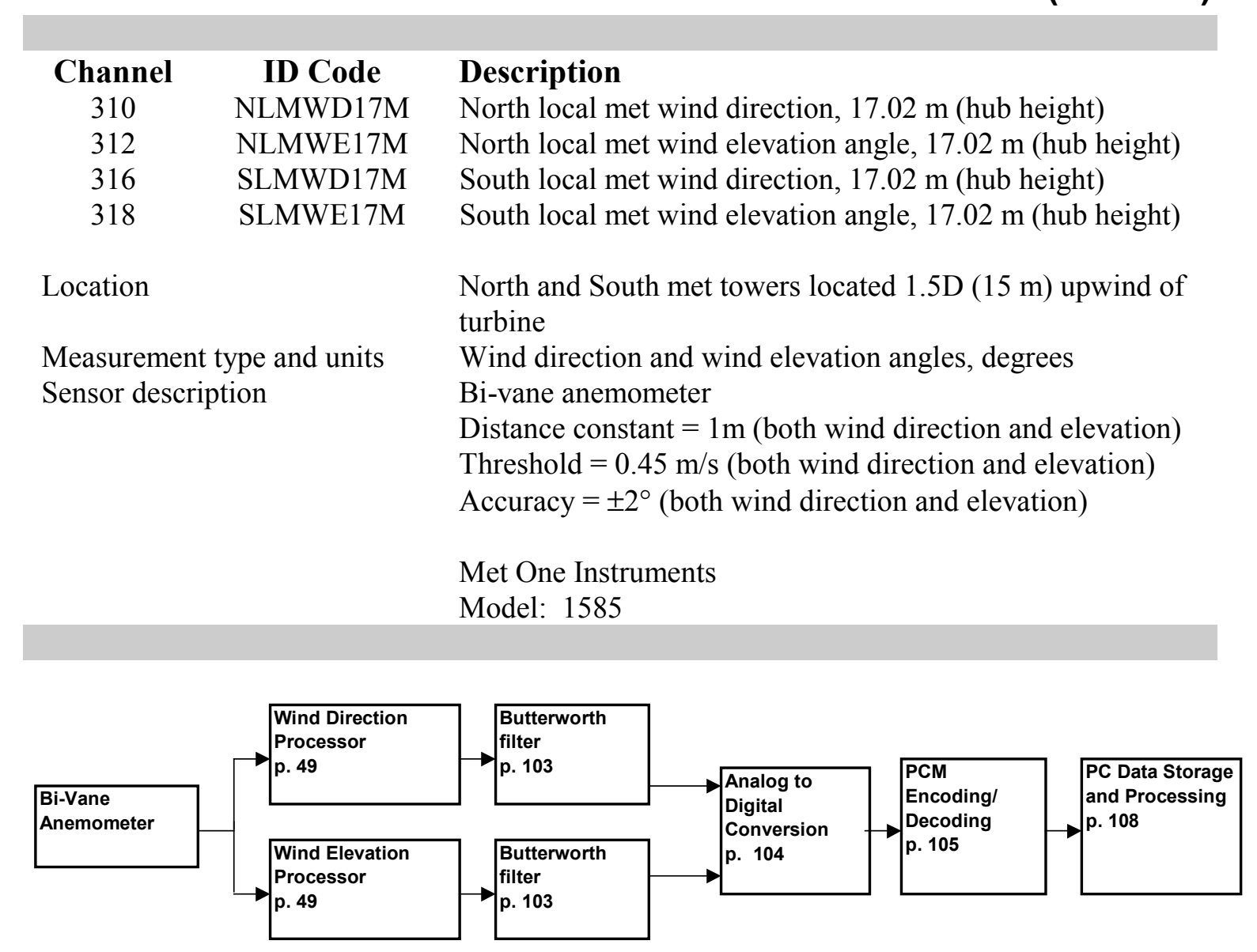




\section{Wind Direction Processor}

\begin{tabular}{|c|c|c|}
\hline Channel & ID Code & Description \\
\hline 310 & NLMWD17M & North local met wind direction, $17.02 \mathrm{~m}$ (hub height) \\
\hline 316 & SLMWD17M & South local met wind direction, $17.02 \mathrm{~m}$ (hub height) \\
\hline \multicolumn{2}{|l|}{ Location } & Met rack in data shed \\
\hline \multicolumn{2}{|l|}{ Range } & $0^{\circ}$ to $360^{\circ}=0 \mathrm{~V}$ to $5 \mathrm{~V}$ \\
\hline \multicolumn{2}{|l|}{ Resolution } & $72 \%$ volt \\
\hline \multicolumn{2}{|c|}{ Calibration method } & $\begin{array}{l}\text { Manufacturer specifications (M2), single-point offset } \\
\text { determination (S1), and electronic path calibration (E1) }\end{array}$ \\
\hline \multirow{3}{*}{\multicolumn{2}{|c|}{$\begin{array}{l}\text { Output level } \\
\text { Linearity } \\
\text { Description }\end{array}$}} & $0-5 \mathrm{Vdc}$ \\
\hline & & $\pm 0.1 \% \max$ \\
\hline & & Wind direction processor \\
\hline & & $\begin{array}{l}\text { Met One Instruments } \\
\text { Model: 49.03A (rack mount), } 21.21 \text { (processor), 48.11B } \\
\text { (power supply) }\end{array}$ \\
\hline
\end{tabular}

\section{Calibration Procedure}

\section{Manufacturer specifications - (M2)}

1. The bi-vane anemometers were calibrated by Met One Instruments according to manufacturer specifications before installation.

2. The wind direction processor is adjusted as follows:

a. With mode switch set to $\mathrm{LO}$, adjust voltage to $0 \mathrm{~V} \pm 1 \mathrm{mV}$.

b. With mode switch set to HI, adjust voltage to $5 \mathrm{~V} \pm 1 \mathrm{mV}$.

c. Set mode switch to OP for normal operation.

3. Enter the slope $\left(360^{\circ} / 5 \mathrm{~V}\right)$ in the slope column of calconst.xls

Single point offset determination - (S1) - (This is a two-person operation requiring one person in the man-lift to position the vanes and one person on the ground to record the voltages.)

1. Man-lift person notifies ground person which transducer is to be calibrated and aligns the vane by eye with the North met tower $\left(292^{\circ}\right.$ true north).

2. The ground person uses the voltmeter to record the vane position. The average voltage reading is inserted in the single-point offset column of calconst.xls.

\section{Electronic path calibration - (E1)}

1. Modify vbl.lst so that the wind direction channels are listed at the top of the file. Set NV (number of variables) in the first line to the number of channels to be calibrated, and ensure that the correct PCM stream is specified in gencal.cap (all meteorological measurements are on PCM stream 3).

2. Connect the precision voltage generator to the processor output.

3. Run the gc.bat batch file which invokes both gencal.exe and genfit.exe. Collect samples for voltages ranging from 0 to $4.5 \mathrm{~V}$ in $0.5 \mathrm{~V}$ increments with two repetitions at each voltage level. The recorded input and output values are stored in the *.cao input file. Genfit.exe 
computes slopes and offsets of the electronic path from the processor output to the computer in units of $\mathrm{V} /$ count and $\mathrm{V}$, respectively. These values are stored in a temporary header file,

*.hdr. These slope and offset values are combined with the manufacturer-provided slope and offset stored in calconst.xls during the buildhdr.bat process to obtain units of engineering unit/count and counts, respectively.

\section{Calibration frequency}

Amplifier adjustment, offset determination, and electronic path calibrations were performed prior to each series of data collection, which lasted less than 1 month. On occasion, the processors were adjusted during data collection. 


\section{Wind Elevation Processor}

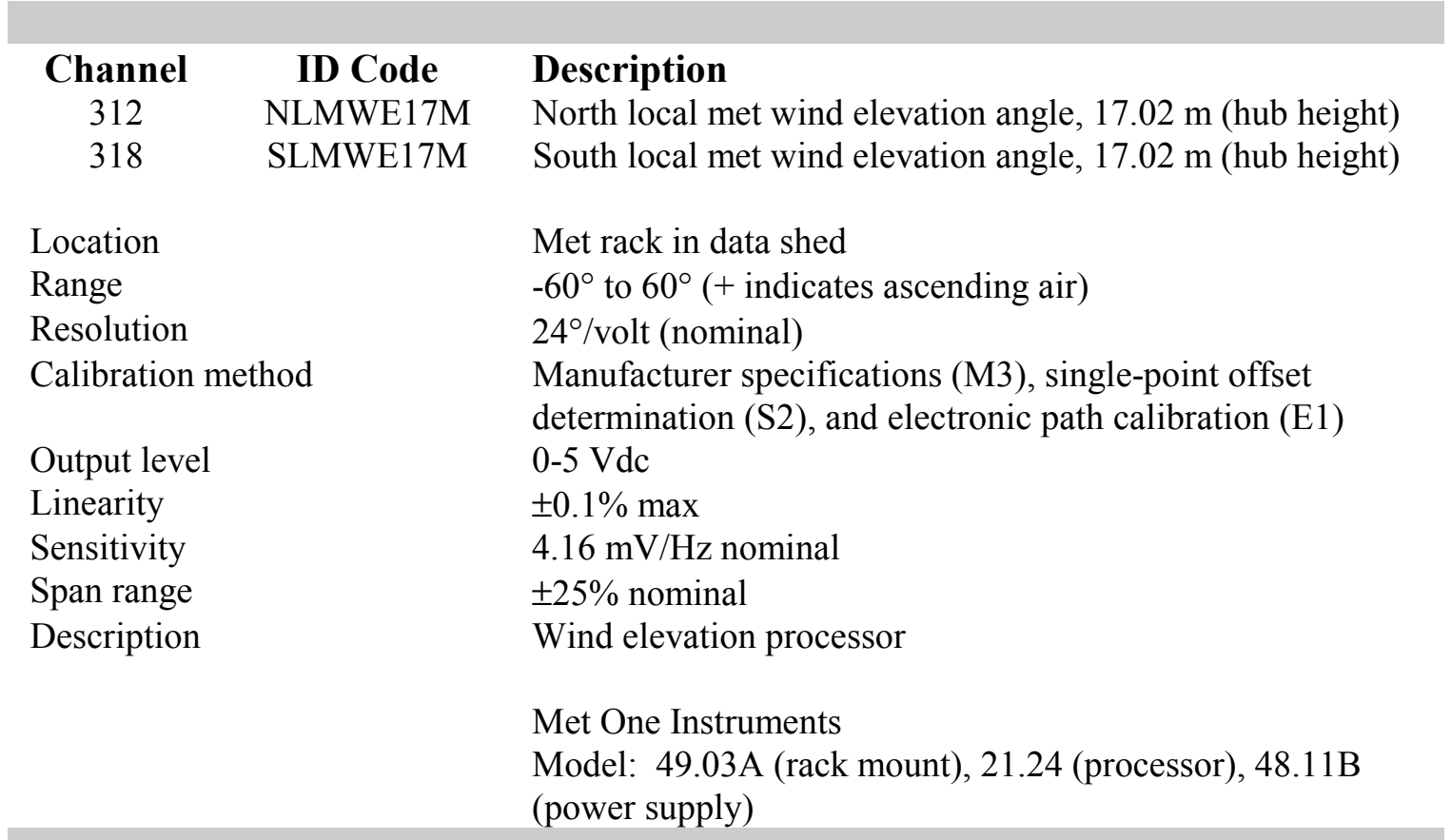

\section{Calibration Procedure}

\section{Manufacturer specifications - (M3)}

1. The bi-vane anemometers were calibrated by Met One Instruments according to manufacturer specifications before installation.

2. The wind elevation processor is adjusted as follows:

a. Determine LO and $\mathrm{HI}$ voltages using sensitivity $\left(\mathrm{SEN}\left[\mathrm{Hz} /{ }^{\circ}\right]\right)$ provided by manufacturer and the full-scale elevation angle $\left(\mathrm{FS}=60^{\circ}\right)$ in the following formulae:

$$
\begin{aligned}
& E L O=2.5 *\left(S E N^{*} F S-600\right) /\left(S E N^{*} F S\right), \\
& E H I=2.5 *\left(S E N^{*} F S+600\right) /\left(S E N^{*} F S\right) .
\end{aligned}
$$

b. With mode switch set to LO, adjust voltage to ELO $\pm 1 \mathrm{mV}$.

c. With mode switch set to HI, adjust voltage to EHI $\pm 1 \mathrm{mV}$.

d. Set mode switch to OP for normal operation.

3. Enter the slope $\left(24^{\circ} /\right.$ volt $)$ in the appropriate column of calconst.xls. The values used during Phases III and IV were determined in an unknown manner, but both bi-vane slopes were within $0.003 \%$ volt of $24 \%$ volt.

Single point offset determination - (S2) - (This is a two-person operation requiring one person in the man-lift to position the vanes and one person on the ground to operate the computer.)

1. Man-lift person notifies ground person which transducer is to be calibrated and, using an Angle-star, positions the vane at $0^{\circ}$.

2. The ground person uses the voltmeter to record the vane position. The average voltage value is inserted in the appropriate column of calconst.xls. 


\section{Electronic path calibration - (E1)}

1. Modify $v b l$.lst so that the wind elevation channels are listed at the top of the file. Set NV (number of variables) in the first line to the number of channels to be calibrated, and ensure that the correct PCM stream is specified in gencal.cap (all meteorological measurements are on PCM stream 3).

2. Connect the precision voltage generator to the processor output.

3. Run the gc.bat batch file which invokes both gencal.exe and genfit.exe. Collect samples for voltages ranging from 0 to $4.5 \mathrm{~V}$ in $0.5 \mathrm{~V}$ increments with two repetitions at each voltage level. The recorded input and output values are stored in the *.cao input file. Genfit.exe computes slopes and offsets of the electronic path from the processor output to the computer in units of $\mathrm{V} /$ count and $\mathrm{V}$, respectively. These values are stored in a temporary header file, *.hdr. These slope and offset values are combined with the manufacturer-provided slope and offset stored in calconst.xls during the buildhdr.bat process to obtain units of engineering unit/count and counts, respectively.

\section{Calibration frequency}

Amplifier adjustment, offset determination, and electronic path calibrations were performed prior to each series of data collection which lasted less than 1 month. On occasion, the processors were adjusted during data collection.

$\mathrm{S} / \mathrm{N} 055$ Sensitivity $=12.75 \mathrm{~Hz} / \mathrm{deg}, \mathrm{ELO}=0.539 \mathrm{~V}, \mathrm{EHI}=4.461 \mathrm{~V}$ (south met tower) $\mathrm{S} / \mathrm{N} 056$ Sensitivity $=12.24 \mathrm{~Hz} / \mathrm{deg}, \mathrm{ELO}=0.458 \mathrm{~V}, \mathrm{EHI}=4.542 \mathrm{~V}$ (north met tower) 


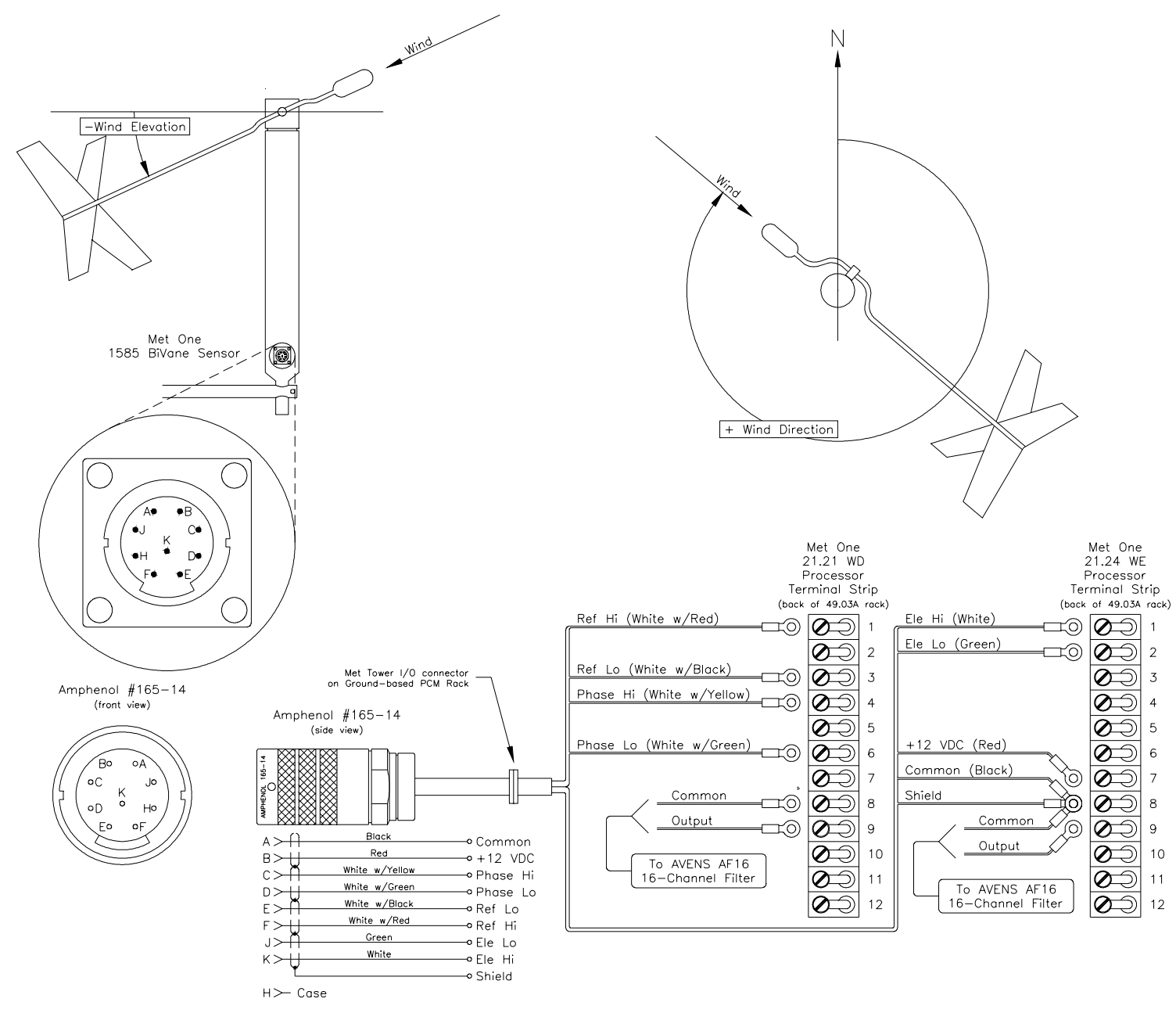

Figure 19. Bi-vane anemometor wiring diagram 


\section{Anemometers (Sonic)}

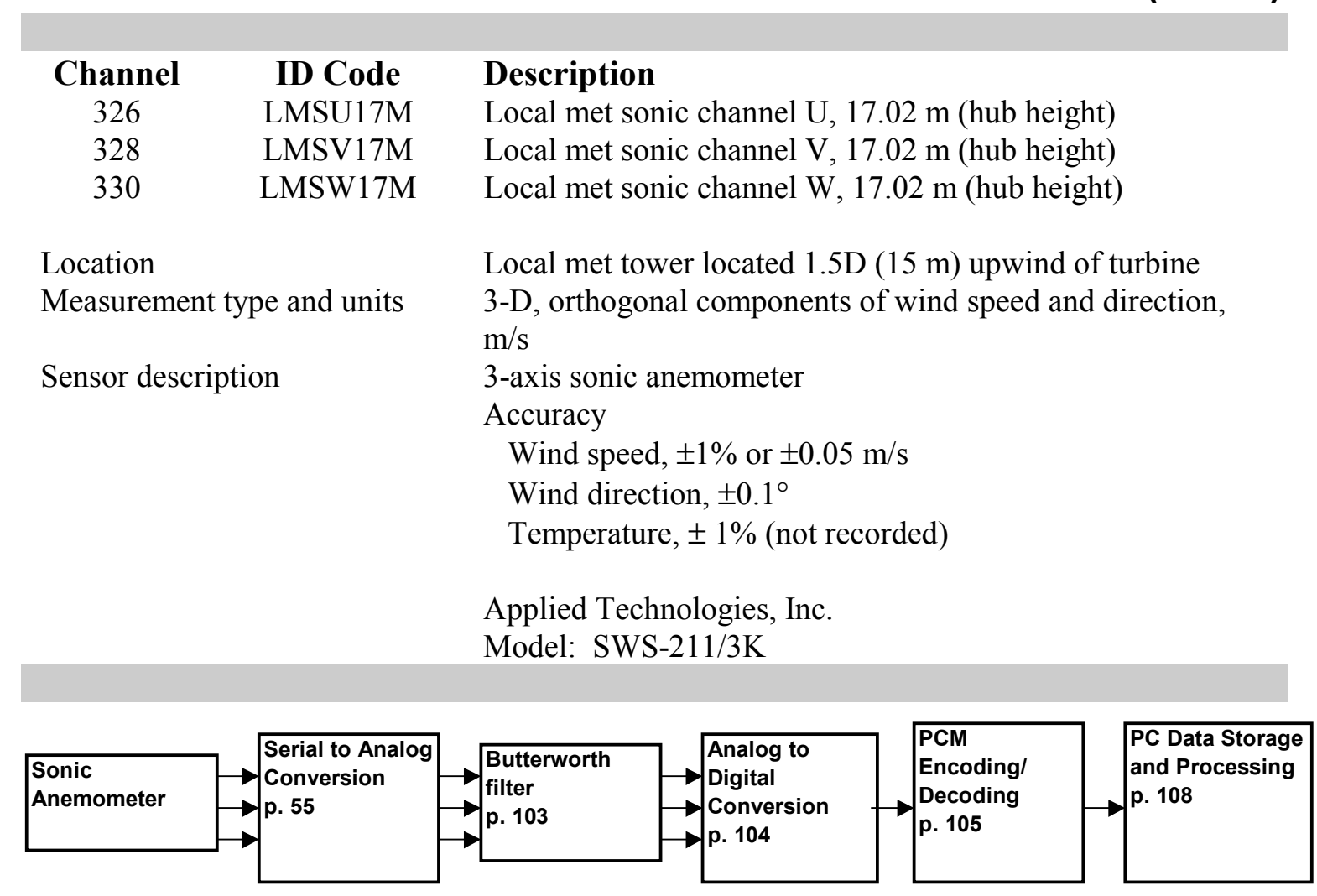

Note: Each of the three wind velocity components is contained in the PCM streams and recorded. Wind speed and direction are determined using these components during post-processing. The sonic's determination of wind speed, wind direction, and temperature is not used. 


\section{Sonic Serial to Analog Converter}

\begin{tabular}{|c|c|c|}
\hline Channel & ID Code & Description \\
\hline 326 & LMSU17M & Local met sonic channel U, $17.02 \mathrm{~m}$ (hub height) \\
\hline 328 & LMSV17M & Local met sonic channel V, $17.02 \mathrm{~m}$ (hub height) \\
\hline 330 & LMSW17M & Local met sonic channel $\mathrm{W}, 17.02 \mathrm{~m}$ (hub height) \\
\hline \multirow{4}{*}{\multicolumn{2}{|c|}{$\begin{array}{l}\text { Location } \\
\text { Range } \\
\text { Resolution } \\
\text { Calibration method }\end{array}$}} & Met rack in data shed \\
\hline & & $\pm 50 \mathrm{~m} / \mathrm{s}$ at $\pm 5 \mathrm{~V}(\mathrm{U}, \mathrm{V}) ; \pm 15 \mathrm{~m} / \mathrm{s}$ at $\pm 5 \mathrm{~V}(\mathrm{~W})$ \\
\hline & & $10 \mathrm{~m} / \mathrm{s} / \operatorname{Volt}(\mathrm{U}, \mathrm{V}) ; 3 \mathrm{~m} / \mathrm{s} / \operatorname{Volt}(\mathrm{W})$ \\
\hline & & $\begin{array}{l}\text { Manufacturer specifications (M4) and electronic path } \\
\text { calibration (E1) }\end{array}$ \\
\hline \multirow{3}{*}{\multicolumn{2}{|c|}{$\begin{array}{l}\text { Input signal } \\
\text { Output signal } \\
\text { Description }\end{array}$}} & Serial RS-232C \\
\hline & & $\pm 5 \mathrm{Vdc}$ \\
\hline & & Serial to analog converter \\
\hline & & $\begin{array}{l}\text { Applied Technologies, Inc. } \\
\text { Model: SA-4 }\end{array}$ \\
\hline
\end{tabular}

\section{Calibration Procedure}

\section{Manufacturer specifications - (M4)}

1. A calibration was performed by Applied Technologies before installation of the anemometer.

2. Enter the slope $(50 \mathrm{~m} / \mathrm{s} / 5 \mathrm{~V}$ for $U$ and $\mathrm{V} ; 15 \mathrm{~m} / \mathrm{s} / 5 \mathrm{~V}$ for $\mathrm{W})$ and the offset $(0 \mathrm{~m} / \mathrm{s} / 0 \mathrm{~V}$ for $\mathrm{U}, \mathrm{V}$, and $\mathrm{W}$ ) in the appropriate columns of calconst.xls.

3. Transducer calibration

a. Place zero-air chamber over axis to be calibrated. (Note: Ideally, this should be done in a controlled environment. Radiation from the sun can heat the inside of the chamber faster than the calibration is performed. If this is done outside, a cloudy day is preferable, and the ambient temperature must be greater than $0^{\circ} \mathrm{C}$.)

b. Enter the appropriate number in the "DATA ENTRY" thumbwheel. ( $\mathrm{U}=01, \mathrm{~V}=$ $02, \mathrm{~W}=03$ )

c. Press the "CALIBRATION" switch and enter the ambient air temperature (within $\pm 1^{\circ} \mathrm{C}$ ) once the "TEMP" light is illuminated. Depress the "CALIBRATION" switch once the temperature is entered.

d. The "TEST" light will blink twice and the new transducer calibration is complete.

\section{Electronic path calibration - (E1)}

1. Modify $v b l$.lst so that the sonic channels are listed at the top of the file. Set NV (number of variables) in the first line to the number of channels to be calibrated, and ensure that the correct PCM stream is specified in gencal.cap (all meteorological channels are on PCM stream 3).

2. Connect the precision voltage generator to the processor output.

3. Run the gc.bat batch file which invokes both gencal.exe and genfit.exe. Collect samples for voltages ranging from -4.5 to $4.5 \mathrm{~V}$ in $1-\mathrm{V}$ increments with two repetitions at each voltage level. The recorded input and output values are stored in the *.cao input file. Genfit.exe 
computes slopes and offsets of the electronic path from the processor output to the computer in units of $\mathrm{V} /$ count and $\mathrm{V}$, respectively. These values are stored in a temporary header file,

*.hdr. These slope and offset values are combined with the manufacturer-provided slope and offset stored in calconst.xls during the buildhdr.bat process to obtain units of engineering unit/count and counts, respectively.

\section{Calibration frequency}

The transducers were calibrated and an electronic path calibration was performed prior to each series of data collection which lasted less than 1 month.

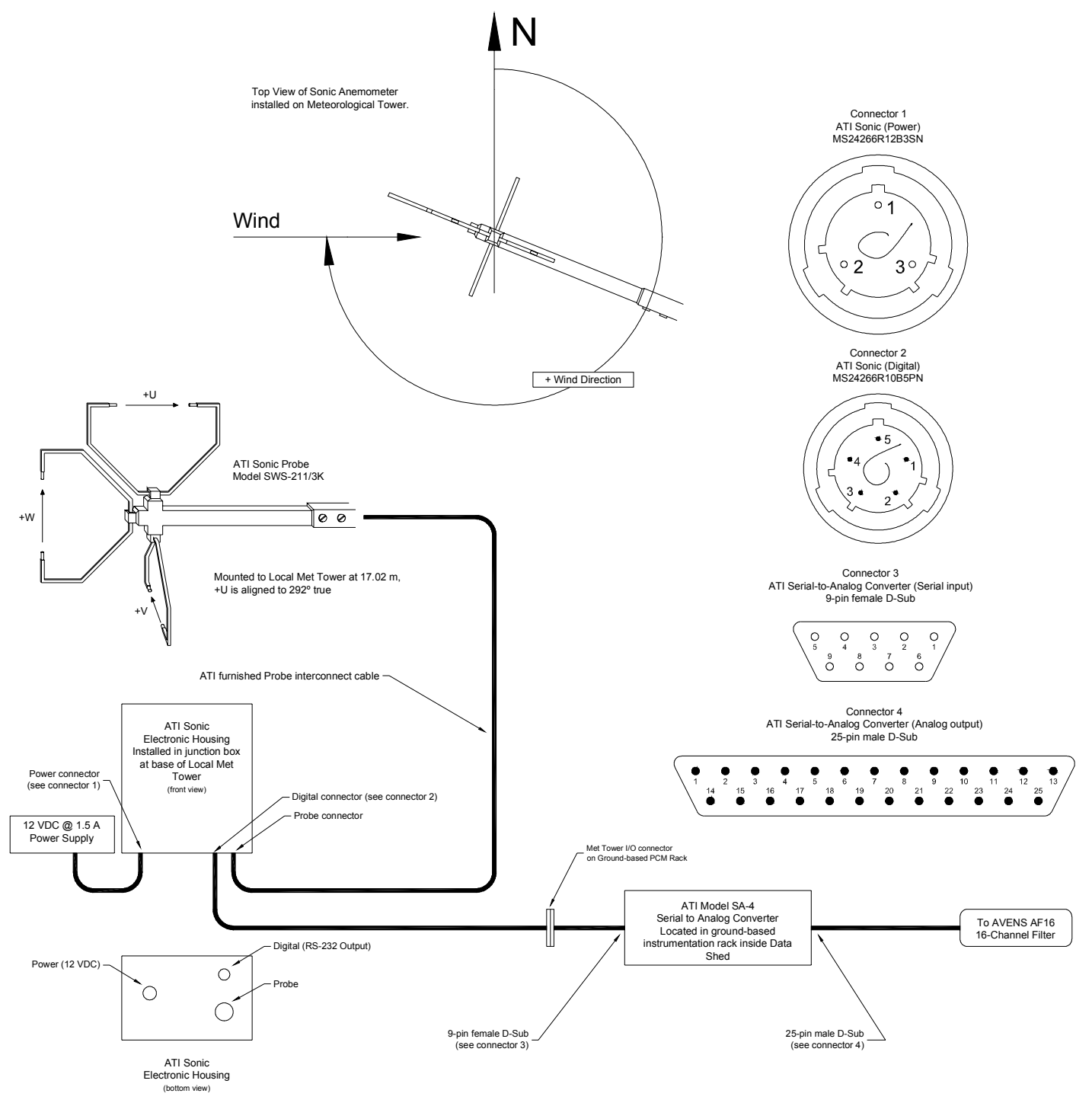

Figure 20. Sonic anemometer wiring diagram 


\section{Temperature (Ambient)}

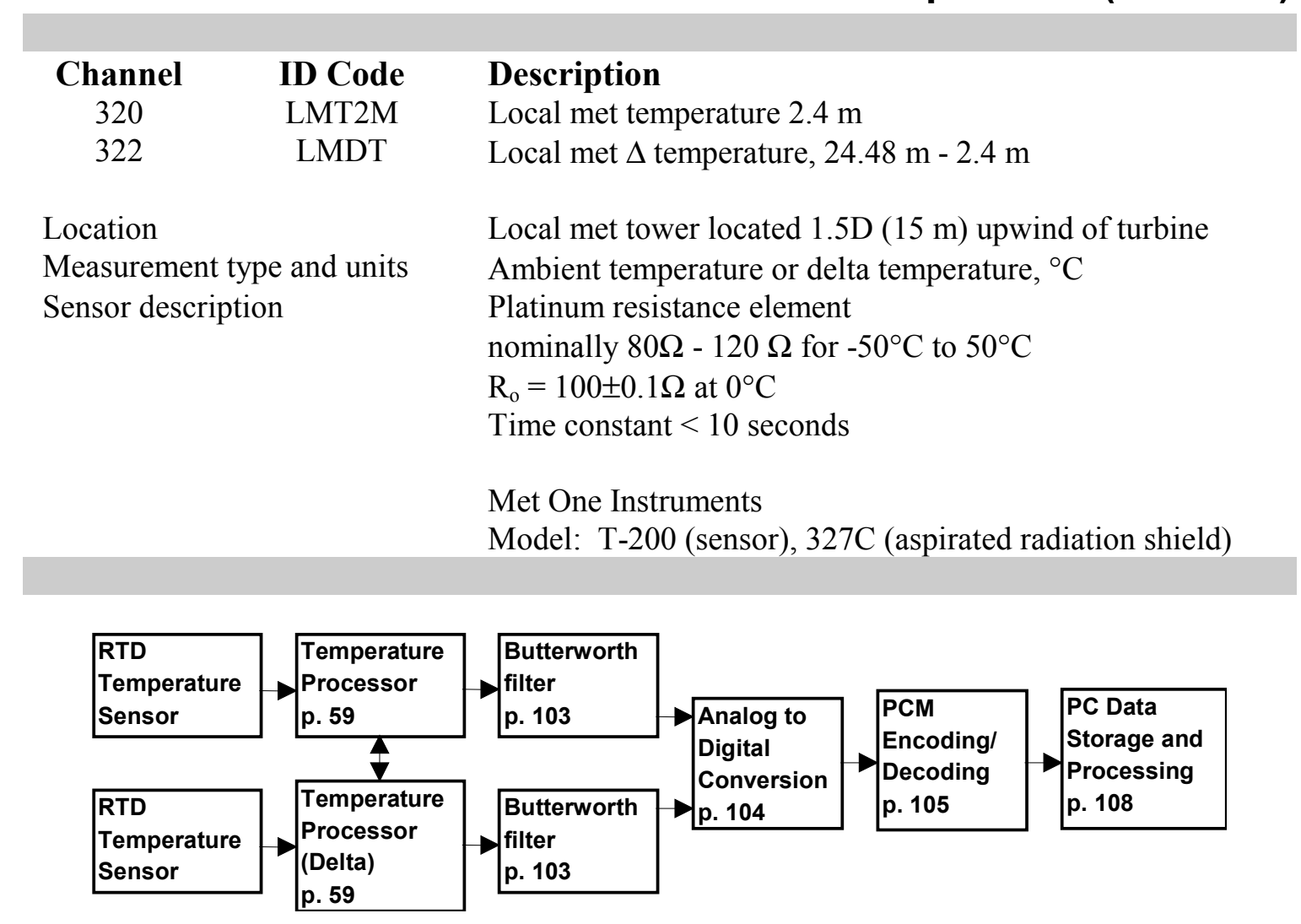

Note: Sensor is mounted in an aspirated radiation shield. If the aspirating fan malfunctions, a light on the met rack is illuminated, an audible alarm sounds, and data collection is halted. 


\section{Temperature (Dew Point)}

\begin{tabular}{|c|c|c|c|c|c|}
\hline $\begin{array}{c}\text { Channel } \\
324\end{array}$ & $\begin{array}{l}\text { ID Code } \\
\text { LMDP2M }\end{array}$ & \multicolumn{4}{|c|}{$\begin{array}{l}\text { Description } \\
\text { Local met dew point } 2.4 \mathrm{~m}\end{array}$} \\
\hline \multicolumn{2}{|c|}{$\begin{array}{l}\text { Location } \\
\text { Measurement type and units } \\
\text { Sensor description }\end{array}$} & \multicolumn{4}{|c|}{$\begin{array}{l}\text { Local met tower located } 1.5 \mathrm{D}(15 \mathrm{~m}) \text { upwind of turbine } \\
\text { Dew-point temperature, }{ }^{\circ} \mathrm{C} \\
\text { Dew-point temperature sensor } \\
\text { DP systematic error }= \pm 0.75^{\circ} \mathrm{C} \\
\text { DP random error }= \pm 0.50^{\circ} \mathrm{C} \\
\text { Met One Instruments } \\
\text { Model: DP200B (sensor), } 327 \mathrm{C} \text { (aspirated radiation shield) }\end{array}$} \\
\hline \begin{tabular}{|l|} 
Dew Point \\
Temperature \\
Sensor
\end{tabular} & $\begin{array}{l}\text { Temperature } \\
\text { Processor } \\
\text { p. } 59\end{array}$ & $\begin{array}{l}\text { Butterworth } \\
\text { filter } \\
\text { p. } 103\end{array}$ & $\rightarrow \sqrt{\begin{array}{l}\text { Analog to } \\
\text { Digital } \\
\text { Conversion } \\
\text { p. } 104\end{array}}$ & \begin{tabular}{|l} 
PCM \\
Encoding/ \\
Decoding \\
p. 105
\end{tabular} & \begin{tabular}{|l|} 
PC Data Storage \\
and Processing \\
p. 108
\end{tabular} \\
\hline
\end{tabular}

Note: Sensor is mounted in an aspirated radiation shield. If the aspirating fan malfunctions, a light on the met rack is illuminated, an audible alarm sounds, and data collection is halted. 


\section{Temperature Processor}

$\begin{array}{lll}\begin{array}{ll}\text { Channel } \\ 320\end{array} & \text { ID Code } & \text { Description } \\ 322 & \text { LMT2M } & \text { Local met temperature } 2.4 \mathrm{~m} \\ 324 & \text { LMDT } & \text { Local met } \Delta \text { temperature, } 24.48 \mathrm{~m}-2.4 \mathrm{~m} \\ & \text { LMDP2M } & \text { Local met dewpoint } 2.4 \mathrm{~m} \\ \text { Location } & & \text { Met rack in data shed } \\ \text { Range } & -50^{\circ} \mathrm{C} \text { to } 50^{\circ} \mathrm{C} \text { (ambient and dew point) } \\ & -8^{\circ} \mathrm{F} \text { to } 12^{\circ} \mathrm{F} \text { (delta) } \\ \text { Resolution } & 20^{\circ} \mathrm{C} / \text { volt (ambient and dew point) } \\ & 2.22^{\circ} \mathrm{C} / \text { volt (delta) } \\ \text { Calibration method } & \text { Manufacturer specifications (M5) and electronic path } \\ & \text { calibration (E1) } \\ \text { Output level } & 0-5 \mathrm{Vdc} \\ \text { Accuracy } & \text { Maximum error of } \pm 0.1^{\circ} \mathrm{C} \text { over specified processor } \\ & \text { operating temperature } \\ \text { Description } & \text { Platinum RTD processor (range specified by customer) } \\ & \\ & \text { Met One Instruments } \\ & \text { Model: 49.03A (rack mount), 21.32/21.43 (processor), } \\ & 48.11 \mathrm{~B} \text { (power supply) }\end{array}$

\section{Amplifier calibration voltage calculation}

1. Manufacturer calibration of RTD sensor yields values for $R_{o}$ and $\alpha$. Customer data sheet accompanying processor contains values for $\mathrm{R}_{2}(\mathrm{LO})$ and $\mathrm{R}_{3}(\mathrm{HI})$.

2. The values for EHI and ELO are determined for a specific sensor/processor pair using the following formulae:

$$
\begin{aligned}
& T C A L=\frac{A-\left(A^{2}-B\right)^{0.5}}{1.1751 E-6} \\
& A=\alpha+0.000058755 \\
& B=2.3502 E-6 \frac{R-R_{o}}{R_{o}}
\end{aligned}
$$

where, $\mathrm{R}$ is $\mathrm{R}_{2}$ for determination of ELO and $\mathrm{R}_{3}$ for determination of EHI.

3. The voltage is then determined using the following formula:

$$
E C A L=5 \frac{T C-T L O}{T H I-T L O}
$$

where THI and TLO describe the temperature range specified when ordering the processor. TC

$=$ TCAL for absolute temperature modules. For delta temperature modules, both modules are calibrated separately, and the voltage is determined using TC = TCAL2 - TCAL1 where TCAL2 represents the delta temperature module and TCAL1 represents the absolute-temperature module. When calibrating dew-point temperature modules, if THI and TLO represent dew-point temperatures, the TCAL value must be converted to dew point using the following formula:

$$
D P C A L=0.68434 * T C A L-23.88 \text {. }
$$


Then the voltage is determined using TC $=$ DPCAL, THI $=$ DPHI, and TLO $=$ DPLO

Here are typical values not corrected for variations in processor and sensor. This results in a probable error of $\pm 0.1{ }^{\circ} \mathrm{C}$ and a worst case error of $\pm 0.3^{\circ} \mathrm{C}$ for the temperature and dew-point measurements. For delta temperature, the error is doubled. It is recommended that the corrections specific to processor and sensor be used to restrict the error to $\pm 0.05^{\circ} \mathrm{C}$. These typical values were used to calibrate the processors for the Phase V, spring 1998 data collection because the manufacturer-supplied parameters were unavailable.

Temperature $\quad \mathrm{EHI}=4.819 \mathrm{~V}, \mathrm{ELO}=2.500 \mathrm{~V}$

Delta $\mathrm{T} \quad \mathrm{EHI}=4.338 \mathrm{~V}, \mathrm{ELO}=2.000 \mathrm{~V}$

Dew point $\quad \mathrm{EHI}=4.445 \mathrm{~V}, \mathrm{ELO}=1.306 \mathrm{~V}$

New processors for temperature and delta temperature were obtained for the fall 1998 series of data collection. The calibration voltages resulting from the manufacturer-supplied values are listed below.

Temperature $\quad \mathrm{EHI}=4.825 \mathrm{~V}, \mathrm{ELO}=2.501 \mathrm{~V}$

Delta $\mathrm{T} \quad \mathrm{EHI}=4.339 \mathrm{~V}, \mathrm{ELO}=1.997 \mathrm{~V}$

\section{Calibration Procedures}

\section{Manufacturer specifications - (M5)}

1. The RTD sensors and the dew-point sensor were calibrated by Met One Instruments before installation.

2. Using the calibration voltages determined above, the temperature processors are adjusted as follows:

a. For each processor set the mode switch to $\mathrm{LO}$, and adjust voltage to $\mathrm{ELO} \pm 2$ $\mathrm{mV}$. Set the mode switch to HI, and adjust voltage to EHI $\pm 2 \mathrm{mV}$.

b. For the delta temperature processor offset, set the mode switch of the delta temperature processor and of the ambient temperature processor to LO.

Determine the $\Delta \mathrm{T}$ offset using the $\mathrm{TC}$ values from step 3. Compute the $\Delta \mathrm{T}$ offset output for this $\Delta \mathrm{T}$ offset temperature.

$$
\text { Voffout }=5\left(\frac{\Delta T o f f s e t-\Delta T L O}{\Delta T H I-\Delta T L O}\right)
$$

Adjust the zero voltage to the calculated offset voltage.

c. Set mode switch to OP for normal operation.

3. Enter the slopes $\left(20^{\circ} \mathrm{C} / \mathrm{V}\right.$ for ambient temperature and dew point, $2.222222^{\circ} \mathrm{C} / \mathrm{V}$ for delta temperature $)$ and offsets $\left(2.5^{\circ} \mathrm{C}\right.$ for ambient temperature and dew point, $2^{\circ} \mathrm{C}$ for delta temperature) in the appropriate columns of calconst.xls.

\section{Electronic path calibration - (E1)}

1. Modify vbl.lst so that the temperature channels are listed at the top of the file. Set NV (number of variables) in the first line to the number of channels to be calibrated, and ensure that the correct PCM stream is specified in gencal.cap (all meteorological channels are on PCM stream 3).

2. Connect the precision voltage generator to the processor output.

3. Run the gc.bat batch file which invokes both gencal.exe and genfit.exe. Collect samples for voltages ranging from 0 to $4.5 \mathrm{~V}$ in $0.5 \mathrm{~V}$ increments with two repetitions at each voltage level. The recorded input and output values are stored in the *.cao input file. Genfit.exe 
computes slopes and offsets of the electronic path from the processor output to the computer in units of $\mathrm{V} /$ count and $\mathrm{V}$, respectively. These values are stored in a temporary header file,

*.hdr. These slope and offset values are combined with the manufacturer-provided slope and offset stored in calconst.xls during the buildhdr.bat process to obtain units of engineering unit/count and counts, respectively.

\section{Calibration frequency}

The RTD sensors were calibrated by the manufacturer prior to Phase V, spring 1998 data collection. New RTD sensors and processors were installed prior to the fall 1998 series of data collection. Amplifier adjustment, offset determination, and electronic path calibrations were performed prior to each series of data collection, which lasted less than 1 month. On occasion, the processors were adjusted during data collection.

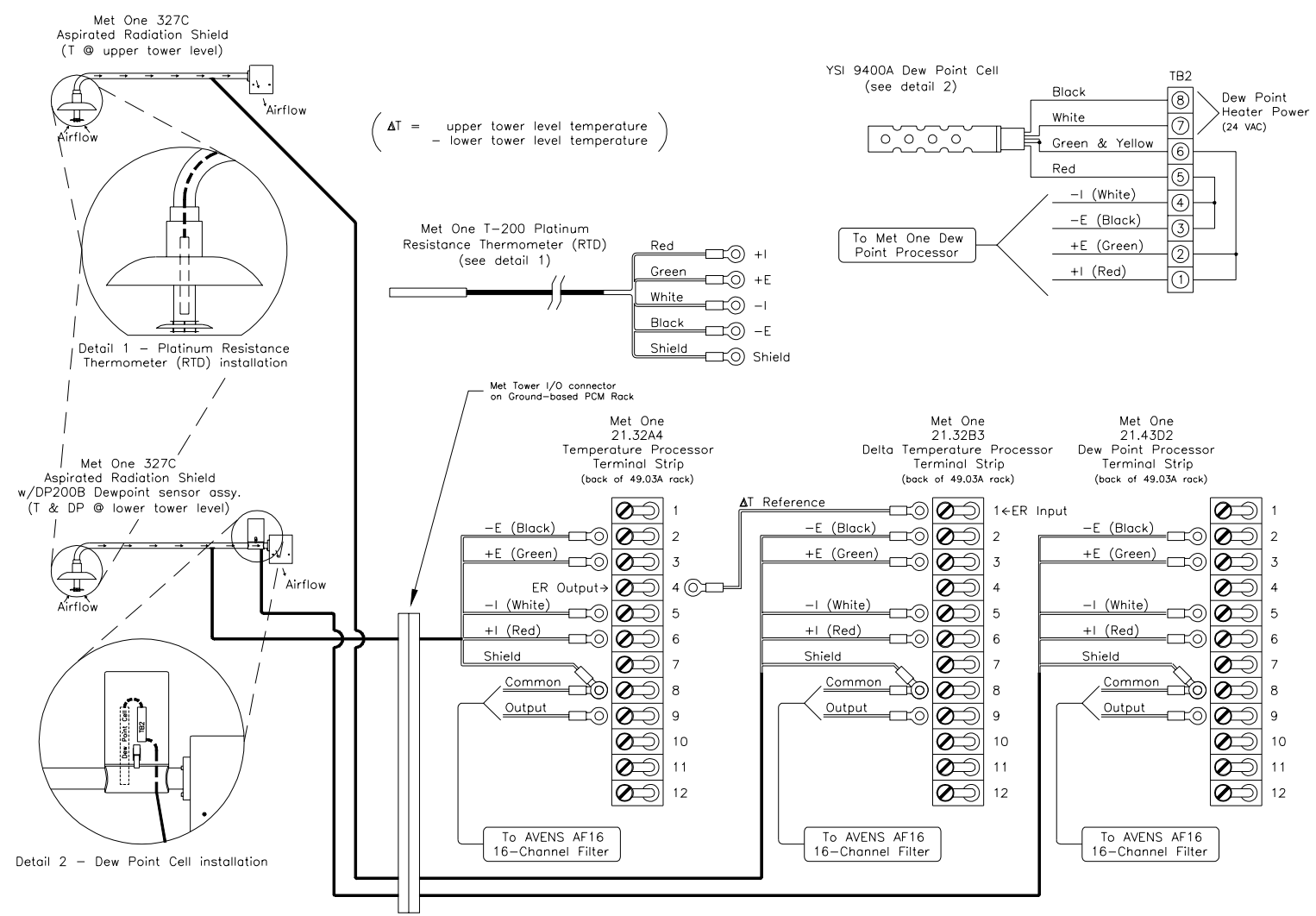

Figure 21. Temperature, delta temperature, and dew-point wiring diagram 


\section{Barometric Pressure}

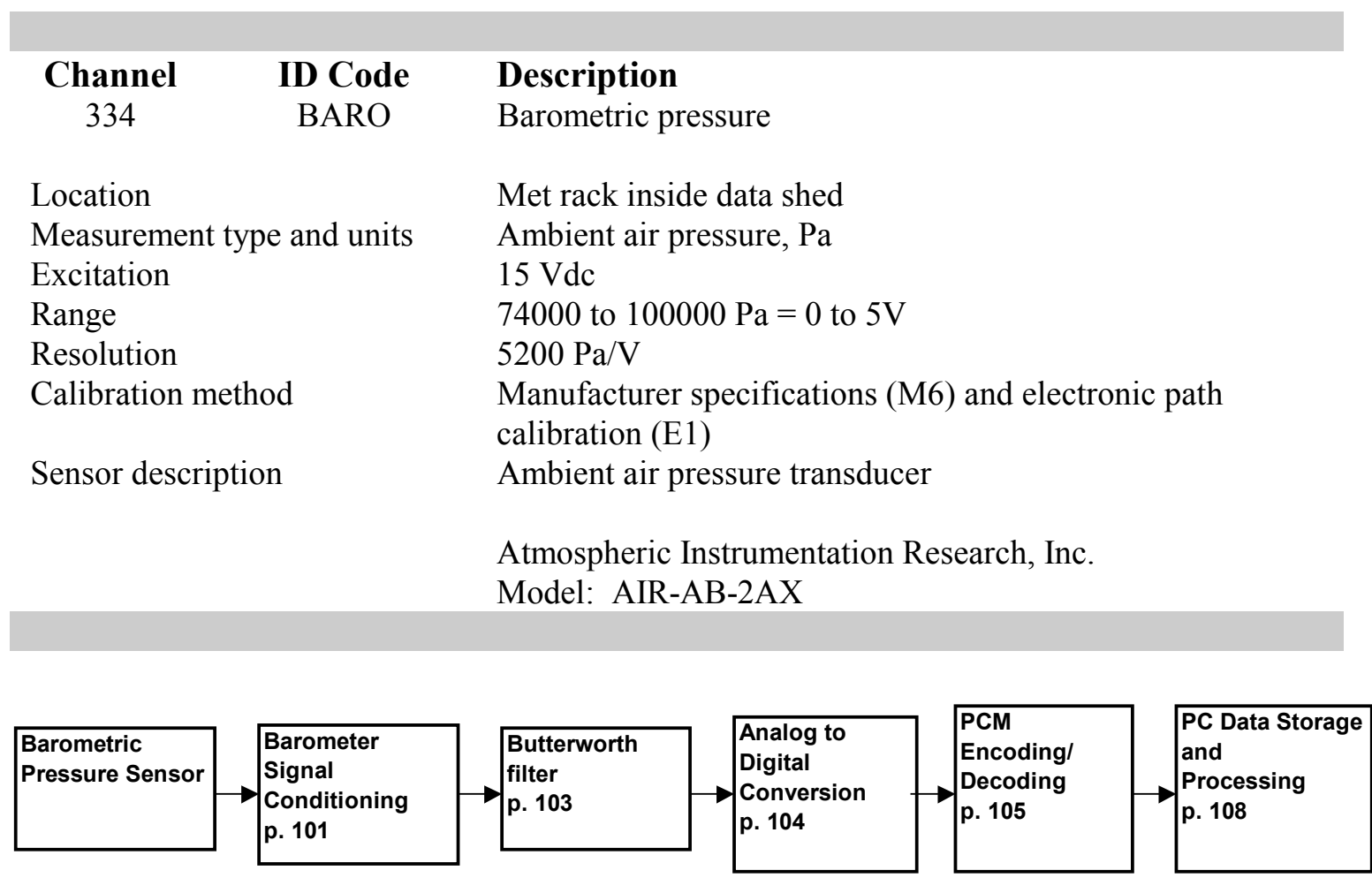

\section{Calibration Procedure}

\section{Manufacturer specifications - (M6)}

1. A calibration was performed by Atmospheric Instrumentation Research before installation of either barometer.

2. Enter the nominal slope $(5200 \mathrm{~Pa} / \mathrm{V})$ and the nominal offset $(74000 \mathrm{~Pa})$ in the appropriate columns of calconst.xls.

\section{Electronic path calibration - (E1)}

1. Modify vbl.lst so that the barometer channel is listed at the top of the file. Set NV (number of variables) in the first line to the number of channels to be calibrated, and ensure that the correct PCM stream is specified in gencal.cap (all meteorological channels were on stream $3)$.

2. Connect the precision voltage generator to the barometer output.

3. Run the gc.bat batch file which invokes both gencal.exe and genfit.exe. Collect samples for voltages ranging from 0 to $4.5 \mathrm{~V}$ in $0.5 \mathrm{~V}$ increments with two repetitions at each voltage level. The recorded input and output values are stored in the *.cao input file. Genfit.exe computes slopes and offsets of the electronic path from the processor output to the computer in units of $\mathrm{V} /$ count and $\mathrm{V}$, respectively. These values are stored in a temporary header file, *.hdr. These slope and offset values are combined with the manufacturer-provided slope and offset stored in calconst.xls during the buildhdr.bat process to obtain units of engineering unit/count and counts, respectively. 


\section{Calibration frequency}

The barometers were calibrated by the manufacturer prior to Phase V data collection. The electronic path calibration was performed prior to each series of data collection, which lasted less than 1 month.
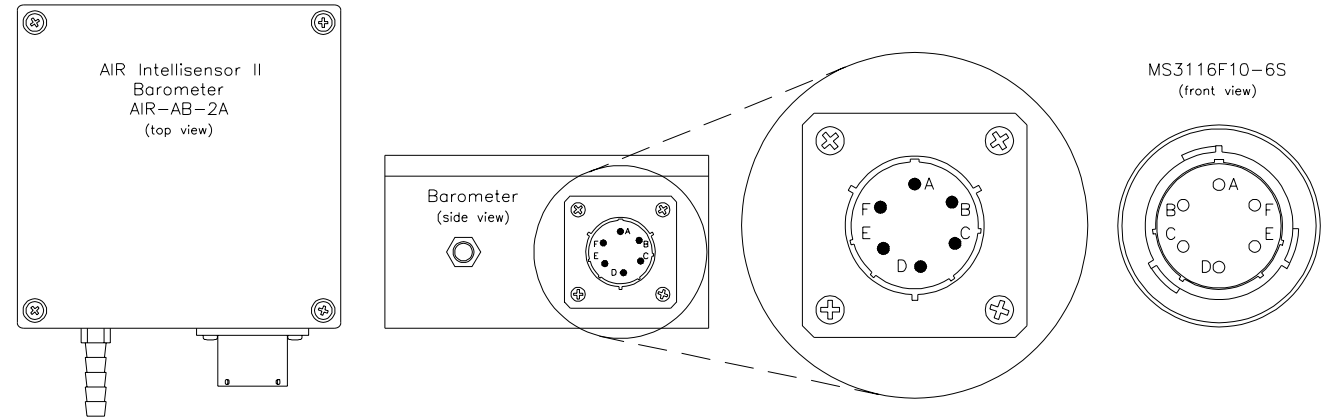

MS $3116 \mathrm{~F} 10-6 \mathrm{~S}$ (side view)
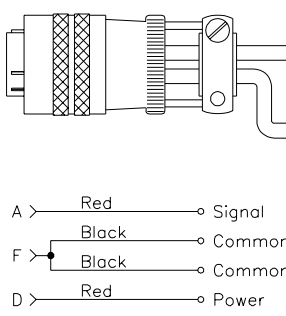

To $+15 V D C$
Power Supply

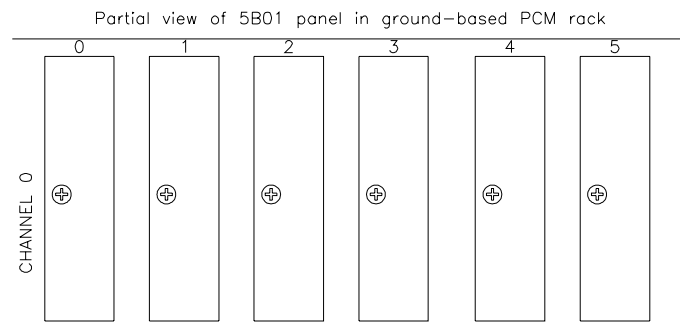

$\mathrm{B} \succ$

C)

$E \succ$

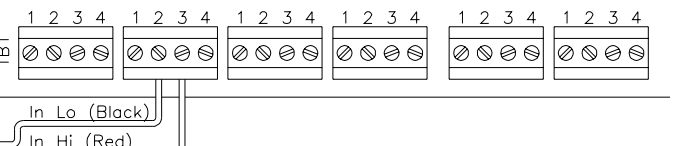

Figure 22. Barometer wiring diagram 


\section{Load Cell (Teeter Link)}

\begin{tabular}{|c|c|c|c|c|c|}
\hline $\begin{array}{c}\text { Channel } \\
223\end{array}$ & $\begin{array}{l}\text { ID Code } \\
\text { TLINKF }\end{array}$ & \multicolumn{4}{|c|}{$\begin{array}{l}\text { Description } \\
\text { Strain Teeter link force }\end{array}$} \\
\hline \multicolumn{2}{|c|}{$\begin{array}{l}\text { Location } \\
\text { Measurement type and } \\
\text { Excitation } \\
\text { Range } \\
\text { Resolution } \\
\text { Calibration method } \\
\text { Sensor description }\end{array}$} & \multicolumn{4}{|c|}{$\begin{array}{l}\text { Teeter link, hub } \\
\text { Tensile and compressive load, N } \\
10 \mathrm{Vdc} \\
\pm 10,000 \mathrm{lbs} \\
32 \mathrm{~N} / \mathrm{bit} \\
\text { Application of known loads (A3) } \\
\text { Hermetically sealed, universal tension and compression } \\
\text { force sensor }\end{array}$} \\
\hline Load Cell & \begin{tabular}{|l|} 
Strain Gage \\
Signal \\
Conditioning p. \\
102
\end{tabular} & $\begin{array}{l}\text { Bessel Filter } \\
\text { p. } 103\end{array}$ & \begin{tabular}{|l|} 
Analog to \\
Digital \\
Conversion \\
p. 104
\end{tabular} & $\rightarrow \begin{array}{l}\text { PCM } \\
\text { Encoding/ } \\
\text { Decoding } \\
\text { p. } 105\end{array}$ & \begin{tabular}{|l} 
PC Data \\
Storage and \\
Processing \\
p. 108
\end{tabular} \\
\hline
\end{tabular}

Note: The sign convention is such that positive teeter link force coincides with positive flap bending moment. Thus, compressive forces are positive.

\section{Calibration Procedure}

\section{Application of known loads - (A3)}

A custom jig was built in order to align two load cells in series and apply a load mechanically. One of the load cells (Transducer Techniques Model SW-10K) was connected to a digital meter, and the other load cell (Transducer Techinques HSW-10K) was placed in the data acquisition system in order to get a full-path calibration. Only the length of cable between the sensor and the data acquisition system differed from that used to collect data in the field.

1. Using the digital meter, loads were applied from $-10,000$ pounds to 10,000 pounds in 2500 $\mathrm{lb}$ increments and the count values noted. A linear regression analysis provided the slope and offset coefficients, which were entered manually in the master.hdr file.

\section{Calibration frequency}

This channel was calibrated prior to Phase V (spring 1998), and the same calibration coefficients were used for Phase V (fall 1998). 


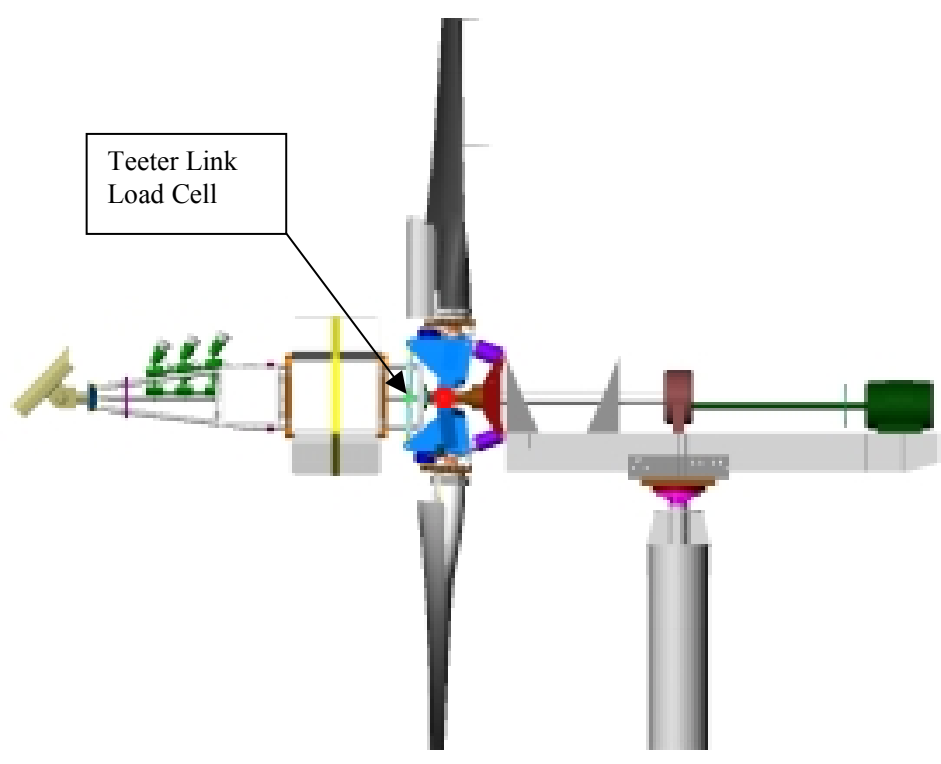

Figure 23. Teeter link load cell location

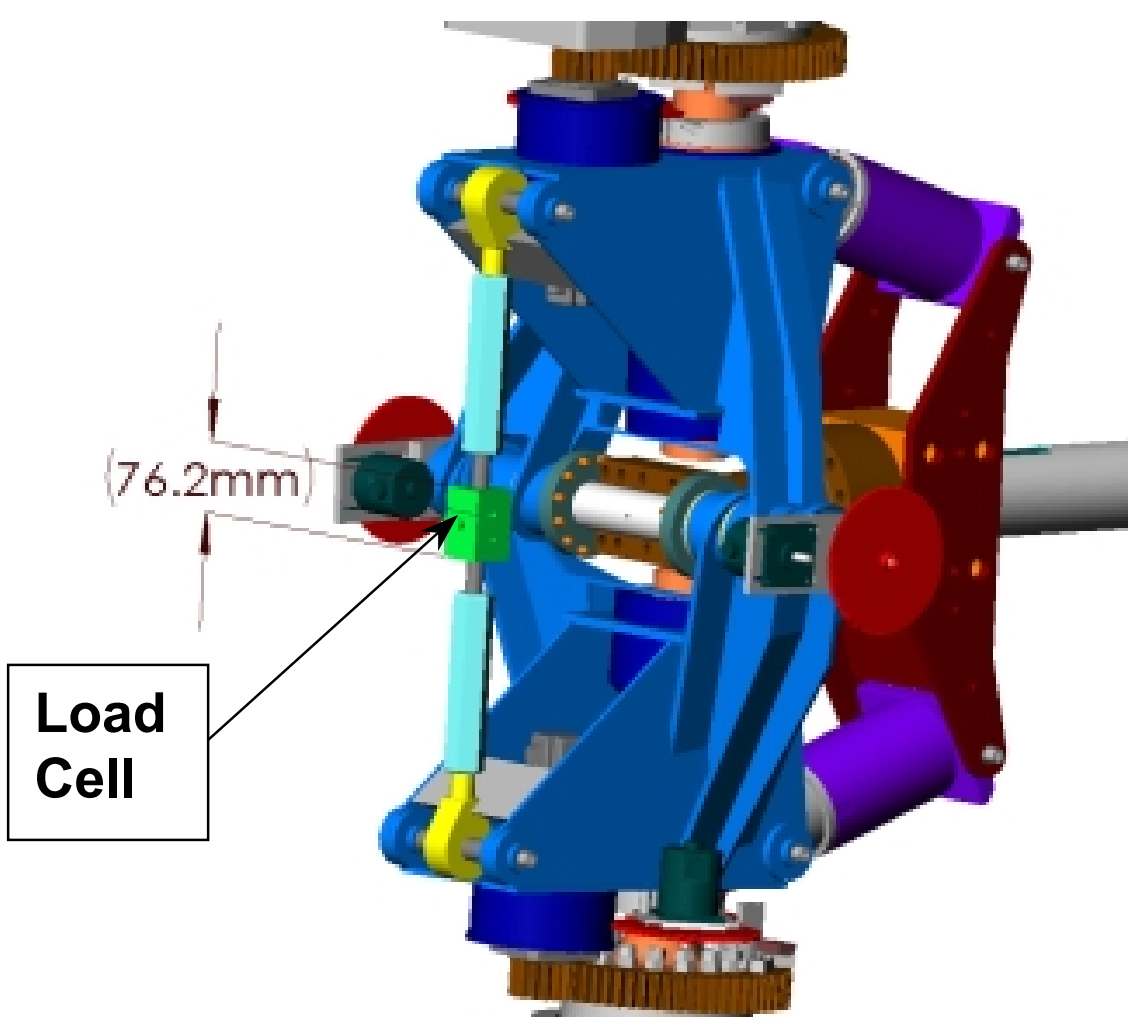

Figure 24. Teeter link load cell 


\section{Load Cell (Button Sensor)}

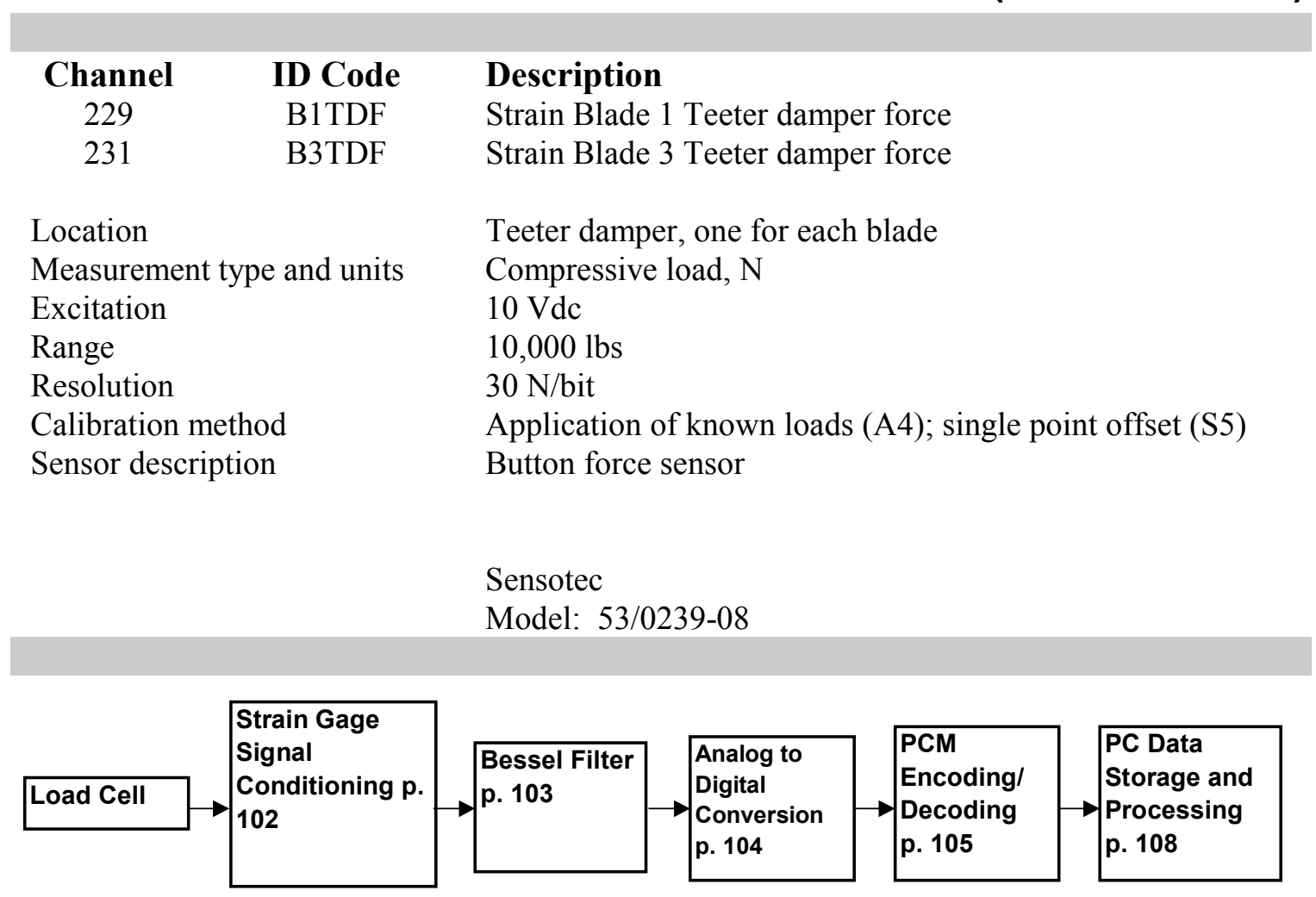

\section{Calibration Procedure}

\section{Application of known loads - (A4)}

1. A custom jig was built in order to align both of the button sensors with the calibration load cell in series. A mechanical load was then applied. The calibration load cell (Transducer Techniques Model SW-10K) was connected to a digital meter, and the button load cells were placed in the data acquisition system in order to get a full-path calibration. This calibration was performed when the rotor was assembled on the ground. Only the length of cable between the sensor and the data acquisition system differed from that used to collect data in the field.

2. Using the digital meter, loads were applied from $0 \mathrm{lbs}$ to $8,000 \mathrm{lbs}$ in increments of $2000 \mathrm{lbs}$, and the count values noted. A linear regression analysis provided the slope and offset coefficients which were entered manually in the master.hdr file.

\section{Single Point Offset - (S5)}

1. During Phase V (fall 1998), the offset was determined by placing the rotor at $0^{\circ}$ teeter angle which corresponds to zero load on the teeter dampers. The count values were noted and manually entered in the master.hdr file. 


\section{Calibration frequency}

The slope and offset were calibrated prior to Phase V (spring 1998), and the same slope coefficient was used for Phase V (fall 1998). The zero offset was calibrated using the singlepoint offset method for Phase V (fall 1998).

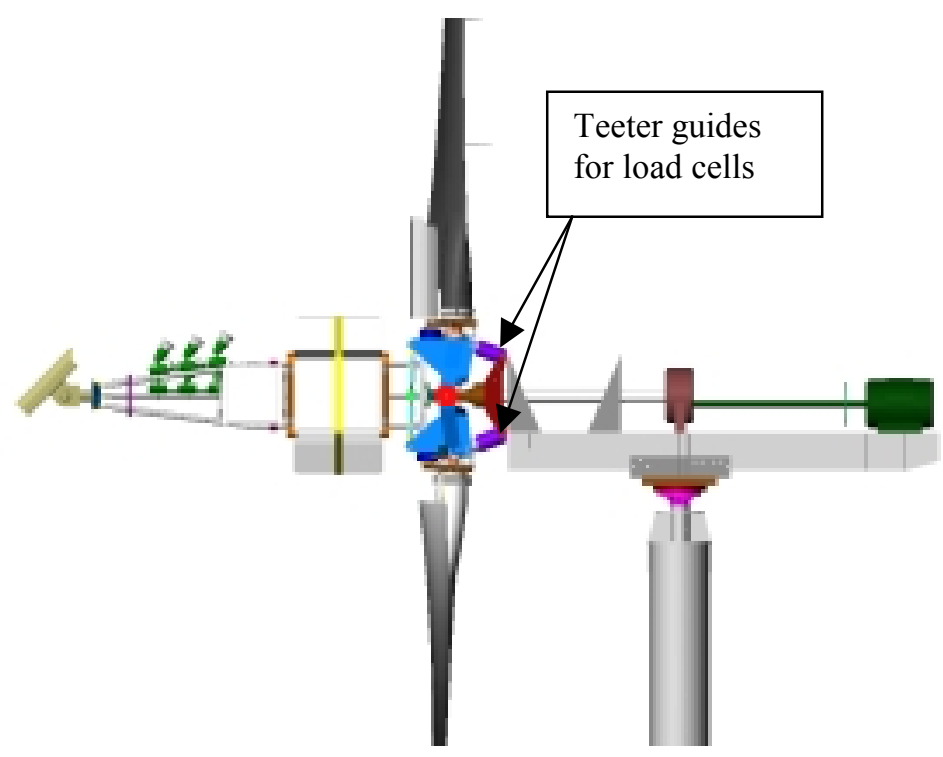

Figure 25. Teeter damper load cell locations

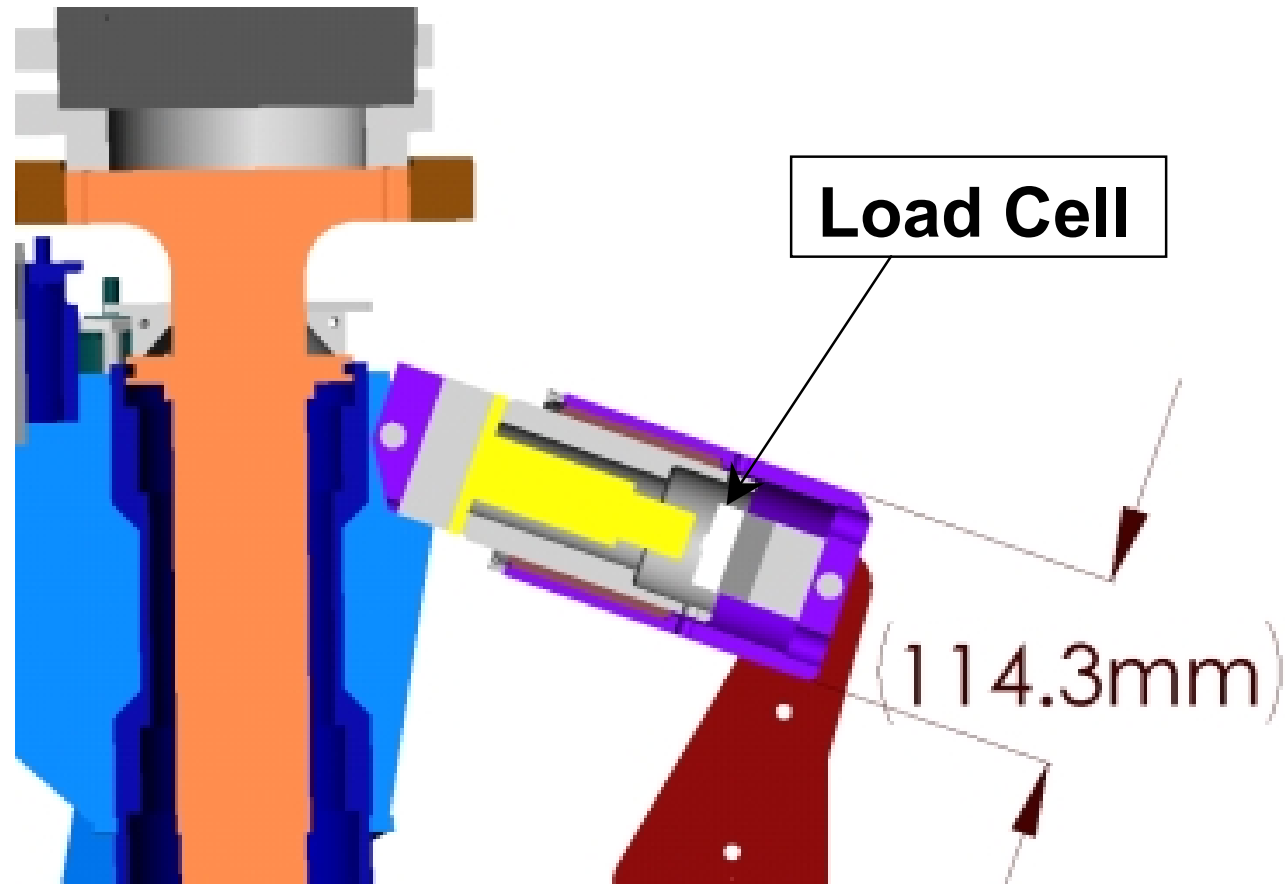

Figure 26. Teeter damper load cell cross-sectional view 


\section{Strain Gauges (Hub Shaft)}

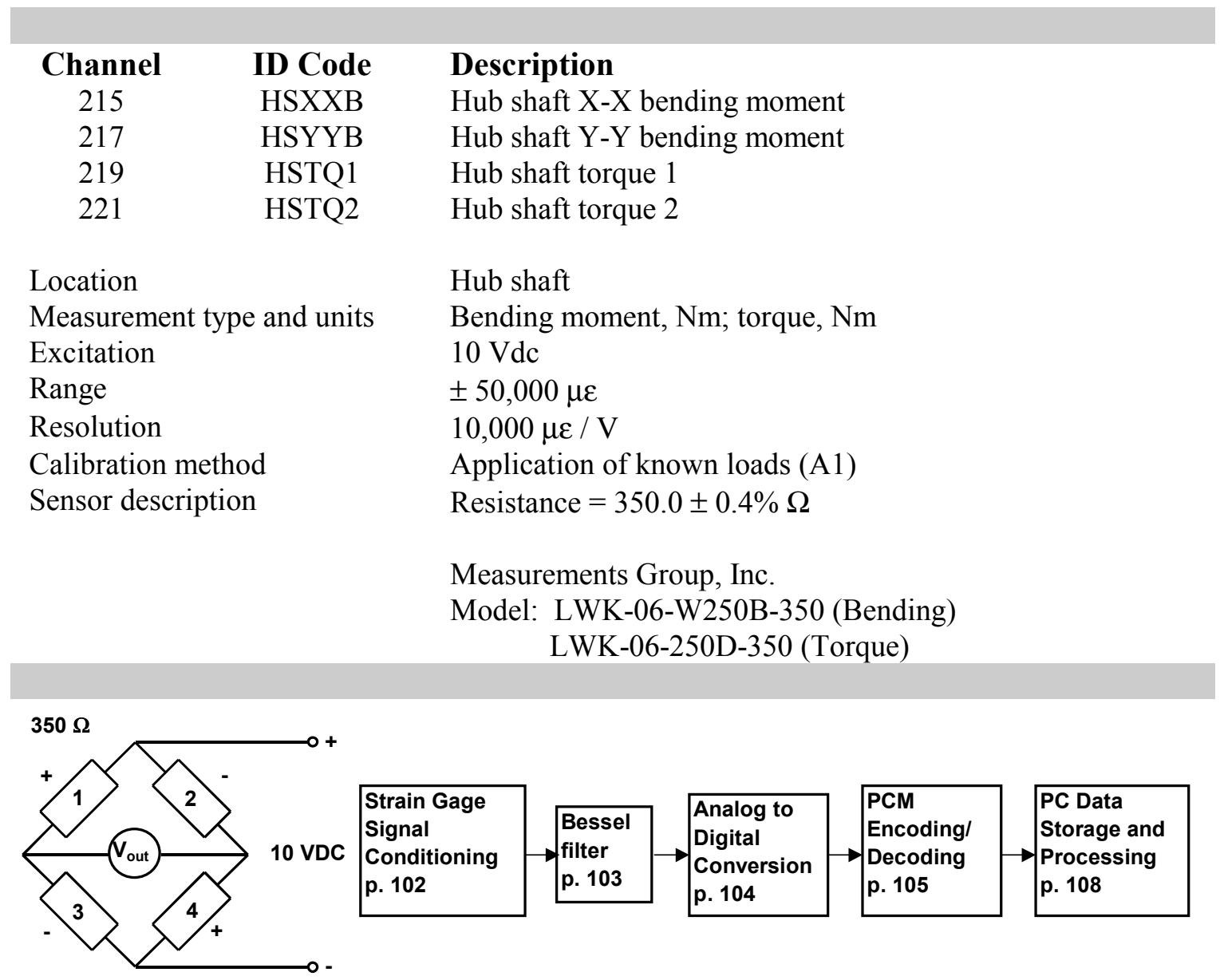

Note: The hub shaft XX bending gauge has a positive peak when blade 3 is at $0^{\circ}$ azimuth and a negative peak when blade 3 is at $180^{\circ}$ azimuth. The hub shaft YY bending gauge has a positive peak when blade 3 is at $90^{\circ}$ azimuth and a negative peak when blade 3 is at $270^{\circ}$ azimuth. The hub shaft torque measurements are positive in the direction of rotation.

\section{Calibration Procedures}

\section{Application of known loads (A1)}

A custom jig was used for strain gauge calibrations in order to isolate load conditions to one direction only (flap or edge). The jig mounts on the blade slightly inboard of the attachment of the tip block. A cord is attached to the jig, and run over a pulley to the ground where weights are applied. One person in the man-lift mounts the jig on the blade and positions the man-lift so that the pulley is level and square with the cord attachment to the jig. Another person applies the weights in 20-1b increments from 0 to $100 \mathrm{lb}$. A third person operates the computer to collect samples at each load condition. The hub shaft bending gauges were calibrated by hanging weights from the boom in a similar manner. These procedures produce new slope values for the strain gauge measurements. Because the low-speed shaft bending gauges were oriented $120^{\circ}$ out of phase of the hub shaft bending gauges, the slope values used for previous phases of data collection were used again for Phase V. The LSSYYB gauges were inoperable during the spring 
session of data collection, and they were replaced prior to the fall session. During the fall session, the low-speed shaft bending gauge slope values were calibrated by suspending weights from the boom.

Determination of the offset values was performed as in previous phases of the experiment. Essentially, the root flap and edge offsets were determined by placing each blade in a position where the respective load is zero. The offset for the low-speed shaft and hub shaft gauges was determined by recording cyclic bending moments and torque. The average over one complete rotation was equivalent to the offset under zero load.

The slope and offset values were inserted in a temporary header file called strains.hdr. This file is read during the buildhdr process, and the values are placed in the master.hdr file.

\section{Slope coefficient calibration:}

1. The man-lift person notifies ground people as to which blade and which direction (flap or edge) will be calibrated first. The computer person selects the appropriate channel(s) in $v b l . l s t$ to place at the top of the file. The number of channels to be collected is specified in the first line with NV, and the PCM stream on which the channels are contained is selected in gencal.cap. All of the strain gauges are on PCM stream 2 except the yaw moment strain gauges (NAYM), which are on PCM stream 3. The yaw moment channel (NAYM) is calibrated separately because it is on a different PCM stream than the other strain gauges. The low-speed shaft torque and both hub shaft torque channels (LSSTQ, HSTQ1, HSTQ2) are included with each of the edge-bending channels (B1REB, B3REB). The flap-bending gauges (B1RFB, B3RFB) are each calibrated alone. The hub shaft and low-speed shaft bending gauges are calibrated separately (HSXXB, HSYYB, LSSXXB, LSSYYB) by suspending weights from immediately downwind of the boom stiffener at rotor positions corresponding to pure bending for each gauge.

2. The gencal program is run while the weights are applied from 0 to $100 \mathrm{lb}$ in $20-\mathrm{lb}$ increments with three repetitions at each level. Gencal is run again while the weights are removed. The recorded weight and count values are stored in the *.cao input files. A few seconds between application of the weight and collection of data allows any vibrations of the turbine to damp. This is done for both flap and edge directions for each of the blades to calibrate flap bending, edge bending, hub shaft torque, low-speed shaft torque, and yaw moment strain gauges. The weights are applied again in each of the above configurations to load the blades in both positive and negative directions. The weights are applied to the boom at rotor positions of $0^{\circ}, 60^{\circ}, 90^{\circ}, 150^{\circ}, 180^{\circ} 240^{\circ}, 270^{\circ}$, and $340^{\circ}$ to load the hub-shaft and low-speed shaft bending gauges in both positive and negative directions.

3. Compute moments in Nm using the following formula:

$$
M=\left(\frac{w *\left(R * 39.37 \frac{i n}{m}-r\right)}{12 \frac{i n}{f t}}\right) 1.35582 \frac{\mathrm{Nm}}{\mathrm{ft} \cdot \mathrm{lb}} \text { where } \mathrm{M}=\text { Bending moment }(\mathrm{Nm}),
$$

$\mathrm{w}=$ weight applied ( 0 to $100 \mathrm{lb}), \mathrm{R}=$ blade radius $(5 \mathrm{~m})$, and $\mathrm{r}=$ radial distance to strain gauge (17 in. from low-speed shaft to blade root gauges). The moment arm from the hubshaft gauges to the point on the boom at which the load was applied is $91.5 \mathrm{in}$. This replaces the term in parentheses in the numerator of the above equation. Plot each curve in Excel, and perform a linear curve fit to determine the slope for both the positive and 
negative bending conditions for each strain gauge. Enter the average of the magnitude of the two slope values in the temporary header file, strains.hdr.

\section{Offset coefficient calibration}

1. All of the strain gauges except yaw moment were listed in two $v b l$.lst files for input to gencal (gencal is limited to input of 8 channels). A batch file was developed to run gencal with each of the two $v b l$.lst files to require only one rotation of the rotor. The instrumented blade was positioned at $30^{\circ}$ increments over one complete rotational cycle. Three samples were obtained at each position. The blade flap angles were positioned to be equal corresponding to zero teeter angle.

2. The offset for flap-bending channels was determined by averaging the count value of each blade at $90^{\circ}$ and at $270^{\circ}$ where the flap load is $0 \mathrm{Nm}$. This number may be compared with the value obtained by averaging the loads at $0^{\circ}$ and at $180^{\circ}$ where the average load should be $0 \mathrm{Nm}$.

3. A similar procedure provided the offset values of the edge-bending channels. The average load at $0^{\circ}$ and at $180^{\circ}$ provided the zero offset while a comparison of the average load at $90^{\circ}$ and $270^{\circ}$ indicated if the procedure worked properly.

4. The low-speed shaft bending for both $\mathrm{X}-\mathrm{X}$ and $\mathrm{Y}-\mathrm{Y}$ axes, the hub-shaft bending for both $\mathrm{X}-\mathrm{X}$ and $Y-Y$ axes, both hub-shaft torque measurements, and the low-speed shaft torque average to zero over the complete rotational cycle. This average count value was used to determine the offset.

5. The yaw moment offset was determined by recording the count value when the yaw brake was released in zero wind conditions.

6. The count values obtained under zero-load conditions for each channel were multiplied by the corresponding slope value and entered in strains.hdr.

Note: The calibration pins must be removed during the blade edge pulls so that the hub shaft torque is not transferred through the pins. The pins must be installed during the blade flap pulls to maintain a $0^{\circ}$ flap angle. During the spring calibrations of the hub-shaft torque slope coefficients, it was determined that the dampers were transferring some of the load to the low-speed shaft. A calibration performed without the dampers attached was repeatable once the damper attachment holes were reamed. However, during the fall calibrations, the slope values were not repeatable, and it was determined that the dampers were once again transferring the load to the low-speed shaft. Thus, the previously used slope values were inserted in strains. $h d r$, but new zero values were obtained for the fall campaigns. 

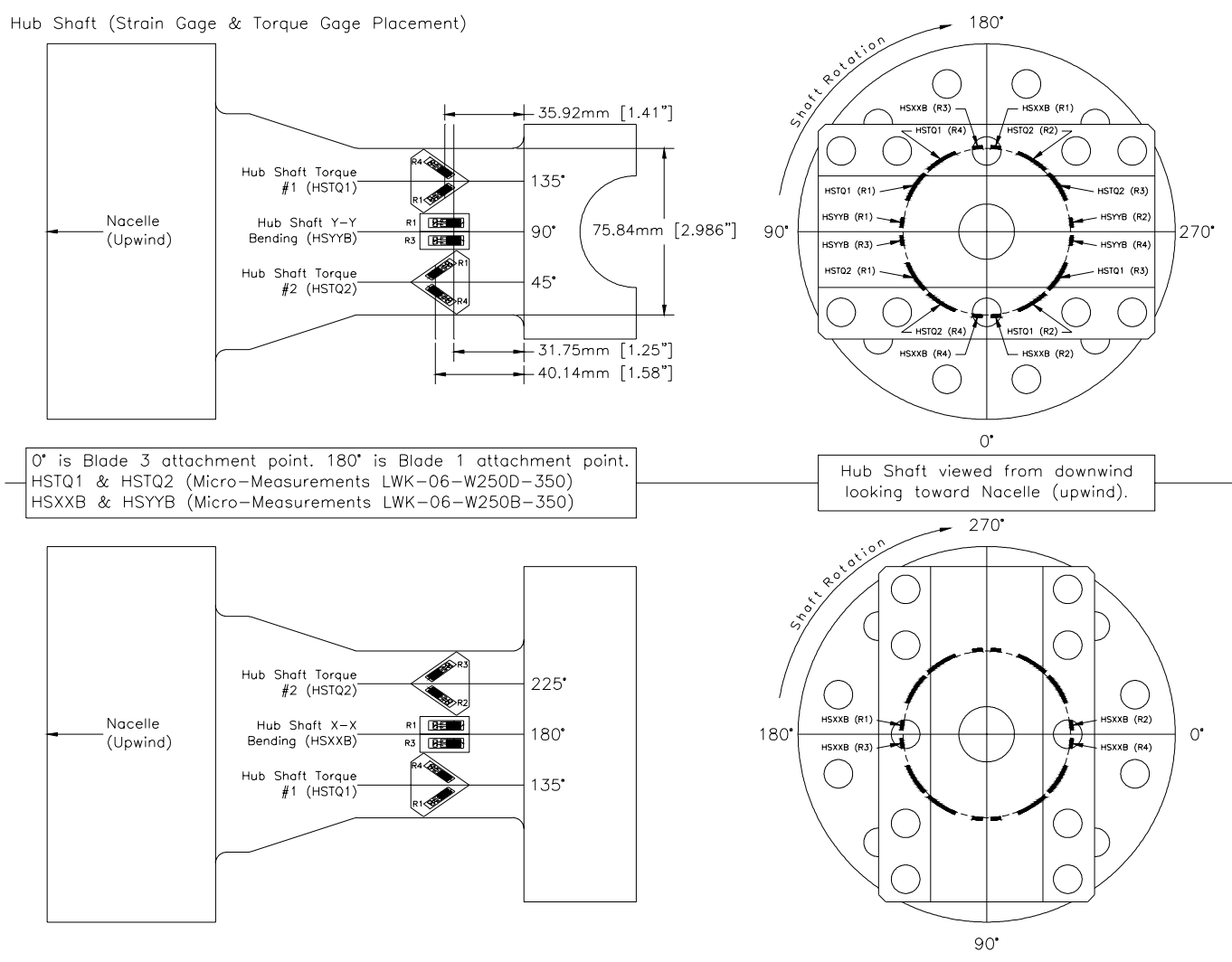

Figure 27. Hub-shaft strain gauge orientation
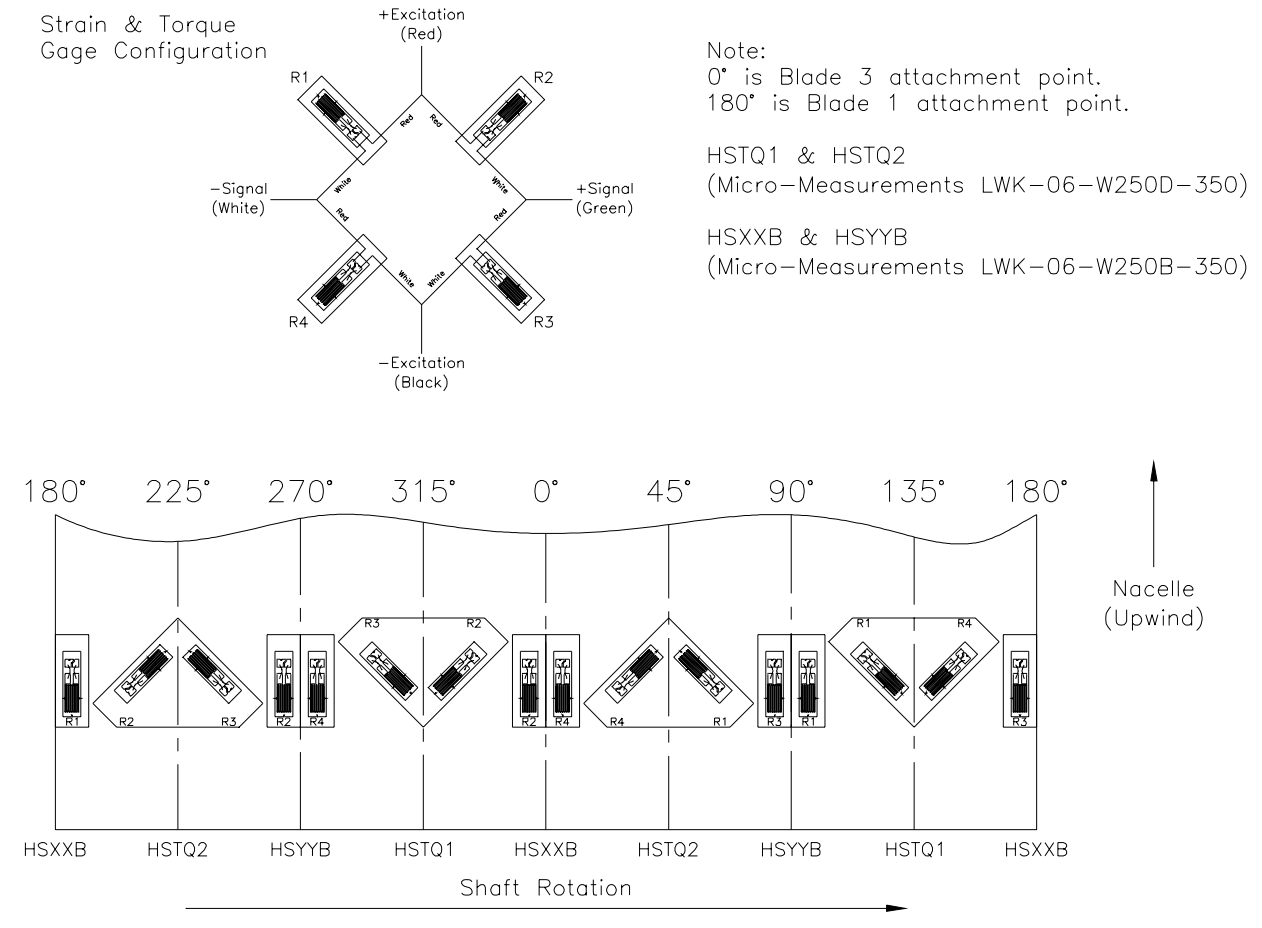

Figure 28. Plan view of hub shaft strain gauges 


\section{Strain Gauges (Root)}

$\begin{array}{ccl}\text { Channel } & \text { ID Code } & \text { Description } \\ 225 & \text { B1RFB } & \text { Blade 1 root flap-bending moment } \\ 227 & \text { B1REB } & \text { Blade 1 root edge-bending moment } \\ 233 & \text { B3RFB } & \text { Blade 3 root flap-bending moment } \\ 235 & \text { B3REB } & \text { Blade 3 root edge-bending moment }\end{array}$

Location

Pitch shaft (8.6\% span), 8360 Steel

Measurement type and units

Excitation

Bending moment, $\mathrm{Nm}$

Range

$5 \mathrm{Vdc}$

Resolution

Calibration method

$\pm 5000 \mu \varepsilon$

$2000 \mu \varepsilon / \mathrm{V}$

Application of known loads (A1)

Sensor description

Resistance $=350.0 \pm 0.4 \% \Omega$

Measurements Group, Inc.

Model: LWK-09-W250B-350

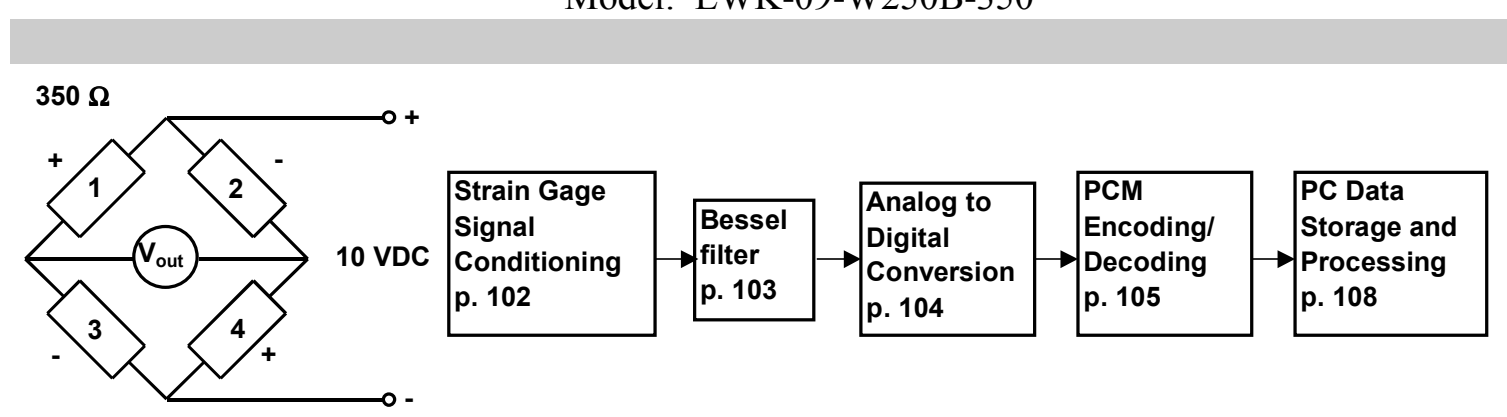

Note: Flap-bending moment is positive when a force acts in the downwind direction; the flap moment vector is parallel to the tip chord. Edge-bending moment is positive when a force acts in the direction of rotation; the edge moment vector is perpendicular to the tip chord.

\section{Calibration Procedures (see p. 67)}

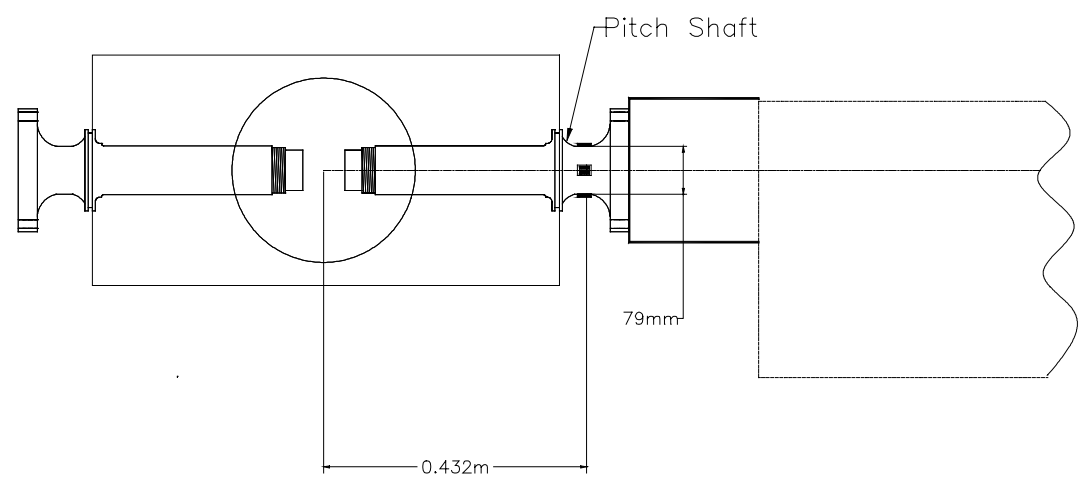

Figure 29. Root-bending gauges, side view 


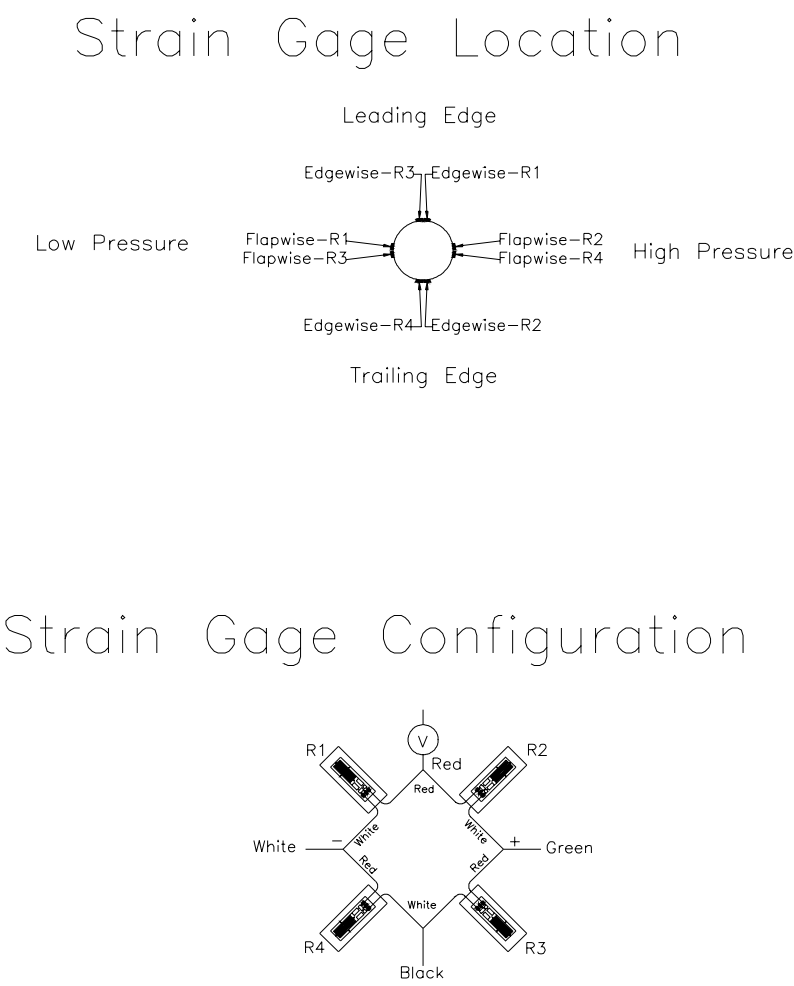

Figure 30. Root-bending strain gauge configuration 


\section{Strain Gauges (Low-speed shaft)}

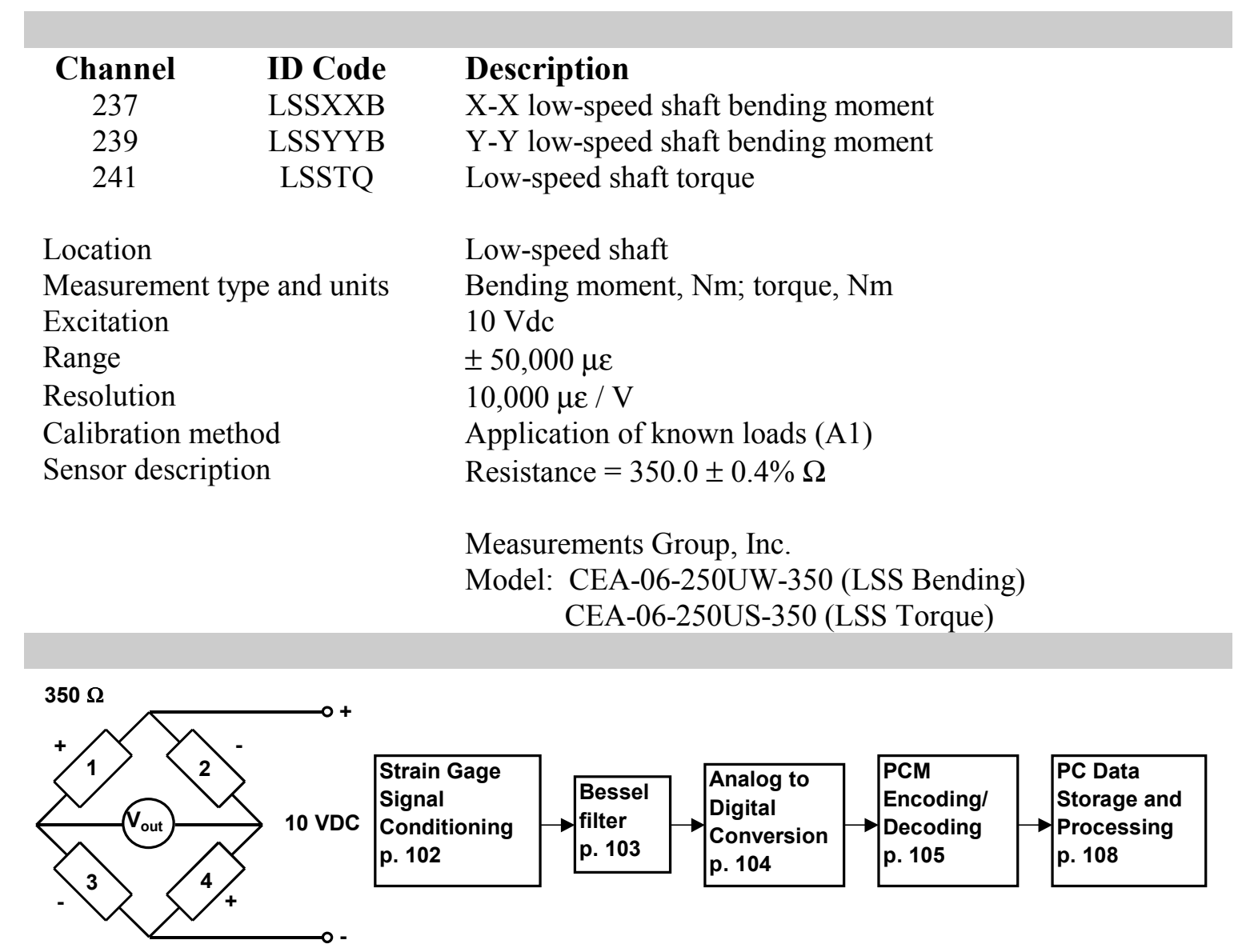

Note: The low-speed shaft XX bending gauge has a positive peak when blade 3 is at $240^{\circ}$ azimuth and a negative peak when blade 3 is at $60^{\circ}$ azimuth. The low-speed shaft YY bending gauge has a positive peak when blade 3 is at $150^{\circ}$ azimuth and a negative peak when blade 3 is at $330^{\circ}$ azimuth. The low-speed shaft torque measurement is positive in the direction of rotation.

Calibration Procedures (see p. 67) 


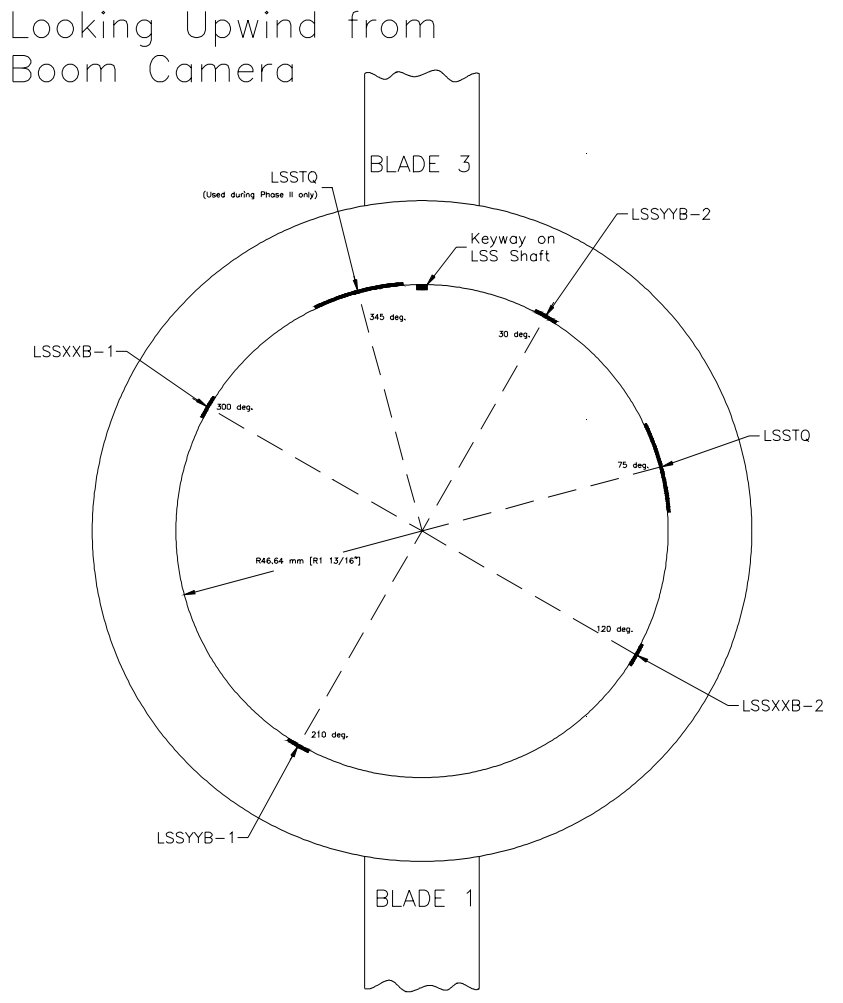

Figure 31. Low-speed shaft strain gauge positions

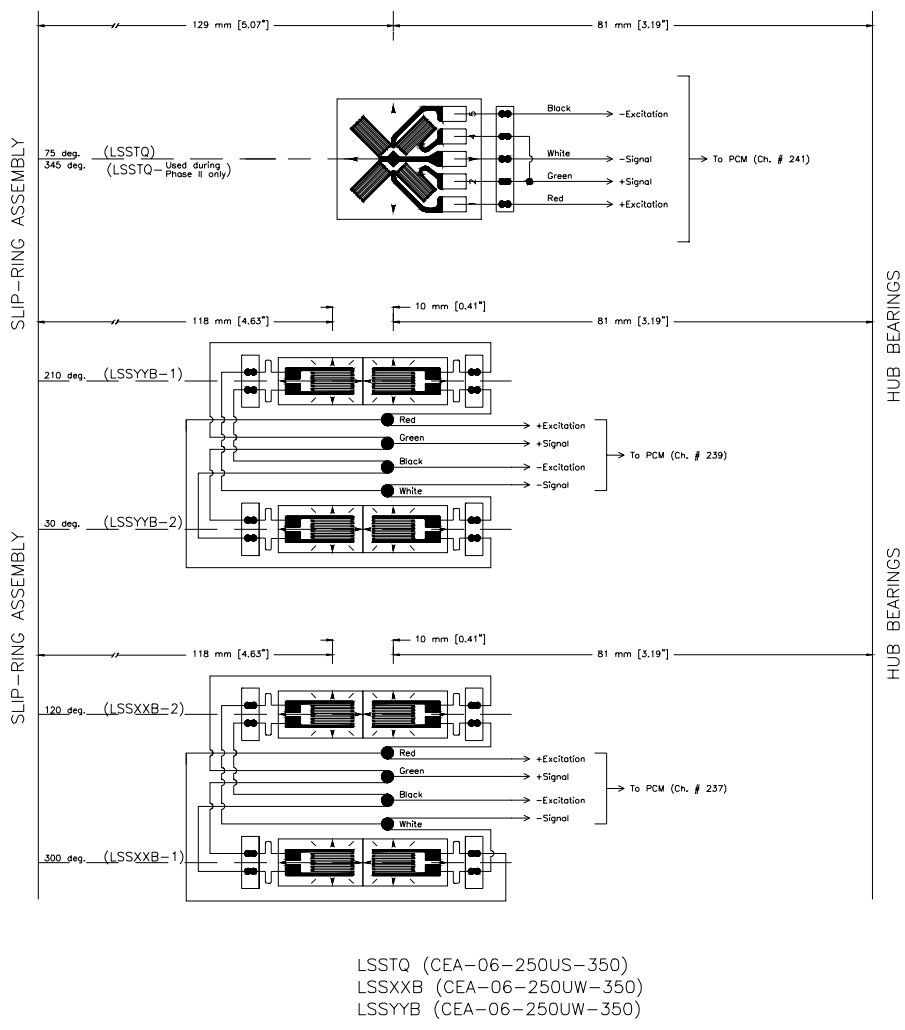

Figure 32. Low-speed shaft strain gauge configuration 


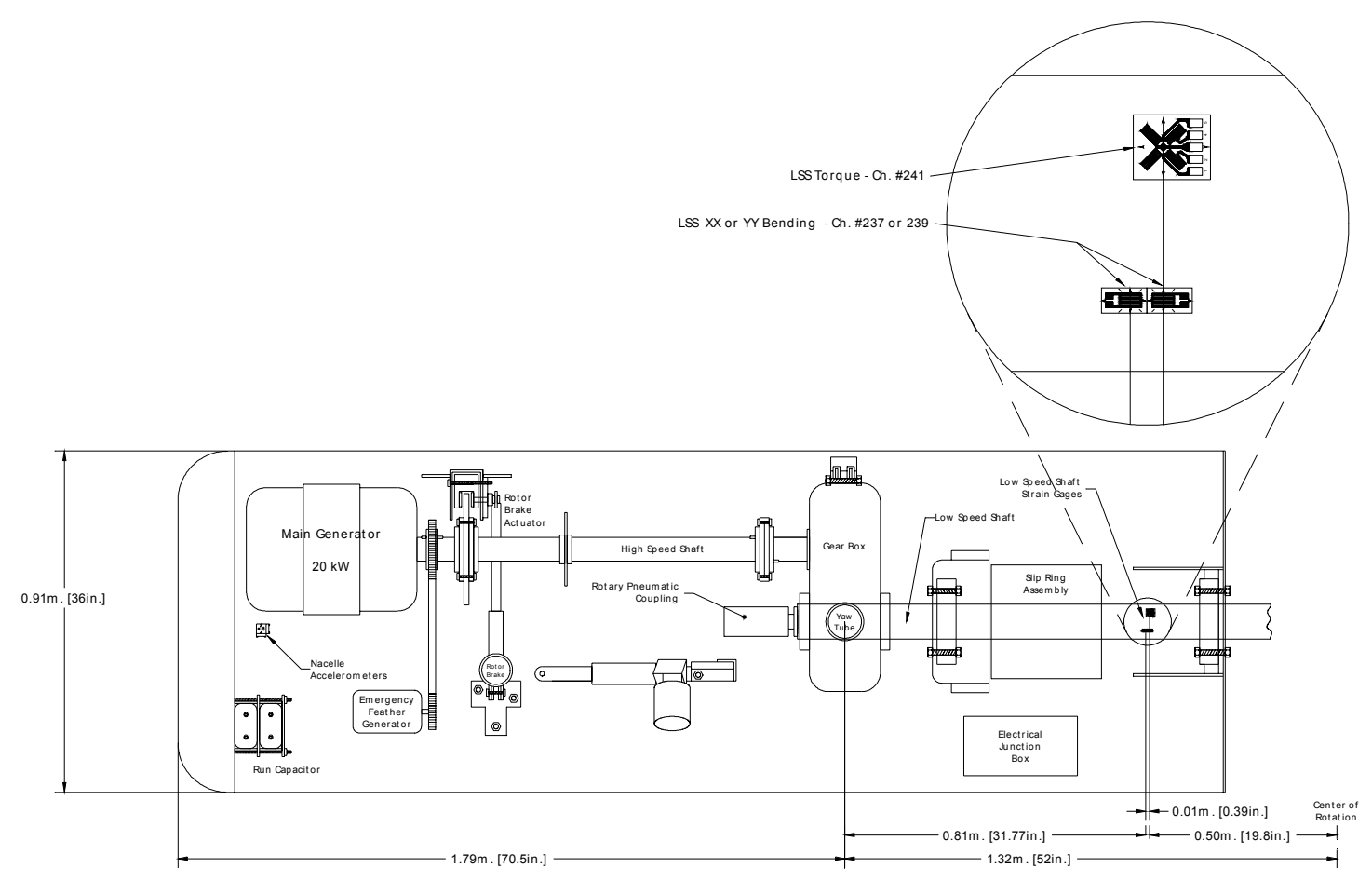

Figure 33. Low-speed shaft strain gauge location within nacelle 


\section{Strain Gauges (Yaw Moment)}

\section{Channel ID Code Description \\ 342 NAYM Nacelle yaw moment}

Location

Measurement type and units

Excitation

Arms of yaw brake mechanism

Bending moment, $\mathrm{Nm}$

$10 \mathrm{Vdc}$

Range

Resolution

Calibration method

Application of known loads (A1)

Sensor description

Resistance $=350.0 \pm 0.4 \% \Omega$

Measurements Group, Inc.

Model:

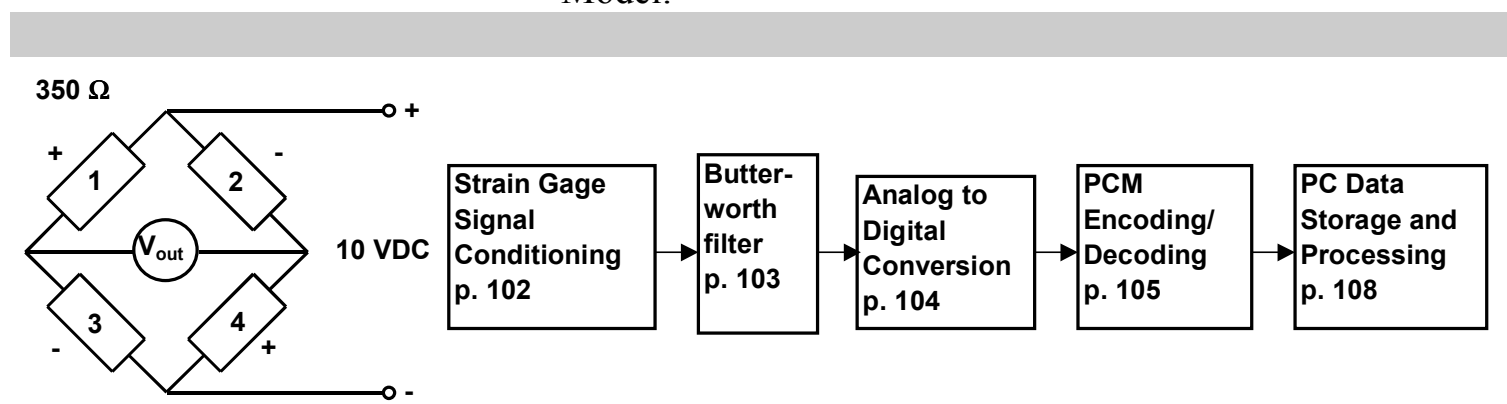

Note: yaw moment is positive due to positive yaw error.

Calibration Procedures (see p. 67)

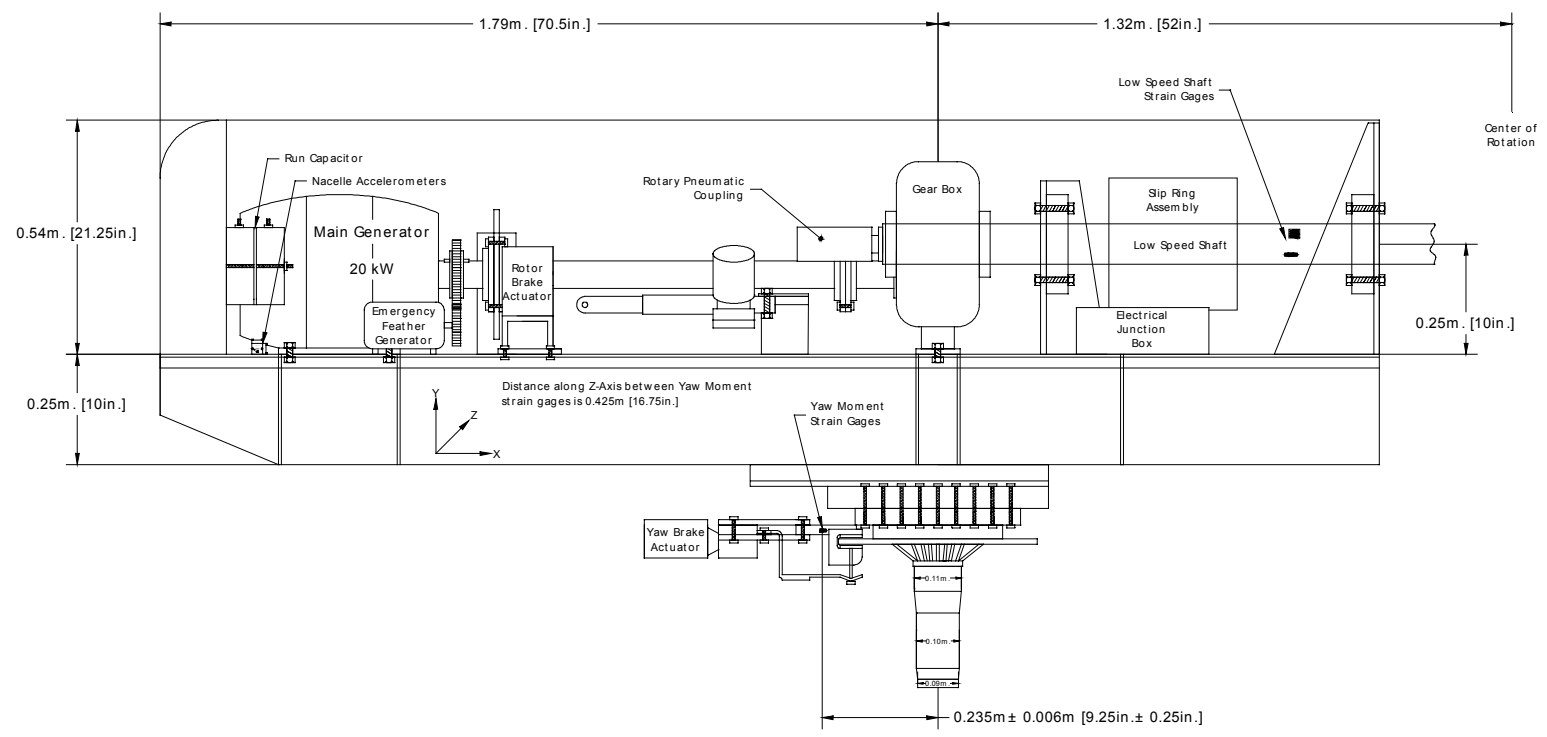

Figure 34. Yaw moment strain gauge configuration 


\section{Accelerometers}

\begin{tabular}{|c|c|c|c|c|c|}
\hline Channel & ID Code & \multicolumn{4}{|c|}{ Description } \\
\hline 201 & B1ACFL & \multicolumn{4}{|c|}{ Blade 1 tip accelerometer - flap } \\
\hline 203 & B1ACED & \multicolumn{4}{|c|}{ Blade 1 tip accelerometer - edge } \\
\hline 209 & B3ACFL & \multicolumn{4}{|c|}{ Blade 3 tip accelerometer - flap } \\
\hline 211 & B3ACED & \multicolumn{4}{|c|}{ Blade 3 tip accelerometer - edge } \\
\hline 336 & NAACYW & \multicolumn{4}{|c|}{ Nacelle accelerometer - yaw } \\
\hline 338 & NAACFA & \multicolumn{4}{|c|}{ Nacelle accelerometer - fore-aft sway } \\
\hline 340 & NAACPI & \multicolumn{4}{|c|}{ Nacelle accelerometer - pitch } \\
\hline \multicolumn{2}{|l|}{ Location } & \multicolumn{4}{|c|}{ Blade tip, inside tip block; nacelle bedplate near generator } \\
\hline \multicolumn{2}{|c|}{ Measurement type and units } & \multicolumn{4}{|c|}{ linear acceleration, g's } \\
\hline \multicolumn{2}{|c|}{ Excitation } & \multicolumn{4}{|c|}{$15 \mathrm{Vdc}$} \\
\hline \multicolumn{2}{|l|}{ Range } & \multicolumn{4}{|c|}{ $\pm 2 \mathrm{~V}= \pm 10 \mathrm{~g}$} \\
\hline \multicolumn{2}{|l|}{ Sensitivity } & \multicolumn{4}{|c|}{$200 \mathrm{mV} / \mathrm{g}$} \\
\hline \multicolumn{2}{|c|}{ Calibration method } & \multicolumn{4}{|c|}{$\begin{array}{l}\text { Manufacturer specifications (M8) and electronic path } \\
\text { calibration (E1) }\end{array}$} \\
\hline \multirow{2}{*}{\multicolumn{2}{|c|}{ Sensor description }} & \multicolumn{4}{|c|}{ Variable capacitance accelerometer } \\
\hline & & \multicolumn{4}{|c|}{$\begin{array}{l}\text { Endevco Corporation } \\
\text { Model: } 7290 \mathrm{~A}-10\end{array}$} \\
\hline Accelerometer & $\begin{array}{l}\text { Accelerometer } \\
\text { Signal } \\
\text { Conditioning } \\
\text { p. } 99\end{array}$ & $\rightarrow \begin{array}{l}\text { Bessel } \\
\text { filter } \\
\text { p. } 103\end{array}$ & $\rightarrow \mid \begin{array}{l}\text { Analog to } \\
\text { Digital } \\
\text { Conversion } \\
\text { p. } 104\end{array}$ & $\rightarrow \sqrt{\begin{array}{l}\text { PCM } \\
\text { Encoding/ } \\
\text { Decoding } \\
\text { p. } 105\end{array}}$ & \begin{tabular}{|l} 
PC Data \\
Storage and \\
Processing \\
p. 108
\end{tabular} \\
\hline
\end{tabular}

\section{Calibration Procedure}

\section{Manufacturer specifications - (M8)}

1. A calibration was performed by Endevco Corporation before installation of the accelerometers.

2. Enter the sensitivity as recorded by Endevco and the offset $(0 \mathrm{~g})$ in the appropriate columns of calconst.xls.

\section{Electronic path calibration (E1)}

1. Modify $v b l . l s t$ so that the accelerometer channels are listed at the top of the file. Set NV in the first line to the number of channels to be calibrated, and ensure that the correct PCM stream is specified in gencal.cap (PCM stream 2 for blade accelerometers and PCM stream 3 for nacelle accelerometers). Because the nacelle accelerometers and the blade tip accelerometers are on different PCM streams, they must be separated into two *.cao files.

2. Connect the precision voltage generator to the accelerometer output prior to the signal conditioners. 
3. Run the $g c$ batch file which invokes both gencal and genfit. Collect samples for voltages ranging from -0.9 to $0.9 \mathrm{~V}$ in $0.2 \mathrm{~V}$ increments for nacelle accelerometers ( -0.8 to 0.8 in 0.2 $\mathrm{V}$ increments for blade accelerometers) with two repetitions at each voltage level. The recorded input and output values are stored in the *.cao input file. Genfit computes slopes and offsets of the electronic path from the processor output to the computer in units of volts / count and volts, respectively. These values are stored in a temporary header file, ${ }^{*} . h d r$.

These slope and offset values are combined with the manufacturer-provided slope and offset during the buildhdr process to obtain units of engineering unit/count and counts, respectively.

\section{Calibration frequency}

The accelerometers were calibrated prior to installation. An electronic path calibration was performed prior to each series of data collection, which lasted less than 1 month.

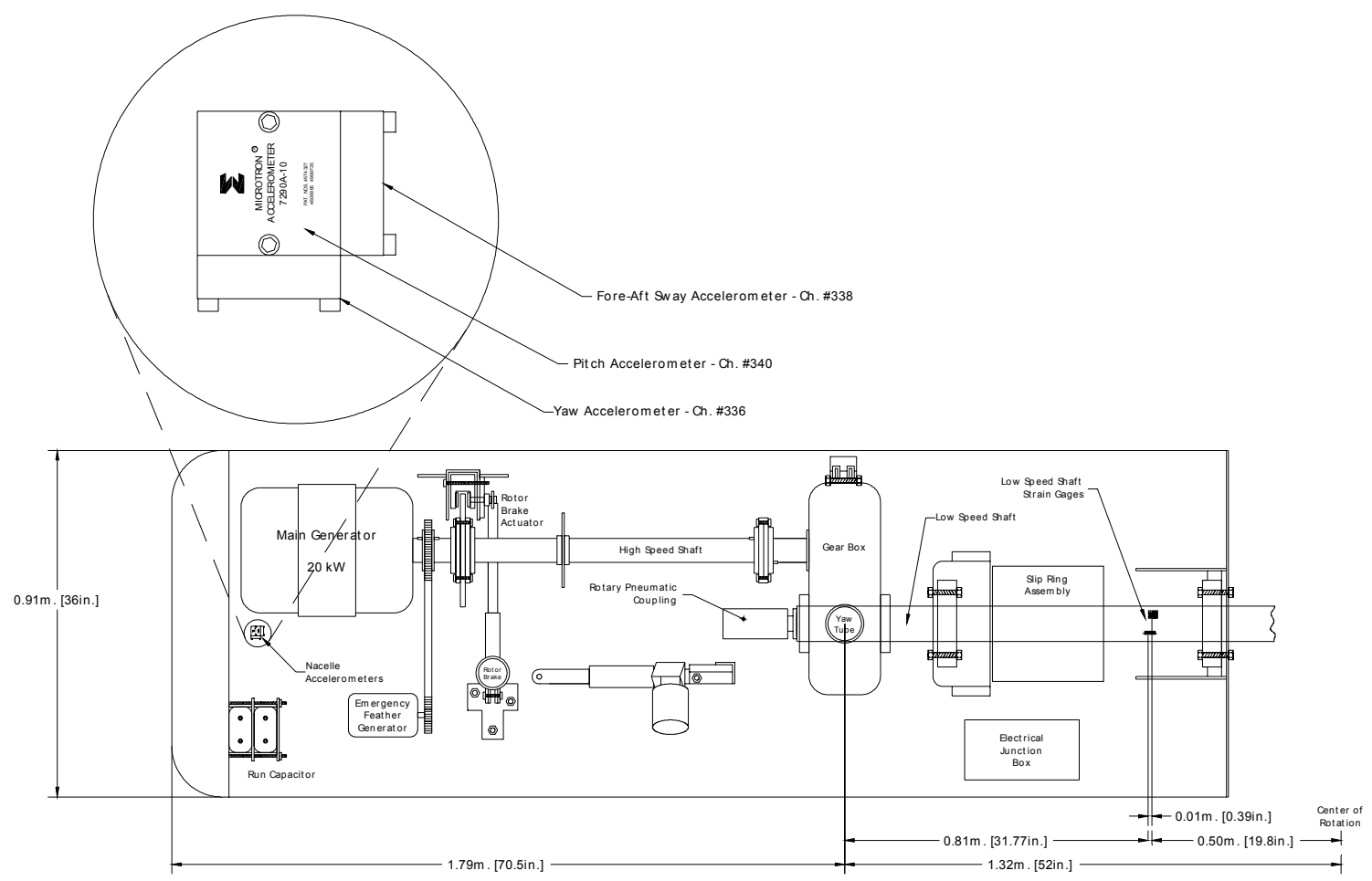

Figure 35. Nacelle accelerometer configuration 


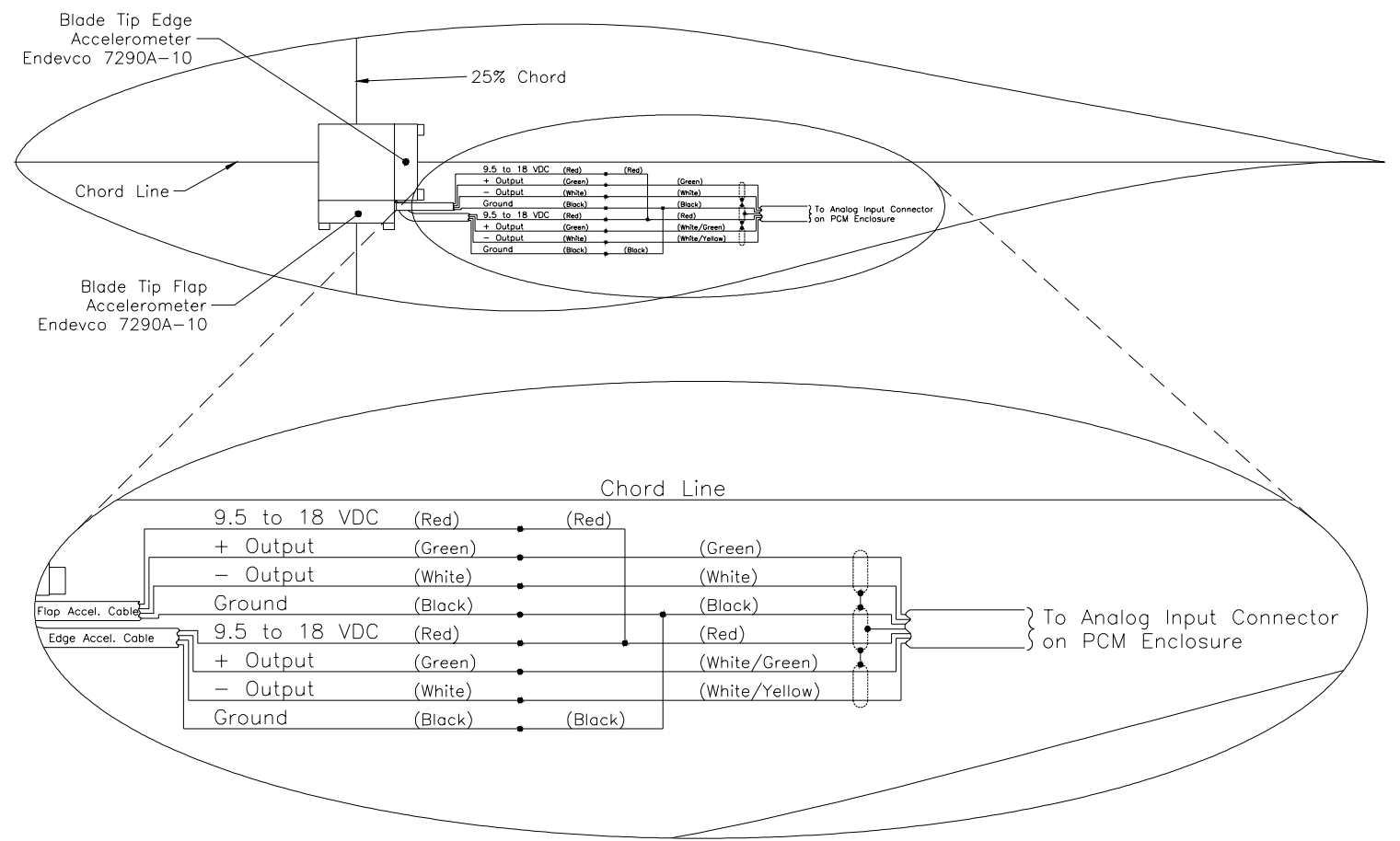

Figure 36. Blade tip accelerometer configuration 


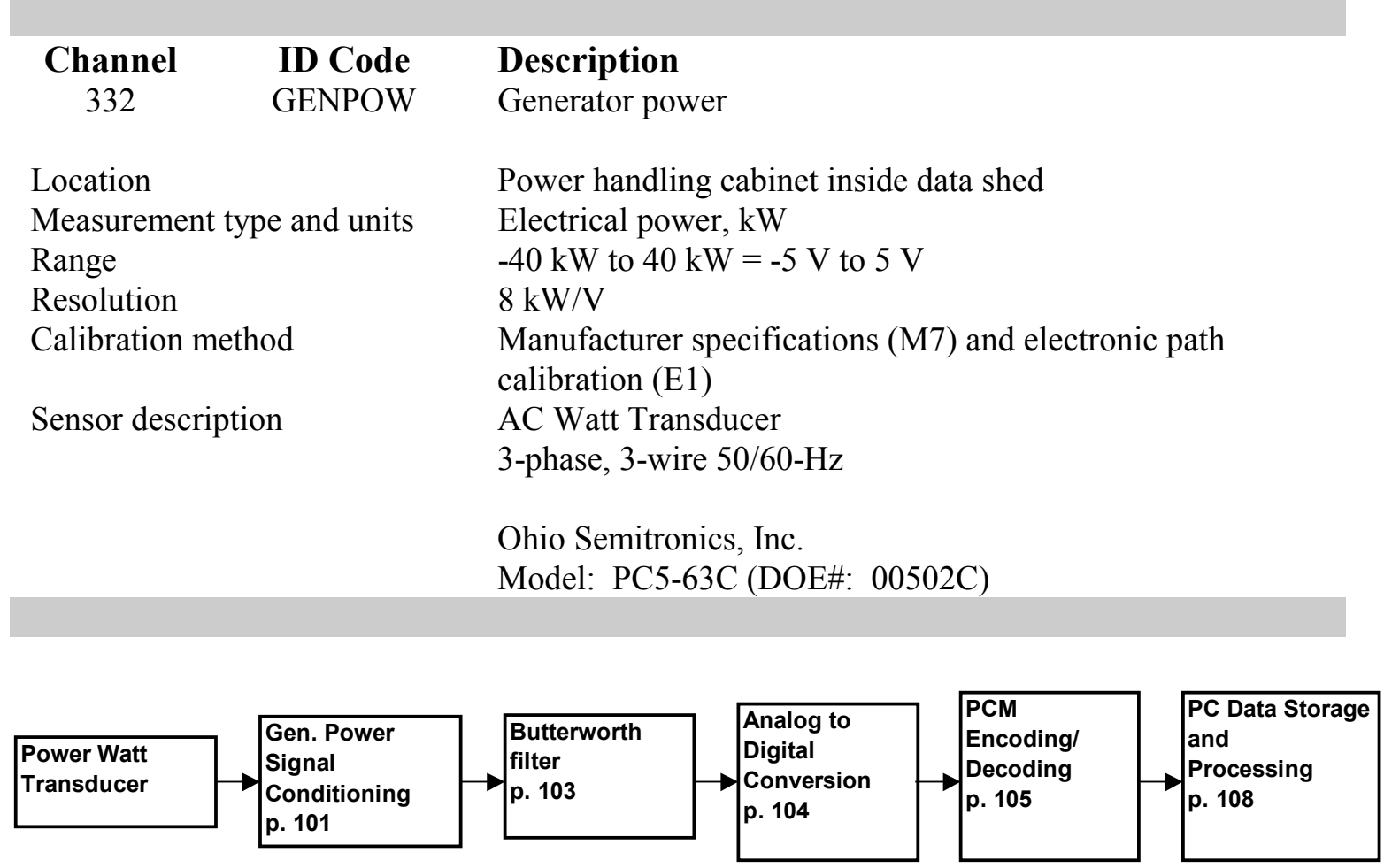

\section{Calibration Procedure}

\section{Manufacturer specifications - (M7)}

1. A calibration was performed by NREL Calibration Laboratory before installation of the power watt transducer.

2. Enter the slope $(8 \mathrm{~kW} / \mathrm{V})$ and the offset $(0 \mathrm{~kW})$ in the appropriate columns of calconst.xls.

\section{Electronic path calibration - (E1)}

1. Modify $v b l$.lst so that the power channel is listed at the top of the file. Set NV (number of variables) in the first line to the number of channels to be calibrated, and ensure that the correct PCM stream is specified in gencal.cap (PCM stream 3).

2. Connect the precision voltage generator to the power transducer output.

3. Run the gc.bat batch file which invokes both gencal.exe and genfit.exe. Collect samples for voltages ranging from -4.5 to $4.5 \mathrm{~V}$ in $1 \mathrm{~V}$ increments with two repetitions at each voltage level. The recorded input and output values are stored in the *.cao input file. Genfit.exe computes slopes and offsets of the electronic path from the processor output to the computer in units of $\mathrm{V} /$ count and $\mathrm{V}$, respectively. These values are stored in a temporary header file, *.hdr. These slope and offset values are combined with the manufacturer-provided slope and offset during the buildhdr.bat process to obtain units of engineering unit/count and counts, respectively. 


\section{Calibration frequency}

The transducer was calibrated in the laboratory prior to installation. The electronic path calibration was performed prior to each series of data collection, which lasted less than 1 month. 


\section{Digital Position Encoders (Rotor)}

$\begin{array}{ccl}\text { Channel } & \text { ID Code } & \text { Description } \\ 253 & \text { B1PITCH } & \text { Blade 1 pitch angle } \\ 257 & \text { B3PITCH } & \text { Blade 3 pitch angle } \\ 349 & \text { B3AZI } & \text { Blade 3 azimuth angle } \\ 351 & \text { YAW } & \text { Turbine yaw angle }\end{array}$

Location

Root attachment of each blade; low-speed shaft in nacelle; yaw axis.

Measurement type and units angular position, degrees

Power requirement $15 \mathrm{Vdc}$

Range

$360^{\circ}=4096$ counts

Resolution

Calibration method

$0.08789 \%$ count

Manufacturer specifications (M9) and single-point offset determination (S3)

Sensor description Digital, gray code resolver Accuracy: $\pm 1 / 2$ Count (LSB), worst case

BEI Motion Systems Company

Model: R25-4096-24
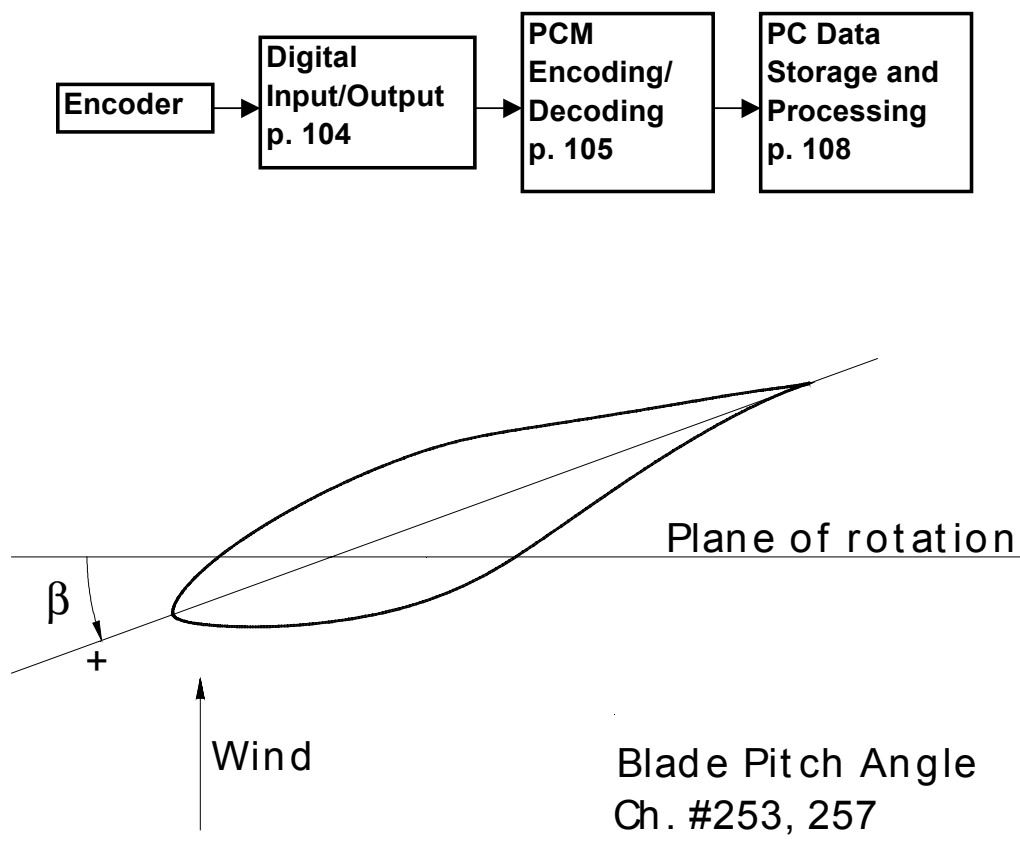

Figure 37. Blade pitch angle orientation 

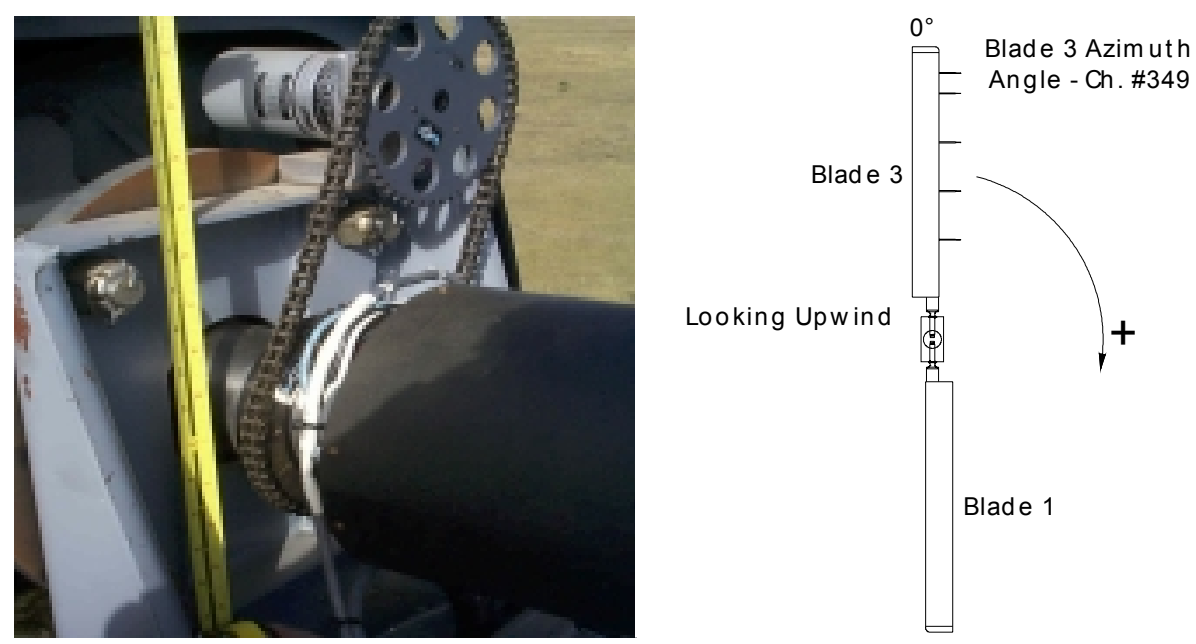

Figure 38. Azimuth angle encoder photograph and orientation
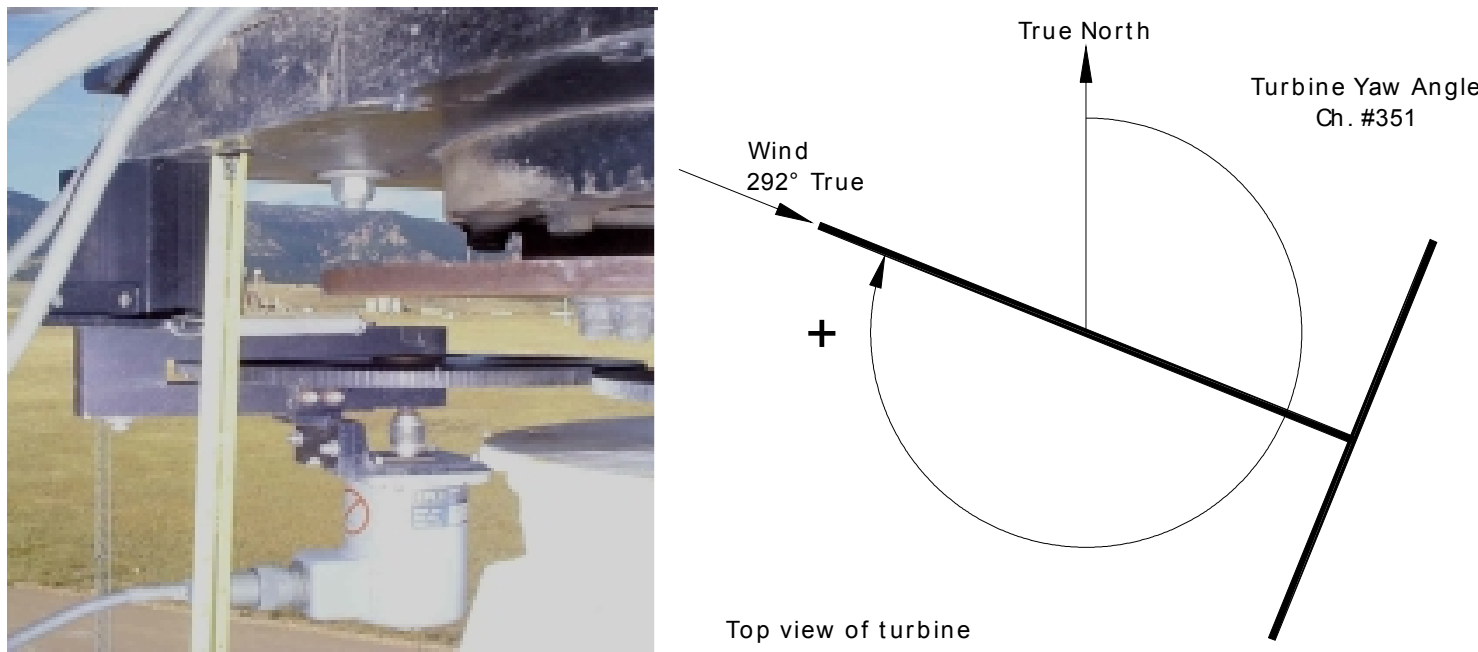

Figure 39. Yaw angle encoder photograph and orientation

\section{Calibration Procedure}

\section{Manufacturer specifications - (M9)}

1. A calibration was performed by BEI Motion Systems before installation of all digital position encoders.

2. Enter the slope $\left(0.08789^{\circ}\right.$ /count $)$ in the appropriate columns of calconst.xls.

Single-point offset determination - (S3) - (This is a two-person operation requiring one person in the man-lift to position the blades or turbine and one person on the ground to operate the computer.)

1. The man-lift person notifies ground person which encoder is to be calibrated. A reference point is used to determine the offset for each encoder as follows:

a. Each blade is individually pitched to $0^{\circ}$, and an Angle-star is used to measure the exact pitch angle. 
b. The nacelle is aligned by eye with the north met tower ( $292^{\circ}$ from true north) to determine the yaw angle offset.

c. The instrumented blade is aligned by eye with the tower $\left(180^{\circ}\right)$ to determine the azimuth angle offset.

2. The difference between the data acquisition system angle and the known angle is determined in counts. This value is added to the current count value listed in calconst.xls. A new master.hdr file is created using the macros Write ang.hdr and Write convert.v2u along with the program vupdate.exe. The angle is then repositioned and the difference obtained. If the difference is greater than 2-3 counts, the process is repeated.

\section{Calibration frequency}

The blade pitch, yaw angle, and azimuth angle offsets were determined prior to each series of data collection. 


\section{Digital Position Encoders (Hub)}

\begin{tabular}{|c|c|c|c|c|}
\hline Channel & ID Code & \multicolumn{3}{|c|}{ Description } \\
\hline 251 & B1FLAP & \multicolumn{3}{|c|}{ Blade 1 flap angle } \\
\hline 255 & B3FLAP & \multicolumn{3}{|c|}{ Blade 3 flap angle } \\
\hline \multirow{3}{*}{\multicolumn{2}{|c|}{$\begin{array}{l}\text { Location } \\
\text { Measurement type and units } \\
\text { Power requirement }\end{array}$}} & \multirow{2}{*}{\multicolumn{3}{|c|}{$\begin{array}{l}\text { Mounted on hub outboard of teeter bearing } \\
\text { angular position, degrees }\end{array}$}} \\
\hline & & & & \\
\hline & & \multicolumn{3}{|l|}{$15 \mathrm{Vdc}$} \\
\hline Range & & \multicolumn{3}{|c|}{$45^{\circ}$ (restricted by damper) } \\
\hline Resolution & & \multicolumn{3}{|c|}{$0.0110^{\circ} /$ count } \\
\hline Calibration 1 & & \multicolumn{3}{|c|}{$\begin{array}{l}\text { Manufacturer specifications (M13) and single-point offset } \\
\text { determination (S6) }\end{array}$} \\
\hline \multirow{3}{*}{\multicolumn{2}{|c|}{ Sensor description }} & \multicolumn{3}{|c|}{ Digital, gray-code resolver } \\
\hline & & \multicolumn{3}{|c|}{ Accuracy: $\pm 1 / 2$ Count (LSB), worst case } \\
\hline & & \multicolumn{3}{|c|}{$\begin{array}{l}\text { BEI Motion Systems Company } \\
\text { Model: RAS- } 25\end{array}$} \\
\hline \multicolumn{2}{|c|}{ Encoder } & $\begin{array}{l}\text { ital } \\
\text { ut/Output } \\
04\end{array}$ & 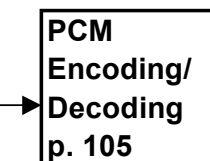 & $\rightarrow \sqrt{\begin{array}{l}\text { PC Data } \\
\text { Storage and } \\
\text { Processing } \\
\text { p. } 108\end{array}}$ \\
\hline
\end{tabular}

\section{Calibration Procedure}

\section{Manufacturer specifications - (M13)}

1. A calibration was performed by BEI Motion Systems before installation of all digital position encoders.

2. Enter the slope $(360 \%(4096$ counts*(8 gear-ratio $)))$ in the appropriate columns of calconst.xls.

Single-point offset determination - (S6) - (This is a two-person operation requiring one person in the man-lift to insert the calibration pins and one person on the ground to operate the computer.)

1. Man-lift person notifies ground person which encoder is to be calibrated. A reference point is used to determine the offset for each encoder as follows:

2. The difference between the data acquisition system angle and the known angle is determined in counts. This value is added to the current count value listed in calconst.xls. A new master.hdr file is created using the macros Write ang.hdr and Write convert.v $2 u$ along with the program vupdate. The angle is then repositioned and the difference obtained. If the difference is greater than 2-3 counts, the process is repeated.

\section{Calibration frequency}

All encoders were calibrated by the manufacturer prior to Phase V data collection. The singlepoint offset determination was done prior to each series of data collection. 


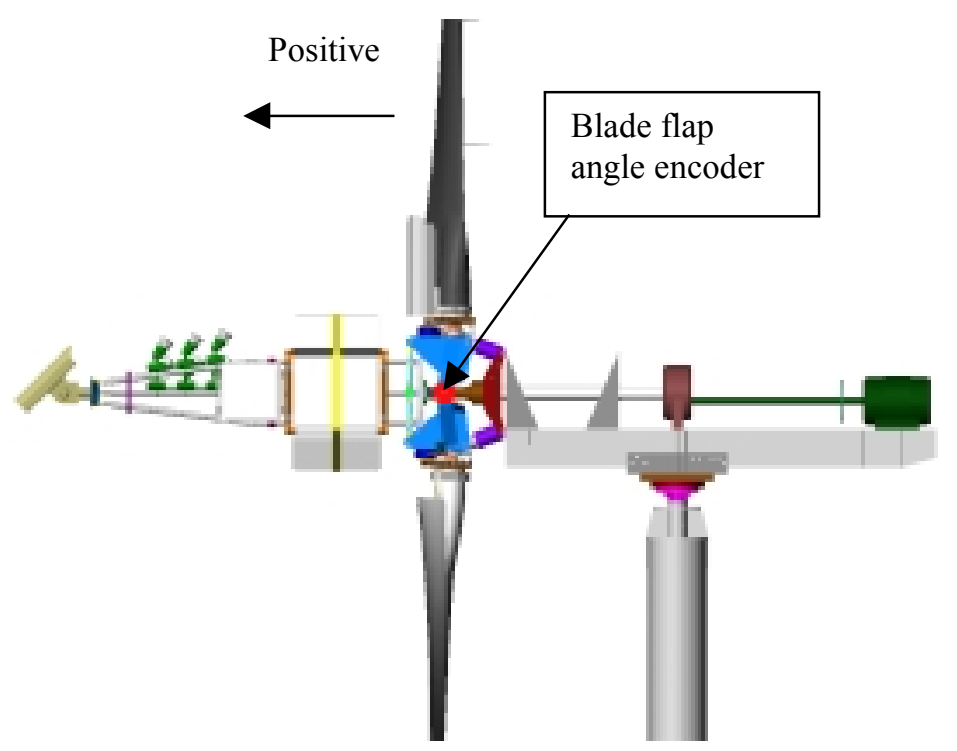

Figure 40. Blade flap angle encoder location

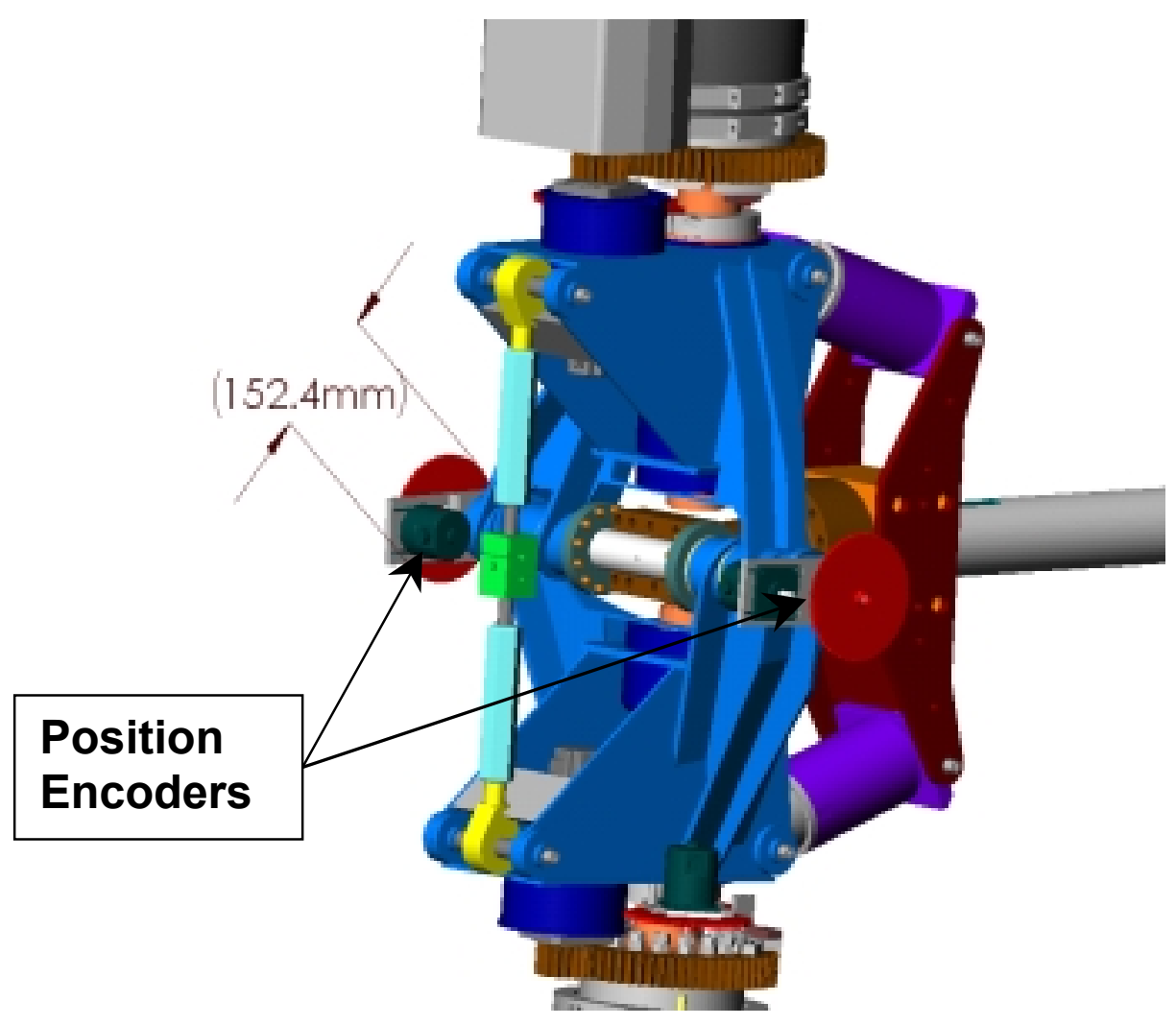

Figure 41. Blade flap angle close-up view 
Where,

$\phi_{3}=$ Blade 3 flap angle,

$\phi_{1}=$ Blade 1 flap angle,

$\tau=$ Teeter angle, and

$2 \alpha=$ Angle subtended by blades.

Figure 42. Blade flap angle convention 


\section{Pressure Transducers ( $30 \%$ and $47 \%$ span)}

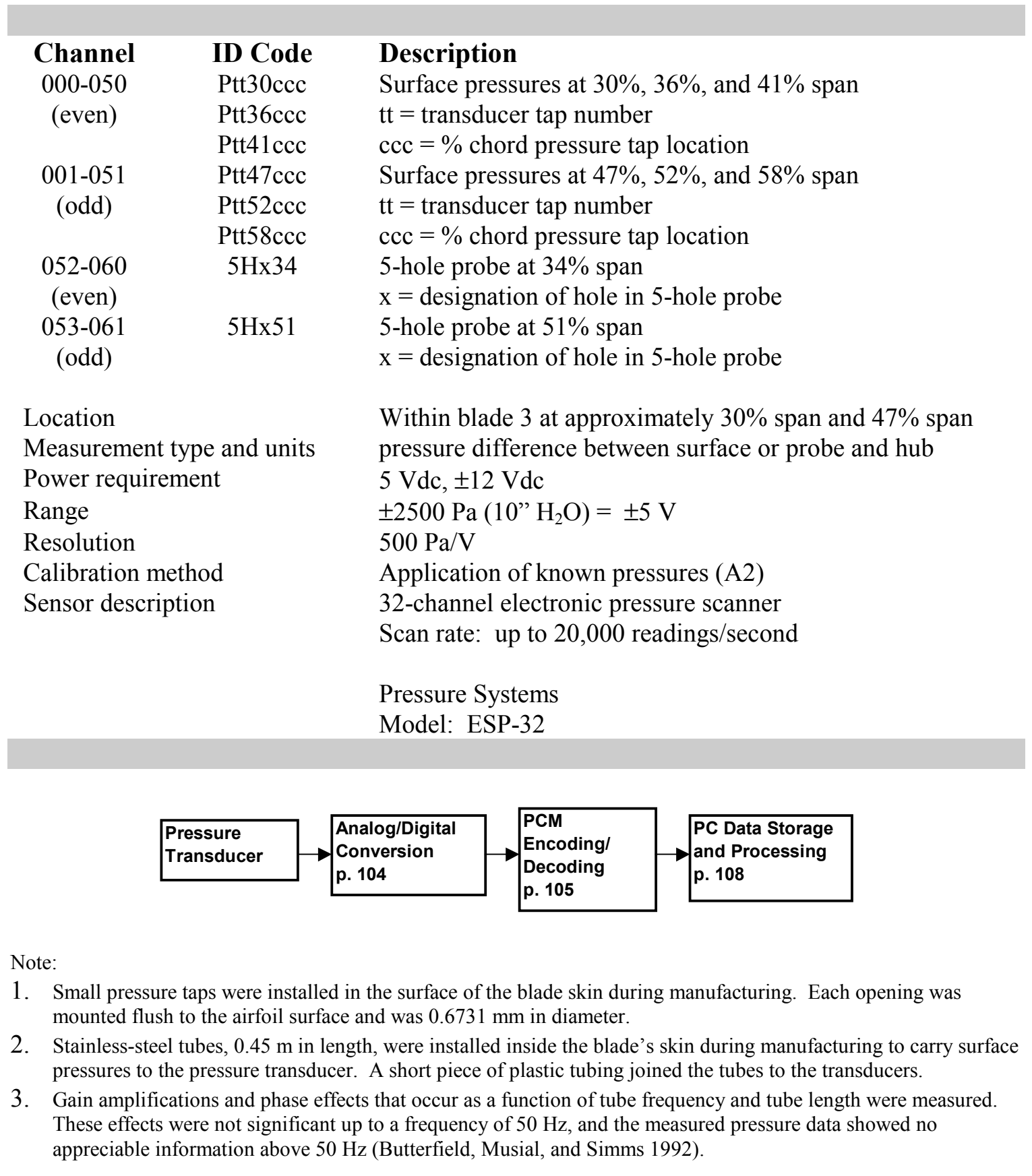

\section{Calibration Procedures}

\section{Application of known pressures - (A2)}

This calibration is designed to provide an accurate slope calibration of the complete pressure system. The pressure system controller is invoked to provide NIST-traceable reference pressures at all pressure ports. The pressures ramp up and down across the measurement range. Linear regression provides calibration coefficients that are automatically updated in master.hdr before 
data acquisition. This calibration is performed immediately before and after each 10-minute segment of data.

1. The batch file (go.bat) that initiates the process of collecting data begins a pressure calibration. After the turbine has been rotating for a few minutes, the temperature variations are minimized. The syringe in a hub-mounted instrumentation box applies a pressure to each transducer at once. Pressures were applied at $-0.9,-0.7,-0.5,-0.3,-0.2,-0.1,0.1$, and 0.2 psi. The actual pressure applied to the transducers is measured with the Mensor digital differential pressure transducer. A linear regression analysis provides slope and offset values, which are incorporated in master.hdr. The calibration is also automatically performed once the 10-minute data segment has been collected. During consecutive runs, the post-calibration of one data segment may also serve as the pre-calibration for the next data segment.

Table 22. Pressure Tap Chord Locations

\begin{tabular}{|c|c|c|c|c|}
\hline $\begin{array}{c}\text { Pressure } \\
\text { Tap Number }\end{array}$ & $\%$ chord & Surface & tt & ccc \\
\hline 1 & $100 \%$ & Trailing edge & 01 & 100 \\
\hline 2 & $92 \%$ & Upper & 02 & $92 \mathrm{U}$ \\
\hline 4 & $80 \%$ & Upper & 04 & $80 \mathrm{U}$ \\
\hline 6 & $68 \%$ & Upper & 06 & $68 \mathrm{U}$ \\
\hline 8 & $56 \%$ & Upper & 08 & $56 \mathrm{U}$ \\
\hline 10 & $44 \%$ & Upper & 10 & $44 \mathrm{U}$ \\
\hline 11 & $36 \%$ & Upper & 11 & $36 \mathrm{U}$ \\
\hline 12 & $28 \%$ & Upper & 12 & $28 \mathrm{U}$ \\
\hline 13 & $20 \%$ & Upper & 13 & $20 \mathrm{U}$ \\
\hline 14 & $14 \%$ & Upper & 14 & $14 \mathrm{U}$ \\
\hline 15 & $10 \%$ & Upper & 15 & $10 \mathrm{U}$ \\
\hline 16 & $8 \%$ & Upper & 16 & $08 \mathrm{U}$ \\
\hline 17 & $6 \%$ & Upper & 17 & 06U \\
\hline 18 & $4 \%$ & Upper & 18 & 04U \\
\hline 19 & $2 \%$ & Upper & 19 & $02 \mathrm{U}$ \\
\hline 20 & $1 \%$ & Upper & 20 & $01 \mathrm{U}$ \\
\hline 21 & $0.5 \%$ & Upper & 21 & $.5 \mathrm{U}$ \\
\hline 22 & $0 \%$ & Leading edge & 22 & 000 \\
\hline 23 & $0.5 \%$ & Lower & 23 & $.5 \mathrm{~L}$ \\
\hline 24 & $1 \%$ & Lower & 24 & $01 \mathrm{~L}$ \\
\hline 25 & $2 \%$ & Lower & 25 & $02 \mathrm{~L}$ \\
\hline 26 & $4 \%$ & Lower & 26 & 04L \\
\hline 27 & $6 \%$ & Lower & 27 & 06L \\
\hline 28 & $8 \%$ & Lower & 28 & 08L \\
\hline 30 & $14 \%$ & Lower & 30 & $14 \mathrm{~L}$ \\
\hline 31 & $20 \%$ & Lower & 31 & $20 \mathrm{~L}$ \\
\hline 32 & $28 \%$ & Lower & 32 & $28 \mathrm{~L}$ \\
\hline 34 & $44 \%$ & Lower & 34 & $44 \mathrm{~L}$ \\
\hline 36 & $68 \%$ & Lower & 36 & $68 \mathrm{~L}$ \\
\hline 38 & $92 \%$ & Lower & 38 & $92 \mathrm{~L}$ \\
\hline
\end{tabular}




\section{Pressure Transducers (63\% span)}

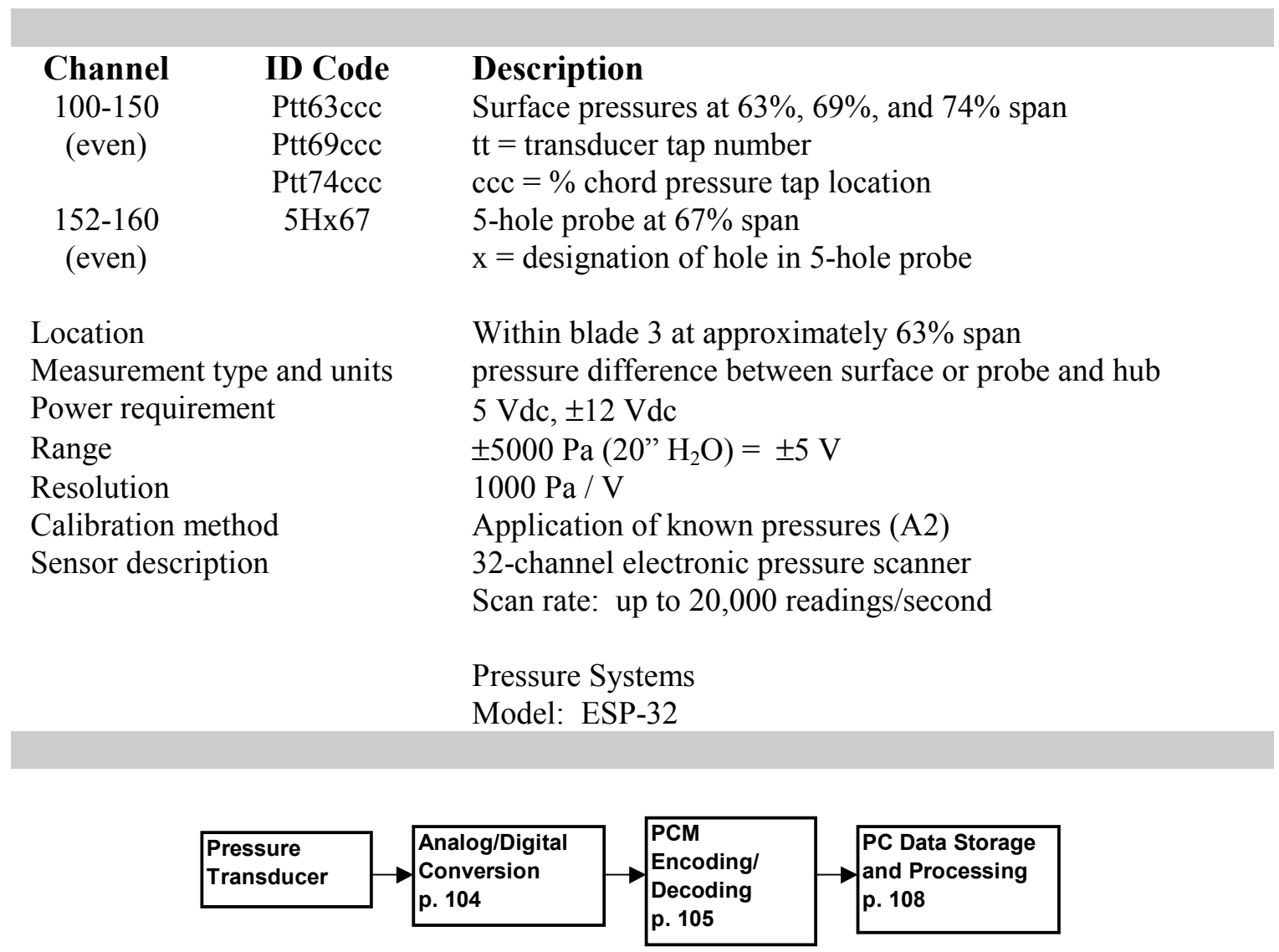

Calibration Procedure (see p. 88) 


\section{Pressure Transducers ( $80 \%$ and $95 \%$ span)}

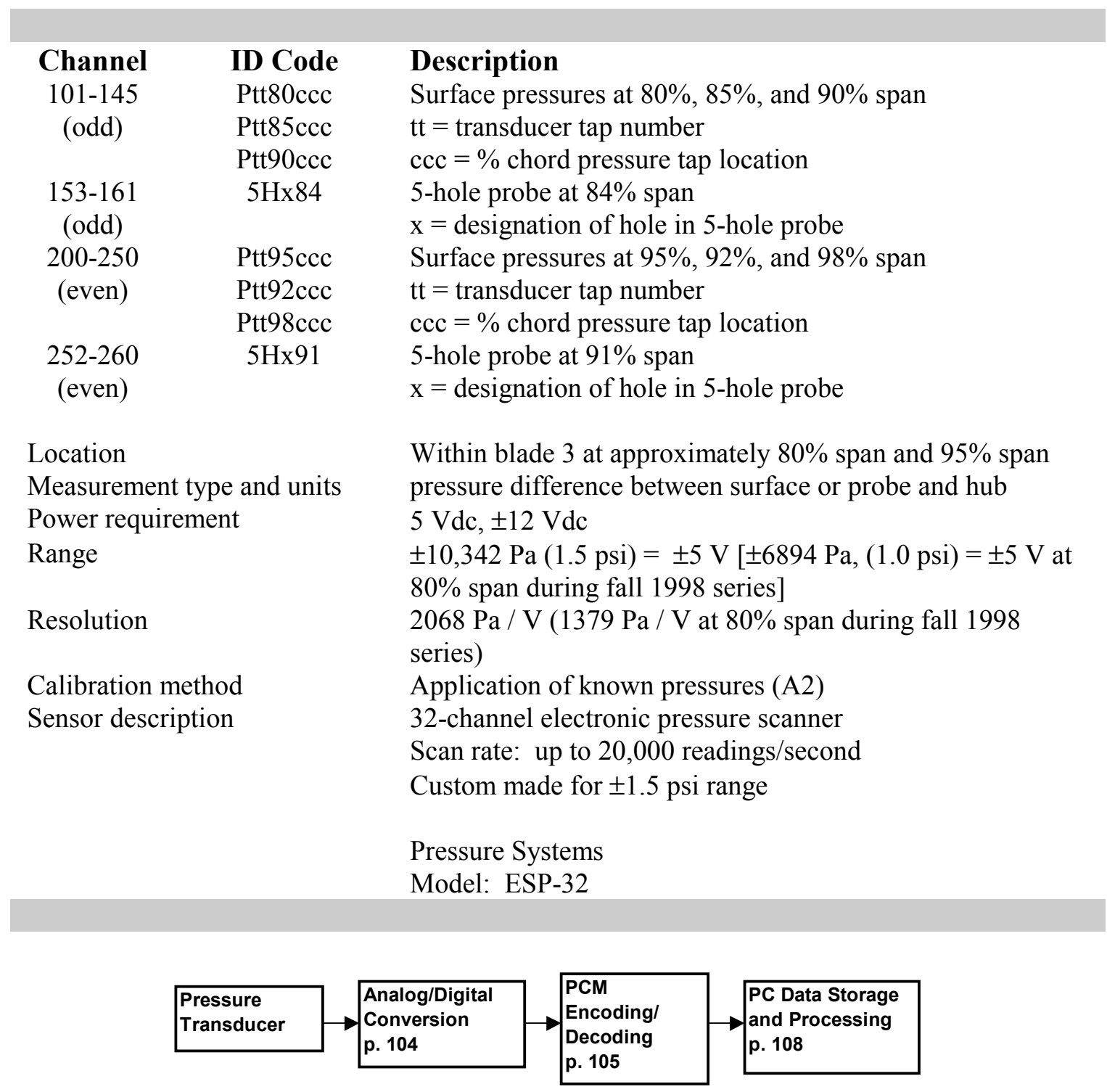

Calibration Procedure (see p. 88) 


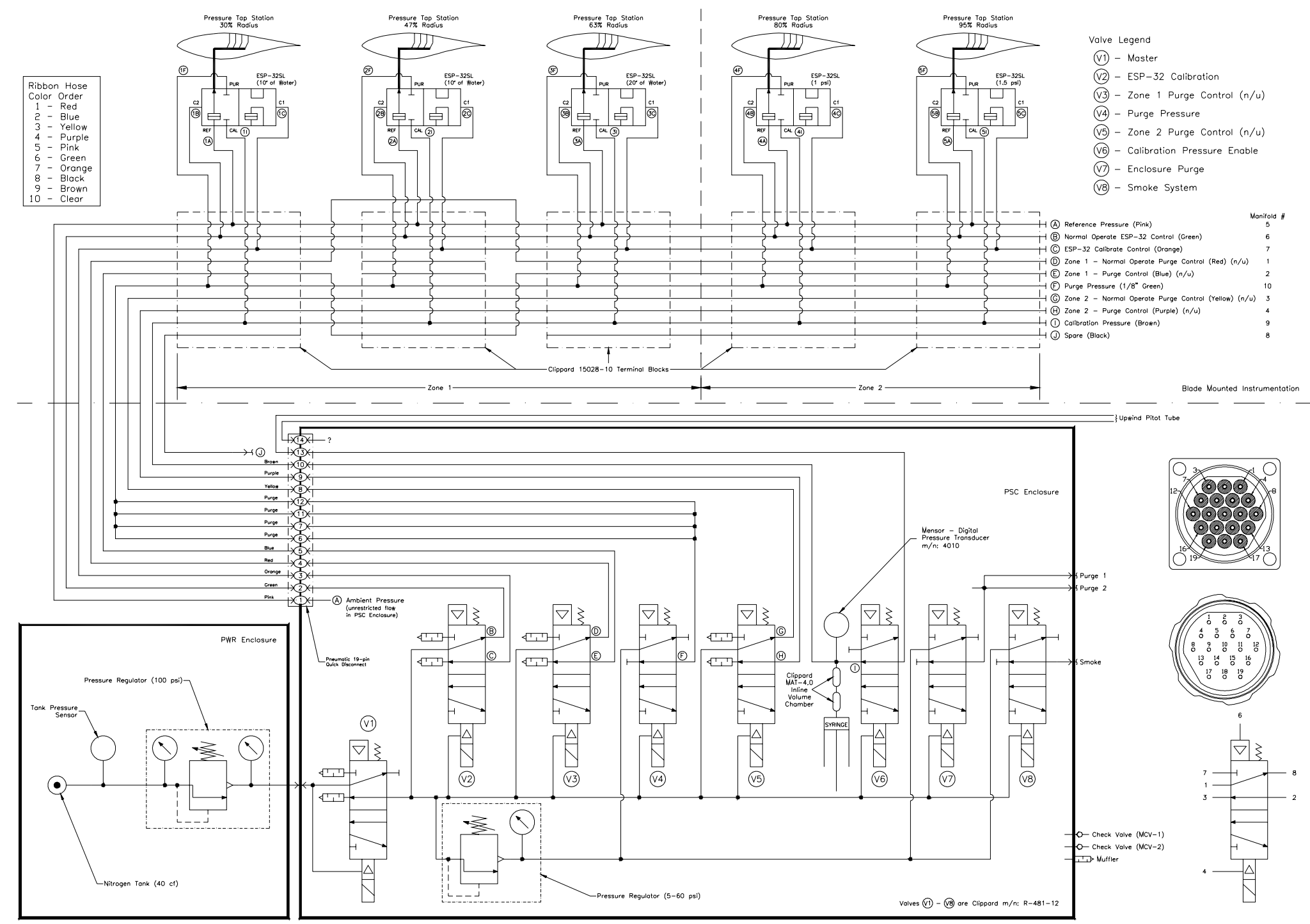

Figure 43. Pneumatic layout for fall 1998 data collection. 


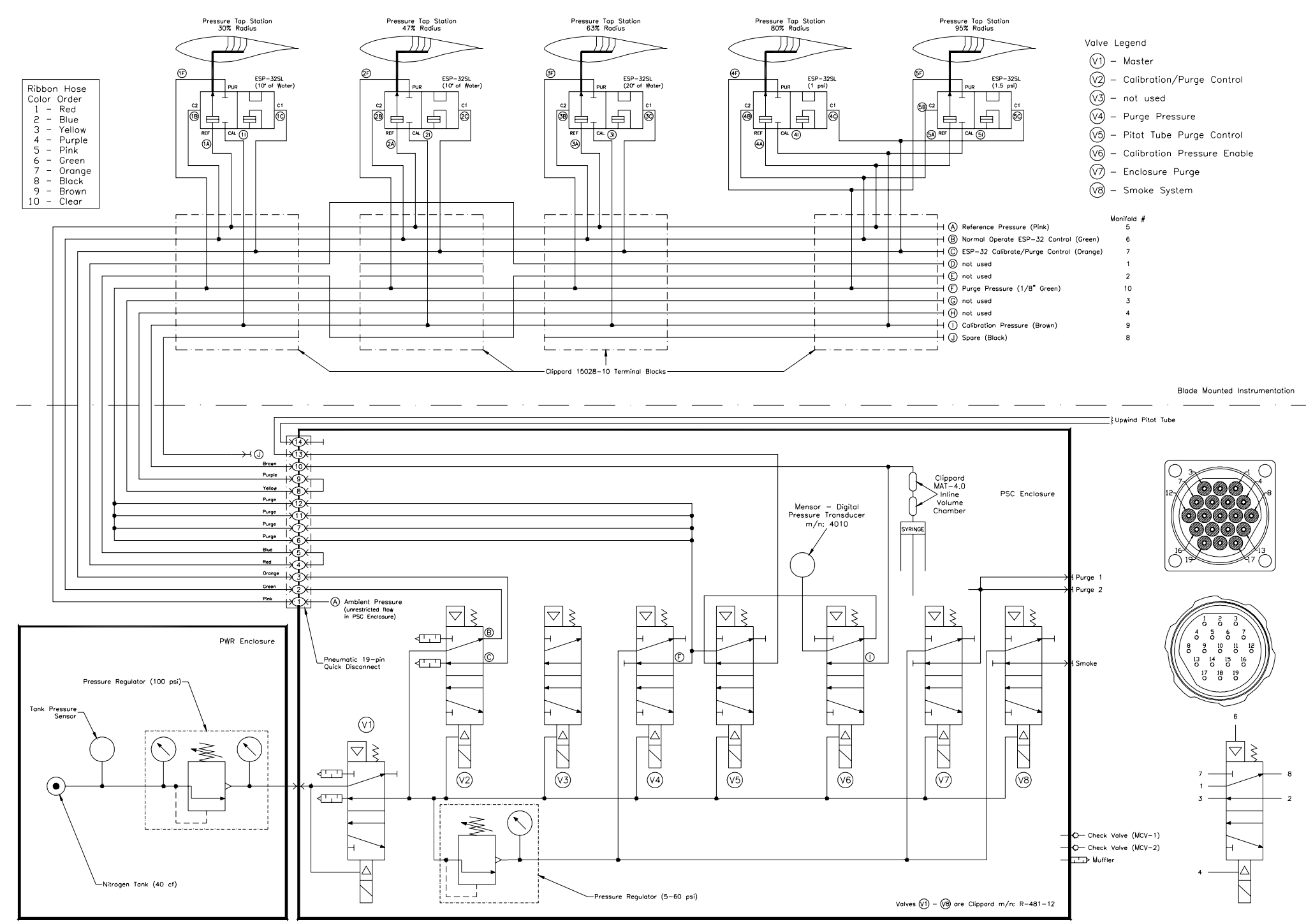

Figure 44. Pneumatic layout for spring 1998 data collection. 


\section{Nitrogen Tank Pressure}

\section{Channel \\ ID Code \\ Description \\ 213 \\ N/A}

Analog nitrogen tank pressure

Location

Measurement type and units

Rotor package

pressure inside nitrogen tank, $\mathrm{Pa}$

Power requirement

Range

0 to $2000 \mathrm{psig}$

Resolution

Calibration method

Sensor description

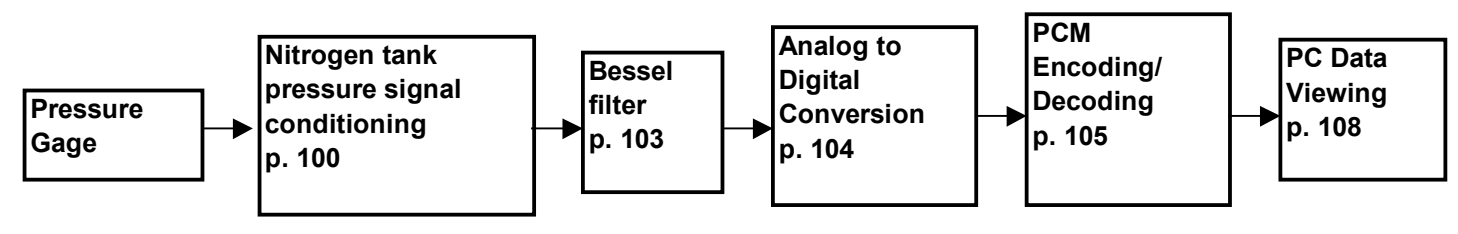

\section{Calibration frequency}

The pressure gauge was calibrated prior to Phase III. This channel is needed only to determine when the tank is nearly empty. The nitrogen is used to purge the pressure lines periodically. This channel is not recorded.

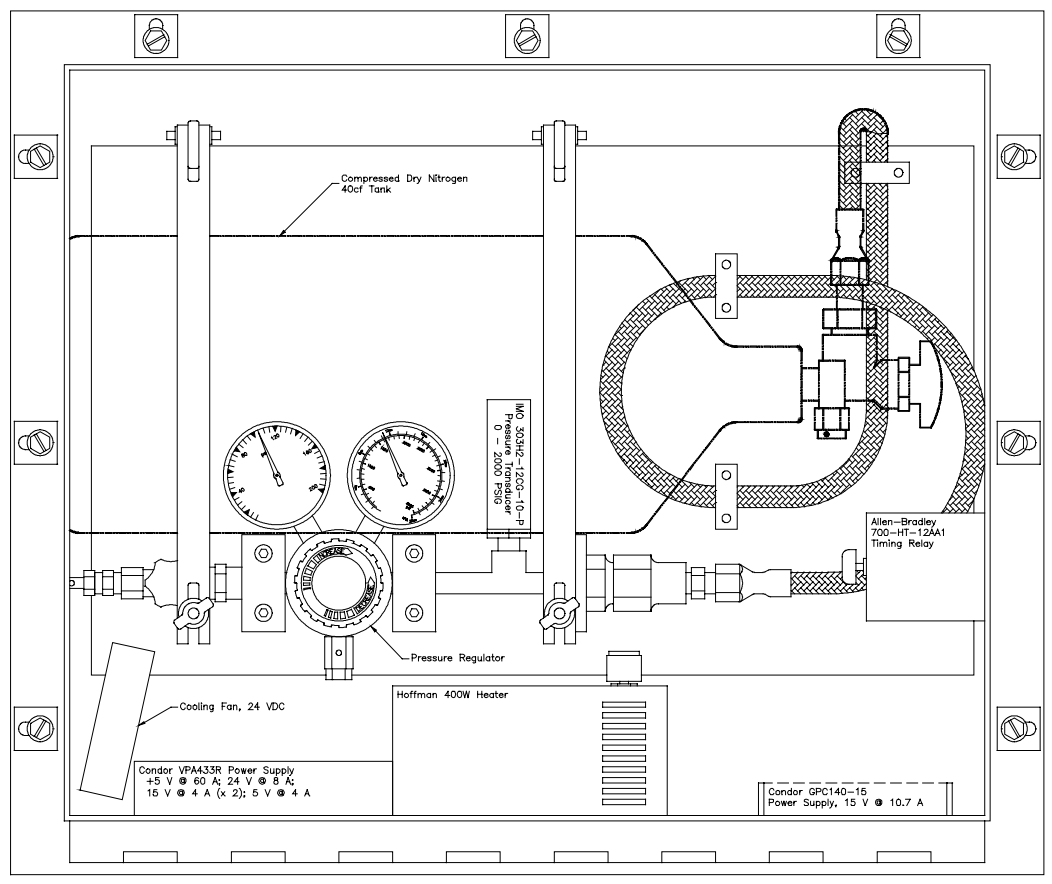

Figure 45. Nitrogen tank enclosure 


\section{Digital Differential Reference Pressure}

\section{Channel ID Code Description \\ $259 \quad$ VBL176 Digital first 12 bits from $\Delta$ pressure \\ $261 \quad$ VBL178 Digital last 12 bits from $\Delta$ pressure}

Location

Rotor package

Measurement type and units

Calibration reference pressure and static differential pressure, $\mathrm{Pa}$

Power requirement $12 \mathrm{Vdc}$

Range

\pm 2 psig $( \pm 13,790 \mathrm{~Pa})$

Resolution

Calibration method

$0.42 \mathrm{~Pa} / \mathrm{bit}$

Manufacturer (M11)

Sensor description

Digital pressure transducer

16 bit binary output

Accuracy: $0.01 \%$ full scale

Mensor Corporation

Model: 4010

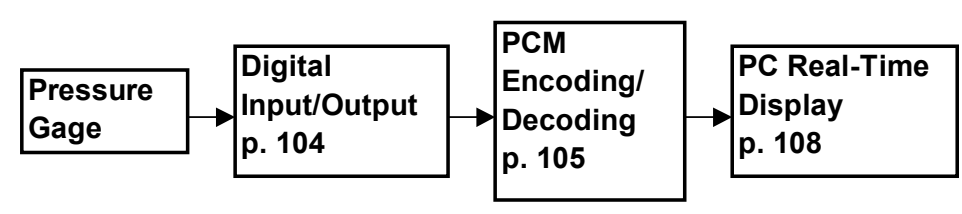

\section{Calibration Procedure}

\section{Manufacturer specifications - (M11)}

1. A calibration was performed by Mensor Corporation before installation of either digital pressure transducer.

2. The zero offset was determined by opening a valve, which provided the instrumentation box pressure to both sides of the Mensor. The tare value was adjusted to eliminate the difference.

\section{Calibration frequency}

The differential pressure transducers were calibrated prior to each series of data collection, which lasted less than 1 month. The zero offset was usually determined each day of data collection. 


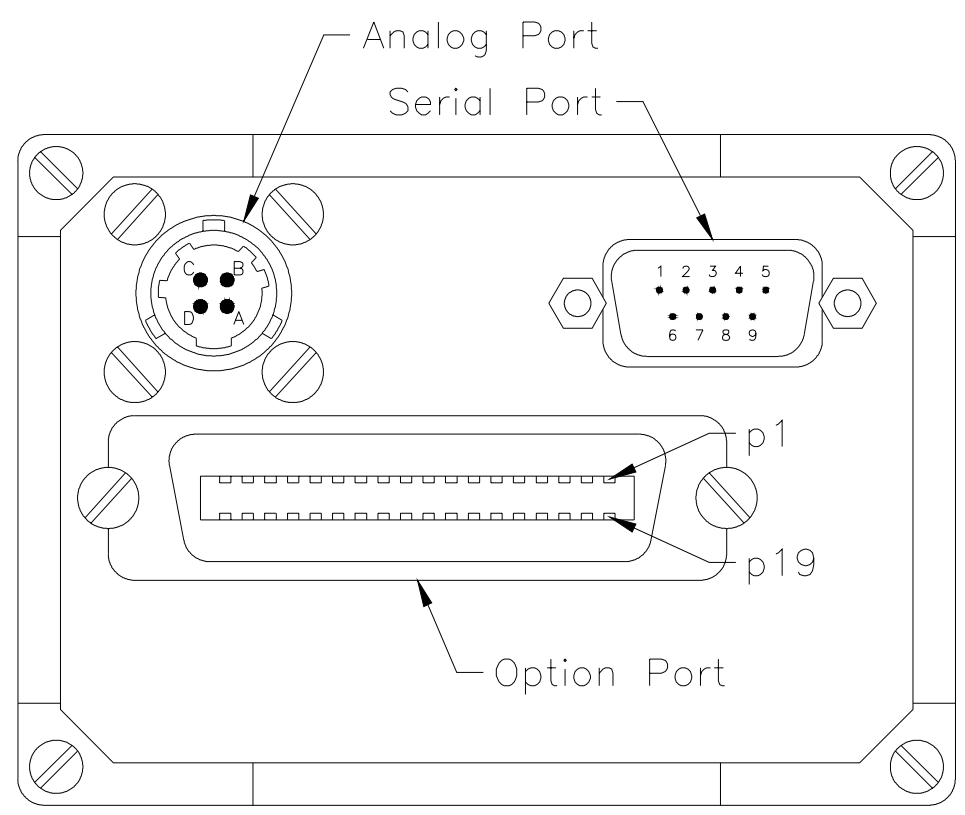

Figure 46. Mensor electrical ports

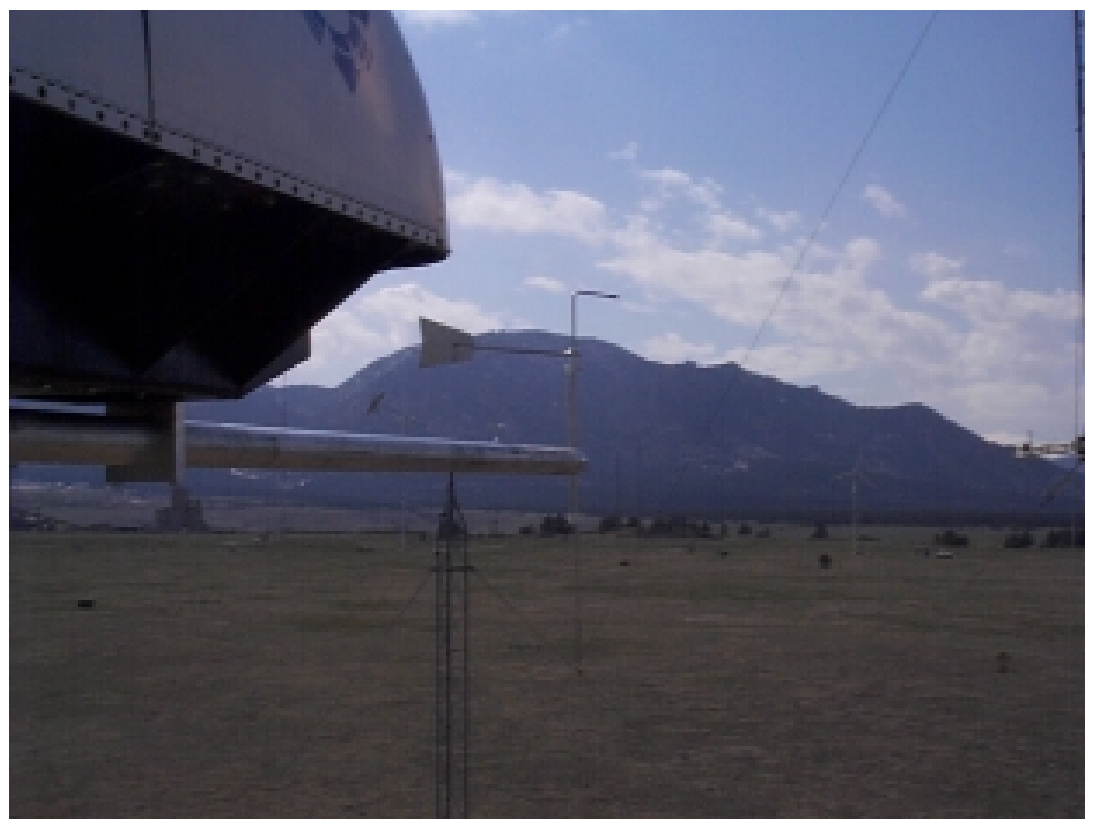

Figure 47. Upwind probe 


\section{Time Code Generator}

\begin{tabular}{|c|c|c|}
\hline Channel & ID Code & Description \\
\hline 353 & DAY & Clock - day \\
\hline 355 & HOUR & Clock - hour \\
\hline 357 & MINUTE & Clock - minute \\
\hline 359 & SECOND & Clock - second \\
\hline 361 & MILLISEC & Clock - millisecond \\
\hline \multicolumn{2}{|l|}{ Location } & Met rack in data shed \\
\hline \multicolumn{2}{|c|}{ Measurement type and units } & Time, day, hour, minute, second, and millisecond \\
\hline \multicolumn{2}{|c|}{ Power requirement } & $120 \mathrm{~V} \mathrm{AC}$ \\
\hline \multicolumn{2}{|c|}{ Calibration method } & Manufacturer (M12) \\
\hline \multicolumn{2}{|c|}{ Sensor description } & $\begin{array}{l}\text { Time code generator } \\
\text { formats: IRIG-A, IRIG-B, IRIG-C, IRIG-E, IRIG-H } \\
\text { frequency stability: } \pm 5 \mathrm{ppm}\end{array}$ \\
\hline
\end{tabular}

Model: 9310-804

\begin{tabular}{|c|c|c|c|}
\hline $\begin{array}{l}\text { Time Code } \\
\text { Generator }\end{array}$ & \begin{tabular}{|l} 
Digital \\
Input/Output \\
p. 104
\end{tabular} & \begin{tabular}{|l} 
PCM \\
Encoding/ \\
Decoding \\
p. 105
\end{tabular} & $\begin{array}{l}\text { PC Data } \\
\text { Storage and } \\
\text { Processing } \\
\text { p. } 108\end{array}$ \\
\hline
\end{tabular}

\section{Calibration Procedure}

\section{Manufacturer specifications - (M12)}

1. A calibration was performed by the manufacturer before installation.

\section{Calibration frequency}

The time code generator was calibrated prior to Phase III data collection. However, prior to each series of data collection (or in the event of a power failure), the clock was set using atomic clock readings. 

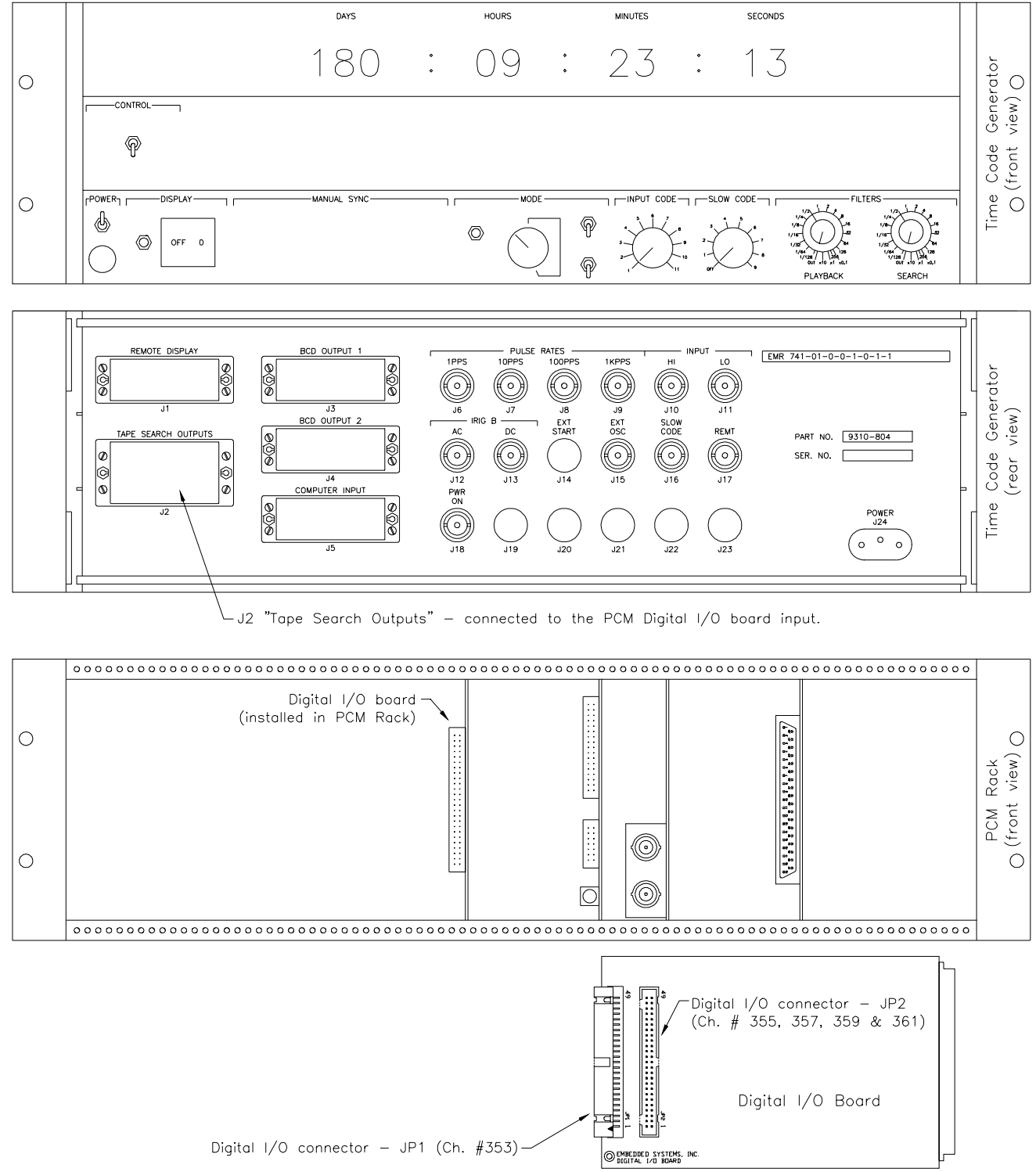

Figure 48. Time code generator 


\section{Accelerometer Signal Conditioning}

\section{Channel}

201, 203, 209, 211, 336-340 (even)

Location

Input level

Output level

Description

\section{Description}

Accelerometers in blade tips and nacelle

Rotor package for blade accelerometers;

Met rack for nacelle accelerometers

$\pm 1 \mathrm{Vdc}$

$\pm 5 \mathrm{Vdc}$

Isolated wide-band voltage input signal conditioning

Analog Devices, Inc.

Model: 5B01 (backplane), 5B41-01 (input module) 
Nitrogen Tank Pressure Signal Conditioning

\section{Channel}

213

Location

Input level

Output level

Description

\section{Description}

Nitrogen tank pressure

Rotor package

$\pm 10 \mathrm{Vdc}$

$\pm 5 \mathrm{Vdc}$

Isolated wide-band voltage input signal conditioning

Analog Devices, Inc.

Model: 5B01 (backplane), 5B41-03 (input module) 


\section{Power Transducer and Barometric Pressure Signal Conditioning}

\section{Channel}

332

334

Location

Input level

Output level

Description

\section{Description}

Generator power

Barometric pressure

Met rack in data shed

$\pm 5 \mathrm{Vdc}$

$\pm 5 \mathrm{Vdc}$

Isolated wide-band voltage input signal conditioning

Analog Devices, Inc.

Model: 5B01 (backplane), 5B41-02 (input module) 


\section{Strain Gauge Signal Conditioning}

\begin{tabular}{ll}
\multicolumn{1}{c}{ Channel } & Description \\
$215-241$ (odd) & $\begin{array}{l}\text { Blade root, yaw moment, hub shaft, and low-speed shaft } \\
\text { strain gauges; teeter damper and teeter link load cells }\end{array}$ \\
& Rotor package \\
Location & $\begin{array}{l}\text { Isolated strain gauge input } \\
\text { Input level }\end{array}$ \\
Output level & \\
Description & Analog Devices, Inc. \\
& Model: 5B01 (backplate), 5B38-01 (input module) \\
\end{tabular}




\section{Butterworth Filter}

\section{Channel}

300-334 (even), 342

Location

Description

\section{Description}

Low-pass, $8^{\text {th }}$ order, Butterworth $10-\mathrm{Hz}$ filter

Met rack in data shed

Anti-alias filter

$\pm 15 \mathrm{~V}$ power requirement

Passband remains flat until 0.7 of $\mathrm{Fc}(-3 \mathrm{~dB}$ frequency), and then roll-off monotonically at a rate of $48 \mathrm{~dB} /$ oct

AVENS Signal Equipment Corp.

Model: AF-16 (container), AMLP8B10HZ

\section{Bessel Filter}

\section{Channel}

336-340 (even), 344-350 (even)

Location

Description

\section{Description}

Low-pass, $8^{\text {th }}$ order, Bessel 100-Hz filter

Met rack in data shed; rotating instrumentation package

Anti-alias filter

$\pm 15 \mathrm{~V}$ power requirement

Passband remains flat until $0.1 \mathrm{Fc}$, and then roll-off

monotonically to $20 \mathrm{~dB}$ at $2.5 \mathrm{Fc}$

AVENS Signal Equipment Corp.

Model: AF-16 (container), AMLP8L100HZ

Note: Yaw moment (342) is Butterworth, but all other strain gauges are Bessel. 


\section{Analog / Digital Conversion}

\begin{tabular}{ll}
\multicolumn{1}{c}{ Channel } & $\begin{array}{l}\text { Description } \\
\text { All analog channels } \\
\text { (even), 201-241 (odd), 300-342 } \\
\text { (even) }\end{array}$ \\
& \\
Location & Met rack in data shed; rotating instrumentation package \\
Description & $\begin{array}{l}\text { Instrumentation amplifier gain } 0.9 \\
\text { Sample and hold capability }\end{array}$ \\
& $7 \mu$ s, 12-bit analog-to-digital conversion \\
& 4.250 V reference with 10-ppm accuracy that is adjusted \\
& within \pm 2 mV \\
& Custom built by Embedded Systems
\end{tabular}

\section{Digital Input / Output}

\section{Channel}

251-261 (odd), 349-361 (odd)

Location

Description

\section{Description}

Position encoders, time code generator

Met rack in data shed; rotating instrumentation package

Digital parallel

Custom built by Embedded Systems 


\section{PCM Encoding / Decoding}

\section{Channel}

All channels

Location

Encode

Decode

\section{Description}

Encode/decode digital data

Met rack in data shed; rotating instrumentation package

CPU encoder board with $400 \mathrm{kbits} / \mathrm{sec}$ capability

Encodes 24 bits at one time; no storage capacity

Bi-Phase L

Filtered at $400 \mathrm{kHz}$

Signal level $\pm 2.5 \mathrm{~V}$

Custom built by Embedded Systems

Phase lock loop

Software set buffer size which uses direct memory access (DMA) to place data in computer memory when the buffer is full

Number of buffers is also variable.

Custom built by Apex Systems 


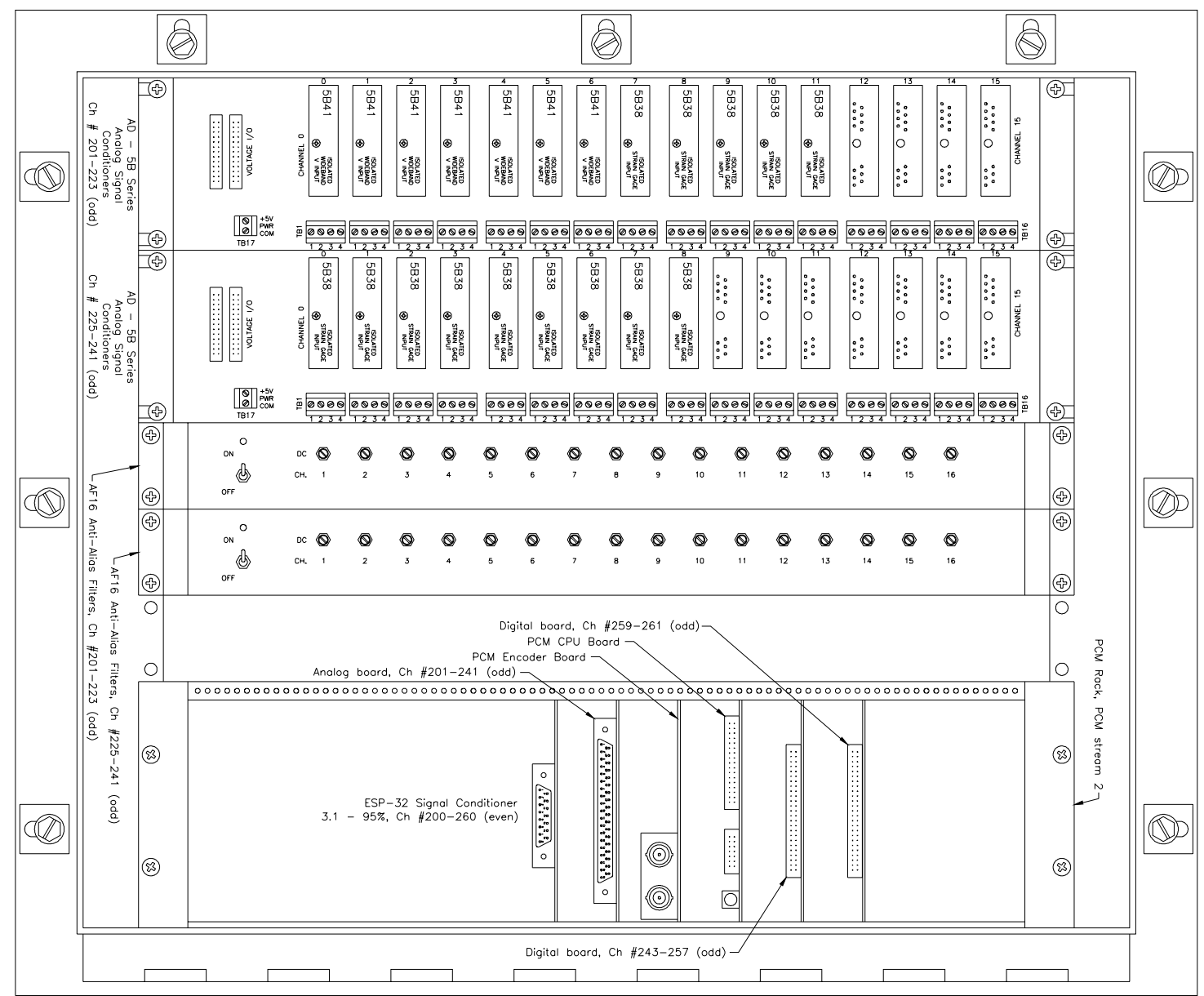

Figure 49. Rotor based PCM enclosure 

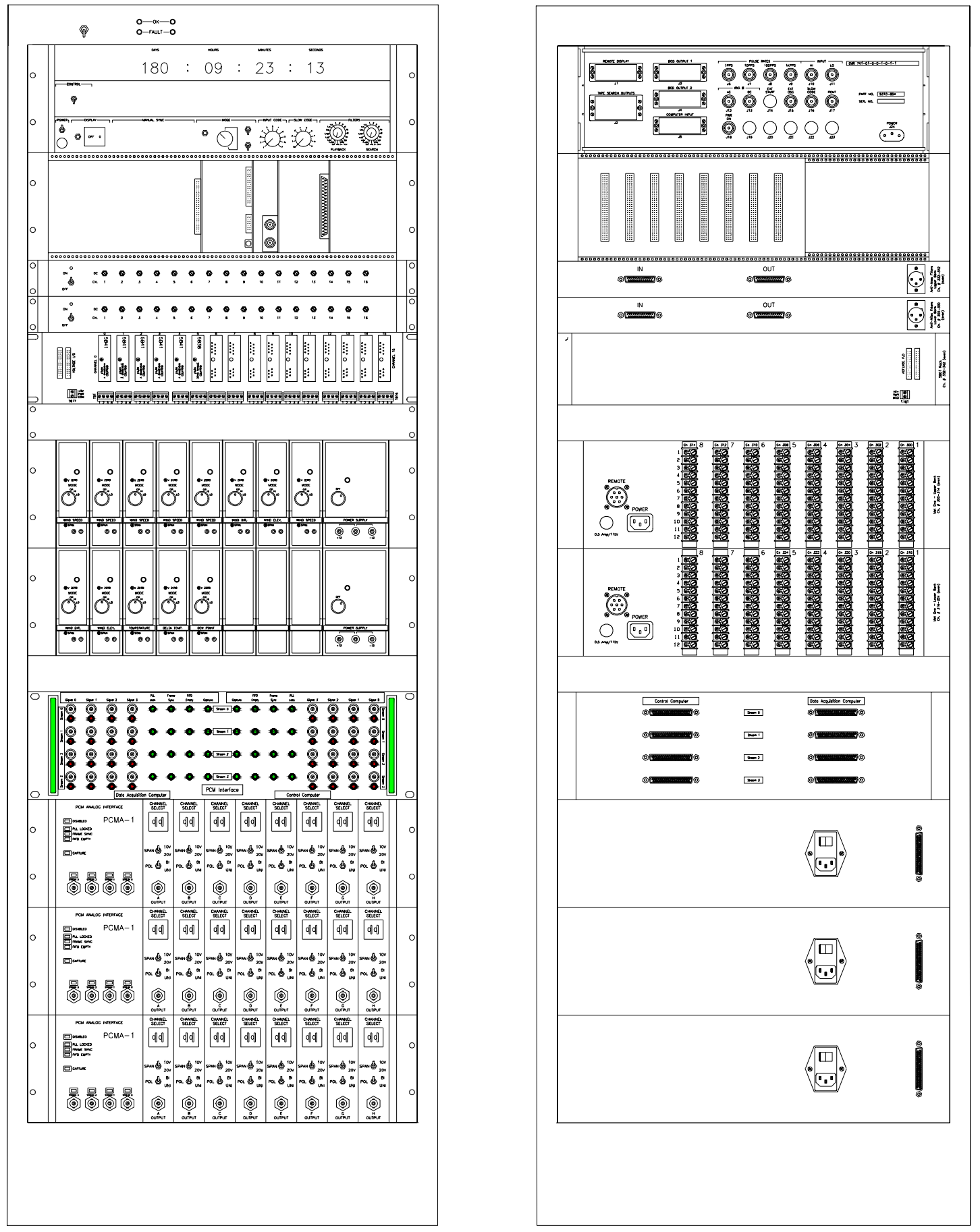

Figure 50. Ground-based PCM rack, front view and rear view 


\section{Data Storage, Processing, and Real-time Display}

\section{Data Collection and Storage}

1. Complete calibrations, and build master.hdr. If there is no new calibration data, use the current master.hdr file.

2. Allow turbine to run at least five minutes before initiating data collection procedure. This allows temperature variations on the blades to stabilize.

3. Run go.bat [go filename(no extension)]. The following procedures are contained in this batch file:

a. Initiate pressure calibration sequence (psc.exe) or use post-calibration from the previous campaign depending upon user selection.

b. Update master.hdr with new pressure calibration coefficients (hupdate.exe).

c. Record 10 minutes of data to optical disk under filename specified when calling the batch file (collect.exe).

d. Initiate pressure post-calibration (psc.exe).

e. Copy all calibration files and collection files to optical disk.

\section{Data Post-Processing}

1. Run MUNCH.EXE to convert raw PCM data to engineering units and calculate derived channels.

2. Write CD-ROM using the following file structure:

$\mathrm{CALIB} \backslash$ (contains all programs and files related to calibrations)

COLLECT $\backslash$ (contains all programs and files related to data collection)

PROCESS $\backslash$ (contains all processing input files)

*.arc (archive file)

*.dat (raw binary data file)

*.eng (binary engineering-unit file)

*.hdl (header file listing each channel, calibration coefficients, and statistics).

\section{Other Post-Processing Options}

1. View data graphically (viewdisk.exe).

2. Extract data subsets (pdis.exe).

3. Compare pre- and post-calibrations of pressure channels (drift.exe).

4. Average each channel over a complete revolution of instrumented blade (cycstat.exe).

5. Select cycles based on user specified range or specified criteria (eventloc.exe).

6. Select cycles based on dynamic stall conditions (dstall.exe).

7. Extract time series of specified cycles (scrunch.exe).

\section{Data Real-Time Display}

1. View data graphically (viewall.exe).

2. Video overlay with data (view.exe).

3. Bar graph showing all four PCM streams (barsall.exe).

4. Single bar chart (onebar.exe).

5. Time-averaged series of user specified channel (strip.exe).

Note: The nitrogen tank pressure channel (213) may be observed using barsall.exe, onebar.exe, or strip.exe. This channel is not recorded in the *.dat file which is necessary for all further processing. 


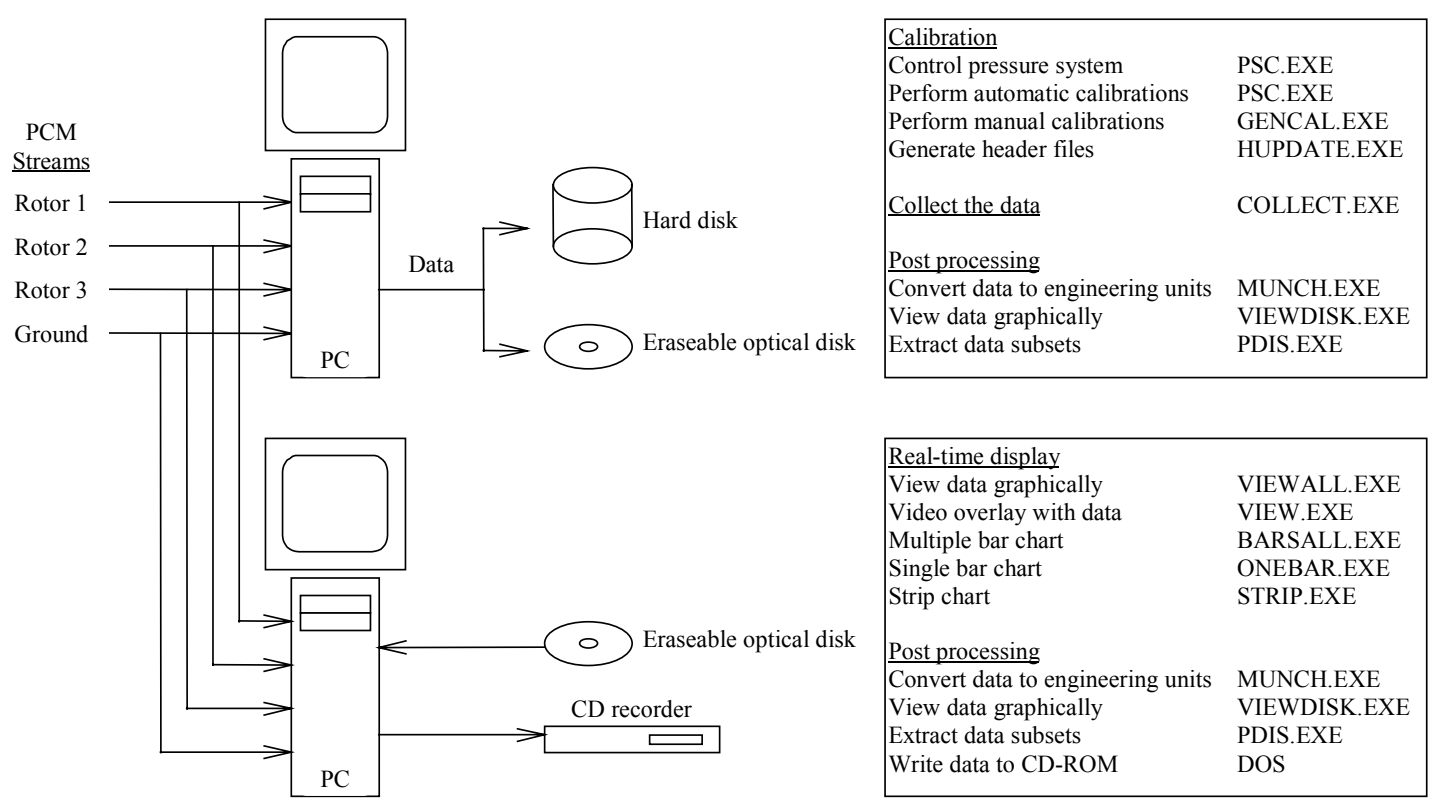

Figure 51. Signal path from PCM streams to useable data

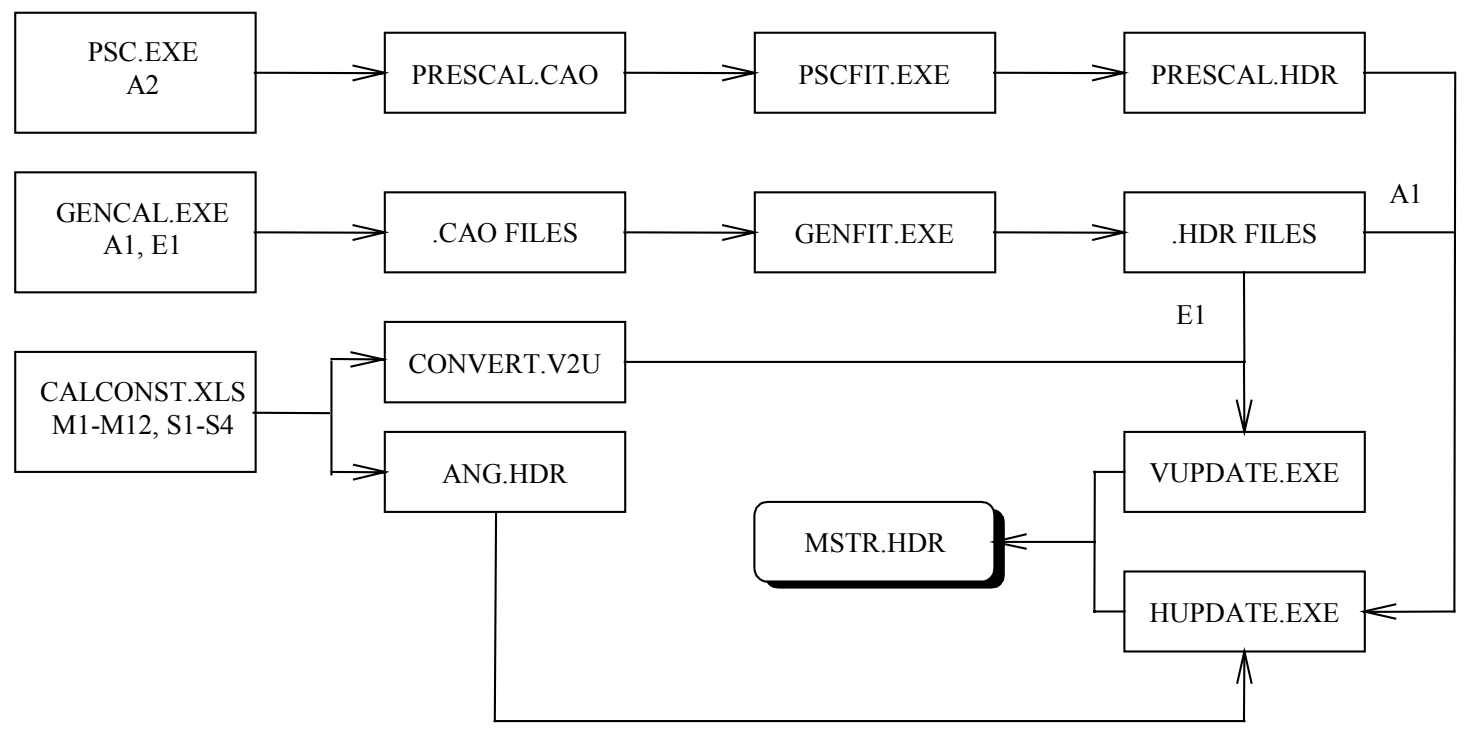

Figure 52. Production of calibration and header files (calibration procedures are summarized on p. 111) 


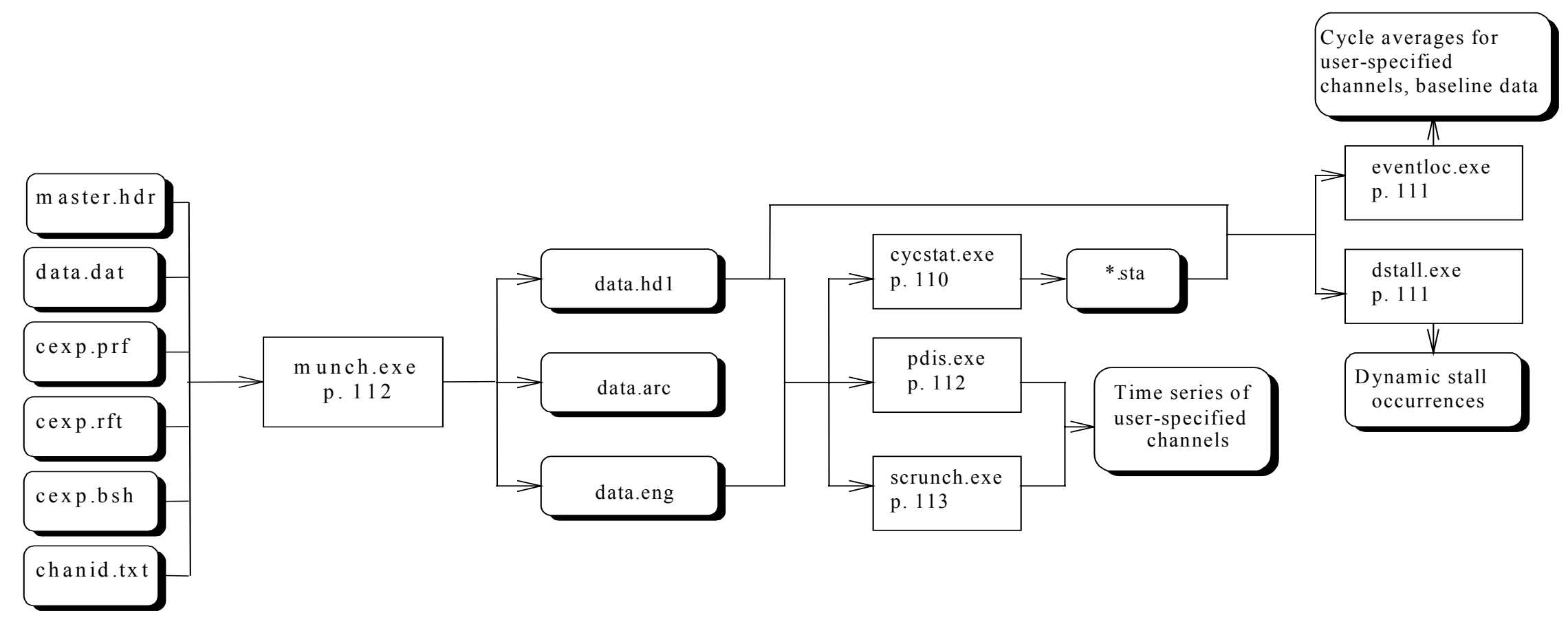

Figure 53. Data processing flow chart 
Calibration Procedure Summary

\section{Applied Load Calibration - (A1-A4)}

The pressure transducers, the strain gauges, and the load cells were calibrated using this method. Known loads were applied and the results recorded in *.cao files. Linear regression provided slopes, and the offsets were determined under zero-load conditions. These values are stored in temporary header files, *.hdr. The buildhdr.bat process incorporates these values in the master.hdr file.

Table 23. Strain Gauge Calibration File Names

\begin{tabular}{|c|c|c|c|c|}
\hline $\begin{array}{l}\text { Channel } \\
\text { Number }\end{array}$ & ID Code & File Name* & $\begin{array}{c}\text { Calibration } \\
\text { Range }\end{array}$ & Increment \\
\hline 225 & B1RFB & $\begin{array}{l}\text { blfpu.cao, blfnu.cao } \\
\text { blfpd.cao, blfnd.cao }\end{array}$ & $\begin{array}{l}0-100 \mathrm{lb} \\
100-0 \mathrm{lb}\end{array}$ & $20 \mathrm{lb}$ \\
\hline 227,241 & $\begin{array}{l}\text { B1REB, HSTQ1, } \\
\text { HSTQ2, LSSTQ }\end{array}$ & $\begin{array}{l}\text { blepu.cao, blenu.cao } \\
\text { blepd.cao, blend.cao }\end{array}$ & $\begin{array}{l}0-100 \mathrm{lb} \\
100-0 \mathrm{lb}\end{array}$ & $20 \mathrm{lb}$ \\
\hline 233,237 & B3RFB & $\begin{array}{l}\text { b3fpu.cao, b3fnu.cao } \\
\text { b3fpd.cao, b3fnd.cao }\end{array}$ & $\begin{array}{l}0-100 \mathrm{lb} \\
100-0 \mathrm{lb}\end{array}$ & $20 \mathrm{lb}$ \\
\hline 235,241 & $\begin{array}{l}\text { B3REB, HSTQ1, } \\
\text { HSTQ2, LSSTQ }\end{array}$ & $\begin{array}{l}\text { b3ери.cao, b3еnu.cao } \\
\text { b3epd.cao, b3end.cao }\end{array}$ & $\begin{array}{l}0-100 \mathrm{lb} \\
100-0 \mathrm{lb}\end{array}$ & $20 \mathrm{lb}$ \\
\hline $\begin{array}{l}215,217, \\
237,239\end{array}$ & $\begin{array}{l}\text { HSXXB, HSYYB, } \\
\text { LSSXXB, } \\
\text { LSSYYB }\end{array}$ & $\begin{array}{l}\text { hsxxpu.cao, hsxxnu.cao, } \\
\text { hsxxpd.cao, hsxxnd.cao, } \\
\text { lssxxpu.cao, lssxxnu.cao, } \\
\text { lssxxpd.cao, lssxxnd.cao } \\
\text { Similarly for hsyy, lssyy. }\end{array}$ & $\begin{array}{l}0-100 \mathrm{lb} \\
100-0 \mathrm{lb}\end{array}$ & $20 \mathrm{lb}$ \\
\hline 342 & NAYM & $\begin{array}{l}\text { b3ympu.cao, b3ymnu.cao, } \\
\text { b3ympd.cao, b3ymnd.cao }\end{array}$ & $\begin{array}{l}0-100 \mathrm{lb} \\
100-0 \mathrm{lb}\end{array}$ & $20 \mathrm{lb}$ \\
\hline $\begin{array}{l}225,227 \\
233,235 \\
237,239 \\
241\end{array}$ & $\begin{array}{l}\text { B1RFB, B1REB, } \\
\text { B3RFB, B3REB, } \\
\text { HSXXB, HSYYB, } \\
\text { HSTQ1, HSTQ2, } \\
\text { LSSXXB, } \\
\text { LSSYYB, LSSTQ }\end{array}$ & $\begin{array}{l}\text { zerox000.cao, zerox030.cao, } \\
\text { zerox060.cao, zerox090.cao, } \\
\text { zerox } 120 . c a o, \text { zerox } 150 . c a o, \\
\text { zerox } 180 . c a o, \text { zerox } 210 . c a o, \\
\text { zerox } 240 . c a o, \text { zerox } 270 . c a o, \\
\text { zerox } 300 . c a o, \text { zerox } 330 . c a o\end{array}$ & $0-330^{\circ}$ & $30^{\circ}$ \\
\hline
\end{tabular}

$* \mathrm{p}$ indicates load in positive direction; $\mathrm{n}$ indicates load in negative direction; $\mathrm{u}$ indicates increasing load; $\mathrm{d}$ indicates decreasing load; zerox = zero1 or zero2: because gencal is limited to 8 channels; the channels were split in two files for the zero offset determination.

\section{Manufacturer Specifications - (M1-M13)}

Calibrations of the instruments were performed by the manufacturer according to accepted practices. The resulting slope and offset values were entered in calconst.xls. The macros Write ang.hdr and Write convert.v2u convert the information in the Excel spreadsheet to text file formats. Using the buildhdr.bat batch file, these values were then combined with the results from the electronic path calibration to producethe slope and offset values stored in master.hdr. 


\section{Single-Point Offset Determination - (S1-S6)}

Each transducer was oriented with a known position using a jig or by line of sight. The associated count value was recorded in calconst.xls. The equation of the line for the manufacturer-supplied slope and the manually determined offset was found. These slope and offset values were transferred to ang.hdr in the case of the digital channels, and the analog channel calibration coefficients were combined with the electronic path calibration coefficients using vupdate.exe. The buildhdr.bat batch file then collected all of this information in the master.hdr file.

\section{Electronic Path Calibration - (E1)}

All of the meteorological instruments, the accelerometers, the barometric pressure transducer and the power transducer use data provided by the manufacturer due to off-site calibrations. The electronic path used by each of these devices is then calibrated by injecting voltages and determining slope and offset values. The precision voltage generator is inserted in the electronic path as near the transducer as possible. The gc.bat batch file uses gencal.exe to collect 500 samples at $520.83 \mathrm{~Hz}$ at each voltage level specified by the user. The genfit.exe program performs a linear curve fit and outputs slope and offset values in *.hdr files. The files are used during the buildhdr.bat process to convert manufacturer-supplied calibration coefficients to units of engineering unit/count. The voltage ranges for the various transducers are listed below.

Table 24. Electronic Path Calibration File Names and Voltage Ranges

\begin{tabular}{|c|c|c|c|c|}
\hline $\begin{array}{l}\text { Channel } \\
\text { Number }\end{array}$ & ID Code & File Name & $\begin{array}{c}\text { Calibration } \\
\text { Range }\end{array}$ & $\begin{array}{c}\text { Voltage } \\
\text { Increment }\end{array}$ \\
\hline 334 & BARO & Baro.cao & $0.0-4.5 \mathrm{~V}$ & $0.5 \mathrm{~V}$ \\
\hline $\begin{array}{l}201,203,205 \\
207,209,211\end{array}$ & $\begin{array}{l}\text { B1ACFL, B1ACED, B2ACFL, } \\
\text { B2ACED, B3ACFL, B3ACED }\end{array}$ & Bladeacl.cao & $-0.8-0.8 \mathrm{~V}$ & $0.2 \mathrm{~V}$ \\
\hline $336,338,340$ & $\begin{array}{l}\text { NAACYW, NAACFA, } \\
\text { NAACPI }\end{array}$ & Grndacl.cao & $-0.9-0.9 \mathrm{~V}$ & $0.2 \mathrm{~V}$ \\
\hline $\begin{array}{l}300,302,304 \\
306,308,310 \\
312,314\end{array}$ & $\begin{array}{l}\text { LMWS24M, LMWS17M, } \\
\text { LMWS10M, LMWS2M, } \\
\text { NLMWS17M, NLMWD17M, } \\
\text { NLMWE17M, SLMWS17M }\end{array}$ & Ground1.cao & $0.0-4.5 \mathrm{~V}$ & $0.5 \mathrm{~V}$ \\
\hline $\begin{array}{l}316,318,320 \\
322,324\end{array}$ & $\begin{array}{l}\text { SLMWD17M, SLMWE17M, } \\
\text { LMT2M, LMDT, LMDP2M }\end{array}$ & Ground2.cao & $0.0-4.5 \mathrm{~V}$ & $0.5 \mathrm{~V}$ \\
\hline 332 & GENPOW & Powercao & $-4.5-4.5 \mathrm{~V}$ & $1.0 \mathrm{~V}$ \\
\hline $326,328,330$ & $\begin{array}{l}\text { LMSU17M, LMSV17M, } \\
\text { LMSW17M }\end{array}$ & Sonic.cao & $-4.5-4.5 \mathrm{~V}$ & $1.0 \mathrm{~V}$ \\
\hline
\end{tabular}

\section{Master Header File Compilation (buildhdr.bat)}

Once each of the above calibration sequences is completed, the master.hdr file containing slope and offset values for every channel is created. Macros (Write ang.hdr and Write convert.v2u) in calconst.xls create text files in the same format as the *.hdr files output by genfit.exe. These two files, ang.hdr and convert.v2u, contain the slope and offset values that were stored in calconst.xls. The buildhdr.bat batch file then compiles all of the calibration coefficients from the manufacturer, the electronic path calibration, and applied load calibrations into one file that is input in the post-processing software, munch. The program vupdate.exe converts the manufacturer data in convert. $v 2 u$ from units of engineering unit/volt to engineering unit/count using information in the *.hdr files from the electronics calibrations. These new values are 
stored in master.hdr. Calibration coefficients for the digital position encoders, pressure channels, and strain gauges are transferred, using vupdate.exe, from their respective *.hdr files to the master header file, master.hdr.

\section{Other Calibrations}

\section{Angle Star}

The zero was determined by placing the Angle Star on a machinist's surface plate. The surface plate was leveled with a machinist's level accurate to $0.0005 \mathrm{in} / \mathrm{ft}$. The slope was determined by placing the device on precision ground angles on the surface plate at $5^{\circ}, 10^{\circ}, 15^{\circ}, 20^{\circ}$, and $30^{\circ}$. The Angle Star was adjusted until the proper readings were attained. This was done prior to the pitch system calibration.

\section{Pitch System}

Each blade was pitched to $0^{\circ}$. The Angle Star was attached to a jig that fit around the leading and trailing edge of the airfoil at the tip. The jig was moved from the upwind side to the downwind side of the airfoil for comparison of the angle measurement. The Angle Star provided the known pitch angle of the blade relative to the ground. The offset value in calconst.xls was adjusted until the data system produced the same value as the Angle Star. This was done for both blades.

The nacelle tilt angle was determined by placing the Angle Star on machined surfaces parallel to the ground. Angles were recorded at five locations, and the average value is the nacelle tilt, $1^{\circ}$. Positive nacelle tilt indicates that the boom tip is higher than the upwind side of the low-speed shaft. The blade pitch angle offset values were then adjusted to account for this tilt angle.

\section{Precision Voltage Generator}

Two devices are available for use during the electronic path calibrations. The HP 3245A

Universal Source was calibrated by the manufacturer on 7/10/90. The Fluke 743B Documenting Process Calibrator was calibrated by the manufacturer on 7/31/97.

\section{Scale}

Two scales were used to weigh the blades, and they were calibrated with known weights prior to weighing the blades. One scale was used on the root end of the blade, and the other scale was used on the tip end of the blade. The combined reading provided the total weight of the blade. 


\section{Processing Program Summary}

bar.exe

bars.exe

calconst.xls

collect.exe

cycstat.exe

drift.exe
Input: *.cfg, *.cap, *.stm, master.hdr, \# of desired PCM stream Output: none

Description: One of the PCM streams is selected, and a horizontal bar chart displays each of the channels on that stream. The spacebar highlights a particular channel, and it's count value and engineering unit value is displayed at the bottom of the screen. This program is useful during calibration of the digital position encoders and observing Ni tank pressure and digital reference pressure channels. This program is written in $\mathrm{C}$.

Input: *.cap, *.cfg, *.stm

Output: None

Description: Bar graphs display each of the four PCM streams in real time. This is a useful program for determining if a channel is railed or not operating. This program was written in C.

Input: Manufacturer supplied slope and offset values, and single-point offsets

Output: ang.hdr, convert.v2u

Description: This spreadsheet contains all manufacturer specified slope and offset values. The single-point offsets determined during calibration are also inserted in the spreadsheet. The offset value is used in conjunction with the manufacturer specified slope to determine the equation of the line representing each sensor. Two macros are run to create two files that contain slope and offset values in the format output by genfit.exe $(* . h d r)$. The calibration coefficients for the digital channels that measure angles are contained in ang.hdr, and all of the other calibration coefficients are contained in convert.v $2 u$.

Input: *.cap, *.cfg, *.stm

Output: *.dat

Description: Decoded PCM data is stored directly to erasable optical disk. This program is written in $\mathrm{C}$.

Input: List of disk names, input pathname, output pathname Output: *.sta

Description: The mean, maximum, minimum, and standard deviation is determined for each channel over each complete revolution of the instrumented blade. The azimuth angle at the maximum value, the azimuth angle at the minimum value, the wind speed at the minimum value, and the yaw error angle at the minimum value are also recorded. A database is created consisting of one *.sta file for each 10-minute campaign. This program is written in FORTRAN.

Input: *.cao (Both the pre- and post-calibration files are required.) Output: drift.txt

Description: A comparison between pre- and post-calibration of pressure transducers is done. The maximum and minimum drift for each pressure channel is recorded. The maximum and minimum drift overall is also recorded. This program is written in $\mathrm{C}$. 
dstall.exe

eventloc.exe

gencal.exe
Input: List of disk names, *.sta files, *.hdl files

Output: User specified file names

Description: The user initially specifies which span location (or all span locations) to analyze. The program reads the leading edge pressure coefficients, minimum wind speed, and minimum yaw error values from the *.sta files. The user is then prompted to limit the data by $\mathrm{C}_{\mathrm{p}}$ magnitude, span location, wind velocity, yaw error angle, or azimuth angle. Once data is selected, the user may see the number of cycles remaining, or the cycles with dynamic stall occurring at more than one span location. The data may then be binned or sorted and written to a user specified file. This program is written in FORTRAN.

Input: list of disk names or list of specific cycles, input pathname, output pathname, *.sta files, *.hdl files.

Output: user specified file names

Description: The user may choose from three options to extract cycleaveraged values. This program is written in FORTRAN.

1. Cycles may be selected based on inflow criteria such as wind speed, yaw error angle, wind shear, etc. Cycles may be analyzed in groups or as single cycles. A user-specified file consisting of ranges of cycles meeting the specified criteria and the values associated with those cycles (i.e., average wind speed) is output. Additionally, a file with the user-specified name and ${ }^{*}$.nam extension is output. This file lists the disk name and median cycle of the specified range. This file may be input to option 2 .

2. The user may specify a file containing a list of disk names and cycle numbers that was created in option $1(*$ nam). The user is then prompted for the desired channels corresponding to these cycles. Options include aerodynamic force coefficients, inflow conditions, channels related to calculations of dynamic pressure, power-related channels or a user specified list of channels. The user then specifies the output file name.

3. This option produces the same type of output as option 2 , but the user specifies a range of cycles common to all user specified disks. Again, the output file is specified by the user.

Input: gencal.cap, vbl.lst

Output: *.cao

Description: This program was developed to automate sample collection. All of the strain gauge and electronic path calibrations are performed using this software (Scott, Unpublished). This program is written in C.

1. Create gencal.exe input file (*.cao) by copying the channel(s) to be calibrated from $v b l . l s t$ to the new input file. Ensure the first line indicates the number of channels in the file, and the appropriate PCM stream is listed in gencal.cap.

2. Apply load or voltage and collect samples according to user keystroke input. The software is hardwired to collect 20 samples at 520 $\mathrm{Hz}$ when the user signals beginning of collection.

3. Repeat until samples are collected up to 20 desired load or voltage conditions. This can be done until the user exits the data collection portion of the program. The *.caoinput file is modified to contain the $\mathrm{x}$ and $\mathrm{y}$ values created using this program. 
genfit.exe

go.bat

hupdate.exe

munch.exe

pdis.exe

psc.exe
Input: *.cao (with modifications from gencal.exe)

Output: *.hdr, *.rpt, *.res

Description: This program was developed to perform a linear-regression analysis on samples collected using gencal.exe. All of the strain gauge and electronic path calibrations are performed using this software. The resulting slopes and offsets are recorded in *.hdr according to the channels contained in the input file (Scott Unpublished). This program was written in $\mathrm{C}$.

Input: user specified filename of data to be collected (i.e., go d403001) Description: This batch file initiates calibration of the pressure transducers, updates master.hdr with the new pressure channel slope and offset values, collects 10 minutes of data, and initiates a post-calibration of the pressure transducers.

Input: *.hdr files corresponding to channels with calibration coefficients in units of engineering unit/count and counts.

Output: *.hdr updated

Description: The slope and offset calibration coefficients are transferred from *.hdr files to master.hdr. This program is written in C.

Input: *.hdr, *.dat, cexp.rft, cexp.bsh, cexp.prf, *.stp, chanid.txt, slpit.tbl, sltpsph.tbl, slyaw.tbl...s5pit.tbl, s5tpsph.tbl, s5yaw.tbl.

Output: *.hd1, *.arc, *.eng, pdiserr.log

Description: Raw PCM data is converted to engineering units using the calibration coefficients listed in master.hdr. In addition to the measured channels, several derived channels are calculated. These include aerodynamic force coefficients, upwash corrected angles of attack, normalized pressure coefficients, and stagnation point pressures. Formulae describing each of these calculations are described in the final report. The output file, *.hdl, contains the mean, maximum, minimum, and standard deviation of each channel over the 10-minute campaign.

One output file, *.arc, is an archive file essentially copying *.dat, and the engineering unit conversions are stored in *.eng. Any errors encountered during processing are indicated in pdiserr.log. The additional input files provide information about the record format (cexp.rft), blade shape (cexp.bsh), pressure profiles (cexp.prf), 8-letter codes corresponding to each channel (chanid.txt), and look-up tables for each of the 5-hole probes (s1pit.tbl, s1tpsph.tbl, slyaw.tbl...s5pit.tbl, s5tpsph.tbl, s5yaw.tbl). These file formats are discussed in the program's documentation (Scott Unpublished). This program is written in $\mathrm{C}$.

Input: *.eng, *.hdl

Output: *.hd2, *.en2

Description: The user may select specific channels and specific frame numbers to be extracted. A new header file is created consisting only of the selected channels, and another file contains all of the selected data. This program is written in $\mathrm{C}$.

Input: rampcal.cai

Output: prescal.cao

Description: The syringe is used to apply pressures to each of the transducers according to the ramp values indicated in rampcal.cai. The 
pscfit.exe

scrunch.exe

strip.exe

view.exe

viewall.exe

vieweng.exe

vupdate.exe count value associated with each applied pressure is recorded to the prescal.cao file. This program is written in $\mathrm{C}$.

Input: prescal.cao, t2c.dat

Output: prescal.hdr, prescal.res, prescal.rpt

Description: A linear-regression analysis is performed using the applied pressures and associated count values resulting from psc.exe. A slope and offset is determined for each channel at each transducer. These slopes and offsets are recorded in prescal.hdr. The file $t 2 c$.dat provides correlation between transducer tap numbers and pressure channel numbers. This program is written in $\mathrm{C}$.

Input: channel list file, *.eng file, *.hdl file Output: user specified file name

Description: This program writes the time series values for a userspecified range of consecutive cycles. The channels are listed in a file specified by the user. This program is written in FORTRAN.

Input: chanfile.txt, master.hdr

Output: none

Description: User-specified channels are displayed as a moving time average. The time interval is specified by the user. This program is generally left running overnight to get a feel for the wind speed variations or for diagnostic purposes. This program is written in $\mathrm{C}$. Input: master.hdr, *.cfg, *.cap, *.stm, incoming decoded PCM streams Output: none

Description: The graphical depiction of measured values provided by viewall.exe is overlaid on video pictures. The screen may be split to show views from two cameras. Any of the four cameras may be selected (boom camera, blade camera, shed camera, or tower camera). This program is written in $\mathrm{C}$.

Input: master.hdr, *.cfg, *.cap, *.stm, incoming decoded PCM streams Output: none

Description: A graphical depiction of various channels is displayed in real time. Pressure distributions for each span location are displayed on the left. The instrumented blade azimuth angle and rotational speed are included. Wind speeds are shown on a vertical graph to provide a visual indication of vertical wind shear. Horizontal wind shear is depicted similarly. Wind direction is shown in relation to turbine angle to provide an indication of yaw error. Other values such as time, temperature, and blade pitch angle are presented as text at the top of the screen. This program is written in $\mathrm{C}$.

Input: *.eng, *.hdl

Output: none

Description: A previously recorded campaign is displayed graphically in the same format as the real-time software viewall.exe. The user may speed up or slow down the display or jump to a specific frame number. This program is written in $\mathrm{C}$.

Input: convert.v2u, *.hdr files corresponding to electronic path calibrations.

Output: *.hdr

Description: All of the slope and offset values that were stored in calconst.xls are contained in the text file convert.v $2 u$, and the slopes are 
in units of engineering unit/volt. The electronic path calibrations performed using gencal.exe and genfit.exe produced slope and offset coefficients in units of volts/count for the electronic pathways. This program converts the calibration coefficients to units of engineering unit/count, and these values are recorded in *.hdr. This program is written in $\mathrm{C}$. 
File Format Examples

$\boldsymbol{a n g . h} \boldsymbol{h} \boldsymbol{r}$ contains the manufacturer-supplied slope and single-point offsets for the position encoders. This file is created by the macro Write ang.hdr in the spreadsheet calconst.xls. The first line indicates the number of channels contained in the file. The following lines list the channel number, description, units, number of calibration coefficients, offset, slope, and other values consistent with the format specified by Scott (unpublished).

6

349,"Azimuth","deg",2,-110.126953125,.087890625,0,0,0,0,-99999,99999,0,"M"

351,"Yaw","deg",2,218.435546875,.087890625,0,0,0,0,-99999,99999,0,"M"

251,"Flap 1","deg",2,32.40966796875,-.010986328125,0,0,0,0,-99999,99999,0,"M"

253,"Pitch 1","deg",2,-20.0390625,.087890625,0,0,0,0,-99999,99999,0,"M"

255,"Flap 3","deg",2,19.599609375,-.010986328125,0,0,0,0,-99999,99999,0,"M"

257,"Pitch 3","deg",2,-21.884765625,.087890625,0,0,0,0,-99999,99999,0,"M"

calconst.xls is a spreadsheet containing all of the manufacturer-supplied slope and offset values. The offsets determined by the single-point offset calibration are also entered in this spreadsheet.

\begin{tabular}{|c|c|c|c|c|c|c|c|c|c|}
\hline Name & \multicolumn{3}{|c|}{ Single point } & Slope & \multicolumn{3}{|c|}{ Coefficients } & Channel & Units \\
\hline Azimuth & $180^{\circ}=$ & 795 & counts & $0.087890625^{\circ} /$ count & -110.1269531 & 0.087890625 & ${ }^{*}$ counts & 349 & deg \\
\hline Yaw & $292^{\circ}=$ & 837 & counts & $0.087890625^{\circ} /$ count & 218.4355469 & 0.087890625 & ${ }^{*}$ counts & 351 & deg \\
\hline Flap 1 & $0^{\circ}=$ & 2950 & counts & $-0.01098633^{\circ} /$ count & 32.40966797 & -0.01098633 & ${ }^{*}$ counts & 251 & deg \\
\hline Pitch 1 & $0^{\circ}=$ & 228 & counts & $0.087890625^{\circ} /$ count & -20.0390625 & 0.087890625 & ${ }^{*}$ counts & 253 & deg \\
\hline Flap 3 & $0^{\circ}=$ & 1784 & counts & $-0.01098633^{\circ} /$ count & 19.59960938 & -0.01098633 & ${ }^{\text {*counts }}$ & 255 & deg \\
\hline Pitch 3 & $0^{\circ}=$ & 249 & counts & $0.087890625^{\circ} /$ count & -21.88476563 & 0.087890625 & ${ }^{*}$ counts & 257 & deg \\
\hline Windspeed - 80' & $0 \mathrm{~m} / \mathrm{s}=$ & 0 & volts & $10 \mathrm{~m} / \mathrm{s} / \mathrm{V}$ & 0 & 10 & ${ }^{*}$ volts & 300 & $\mathrm{mps}$ \\
\hline Windspeed - 56' & $0 \mathrm{~m} / \mathrm{s}=$ & 0 & volts & $10 \mathrm{~m} / \mathrm{s} / \mathrm{V}$ & 0 & 10 & *volts & 302 & mps \\
\hline Windspeed - 33' & $0 \mathrm{~m} / \mathrm{s}=$ & 0 & volts & $10 \mathrm{~m} / \mathrm{s} / \mathrm{V}$ & 0 & 10 & *volts & 304 & mps \\
\hline Windspeed - 8' & $0 \mathrm{~m} / \mathrm{s}=$ & 0 & volts & $10 \mathrm{~m} / \mathrm{s} / \mathrm{V}$ & 0 & 10 & *volts & 306 & mps \\
\hline Windspeed - N & $0 \mathrm{~m} / \mathrm{s}=$ & 0 & volts & $10 \mathrm{~m} / \mathrm{s} / \mathrm{V}$ & 0 & 10 & *volts & 308 & mps \\
\hline Windspeed - S & $0 \mathrm{~m} / \mathrm{s}=$ & 0 & volts & $10 \mathrm{~m} / \mathrm{s} / \mathrm{V}$ & 0 & 10 & *volts & 314 & mps \\
\hline Wind direction - N & $292^{\circ}=$ & 2.594 & volts & $72^{\circ} / \mathrm{V}$ & 105.232 & 72 & *volts & 310 & deg \\
\hline Wind direction - S & $292^{\circ}=$ & 2.594 & volts & $72^{\circ} / \mathrm{V}$ & 105.232 & 72 & *volts & 316 & deg \\
\hline Wind elevation - N & $0^{\circ}=$ & 2.465 & volts & $-24.0021122^{\circ} / \mathrm{V}$ & 59.15320548 & -24.0021122 & *volts & 312 & deg \\
\hline Wind elevation - S & $0^{\circ}=$ & 2.376 & volts & $-23.9973603^{\circ} / \mathrm{V}$ & 57.01772805 & -23.9973603 & *volts & 318 & deg \\
\hline Delta Temperature & $0^{\circ}=$ & 2 & volts & $2.22222222{ }^{\circ} \mathrm{C} / \mathrm{V}$ & -4.44444444 & 2.22222222 & *volts & 322 & $\operatorname{deg} C$ \\
\hline Temperature - 8' & $0^{\circ}=$ & 2.5 & volts & $20^{\circ} \mathrm{C} / \mathrm{V}$ & -50 & 20 & *volts & 320 & $\operatorname{deg} C$ \\
\hline Dew point & $0^{\circ}=$ & 2.5 & volts & $20^{\circ} \mathrm{C} / \mathrm{V}$ & -50 & 20 & *volts & 324 & $\operatorname{deg} C$ \\
\hline Sonic U & $0 \mathrm{~m} / \mathrm{s}=$ & 0 & volts & $10 \mathrm{~m} / \mathrm{s} / \mathrm{V}$ & 0 & 10 & ${ }^{*}$ volts & 326 & mps \\
\hline Sonic V & $0 \mathrm{~m} / \mathrm{s}=$ & 0 & volts & $10 \mathrm{~m} / \mathrm{s} / \mathrm{V}$ & 0 & 10 & *volts & 328 & $\mathrm{mps}$ \\
\hline Sonic $\mathrm{W}$ & $0 \mathrm{~m} / \mathrm{s}=$ & 0 & volts & $3 \mathrm{~m} / \mathrm{s} / \mathrm{V}$ & 0 & 3 & ${ }^{*}$ volts & 330 & $\mathrm{mps}$ \\
\hline Barometer & $74000 \mathrm{~Pa}=$ & 0 & volts & $5200 \mathrm{mBar} / \mathrm{V}$ & 74000 & 5200 & *volts & 334 & Pascal \\
\hline Generator power & $0 \mathrm{~kW}=$ & 0 & volts & $8 \mathrm{~kW} / \mathrm{V}$ & 0 & 8 & *volts & 332 & $\mathrm{~kW}$ \\
\hline Blade 1 Flap Accel & $0 \mathrm{~g}=$ & 0 & volts & $199 \mathrm{mV} / \mathrm{g}$ & 0 & 49.24623116 & *volts & 201 & mps2 \\
\hline Blade 1 Edge Accel & $0 \mathrm{~g}=$ & 0 & volts & $198.7 \mathrm{mV} / \mathrm{g}$ & 0 & 49.32058379 & *volts & 203 & $\mathrm{mps} 2$ \\
\hline Blade 3 Flap Accel & $0 \mathrm{~g}=$ & 0 & volts & $201 \mathrm{mV} / \mathrm{g}$ & 0 & 48.75621891 & *volts & 209 & $\mathrm{mps} 2$ \\
\hline Blade 3 Edge Accel & $0 \mathrm{~g}=$ & 0 & volts & $200.7 \mathrm{mV} / \mathrm{g}$ & 0 & 48.82909816 & *volts & 211 & $\mathrm{mps} 2$ \\
\hline Nacelle Yaw Accel & $0 \mathrm{~g}=$ & 0 & volts & $199.9 \mathrm{mV} / \mathrm{g}$ & 0 & 49.02451226 & ${ }^{*}$ volts & 336 & mps2 \\
\hline Nacelle Fore-Aft Accel & $0 \mathrm{~g}=$ & 0 & volts & $200.9 \mathrm{mV} / \mathrm{g}$ & 0 & 48.7804878 & *volts & 338 & mps3 \\
\hline Nacelle Pitch Accel & $0 \mathrm{~g}=$ & 0 & volts & $201 \mathrm{mV} / \mathrm{g}$ & 0 & 48.75621891 & *volts & 340 & mps2 \\
\hline
\end{tabular}

convert.v $2 \boldsymbol{u}$ contains the manufacturer-supplied slope and offsets in units of e.u./V and V, respectively. This file is created by the macro Write convert. $v 2 u$ in the spreadsheet calconst.xls. The first line indicates the number of channels contained in the file. The following lines list the channel number, description, units, number of calibration coefficients, offset, and slope. 
300,"Windspeed - 80"',"mps",2,0,10

302,"Windspeed - 56"',"mps",2,0,10

304,"Windspeed - 33"',"mps",2,0,10

306,"Windspeed - 8"',"mps",2,0,10

308,"Windspeed - N","mps",2,0,10

314,"Windspeed - S","mps",2,0,10

310,"Wind direction - N","deg",2,105.232,72

316,"Wind direction - S","deg",2,105.232,72

312,"Wind elevation - N","deg",2,59.1532054820824,-24.0021121858724

318,"Wind elevation - S","deg",2,57.0177280499145,-23.9973602903681

322,"Delta Temperature","degC",2,-4.44444444,2.22222222

320 ,"Temperature - 8'","degC",2,-50,20

324, ,Dew point","degC",2,-50,20

326,"Sonic U","mps",2,0,10

328,"Sonic V","mps",2,0,10

330,"Sonic W","mps",2,0,3

334,"Barometer","Pascal",2,74000,5200

332 ,"Generator power","kW",2,0,8

201,"Blade 1 Flap Accel","mps2",2,0,49.2462311557789

203,"Blade 1 Edge Accel","mps2",2,0,49.3205837946653

209,"Blade 3 Flap Accel","mps2",2,0,48.7562189054726

211,"Blade 3 Edge Accel","mps2",2,0,48.8290981564524

336,"Nacelle Yaw Accel","mps2",2,0,49.0245122561281

338,"Nacelle Fore-Aft Accel","mps3",2,0,48.7804878048781

340,"Nacelle Pitch Accel","mps2",2,0,48.7562189054726

gencal.cap contains the PCM stream capture information necessary for gencal.exe to obtain the required channels. For the channels specified in a given *.cao file, the corresponding PCM stream must be specified in the line 'USE SIGNAL *;'.

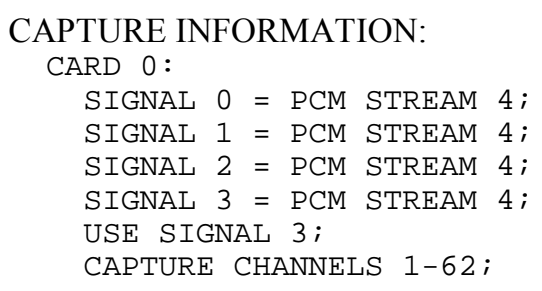

ground2.cao is an example of the file input to gencal. This file was used to calibrate the electronic path for several of the ground-based meteorological channels. The first line indicates the number of channels contained in the file. The following lines are copied from vbl.lst. The line of text containing a date begins the modification that occurs when gencal is run. The following $\mathrm{x}, \mathrm{y}$ coordinates were obtained on the date specified. The first two columns correspond to voltages injected and count values read from the "South wind direction" channel. The next two columns correspond to the "South wind elevation" channel, etc.

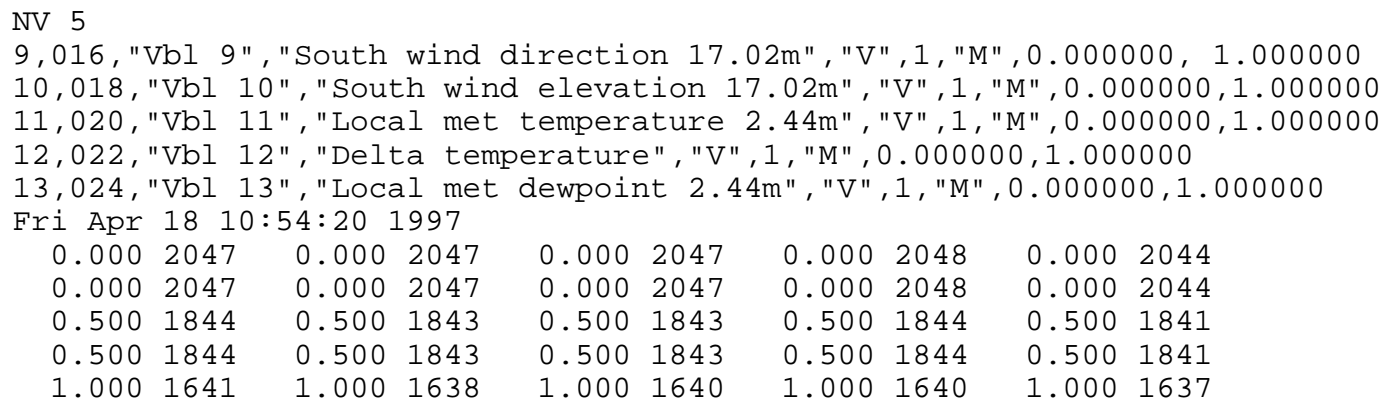




$\begin{array}{rrrrrrrrrr}1.000 & 1641 & 1.000 & 1639 & 1.000 & 1640 & 1.000 & 1640 & 1.000 & 1637 \\ 1.500 & 1437 & 1.500 & 1434 & 1.500 & 1436 & 1.500 & 1436 & 1.500 & 1434 \\ 1.500 & 1437 & 1.500 & 1434 & 1.500 & 1436 & 1.500 & 1436 & 1.500 & 1434 \\ 2.000 & 1233 & 2.000 & 1230 & 2.000 & 1233 & 2.000 & 1232 & 2.000 & 1230 \\ 2.000 & 1234 & 2.000 & 1230 & 2.000 & 1233 & 2.000 & 1232 & 2.000 & 1230 \\ 2.500 & 1030 & 2.500 & 1026 & 2.500 & 1029 & 2.500 & 1028 & 2.500 & 1027 \\ 2.500 & 1030 & 2.500 & 1026 & 2.500 & 1029 & 2.500 & 1028 & 2.500 & 1026 \\ 3.000 & 827 & 3.000 & 821 & 3.000 & 825 & 3.000 & 824 & 3.000 & 823 \\ 3.000 & 827 & 3.000 & 821 & 3.000 & 825 & 3.000 & 824 & 3.000 & 823 \\ 3.500 & 623 & 3.500 & 617 & 3.500 & 622 & 3.500 & 620 & 3.500 & 620 \\ 3.500 & 623 & 3.500 & 617 & 3.500 & 622 & 3.500 & 620 & 3.500 & 619 \\ 4.000 & 420 & 4.000 & 412 & 4.000 & 418 & 4.000 & 416 & 4.000 & 416 \\ 4.000 & 420 & 4.000 & 412 & 4.000 & 418 & 4.000 & 416 & 4.000 & 416 \\ 4.500 & 216 & 4.500 & 208 & 4.500 & 214 & 4.500 & 212 & 4.500 & 213 \\ 4.500 & 216 & 4.500 & 208 & 4.500 & 215 & 4.500 & 212 & 4.500 & 213\end{array}$

ground2.hdr is an example of the file output from genfit. A linear regression was performed on the data added to ground2.cao during the gencal program. The resulting slope and offset are inserted in the appropriate locations of the ${ }^{*} . h d r$ file. This file is then used together with convert. $v 2 u$ during the vupdate program to create the master.hdr file.

005

316, "South wind direction $17.02 \mathrm{~m} ", " \mathrm{~V} ", 2,5.0315 \mathrm{e}+000,-2.4575 \mathrm{e}-003,1,, 0,0,0,0, \mathrm{M}$ " 318, "South wind elevation $17.02 \mathrm{~m} ", " V ", 2,5.0091 \mathrm{e}+000,-2.4467 \mathrm{e}-003,, 1,0,0,0,0, " \mathrm{M"}$ 320, "Local met temperature 2.44m", "V",2,5.0268e+000,-2.4558e-003, , , 0,0,0,0, "M" 322, "Delta temperature", "V", 2,5.0196e+000,-2.4510e-003, , , 0,0,0,0, "M"

324, "Local met dewpoint 2.44m", "V",2,5.0224e+000,-2.4570e-003, , , 0, 0,0,0, "M"

master.hdr is a portion of the file containing all calibration coefficients. This file is input to the munch processing software. The first line indicates the number of lines of text in the file, and each channel is represented with text on one line. Each line consists of the channel number, description, units, number of calibration coefficients, offset, slope, and dummy values for the mean, maximum, minimum, and standard deviation. The last entry indicates the type of measurement (Scott, unpublished).

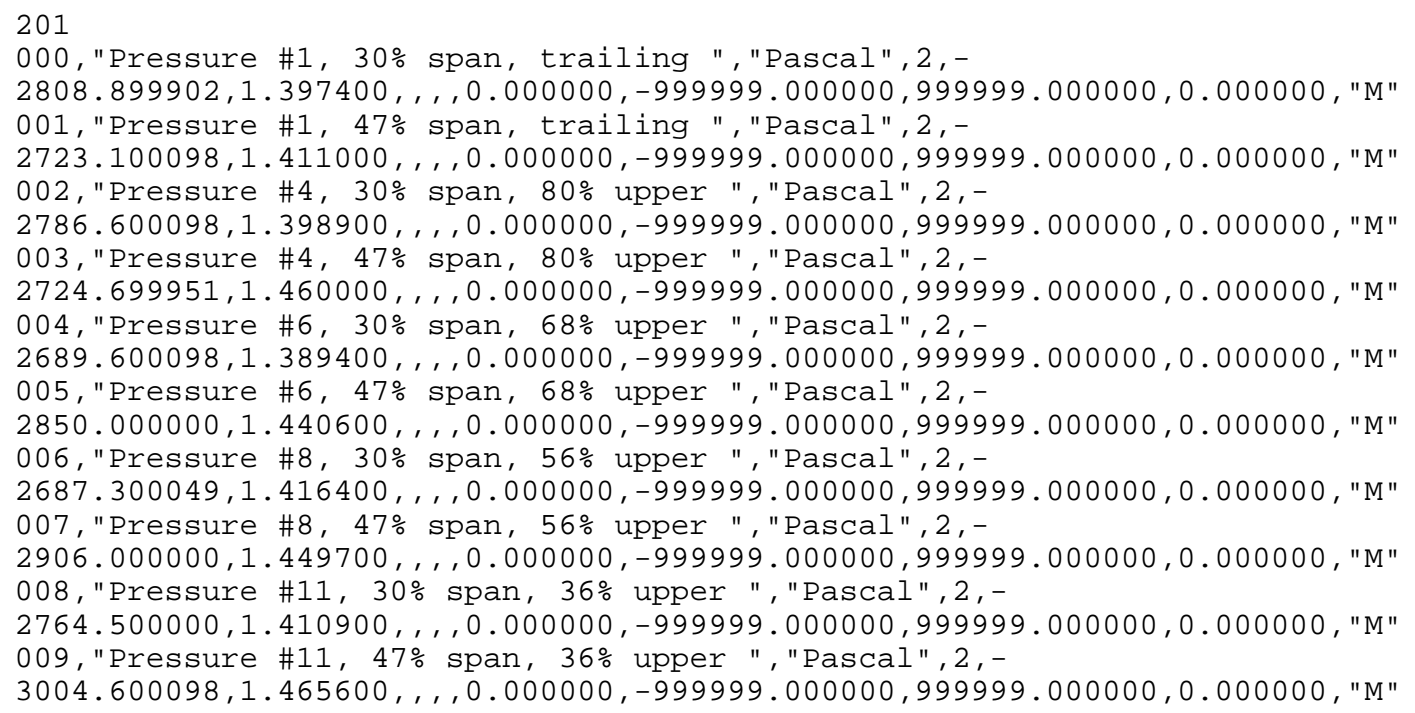

*.hd1 is a portion of the header file produced by the post-processing software, munch. This file contains statistics for the 10-minute campaign. The second line lists the number of channels, the number of records in the corresponding *.eng file, and the time step between records. Next, each channel is represented by one line of text beginning with the channel number. The channel 
description, units, number of calibration coefficients, offset, slope, mean, maximum, minimum, and standard deviation follow. The last entries are the channel type (Scott, unpublished), location of maximum, location of minimum, and number of frames in which an error occurred.

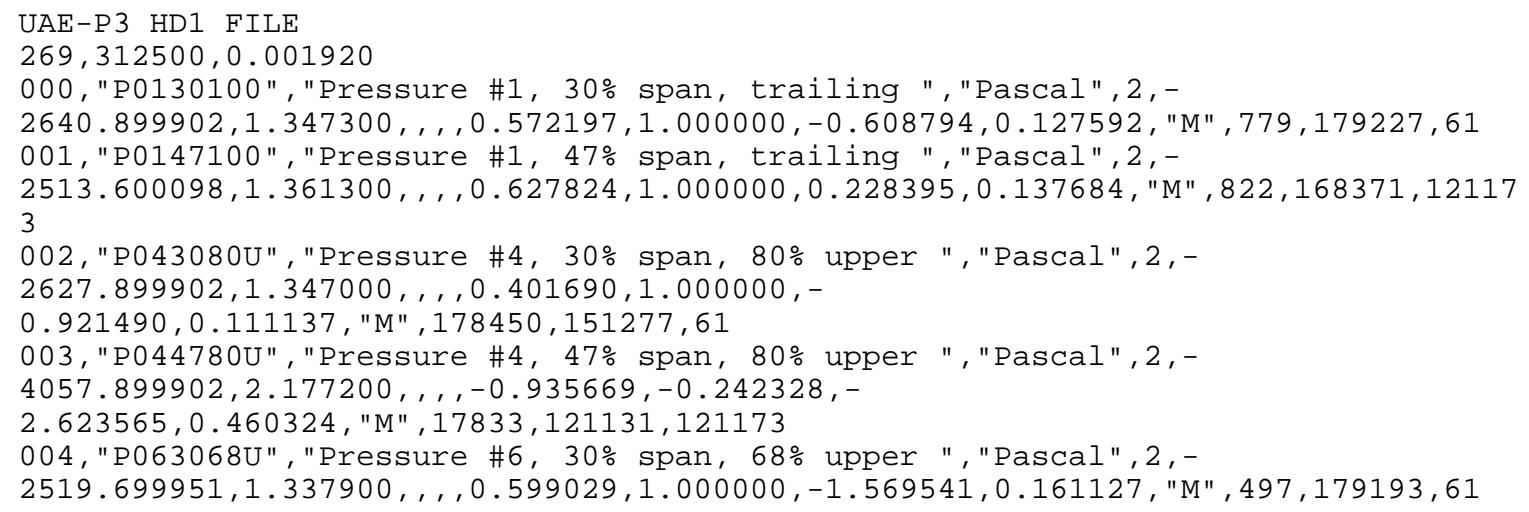

*.eng files contain the calibrated data parameters in engineering units along with all of the derived parameters. These binary files contain a series of 32-bit floating-point real numbers and one 8-bit byte for each frame of data. A 10-minute campaign consists of 312,500 records for 269 channels. Each line is one time step of $1.92 \mathrm{~ms}$.

\begin{tabular}{|c|c|c|c|c|c|c|}
\hline $\begin{array}{c}\text { Channel } \\
000\end{array}$ & $\begin{array}{c}\text { Channel } \\
001\end{array}$ & $\begin{array}{c}\text { Channel } \\
002\end{array}$ & $\begin{array}{c}\text { Channel } \\
003\end{array}$ & $\ldots$ & $\begin{array}{c}\text { Channel } \\
981\end{array}$ & Error Byte \\
\hline FLOAT & FLOAT & FLOAT & FLOAT & $\ldots$ & FLOAT & BYTE \\
\hline FLOAT & FLOAT & FLOAT & FLOAT & $\ldots$ & FLOAT & BYTE \\
\hline FLOAT & FLOAT & FLOAT & FLOAT & $\ldots$ & FLOAT & BYTE \\
\hline
\end{tabular}

$\cdots$

*.sta files contain the cycle-averaged values of each channel throughout the 10-minute campaign. The first cycle, 0 , is the partial cycle at the beginning of the campaign. In addition to the mean values, the standard deviation, maximum, azimuth angle at the maximum, minimum, azimuth angle at the minimum, cup-average wind speed at the minimum value, and yaw error angle at the minimum are included. Additional "channels" are created and appended to the cycle-average record. The average wind speed of the cup-anemometers, excluding the one at $2 \mathrm{~m}$, is calculated. The yaw error angle based on the vector average of the two bi-vane anemometers and the turbine yaw angle is determined. Vertical and horizontal wind shears are calculated using the cup anemometers. Lastly, each record contains eight integer values representing the cumulative total per cycle of each bit of the eight-bit error byte. These files are stored in binary format. 
Appendix C

Instrumentation Summaries 
Table 25. Phase V Instrumentation Summary

\begin{tabular}{|c|c|c|c|c|c|}
\hline Channel & ID Code & Description & Sensor Location & Measurement Type and Units & Sensor Type \\
\hline $\begin{array}{c}000-050 \\
\text { (even) }\end{array}$ & $\begin{array}{l}\text { Ptt30ccc } \\
\text { Ptt36ccc } \\
\text { Ptt41ccc }\end{array}$ & $\begin{array}{l}\text { Surface pressures at } 30 \%, 36 \% \text {, and } 41 \% \text { span } \\
\mathrm{tt}=\text { transducer tap number } \\
\mathrm{ccc}=\% \text { chord pressure tap location }\end{array}$ & Within blade 3 at approximately $30 \%$ span & Differential pressure, $\mathrm{Pa}$ & $\begin{array}{l}32 \text { channel scanning, electronic pressure } \\
\text { transducer }\end{array}$ \\
\hline 052-060 (even) & $5 \mathrm{H} \times 34$ & $\begin{array}{l}5 \text {-hole probe at 34\% span } \\
x=\text { designation of hole in } 5 \text {-hole probe }\end{array}$ & Within blade 3 at approximately $30 \%$ span & Differential pressure, $\mathrm{Pa}$ & $\begin{array}{l}32 \text { channel scanning, electronic pressure } \\
\text { transducer }\end{array}$ \\
\hline $\begin{array}{c}001-051 \\
\text { (odd) }\end{array}$ & $\begin{array}{l}\text { Ptt47ccc } \\
\text { Ptt52ccc } \\
\text { Ptt58ccc }\end{array}$ & $\begin{array}{l}\text { Surface pressures at } 47 \%, 52 \% \text {, and } 58 \% \text { span } \\
\mathrm{tt}=\text { transducer tap number } \\
\mathrm{ccc}=\% \text { chord pressure tap location }\end{array}$ & Within blade 3 at approximately $47 \%$ span & Differential pressure, $\mathrm{Pa}$ & $\begin{array}{l}32 \text { channel scanning, electronic pressure } \\
\text { transducer }\end{array}$ \\
\hline 053-061 (odd) & $5 \mathrm{H} \times 51$ & $\begin{array}{l}\text { 5-hole probe at 51\% span } \\
x=\text { designation of hole in } 5 \text {-hole probe }\end{array}$ & Within blade 3 at approximately $47 \%$ span & Differential pressure, $\mathrm{Pa}$ & $\begin{array}{l}32 \text { channel scanning, electronic pressure } \\
\text { transducer }\end{array}$ \\
\hline $100-150$ (even) & $\begin{array}{l}\text { Ptt63ccc } \\
\text { Ptt69ccc } \\
\text { Ptt74ccc }\end{array}$ & $\begin{array}{l}\text { Surface pressure at } 63 \%, 69 \%, \text { and } 74 \% \text { span } \\
\mathrm{tt}=\text { transducer tap number } \\
\mathrm{ccc}=\% \text { chord pressure tap location }\end{array}$ & Within blade 3 at approximately $63 \%$ span & Differential pressure, $\mathrm{Pa}$ & $\begin{array}{l}32 \text { channel scanning, electronic pressure } \\
\text { transducer }\end{array}$ \\
\hline $152-160$ (even) & $5 \mathrm{H} \times 67$ & $\begin{array}{l}5 \text {-hole probe at } 67 \% \text { span } \\
x=\text { designation of hole in } 5 \text {-hole probe }\end{array}$ & Within blade 3 at approximately $63 \%$ span & Differential pressure, $\mathrm{Pa}$ & $\begin{array}{l}32 \text { channel scanning, electronic pressure } \\
\text { transducer }\end{array}$ \\
\hline 101-151 (odd) & $\begin{array}{l}\text { Ptt80ccc } \\
\text { Ptt85ccc } \\
\text { Ptt90ccc }\end{array}$ & $\begin{array}{l}\text { Surface pressures at } 80 \%, 85 \% \text {, and } 90 \% \text { span } \\
\mathrm{tt}=\text { transducer tap number } \\
\mathrm{ccc}=\% \text { chord pressure tap location }\end{array}$ & Within blade 3 at approximately $80 \%$ span & Differential pressure, $\mathrm{Pa}$ & $\begin{array}{l}32 \text { channel scanning, electronic pressure } \\
\text { transducer }\end{array}$ \\
\hline 153-161 (odd) & $5 \mathrm{H} \times 84$ & $\begin{array}{l}\text { 5-hole probe at } 84 \% \text { span } \\
x=\text { designation of hole in } 5 \text {-hole probe }\end{array}$ & Within blade 3 at approximately $80 \%$ span & Differential pressure, $\mathrm{Pa}$ & $\begin{array}{l}32 \text { channel scanning, electronic pressure } \\
\text { transducer }\end{array}$ \\
\hline 200-250 (even) & $\begin{array}{l}\text { Ptt95ccc } \\
\text { Ptt92ccc } \\
\text { Ptt98ccc }\end{array}$ & $\begin{array}{l}\text { Surface pressures at } 95 \%, 92 \%, \text { and } 98 \% \text { span } \\
\mathrm{tt}=\text { transducer tap number } \\
\mathrm{ccc}=\% \text { chord pressure tap location }\end{array}$ & Within blade 3 at approximately $95 \%$ span & Differential pressure, $\mathrm{Pa}$ & $\begin{array}{l}32 \text { channel scanning, electronic pressure } \\
\text { transducer }\end{array}$ \\
\hline $\begin{array}{c}252-260 \\
\text { (even) }\end{array}$ & $5 \mathrm{H} \times 91$ & $\begin{array}{l}\text { 5-hole probe at } 91 \% \text { span } \\
x=\text { designation of hole in } 5 \text {-hole probe }\end{array}$ & Within blade 3 at approximately $95 \%$ span & Differential pressure, $\mathrm{Pa}$ & $\begin{array}{l}32 \text { channel scanning, electronic pressure } \\
\text { transducer }\end{array}$ \\
\hline 201 & B1ACFL & Accelerometer Blade 1-Flap & Tip of blade 1 & Linear flap acceleration, mps2 & Accelerometer \\
\hline 203 & B1ACED & Accelerometer Blade 1-Edge & Tip of blade 1 & Linear edge acceleration, mps2 & Accelerometer \\
\hline 209 & B3ACFL & Accelerometer Blade 3-Flap & Tip of blade 3 & Linear flap acceleration, mps2 & Accelerometer \\
\hline 211 & B3ACED & Accelerometer Blade 3-Edge & Tip of blade 3 & Linear edge acceleration, mps2 & Accelerometer \\
\hline 213 & Not recorded & Analog Nitrogen tank pressure & Rotating instrumentation package & Pressure inside $\mathrm{Ni}$ tank, $\mathrm{Pa}$ & Pressure transducer \\
\hline 215 & HSXXB & Strain HS XX Bending & Universal hub shaft & Bending moment, $\mathrm{Nm}$ & Strain gauge $-350 \mathrm{ohm}$ \\
\hline 217 & HSYYB & Strain HS YY Bending & Universal hub shaft & Bending moment, $\mathrm{Nm}$ & Strain gauge - $350 \mathrm{ohm}$ \\
\hline 219 & HSTQ1 & Strain HS Torque 1 & Universal hub shaft & Torque, $\mathrm{Nm}$ & Strain gauge - $350 \mathrm{ohm}$ \\
\hline 221 & HSTQ2 & Strain HS Torque 2 & Universal hub shaft & Torque, $\mathrm{Nm}$ & Strain gauge - $350 \mathrm{ohm}$ \\
\hline 223 & TLINKF & Strain Teeter link force & Rigid link between blades & Force, $\mathrm{N}$ & Tension and compression sensor \\
\hline
\end{tabular}


Table 25. Phase V Instrumentation Summary (continued)

\begin{tabular}{|c|c|c|c|c|c|}
\hline Channel & ID Code & Description & Sensor Location & Measurement Type and Units & Sensor Type \\
\hline 225 & B1RFB & Strain Blade 1 root flap bending & Blade 1 pitch shaft (8\% span) & Bending moment, $\mathrm{Nm}$ & Strain gauge - $350 \mathrm{ohm}$ \\
\hline 227 & B1REB & Strain Blade 1 root edge bending & Blade 1 pitch shaft ( $8 \%$ span) & Bending moment, $\mathrm{Nm}$ & Strain gauge - $350 \mathrm{ohm}$ \\
\hline 229 & B1TDAMP & Strain Blade 1 teeter damper force & Blade 1 teeter damper & Force, $\mathrm{N}$ & Button force sensor \\
\hline 231 & BЗTDAMP & Strain Blade 3 teeter damper force & Blade 3 teeter damper & Force, $\mathrm{N}$ & Button force sensor \\
\hline 233 & B3RFB & Strain Blade 3 root flap bending & Blade 3 pitch shaft ( $8 \%$ span) & Bending moment, $\mathrm{Nm}$ & Strain gauge - $350 \mathrm{ohm}$ \\
\hline 235 & B3REB & Strain Blade 3 root edge bending & Blade 3 pitch shaft ( $8 \%$ span) & Bending moment, $\mathrm{Nm}$ & Strain gauge $-350 \mathrm{ohm}$ \\
\hline 237 & LSSXXB & Strain X-X LSS bending & Low-speed shaft & Bending moment, $\mathrm{Nm}$ & Strain gauge - $350 \mathrm{ohm}$ \\
\hline 239 & LSSYYB & Strain Y-Y LSS bending & Low-speed shaft & Bending moment, $\mathrm{Nm}$ & Strain gauge - $350 \mathrm{ohm}$ \\
\hline 241 & LSSTQ & Strain LSS torque & Low-speed shaft & Torque, Nm & Strain gauge - $350 \mathrm{ohm}$ \\
\hline 251 & B1FLAP & Digital Blade 1 flap angle & Universal hub outboard of teeter bearing & Angular position, deg & Digital position encoder \\
\hline 253 & B1PITCH & Digital Blade 1 pitch & Blade 1 root/hub attachment & Angular position, deg & Digital position encoder \\
\hline 255 & B3FLAP & Digital Blade 3 flap angle & Universal hub outboard of teeter bearing & Angular position, deg & Digital position encoder \\
\hline 257 & B3PITCH & Digital Blade 3 pitch & Blade 3 root/hub attachment & Angular position, deg & Digital position encoder \\
\hline 259,261 & $\begin{array}{l}\text { VBL176 } \\
\text { VBL178 } \\
\end{array}$ & $\begin{array}{l}\text { Digital first } 12 \text { bits from Delta pressure, } \\
\text { Digital last } 12 \text { bits from Delta pressure }\end{array}$ & Rotating instrumentation package & $\begin{array}{l}\text { Reference pressure, } \\
16 \text { bit binary }\end{array}$ & Digital reference pressure \\
\hline 300 & LMWS24M & Local met WS 24.38 m & Central MET Tower & Wind speed, $\mathrm{m} / \mathrm{s}$ & Cup anemometer \\
\hline 302 & LMWS17M & Local met WS 17.02 m (hub height) & Central MET Tower & Wind speed, $\mathrm{m} / \mathrm{s}$ & Cup anemometer \\
\hline 304 & LMWS10M & Local met WS 10.06 m & Central MET Tower & Wind speed, $\mathrm{m} / \mathrm{s}$ & Cup anemometer \\
\hline 306 & LMWS2M & Local met WS $2.4 \mathrm{~m}$ & Central MET Tower & Wind speed, $\mathrm{m} / \mathrm{s}$ & Cup anemometer \\
\hline 308 & NLMWS17M & N local met WS 17.02 m (hub height) & North MET Tower & Wind speed, $\mathrm{m} / \mathrm{s}$ & Cup anemometer \\
\hline 310 & NLMWD17M & N local met WD $17.02 \mathrm{~m}$ (hub height) & North MET Tower & Wind Direction, deg & Bi-vane anemometer \\
\hline 312 & NLMWE17M & N local met WE 17.02 m (hub height) & North MET Tower & Wind Elevation, deg & Bi-vane anemometer \\
\hline 314 & SLMWS17M & S local met WS $17.02 \mathrm{~m}$ (hub height) & South MET Tower & Wind speed, $\mathrm{m} / \mathrm{s}$ & Cup anemometer \\
\hline 316 & SLMWD17M & S local met WD 17.02 m (hub height) & South MET Tower & Wind Direction, deg & Bi-vane anemometer \\
\hline 318 & SLMWE17M & S local met WE $17.02 \mathrm{~m}$ (hub height) & South MET Tower & Wind Elevation, deg & Bi-vane anemometer \\
\hline 320 & LMT2M & Local met temperature $2.4 \mathrm{~m}$ & Central MET Tower & Ambient air temperature, degC & Platinum resistance element $(100 \mathrm{ohm}$ ) \\
\hline 322 & LMDT & Local met Delta Temperature & Central MET Tower & Delta temperature, degC & Platinum resistance element (100 ohm) \\
\hline 324 & LMDP2M & Local met dewpoint $2.4 \mathrm{~m}$ & Central MET Tower & Dewpoint temperature, $\operatorname{deg} C$ & Dewpoint temperature sensor \\
\hline 326 & LMSU17M & Local met sonic channel U 17.02 m & Central MET Tower & $\begin{array}{l}\text { Horizontal wind speed perpendicular to } \\
\text { rotor plane, } \mathrm{m} / \mathrm{s}\end{array}$ & Sonic Anemometer \\
\hline 328 & LMSV17M & Local met sonic channel V $17.02 \mathrm{~m}$ & Central MET Tower & $\begin{array}{l}\text { Horizontal wind speed parallel } \\
\text { to rotor plane, } \mathrm{m} / \mathrm{s}\end{array}$ & Sonic Anemometer \\
\hline 330 & LMSW17M & Local met sonic channel W 17.02 m & Central MET Tower & Vertical wind speed, $\mathrm{m} / \mathrm{s}$ & Sonic Anemometer \\
\hline
\end{tabular}


Table 25. Phase V Instrumentation Summary (continued)

\begin{tabular}{|c|c|c|c|c|c|}
\hline Channel & ID Code & Description & Sensor Location & Measurement Type and Units & Sensor Type \\
\hline 332 & GENPOW & Generator power & Nacelle bed plate & Generator power, kW & AC watt transducer \\
\hline 334 & BARO & Barometric pressure & Data shed & Ambient air pressure, $\mathrm{Pa}$ & Ambient air pressure transducer \\
\hline 336 & NAACYW & Nacelle Accelerometer Yaw & Nacelle bed plate & Linear yaw acceleration, $\mathrm{m} / \mathrm{s} 2$ & Accelerometer \\
\hline 338 & NAACFA & Nacelle Accelerometer Fore-Aft & Nacelle bed plate & Linear fore-aft acceleration, $\mathrm{m} / \mathrm{s} 2$ & Accelerometer \\
\hline 340 & NAACPI & Nacelle Accelerometer Pitch & Nacelle bed plate & Linear pitch acceleration, m/s2 & Accelerometer \\
\hline 342 & NAYM & Nacelle Yaw Moment & Arm of yaw brake & Bending moment, $\mathrm{Nm}$ & Strain gauge \\
\hline 349 & B3AZI & Blade azimuth angle & Blade 3 hub/nacelle attachment & Angular position, deg & Digital position encoder \\
\hline 351 & YAW & Yaw angle & Tower/nacelle attachment & Angular position, deg & Digital position encoder \\
\hline 353 & DAY & Clock - day & Data shed & Time, day & Time code generator \\
\hline 355 & HOUR & Clock - hour & Data shed & Time, hour & \\
\hline 357 & MINUTE & Clock - minute & Data shed & Time, minute & \\
\hline 359 & SECOND & Clock - second & Data shed & Time, second & \\
\hline 361 & MILLISEC & Clock - millisecond & Data shed & Time, millisecond & \\
\hline
\end{tabular}


Table 25. Phase V Instrumentation Summary (continued)

\begin{tabular}{|c|c|c|c|c|c|c|}
\hline Channel & ID Code & $\begin{array}{c}\text { Power } \\
\text { Requirement }\end{array}$ & Sensor Range & $\begin{array}{c}\text { Nominal 12-bit DAS } \\
\text { Resolution }\end{array}$ & $\begin{array}{c}\text { Manufacturer-Stated } \\
\text { Sensor Accuracy }\end{array}$ & Manufacturer and Model Number \\
\hline $\begin{array}{c}000-050 \\
\text { (even) }\end{array}$ & $\begin{array}{l}\mathrm{Ptt30ccc} \\
\mathrm{Ptt36ccc} \\
\mathrm{Ptt41ccc}\end{array}$ & $\begin{array}{c}\text { 5Vdc, } \\
+/-12 \mathrm{Vdc}\end{array}$ & $+/-5 \mathrm{~V}=+/-2500 \mathrm{~Pa}$ & $1.2 \mathrm{~Pa} / \mathrm{bit}$ & $+/-0.1 \%$ full scale (static) & Pressure Systems, Inc. ESP-32 \\
\hline \begin{tabular}{|l|}
$052-060$ (even) \\
\end{tabular} & $5 \mathrm{H} \times 34$ & $\begin{array}{c}5 \mathrm{Vdc}, \\
+/-12 \mathrm{Vdc}\end{array}$ & $+/-5 \mathrm{~V}=+/-2500 \mathrm{~Pa}$ & $1.2 \mathrm{~Pa} / \mathrm{bit}$ & $+/-0.1 \%$ full scale (static) & Pressure Systems, Inc. ESP-32 \\
\hline $\begin{array}{c}001-051 \\
\text { (odd) }\end{array}$ & $\begin{array}{l}\text { Ptt47ccc } \\
\text { Ptt52ccc } \\
\text { Ptt58ccc }\end{array}$ & $\begin{array}{c}5 \mathrm{Vdc} \\
+/-12 \mathrm{Vdc}\end{array}$ & $+/-5 \mathrm{~V}=+/-2500 \mathrm{~Pa}$ & $1.2 \mathrm{~Pa} / \mathrm{bit}$ & $+/-0.1 \%$ full scale (static) & Pressure Systems, Inc. ESP-32 \\
\hline 053-061 (odd) & $5 \mathrm{H} \times 51$ & $\begin{array}{c}5 \mathrm{Vdc}, \\
+/-12 \mathrm{Vdc}\end{array}$ & $+/-5 \mathrm{~V}=+/-2500 \mathrm{~Pa}$ & $1.2 \mathrm{~Pa} / \mathrm{bit}$ & $+/-0.1 \%$ full scale (static) & Pressure Systems, Inc. ESP-32 \\
\hline $100-150$ (even) & $\begin{array}{l}\text { Ptt63ccc } \\
\text { Ptt69ccc } \\
\text { Ptt74ccc }\end{array}$ & $\begin{array}{c}5 \mathrm{Vdc}, \\
+/-12 \mathrm{Vdc}\end{array}$ & $+/-5 \mathrm{~V}=+/-5000 \mathrm{~Pa}$ & $2.4 \mathrm{~Pa} / \mathrm{bit}$ & $+/-0.1 \%$ full scale (static) & Pressure Systems, Inc. ESP-32 \\
\hline $152-160$ (even) & $5 \mathrm{H} \times 67$ & $\begin{array}{c}5 \mathrm{Vdc}, \\
+/-12 \mathrm{Vdc}\end{array}$ & $+/-5 \mathrm{~V}=+/-5000 \mathrm{~Pa}$ & $2.4 \mathrm{~Pa} / \mathrm{bit}$ & $+/-0.1 \%$ full scale (static) & Pressure Systems, Inc. ESP-32 \\
\hline 101-151 (odd) & $\begin{array}{l}\text { Ptt80ccc } \\
\text { Ptt85ccc } \\
\text { Ptt90ccc }\end{array}$ & $\begin{array}{c}5 \mathrm{Vdc}, \\
+/-12 \mathrm{Vdc}\end{array}$ & $+/-5 \mathrm{~V}=+/-10342 \mathrm{~Pa}$ & $5.0 \mathrm{~Pa} / \mathrm{bit}$ & $+/-0.1 \%$ full scale (static) & Pressure Systems, Inc. ESP-32 \\
\hline 153-161 (odd) & $5 \mathrm{H} \times 84$ & $\begin{array}{c}5 \mathrm{Vdc}, \\
+/-12 \mathrm{Vdc}\end{array}$ & $+/-5 \mathrm{~V}=+/-10342 \mathrm{~Pa}$ & $5.0 \mathrm{~Pa} / \mathrm{bit}$ & $+/-0.1 \%$ full scale (static) & Pressure Systems, Inc. ESP-32 \\
\hline 200-250 (even) & $\begin{array}{l}\text { Ptt95ccc } \\
\text { Ptt92ccc } \\
\text { Ptt98ccc }\end{array}$ & $\begin{array}{c}\text { 5Vdc, } \\
+/-12 \mathrm{Vdc}\end{array}$ & $+/-5 \mathrm{~V}=+/-10342 \mathrm{~Pa}$ & $5.0 \mathrm{~Pa} / \mathrm{bit}$ & $+/-0.1 \%$ full scale (static) & Pressure Systems, Inc. ESP-32 \\
\hline $\begin{array}{c}252-260 \\
\text { (even) }\end{array}$ & $5 \mathrm{H} \times 91$ & $\begin{array}{c}5 \mathrm{Vdc}, \\
+/-12 \mathrm{Vdc}\end{array}$ & $+/-5 \mathrm{~V}=+/-10342 \mathrm{~Pa}$ & $5.0 \mathrm{~Pa} / \mathrm{bit}$ & $+/-0.1 \%$ full scale (static) & Pressure Systems, Inc. ESP-32 \\
\hline 201 & B1ACFL & $15 \mathrm{Vdc}$ & $+/-2 \mathrm{~V}=+/-10 \mathrm{~g}$ & $0.024 \mathrm{mps} 2$ / bit & $200 \mathrm{mV} / \mathrm{g}$ & Endevco Corporation 7290A-10 \\
\hline 203 & B1ACED & $15 \mathrm{Vdc}$ & $+/-2 V=+/-10 \mathrm{~g}$ & $0.024 \mathrm{mps} 2 / \mathrm{bit}$ & $200 \mathrm{mV} / \mathrm{g}$ & Endevco Corporation 7290A-10 \\
\hline 209 & B3ACFL & $15 \mathrm{Vdc}$ & $+/-2 \mathrm{~V}=+/-10 \mathrm{~g}$ & $0.024 \mathrm{mps} 2 / \mathrm{bit}$ & $200 \mathrm{mV} / \mathrm{g}$ & Endevco Corporation 7290A-10 \\
\hline 211 & B3ACED & $15 \mathrm{Vdc}$ & $+/-2 V=+/-10 \mathrm{~g}$ & $0.024 \mathrm{mps} 2 / \mathrm{bit}$ & $200 \mathrm{mV} / \mathrm{g}$ & Endevco Corporation 7290A-10 \\
\hline 213 & Not recorded & & 0 to $13.8 \mathrm{MPa}$ & $3.3 \mathrm{kPa} / \mathrm{bit}$ & & IMO 303H2-12CG-10-P \\
\hline 215 & HSXXB & $+/-10 \mathrm{Vdc}$ & $0-4096$ counts $=+/-14000 \mathrm{Nm}$ & $7 \mathrm{Nm} / \mathrm{bit}$ & & Measurements Group, Inc. LWK-06-W250B-350 \\
\hline 217 & HSYYB & $+/-10 \mathrm{Vdc}$ & $0-4096$ counts $=+/-14000 \mathrm{Nm}$ & $7 \mathrm{Nm} / \mathrm{bit}$ & & Measurements Group, Inc. LWK-06-W250B-350 \\
\hline 219 & HSTQ1 & $+/-10 \mathrm{Vdc}$ & $0-4096$ counts $=+1-20000 \mathrm{Nm}$ & $10.5 \mathrm{Nm} / \mathrm{bit}$ & & Measurements Group, Inc. LWK-06-W250D-350 \\
\hline 221 & HSTQ2 & $+/-10 \mathrm{Vdc}$ & $0-4096$ counts $=+/-20000 \mathrm{Nm}$ & $10.5 \mathrm{Nm} / \mathrm{bit}$ & & Measurements Group, Inc. LWK-06-W250D-350 \\
\hline 223 & TLINKF & $10 \mathrm{Vdc}$ & $0-10 V=+/-10,000 \mathrm{lbs}$ & $32 \mathrm{~N} / \mathrm{bit}$ & $0.1 \%$ full scale & Transducer Techniques HSW-10K \\
\hline
\end{tabular}


Table 25. Phase V Instrumentation Summary (continued)

\begin{tabular}{|c|c|c|c|c|c|c|}
\hline Channel & ID Code & $\begin{array}{c}\text { Power } \\
\text { Requirement }\end{array}$ & Sensor Range & $\begin{array}{c}\text { Nominal 12-bit DAS } \\
\text { Resolution }\end{array}$ & $\begin{array}{l}\text { Manufacturer-Stated } \\
\text { Sensor Accuracy }\end{array}$ & Manufacturer and Model Number \\
\hline 225 & B1RFB & $+/-10 \mathrm{Vdc}$ & $0-4096$ counts $=+/-16000 \mathrm{Nm}$ & $8 \mathrm{Nm} / \mathrm{bit}$ & & Measurements Group, Inc. LWK-09-W250B-350 \\
\hline 227 & B1REB & $+/-10 \mathrm{Vdc}$ & $0-4096$ counts $=+/-16000 \mathrm{Nm}$ & $8 \mathrm{Nm} / \mathrm{bit}$ & & Measurements Group, Inc. LWK-09-W250B-350 \\
\hline 229 & B1TDAMP & $10 \mathrm{Vdc}$ & $0-10 \mathrm{~V}=0-10,000 \mathrm{lbs}$ & $30 \mathrm{~N} / \mathrm{bit}$ & $0.25 \%$ full scale & Sensotec $5310239-08$ \\
\hline 231 & B3TDAMP & $10 \mathrm{Vdc}$ & $0-10 V=0-10,000 \mathrm{lbs}$ & $30 \mathrm{~N} / \mathrm{bit}$ & $0.25 \%$ full scale & Sensotec 5310239-08 \\
\hline 233 & B3RFB & $+/-10 \mathrm{Vdc}$ & $0-4096$ counts $=+/-16000 \mathrm{Nm}$ & $8 \mathrm{Nm} / \mathrm{bit}$ & & Measurements Group, Inc. LWK-09-W250B-350 \\
\hline 235 & B3REB & $+/-10 \mathrm{Vdc}$ & $0-4096$ counts $=+/-16000 \mathrm{Nm}$ & $8 \mathrm{Nm} / \mathrm{bit}$ & & Measurements Group, Inc. LWK-09-W250B-350 \\
\hline 237 & LSSXXB & $+/-10 \mathrm{Vdc}$ & $0-4096$ counts $=+/-33000 \mathrm{Nm}$ & $16.5 \mathrm{Nm} / \mathrm{bit}$ & & Measurements Group, Inc. CEA-06-250UW-350 \\
\hline 239 & LSSYYB & $+/-10 \mathrm{Vdc}$ & $0-4096$ counts $=+/-33000 \mathrm{Nm}$ & $16.5 \mathrm{Nm} / \mathrm{bit}$ & & Measurements Group, Inc. CEA-06-250UW-350 \\
\hline 241 & LSSTQ & $+/-10 \mathrm{Vdc}$ & $0-4096$ counts $=+/-39000 \mathrm{Nm}$ & $19.5 \mathrm{Nm} / \mathrm{bit}$ & & Measurements Group, Inc. CEA-06-250US-350 \\
\hline 251 & B1FLAP & $15 \mathrm{Vdc}$ & $0-4096$ counts $=0-45$ deg & $0.11 \mathrm{deg} / \mathrm{bit}$ & $+/-0.5$ count (worst case) & BEI Motion Systems Company, RAS-25-4096 \\
\hline 253 & B1PITCH & $+/-15 \mathrm{Vdc}, 5 \mathrm{~V}$ & $0-4096$ counts $=0-360 \mathrm{deg}$ & $0.088 \mathrm{deg} / \mathrm{bit}$ & $+/-0.5$ count (worst case) & BEI Motion Systems Company, R25-4096-24 \\
\hline 255 & B3FLAP & $15 \mathrm{Vdc}$ & $0-4096$ counts $=0-45$ deg & $0.11 \mathrm{deg} / \mathrm{bit}$ & $+/-0.5$ count (worst case) & BEI Motion Systems Company, RAS-25-4096 \\
\hline 257 & B3PITCH & $+/-15 \mathrm{Vdc}, 5 \mathrm{~V}$ & $0-4096$ counts $=0-360 \mathrm{deg}$ & $0.088 \mathrm{deg} / \mathrm{bit}$ & $+/-0.5$ count (worst case) & BEI Motion Systems Company, R25-4096-24 \\
\hline 259,261 & $\begin{array}{l}\text { VBL176 } \\
\text { VBL178 } \\
\end{array}$ & $12 \mathrm{Vdc}$ & $+/-13,790 \mathrm{~Pa}$ & $0.42 \mathrm{~Pa} / \mathrm{bit}$ & $0.025 \%$ full scale (standard) & Mensor Corporation 4010 \\
\hline 300 & LMWS24M & $+/-12 \mathrm{Vdc}$ & $0-5 \mathrm{~V}=0-50 \mathrm{~m} / \mathrm{s}$ & $0.01 \mathrm{~m} / \mathrm{s} / \mathrm{bit}$ & $+/-1 \%$ of true & Met One Instruments 1564B, 170-41, 21.11 \\
\hline 302 & LMWS17M & $+/-12 \mathrm{Vdc}$ & $0-5 \mathrm{~V}=0-50 \mathrm{~m} / \mathrm{s}$ & $0.01 \mathrm{~m} / \mathrm{s} / \mathrm{bit}$ & $+/-1 \%$ of true & Met One Instruments 1564B, 170-41, 21.11 \\
\hline 304 & LMWS10M & $+/-12 \mathrm{Vdc}$ & $0-5 \mathrm{~V}=0-50 \mathrm{~m} / \mathrm{s}$ & $0.01 \mathrm{~m} / \mathrm{s} / \mathrm{bit}$ & $+/-1 \%$ of true & Met One Instruments 1564B, 170-41, 21.11 \\
\hline 306 & LMWS2M & $+/-12 \mathrm{Vdc}$ & $0-5 V=0-50 \mathrm{~m} / \mathrm{s}$ & $0.01 \mathrm{~m} / \mathrm{s} / \mathrm{bit}$ & $+/-1 \%$ of true & Met One Instruments 1564B, 170-41, 21.11 \\
\hline 308 & NLMWS17M & $+/-12 \mathrm{Vdc}$ & $0-5 V=0-50 \mathrm{~m} / \mathrm{s}$ & $0.01 \mathrm{~m} / \mathrm{s} / \mathrm{bit}$ & $+/-1 \%$ of true & Met One Instruments 1564B, 170-41, 21.11 \\
\hline 310 & NLMWD17M & $+/-12 \mathrm{Vdc}$ & $0-5 V=0-360 \mathrm{deg}$ & $0.088 \mathrm{deg} / \mathrm{bit}$ & $+/-2$ deg & Met One Instruments 1585, 21.21 \\
\hline 312 & NLMWE17M & $+/-12 \mathrm{Vdc}$ & $0-5 V=-60$ to $60 \mathrm{deg}$ & $0.03 \mathrm{deg} / \mathrm{bit}$ & +/- 2 deg & Met One Instruments 1585, 21.21 \\
\hline 314 & SLMWS17M & $+/-12 \mathrm{Vdc}$ & $0-5 V=0-50 \mathrm{~m} / \mathrm{s}$ & $0.01 \mathrm{~m} / \mathrm{s} / \mathrm{bit}$ & $+/-1 \%$ of true & Met One Instruments 1564B, 170-41, 21.11 \\
\hline 316 & SLMWD17M & $+/-12 \mathrm{Vdc}$ & $0-5 V=0-360 \mathrm{deg}$ & $0.088 \mathrm{deg} / \mathrm{bit}$ & +/- 2 deg & Met One Instruments 1585, 21.21 \\
\hline 318 & SLMWE17M & $+/-12 \mathrm{Vdc}$ & $0-5 V=-60$ to $60 \mathrm{deg}$ & $0.03 \mathrm{deg} / \mathrm{bit}$ & $+/-2$ deg & Met One Instruments 1585, 21.21 \\
\hline 320 & LMT2M & $+/-12 \mathrm{Vdc}$ & $0-5 V=-50$ to 50 deg $C$ & $0.02 \mathrm{deg} / \mathrm{bit}$ & $+/-0.1$ deg $\mathrm{C}$ to $+/-0.3 \operatorname{deg} \mathrm{C}$ & Met One Instruments T200, 21.32A4 \\
\hline 322 & LMDT & $+/-12 \mathrm{Vdc}$ & $0-5 V=-8$ to $12 \operatorname{deg} F$ & $0.005 \mathrm{deg} \mathrm{C} / \mathrm{bit}$ & $+/-0.2 \operatorname{deg} C$ to $+/-0.6 \operatorname{deg} C$ & Met One Instruments T200, Teledyne ModS22 rev. E \\
\hline 324 & LMDP2M & $+/-12 \mathrm{Vdc}$ & $0-5 V=-50$ to $50 \operatorname{deg} C$ & $0.02 \mathrm{deg} / \mathrm{bit}$ & $+/-0.1$ deg $C$ to $+/-0.3$ deg $C$ & Met One Instruments DP200B, 21.43D2 \\
\hline 326 & LMSU17M & $120 \mathrm{Vac}$ & $+/-5 \mathrm{~V}=+/-50 \mathrm{~m} / \mathrm{s}$ & $0.02 \mathrm{~m} / \mathrm{s} / \mathrm{bit}$ & $+/-1 \%$ or $+/-0.05 \mathrm{~m} / \mathrm{s}$ & Applied Technologies, Inc. SWS-211/3K \\
\hline 328 & LMSV17M & $120 \mathrm{Vac}$ & $+/-5 \mathrm{~V}=+/-50 \mathrm{~m} / \mathrm{s}$ & $0.02 \mathrm{~m} / \mathrm{s} / \mathrm{bit}$ & $+/-1 \%$ or $+/-0.05 \mathrm{~m} / \mathrm{s}$ & Applied Technologies, Inc. SWS-211/3K \\
\hline 330 & LMSW17M & $120 \mathrm{Vac}$ & $+/-5 \mathrm{~V}=+/-15 \mathrm{~m} / \mathrm{s}$ & $0.01 \mathrm{~m} / \mathrm{s} / \mathrm{bit}$ & $+/-1 \%$ or $+/-0.05 \mathrm{~m} / \mathrm{s}$ & Applied Technologies, Inc. SWS-211/3K \\
\hline
\end{tabular}


Table 25. Phase V Instrumentation Summary (continued)

\begin{tabular}{|c|c|c|c|c|c|c|}
\hline Channel & ID Code & $\begin{array}{c}\text { Power } \\
\text { Requirement }\end{array}$ & Sensor Range & $\begin{array}{c}\text { Nominal 12-bit DAS } \\
\text { Resolution }\end{array}$ & $\begin{array}{l}\text { Manufacturer-Stated } \\
\text { Sensor Accuracy }\end{array}$ & Manufacturer and Model Number \\
\hline 332 & GENPOW & $240 \mathrm{Vac}$ & $+/-5 \mathrm{~V}=+1-40 \mathrm{~kW}$ & $0.02 \mathrm{~kW} / \mathrm{bit}$ & $+/-0.5 \%$ at rated power & Ohio Semitronics, Inc. PC5-63C \\
\hline 334 & BARO & $15 \mathrm{Vdc}$ & $0-5 \mathrm{~V}=74000-100000 \mathrm{~Pa}$ & $6.3 \mathrm{~Pa} / \mathrm{bit}$ & & Atmospheric Instrumentation Research, Inc. AIR-AB-2AX \\
\hline $\begin{array}{l}336 \\
338 \\
340 \\
342 \\
349\end{array}$ & $\begin{array}{l}\text { NAACYW } \\
\text { NAACFA } \\
\text { NAACPI } \\
\text { NAYM } \\
\text { B3AZI }\end{array}$ & $\begin{array}{c}15 \mathrm{Vdc} \\
15 \mathrm{Vdc} \\
15 \mathrm{Vdc} \\
+/-10 \mathrm{Vdc} \\
15 \mathrm{Vdc}\end{array}$ & $\begin{array}{l}+/-2 \mathrm{~V}=+/-10 \mathrm{~g} \\
+-2 \mathrm{~V}=+/-10 \mathrm{~g} \\
+/-2 \mathrm{~V}=+/-10 \mathrm{~g} \\
0-4096 \text { counts }=+/-5500 \mathrm{Nm} \\
0-4096 \text { counts }=0-360 \mathrm{deg}\end{array}$ & $\begin{array}{l}0.024 \mathrm{mps} 2 / \text { bit } \\
0.024 \mathrm{mps} 2 / \text { bit } \\
0.024 \mathrm{mps} 2 / \text { bit } \\
2.7 \mathrm{Nm} / \text { bit } \\
0.088 \mathrm{deg} / \text { bit }\end{array}$ & $\begin{array}{l}200 \mathrm{mV} / \mathrm{g} \\
200 \mathrm{mV} / \mathrm{g} \\
200 \mathrm{mV} / \mathrm{g} \\
+/-0.5 \text { count (worst case) }\end{array}$ & $\begin{array}{l}\text { Endevco Corporation 7290A-10 } \\
\text { Endevco Corporation 7290A-10 } \\
\text { Endevco Corporation 7290A-10 } \\
\text { Measurements Group, Inc. } \\
\text { BEI Motion Systems Company, R25-4096-24 }\end{array}$ \\
\hline 351 & YAW & $15 \mathrm{Vdc}$ & $0-4096$ counts $=0-360$ deg & $0.088 \mathrm{deg} / \mathrm{bit}$ & $+/-0.5$ count (worst case) & BEI Motion Systems Company, R25-4096-25 \\
\hline $\begin{array}{l}353 \\
355 \\
357 \\
359 \\
361\end{array}$ & $\begin{array}{c}\text { DAY } \\
\text { HOUR } \\
\text { MINUTE } \\
\text { SECOND } \\
\text { MILLISEC }\end{array}$ & 120 Vac & $\begin{array}{l}0-4096 \text { counts=binary coded } \\
\text { decimal digital }\end{array}$ & $0.1 \mathrm{~ms}$ & Frequency stability $+1-5 \mathrm{ppm}$ & $9310-804$ \\
\hline
\end{tabular}


Table 25. Phase V Instrumentation Summary (continued)

\begin{tabular}{|c|c|c|c|c|c|}
\hline Channel & ID Code & Signal Conditioning & $\begin{array}{l}\text { Analog Anti- } \\
\text { Alias Filters }\end{array}$ & $\begin{array}{c}\text { Calibration } \\
\text { Methods }\end{array}$ & $\begin{array}{c}\text { Page } \\
\text { Number }\end{array}$ \\
\hline $\begin{array}{c}000-050 \\
\text { (even) }\end{array}$ & $\begin{array}{l}\text { Ptt30ccc } \\
\text { Ptt36ccc } \\
\text { Ptt41ccc }\end{array}$ & $+/-5$ Vdc multiplexed (Pressure Systems, Inc. ESP-32) & & $\overline{\mathrm{A} 2}$ & $\overline{\mathrm{B}-46}$ \\
\hline 052-060 (even) & $5 \mathrm{H} \times 34$ & +/- 5 Vdc multiplexed (Pressure Systems, Inc. ESP-32) & & $\bar{A} 2$ & B-46 \\
\hline $\begin{array}{l}001-051 \\
\text { (odd) }\end{array}$ & $\begin{array}{l}\text { Ptt47ccc } \\
\text { Ptt52ccc } \\
\text { Ptt58ccc }\end{array}$ & +/- 5 Vdc multiplexed (Pressure Systems, Inc. ESP-32) & & A2 & B-46 \\
\hline 053-061 (odd) & $5 \mathrm{H} \times 51$ & $+/-5$ Vdc multiplexed (Pressure Systems, Inc. ESP-32) & & A2 & $\mathrm{B}-46$ \\
\hline $100-150$ (even) & $\begin{array}{l}\text { Ptt63ccc } \\
\text { Ptt69ccc } \\
\text { Ptt74ccc }\end{array}$ & +/- 5 Vdc multiplexed (Pressure Systems, Inc. ESP-32) & & A2 & $\mathrm{B}-48$ \\
\hline 152-160 (even) & $5 \mathrm{H} \times 67$ & $+/-5$ Vdc multiplexed (Pressure Systems, Inc. ESP-32) & & A2 & B-48 \\
\hline 101-151 (odd) & $\begin{array}{l}\text { Ptt80ccc } \\
\text { Ptt85ccc } \\
\text { Ptt90ccc }\end{array}$ & +/- 5 Vdc multiplexed (Pressure Systems, Inc. ESP-32) & & $\mathrm{A} 2$ & B-49 \\
\hline 153-161 (odd) & $5 \mathrm{H} \times 84$ & +/- 5 Vdc multiplexed (Pressure Systems, Inc. ESP-32) & & A2 & B-49 \\
\hline $200-250$ (even) & $\begin{array}{l}\text { Ptt95ccc } \\
\text { Ptt92ccc } \\
\text { Ptt98ccc }\end{array}$ & $+/-5$ Vdc multiplexed (Pressure Systems, Inc. ESP-32) & & $\overline{A 2}$ & $\bar{B}-49$ \\
\hline $\begin{array}{c}252-260 \\
\text { (even) }\end{array}$ & $5 \mathrm{H} \times 91$ & +/- 5 Vdc multiplexed (Pressure Systems, Inc. ESP-32) & & $\bar{A} 2$ & B-49 \\
\hline 201 & B1ACFL & $+/-1$ Vdc to +/- $5 \mathrm{~V} \mathrm{dc}$ (Analog Devices, Inc. 5B41-01) & Bessel Filter & M8, E1 & B-35 \\
\hline 203 & B1ACED & $+/-1$ Vdc to +/- 5 V dc (Analog Devices, Inc. 5B41-01) & Bessel Filter & M8, E1 & B-35 \\
\hline 209 & B3ACFL & $+/-1 \mathrm{Vdc}$ to $+/-5 \mathrm{~V} \mathrm{dc}$ (Analog Devices, Inc. 5B41-01) & Bessel Filter & M8, E1 & B-35 \\
\hline 211 & B3ACED & $+/-1 \mathrm{Vdc}$ to $+/-5 \mathrm{~V} \mathrm{dc}$ (Analog Devices, Inc. 5B41-01) & Bessel Filter & M8, E1 & B-35 \\
\hline 213 & Not recorded & $+/-1 \mathrm{Vdc}$ to $+/-5 \mathrm{~V}$ dc (Analog Devices, Inc. 5B41-01) & Bessel Filter & & B-51 \\
\hline 215 & HSXXB & $+/-30 \mathrm{mV}$ to $+/-5 \mathrm{~V}$ dc (Analog Devices, Inc. 5B38-01) & Bessel Filter & A1 & B-25 \\
\hline 217 & HSYYB & +/- $30 \mathrm{mV}$ to +/- $5 \mathrm{~V} \mathrm{dc}$ (Analog Devices, Inc. 5B38-01) & Bessel Filter & A1 & B-25 \\
\hline 219 & HSTQ1 & $+/-30 \mathrm{mV}$ to $+/-5 \mathrm{~V}$ dc (Analog Devices, Inc. 5B38-01) & Bessel Filter & A1 & B-25 \\
\hline 221 & HSTQ2 & $+/-30 \mathrm{mV}$ to $+/-5 \mathrm{~V}$ dc (Analog Devices, Inc. 5B38-01) & Bessel Filter & A1 & B-25 \\
\hline 223 & TLINKF & $+/-30 \mathrm{mV}$ to $+/-5 \mathrm{~V} \mathrm{dc}$ (Analog Devices, Inc. 5B38-01) & Bessel Filter & A3 & B-21 \\
\hline
\end{tabular}


Table 25. Phase V Instrumentation Summary (continued)

\begin{tabular}{|c|c|c|c|c|c|}
\hline Channel & ID Code & Signal Conditioning & $\begin{array}{l}\text { Analog Anti- } \\
\text { Alias Filters }\end{array}$ & $\begin{array}{l}\text { Calibration } \\
\text { Methods }\end{array}$ & $\begin{array}{l}\text { Page } \\
\text { Number }\end{array}$ \\
\hline 225 & B1RFB & $+/-30 \mathrm{mV}$ to +/- $5 \mathrm{~V}$ dc (Analog Devices, Inc. 5B38-01) & Bessel Filter & $\mathrm{A} 1$ & $\mathrm{~B}-29$ \\
\hline 227 & B1REB & $+/-30 \mathrm{mV}$ to $+/-5 \mathrm{~V}$ dc (Analog Devices, Inc. 5B38-01) & Bessel Filter & $\mathrm{A} 1$ & B-29 \\
\hline 229 & B1TDAMP & +/- $30 \mathrm{mV}$ to +/- 5V dc (Analog Devices, Inc. 5B38-01) & Bessel Filter & A4, S5 & B-23 \\
\hline 231 & B3TDAMP & $+/-30 \mathrm{mV}$ to $+/-5 \mathrm{~V}$ dc (Analog Devices, Inc. 5B38-01) & Bessel Filter & A4, S5 & B-23 \\
\hline 233 & B3RFB & $+/-30 \mathrm{mV}$ to $+/-5 \mathrm{~V}$ dc (Analog Devices, Inc. 5B38-01) & Bessel Filter & A1 & B-29 \\
\hline 235 & B3REB & +/- $30 \mathrm{mV}$ to +/- 5V dc (Analog Devices, Inc. 5B38-01) & Bessel Filter & A1 & B-29 \\
\hline 237 & LSSXXB & $+/-30 \mathrm{mV}$ to $+/-5 \mathrm{~V}$ dc (Analog Devices, Inc. 5B38-01) & Bessel Filter & A1 & B-31 \\
\hline 239 & LSSYYB & +/- $30 \mathrm{mV}$ to +/- 5V dc (Analog Devices, Inc. 5B38-01) & Bessel Filter & $\mathrm{A} 1$ & B-31 \\
\hline 241 & LSSTQ & $+/-30 \mathrm{mV}$ to $+/-5 \mathrm{~V}$ dc (Analog Devices, Inc. 5B38-01) & Bessel Filter & A1 & B-31 \\
\hline 251 & B1FLAP & & & $\mathrm{M} 13, \mathrm{~S} 6$ & $\mathrm{~B}-43$ \\
\hline 253 & B1PITCH & & & M9, S3 & B-40 \\
\hline 255 & B3FLAP & & & $\mathrm{M} 13, \mathrm{~S} 6$ & B-43 \\
\hline 257 & B3PITCH & & & M9, S3 & B-40 \\
\hline 259,261 & $\begin{array}{l}\text { VBL176 } \\
\text { VBL178 }\end{array}$ & & & M11 & B-52 \\
\hline 300 & LMWS24M & Wind speed processor (Met One Instruments, 21.11) & Butterworth Filter & M1, E1 & B-2 \\
\hline 302 & LMWS17M & Wind speed processor (Met One Instruments, 21.11) & Butterworth Filter & M1, E1 & B-2 \\
\hline 304 & LMWS10M & Wind speed processor (Met One Instruments, 21.11) & Butterworth Filter & M1, E1 & B-2 \\
\hline 306 & LMWS2M & Wind speed processor (Met One Instruments, 21.11) & Butterworth Filter & M1, E1 & B-2 \\
\hline 308 & NLMWS17M & Wind speed processor (Met One Instruments, 21.11) & Butterworth Filter & M1, E1 & B-2 \\
\hline 310 & NLMWD17M & Wind direction processor (Met One Inst., 21.21) & Butterworth Filter & $\mathrm{M} 2, \mathrm{~S} 1, \mathrm{E} 1$ & B-5 \\
\hline 312 & NLMWE17M & Wind direction processor (Met One Inst., 21.21) & Butterworth Filter & M3, S2, E1 & B-5 \\
\hline 314 & SLMWS17M & Wind speed processor (Met One Instruments, 21.11) & Butterworth Filter & M1, E1 & B-2 \\
\hline 316 & SLMWD17M & Wind direction processor (Met One Inst., 21.21) & Butterworth Filter & $M 2, S 1, E 1$ & B-5 \\
\hline 318 & SLMWE17M & Wind direction processor (Met One Inst., 21.21) & Butterworth Filter & $\mathrm{M} 3, \mathrm{~S} 2, \mathrm{E} 1$ & B-5 \\
\hline 320 & LMT2M & $\begin{array}{l}\text { Temperature processor } \\
\text { (Met One Instruments, 21.32A4) }\end{array}$ & Butterworth Filter & M5, E1 & B-14 \\
\hline 322 & LMDT & $\begin{array}{l}\text { Delta temperature processor } \\
\text { (Teledyne ModS22 rev. E and Met One Inst., 21.32) }\end{array}$ & Butterworth Filter & M5, E1 & B-14 \\
\hline 324 & LMDP2M & Dewpoint temperature processor (Met One Inst., 21.43D2) & Butterworth Filter & M5, E1 & B-15 \\
\hline 326 & LMSU17M & RS232C to +/- 5 Vdc (Applied Technologies, Inc., SA-4) & Butterworth Filter & M4, E1 & B-11 \\
\hline 328 & LMSV17M & RS232C to +/- 5 Vdc (Applied Technologies, Inc., SA-4) & Butterworth Filter & M4, E1 & B-11 \\
\hline 330 & LMSW17M & RS232C to +/- 5 Vdc (Applied Technologies, Inc., SA-4) & Butterworth Filter & M4, E1 & B-11 \\
\hline
\end{tabular}


Table 25. Phase V Instrumentation Summary (continued)

\begin{tabular}{|c|c|c|c|c|c|}
\hline Channel & ID Code & Signal Conditioning & $\begin{array}{l}\text { Analog Anti- } \\
\text { Alias Filters }\end{array}$ & $\begin{array}{c}\text { Calibration } \\
\text { Methods }\end{array}$ & $\begin{array}{l}\text { Page } \\
\text { Number }\end{array}$ \\
\hline 332 & GENPOW & $+/-5 \mathrm{Vdc}$ to $+/-5 \mathrm{Vdc}$ (Analog Devices, Inc. 5B41-02) & Butterworth Filter & $\mathrm{M7,E1}$ & $\mathrm{B}-38$ \\
\hline 334 & BARO & +/- 5 Vdc to +/- 5 Vdc (Analog Devices, Inc. 5B41-02) & Butterworth Filter & M6, E1 & B-19 \\
\hline 336 & NAACYW & $+/-1 \mathrm{Vdc}$ to $+/-5 \mathrm{~V} d \mathrm{dc}$ (Analog Devices, Inc. 5B41-01) & Bessel Filter & M8, E1 & B-35 \\
\hline 338 & NAACFA & +/- $1 \mathrm{Vdc}$ to $+/-5 \mathrm{Vdc}$ (Analog Devices, Inc. 5B41-01) & Bessel Filter & M8, E1 & B-35 \\
\hline 340 & NAACPI & $+/-1 \mathrm{Vdc}$ to $+/-5 \mathrm{Vdc}$ (Analog Devices, Inc. 5B41-01) & Bessel Filter & M8, E1 & B-35 \\
\hline 342 & NAYM & $+/-30 \mathrm{mV}$ to $+/-5 \mathrm{~V}$ dc (Analog Devices, Inc. 5B38-01) & Butterworth Filter & A1 & B-34 \\
\hline 349 & B3AZI & & & M9, S3 & B- 40 \\
\hline 351 & YAW & & & M9, S3 & B-40 \\
\hline 353 & DAY & & & M12 & B-54 \\
\hline 355 & HOUR & & & & \\
\hline 357 & MINUTE & & & & \\
\hline 359 & SECOND & & & & \\
\hline 361 & MILLISEC & & & & \\
\hline
\end{tabular}


Appendix D

Data Index 
Table 26. Phase V Data Index

\begin{tabular}{|c|c|c|c|c|c|c|c|c|c|c|c|c|c|}
\hline Campaign & $\begin{array}{c}\text { Mean } \\
\text { Blade 3 } \\
\text { Pitch } \\
\text { (deg) }\end{array}$ & $\begin{array}{c}\text { Mean } \\
\text { H.H. } \\
\text { Wind } \\
\text { Speed } \\
(\mathrm{m} / \mathrm{s})\end{array}$ & $\begin{array}{c}\text { Mean } \\
\text { Sonic } \\
\text { Wind } \\
\text { Speed } \\
(\mathbf{m} / \mathbf{s})\end{array}$ & $\begin{array}{c}\text { Mean } \\
\text { North } \\
\text { Wind } \\
\text { Direction } \\
\text { (deg) }\end{array}$ & $\begin{array}{c}\text { Mean } \\
\text { South } \\
\text { Wind } \\
\text { Direction } \\
\text { (deg) }\end{array}$ & $\begin{array}{l}\text { Mean Sonic } \\
\text { Wind } \\
\text { Direction } \\
\text { (deg) }\end{array}$ & $\begin{array}{c}\text { Mean } \\
\text { Richardson } \\
\text { Number }\end{array}$ & $\begin{array}{c}\text { Mean } \\
\text { Yaw } \\
\text { Error } \\
\text { Angle } \\
\text { (deg) }\end{array}$ & $\begin{array}{c}\text { Blade 1 } \\
\text { Max. Teeter } \\
\text { Damper } \\
\text { Force (N) }\end{array}$ & $\begin{array}{c}\text { Blade } 3 \\
\text { Max. } \\
\text { Teeter } \\
\text { Damper } \\
\text { Force (N) }\end{array}$ & Comments & Problems & $\begin{array}{c}\text { Calibration } \\
\text { History }\end{array}$ \\
\hline $\mathrm{d} 503003$ & 2.981 & 8.710 & 8.588 & 288.815 & 289.214 & 288.559 & -0.038 & -5.622 & -135.216 & 229.844 & 2 & $\bar{A}$ & $\overline{\mathrm{I}, \mathrm{II}}$ \\
\hline $\mathrm{d} 503004$ & 2.990 & 9.774 & 9.470 & 294.941 & 294.595 & 294.592 & -0.105 & -4.765 & -136.440 & 218.164 & 2,6 & $\mathrm{~A}$ & III \\
\hline d503005 & 2.968 & 8.911 & 8.662 & 301.331 & 301.872 & 301.558 & -0.054 & -2.734 & -141.410 & 210.080 & 2 & $\mathrm{~A}, \mathrm{~B}$ & III \\
\hline d503006 & 2.939 & 7.520 & 7.279 & 289.100 & 288.737 & 288.183 & -0.019 & -1.620 & -136.150 & 220.797 & 2 & $\mathrm{~A}, \mathrm{~B}$ & III \\
\hline d503007 & 2.938 & 7.614 & 7.474 & 279.590 & 279.485 & 278.808 & -0.046 & -4.454 & -133.691 & 221.166 & 2 & $\mathrm{~A}, \mathrm{~B}$ & III \\
\hline $\mathrm{d} 503008$ & 2.994 & 8.900 & 8.649 & 297.217 & 297.235 & 297.222 & 0.020 & -1.172 & -125.992 & 246.943 & 2,6 & A & III \\
\hline d503009 & 2.990 & 8.485 & 8.249 & 282.456 & 282.562 & 281.809 & 0.036 & -4.346 & -120.282 & 260.656 & 2 & $\mathrm{~A}$ & III \\
\hline $\mathrm{d} 503010$ & 2.970 & 8.652 & 8.541 & 268.562 & 268.983 & 267.511 & 0.031 & -3.363 & -111.972 & 274.470 & $2,6,7$ & $\mathrm{~A}$ & III \\
\hline d503011 & 2.989 & 11.194 & 11.089 & 271.291 & 271.600 & 270.526 & 0.021 & -1.701 & -107.773 & 279.094 & 2 & $\mathrm{~A}$ & III \\
\hline d503012 & 2.989 & 10.129 & 9.999 & 268.977 & 269.077 & 267.825 & 0.021 & -0.620 & -101.611 & 289.912 & 2 & $\mathrm{~A}$ & III \\
\hline d503013 & 2.989 & 10.876 & 10.765 & 268.390 & 268.915 & 267.524 & 0.022 & -2.279 & -100.647 & 297.176 & 2 & A & III \\
\hline d503014 & 2.989 & 10.188 & 10.081 & 266.673 & 266.842 & 265.468 & 0.024 & -1.977 & -98.061 & 300.670 & 2 & $\mathrm{~A}$ & III \\
\hline $\mathrm{d} 5 \mathrm{~m} 3001$ & -2.990 & 9.440 & 9.322 & 270.667 & 271.088 & 270.052 & 0.026 & -2.966 & -95.528 & 303.064 & 1,7 & A & III \\
\hline $\mathrm{d} 5 \mathrm{~m} 3002$ & -2.996 & 6.882 & 6.637 & 286.037 & 286.698 & 285.359 & 0.050 & -2.704 & -96.571 & 301.070 & 1,8 & $\mathrm{~A}$ & III \\
\hline $\mathrm{d} 5 \mathrm{~m} 3003$ & -3.007 & 5.508 & 5.285 & 301.741 & 301.670 & 301.174 & 0.058 & 2.715 & -95.417 & 303.157 & 1,8 & $\mathrm{~A}$ & III \\
\hline $\mathrm{d} 5 \mathrm{~m} 3004$ & -2.990 & 5.805 & 5.884 & 213.140 & 212.767 & 211.856 & 0.098 & 15.480 & -97.361 & 300.290 & 1 & $\mathrm{~A}$ & III \\
\hline $\mathrm{d} 503017$ & 2.988 & 7.084 & 6.846 & 280.508 & 281.334 & 279.749 & -0.019 & 3.888 & -88.431 & 335.929 & 2,8 & $\bar{A}, \mathrm{C}$ & II,IV,V \\
\hline d503018 & 2.974 & 6.235 & 5.975 & 287.377 & 287.638 & 286.775 & -0.011 & -3.336 & -85.492 & 334.983 & 2,6 & $\mathrm{~A}$ & III \\
\hline $\mathrm{d} 5 \mathrm{~m} 9001$ & -8.970 & 7.425 & 7.197 & 314.683 & 314.712 & 314.503 & -0.136 & -6.811 & -99.809 & 294.716 & 4 & $\mathrm{~A}$ & III \\
\hline $\mathrm{d} 5 \mathrm{~m} 9002$ & -8.971 & 6.265 & 5.999 & 290.000 & 290.471 & 289.389 & -0.208 & 0.293 & -102.659 & 281.952 & 4 & A & III \\
\hline $\mathrm{d} 503019$ & 2.987 & 4.668 & 4.424 & 272.597 & 278.222 & 275.391 & -0.471 & 20.514 & -110.163 & 271.450 & 2 & $\mathrm{~A}$ & III \\
\hline $\mathrm{d} 503020$ & 2.988 & 6.229 & 5.798 & 290.908 & 289.446 & 289.731 & -0.348 & 1.330 & -115.622 & 262.140 & 2 & $\mathrm{~A}$ & III \\
\hline $\mathrm{d} 5 \mathrm{~m} 3008$ & -2.991 & 11.013 & 10.789 & 280.094 & 280.622 & 279.681 & -0.121 & -3.778 & -120.352 & 252.115 & 1,7 & $\mathrm{~A}$ & II \\
\hline d503021 & 2.989 & 8.972 & 8.748 & 278.193 & 278.392 & 276.937 & -0.171 & -1.667 & -118.904 & 251.969 & 2,7 & A & III \\
\hline d503022 & 2.988 & 10.301 & 10.143 & 276.010 & 276.532 & 275.103 & -0.178 & -4.708 & -117.600 & 251.169 & 2,7 & $\mathrm{~A}$ & III \\
\hline $\mathrm{d} 503023$ & 2.988 & 9.939 & 9.808 & 271.648 & 272.092 & 270.707 & -0.143 & -3.409 & -116.351 & 251.130 & 2,7 & $\mathrm{~A}$ & III \\
\hline d503024 & 2.988 & 10.354 & 10.223 & 271.338 & 271.829 & 270.378 & -0.148 & -2.054 & -116.609 & 249.220 & 2,7 & A & III \\
\hline $\mathrm{d} 508007$ & 7.997 & 11.277 & 11.122 & 281.431 & 281.696 & 280.638 & -0.098 & -5.412 & -117.086 & 249.470 & 2,7 & A & III \\
\hline $\mathrm{d} 508008$ & 7.997 & 9.666 & 9.423 & 276.282 & 275.932 & 275.279 & -0.118 & -6.159 & -115.134 & 252.210 & 2,7 & $\mathrm{~A}$ & III \\
\hline $\mathrm{d} 5 \mathrm{~m} 3009$ & -2.991 & 8.984 & 8.794 & 274.010 & 274.443 & 273.217 & -0.161 & -0.879 & -114.161 & 249.038 & 1,7 & $\mathrm{~A}$ & III \\
\hline $\mathrm{d} 5 \mathrm{~m} 3010$ & -2.991 & 10.590 & 10.410 & 263.098 & 263.369 & 261.703 & -0.073 & -0.535 & -114.671 & 251.687 & 1,7 & $\mathrm{~A}$ & III \\
\hline $\mathrm{d} 5 \mathrm{~m} 3011$ & -2.991 & 8.884 & 8.702 & 274.537 & 274.706 & 273.761 & -0.082 & -0.580 & -109.584 & 257.484 & 1,7 & $\mathrm{~A}$ & III \\
\hline
\end{tabular}


Table 26. Phase V Data Index (continued)

\begin{tabular}{|c|c|c|c|c|c|c|c|c|c|c|c|c|c|}
\hline Campaign & $\begin{array}{l}\text { Mean } \\
\text { Blade } 3 \\
\text { Pitch } \\
\text { (deg) }\end{array}$ & $\begin{array}{l}\text { Mean } \\
\text { H.H. } \\
\text { Wind } \\
\text { Speed } \\
(\mathrm{m} / \mathrm{s})\end{array}$ & $\begin{array}{l}\text { Mean } \\
\text { Sonic } \\
\text { Wind } \\
\text { Speed } \\
(\mathrm{m} / \mathrm{s})\end{array}$ & $\begin{array}{c}\text { Mean } \\
\text { North } \\
\text { Wind } \\
\text { Direction } \\
\text { (deg) }\end{array}$ & $\begin{array}{c}\text { Mean } \\
\text { South } \\
\text { Wind } \\
\text { Direction } \\
\text { (deg) }\end{array}$ & $\begin{array}{l}\text { Mean Sonic } \\
\text { Wind } \\
\text { Direction } \\
\text { (deg) }\end{array}$ & $\begin{array}{c}\text { Mean } \\
\text { Richardson } \\
\text { Number }\end{array}$ & $\begin{array}{c}\text { Mean } \\
\text { Yaw } \\
\text { Error } \\
\text { Angle } \\
\text { (deg) }\end{array}$ & $\begin{array}{c}\text { Blade 1 } \\
\text { Max. Teeter } \\
\text { Damper } \\
\text { Force (N) }\end{array}$ & $\begin{array}{c}\text { Blade } 3 \\
\text { Max. } \\
\text { Teeter } \\
\text { Damper } \\
\text { Force (N) }\end{array}$ & Comments & Problems & $\begin{array}{c}\text { Calibration } \\
\text { History }\end{array}$ \\
\hline $\mathrm{d} 5 \mathrm{~m} 3012$ & -2.990 & 5.697 & 5.412 & 279.884 & 280.649 & 279.255 & -0.231 & -1.406 & -109.313 & 255.183 & 1,7 & $\bar{A}$ & III \\
\hline $\mathrm{d} 503025$ & 2.987 & 9.178 & 8.903 & 294.935 & 295.248 & 294.696 & -0.148 & -3.423 & -112.238 & 242.138 & 2,7 & $\mathrm{~A}$ & III \\
\hline d503026 & 2.988 & 9.417 & 9.217 & 306.118 & 305.842 & 306.035 & -0.171 & -3.873 & -113.694 & 238.363 & 2,7 & $\mathrm{~A}$ & III \\
\hline d503027 & 2.987 & 7.937 & 7.692 & 273.235 & 273.210 & 272.281 & -0.225 & -2.444 & -111.332 & 235.840 & 2,7 & $\mathrm{~A}$ & III \\
\hline d503028 & 2.989 & 16.563 & 16.271 & 251.460 & 251.756 & 249.684 & -0.049 & 1.530 & -113.948 & 233.736 & 2,7 & $\mathrm{~A}$ & III \\
\hline d503029 & 2.988 & 11.018 & 10.874 & 236.607 & 236.291 & 233.901 & -0.144 & 2.671 & -119.131 & 242.174 & 2,7 & $\mathrm{~A}$ & III \\
\hline $\mathrm{d} 503030$ & 2.988 & 10.926 & 10.707 & 251.225 & 251.658 & 249.579 & -0.096 & -2.474 & -114.123 & 239.210 & 2,7 & $\mathrm{~A}$ & II \\
\hline d508009 & 7.997 & 9.453 & 9.265 & 255.188 & 255.620 & 253.699 & -0.126 & -0.345 & -118.090 & 230.318 & 3,7 & $\mathrm{~A}$ & III \\
\hline d508010 & 7.997 & 11.515 & 11.281 & 253.749 & 254.073 & 252.251 & -0.094 & 1.202 & -120.333 & 225.928 & 3,7 & $\mathrm{~A}$ & III \\
\hline d508011 & 7.996 & 10.339 & 10.165 & 259.081 & 259.295 & 257.833 & -0.085 & 1.103 & -114.942 & 232.180 & 3,7 & $\mathrm{~A}$ & III \\
\hline $\mathrm{d} 508012$ & 7.996 & 7.990 & 7.858 & 252.039 & 252.106 & 250.029 & -0.209 & 7.448 & -116.080 & 229.714 & 3,7 & A & III \\
\hline $\mathrm{d} 5 \mathrm{~m} 9003$ & -8.972 & 5.387 & 5.224 & 261.313 & 262.586 & 260.077 & -0.244 & 1.965 & -120.486 & 227.879 & 4,7 & $\mathrm{~A}$ & III \\
\hline $\mathrm{d} 5 \mathrm{~m} 9004$ & -8.971 & 6.712 & 6.532 & 251.407 & 251.826 & 249.211 & 0.011 & 3.930 & -115.370 & 237.860 & 4,7 & $\mathrm{~A}$ & III \\
\hline $\mathrm{d} 5 \mathrm{~m} 9005$ & -8.973 & 12.196 & 12.046 & 264.938 & 265.374 & 263.993 & 0.003 & 5.140 & -107.782 & 247.534 & 4,7 & $\mathrm{~A}$ & III \\
\hline $\mathrm{d} 512001$ & 11.977 & 11.112 & 10.932 & 255.516 & 255.833 & 254.001 & 0.013 & 1.629 & -105.490 & 247.983 & 5,7 & $\mathrm{~A}$ & III \\
\hline d5y3001 & 2.989 & 9.558 & 9.466 & 271.329 & 271.215 & 270.204 & -0.026 & -5.959 & -105.822 & 249.180 & $2,7,9$ & $\mathrm{~A}$ & III \\
\hline d5y3002 & 2.987 & 10.715 & 10.551 & 250.744 & 250.979 & 248.993 & 0.024 & 29.845 & -103.068 & 254.737 & $2,7,9$ & $\mathrm{~A}$ & III \\
\hline $\mathrm{d} 503031$ & 2.988 & 10.839 & 10.723 & 254.011 & 254.374 & 252.371 & 0.025 & 2.208 & -101.380 & 260.929 & 2,7 & $\mathrm{~A}$ & III \\
\hline d503032 & 2.988 & 8.789 & 8.695 & 247.098 & 247.334 & 244.847 & 0.075 & 5.326 & -101.255 & 261.418 & 2,7 & $\mathrm{~A}$ & III \\
\hline d503033 & 2.988 & 8.128 & 8.101 & 264.474 & 265.279 & 263.366 & 0.086 & 1.841 & -95.882 & 280.868 & 2 & $\mathrm{~A}$ & III \\
\hline $\mathrm{d} 5 \mathrm{~m} 9006$ & -8.970 & 6.151 & 6.045 & 268.418 & 268.853 & 267.095 & 0.202 & -1.985 & -91.374 & 282.011 & 4 & $\mathrm{~A}$ & III \\
\hline d503034 & 2.988 & 9.749 & 9.527 & 265.694 & 264.150 & 264.174 & 0.013 & 0.274 & 109.747 & 163.838 & 2 & & $\mathrm{I}, \mathrm{II}$ \\
\hline $\mathrm{d} 503035$ & 2.988 & 9.749 & 9.556 & 270.811 & 268.885 & 269.144 & 0.011 & 2.011 & 109.688 & 165.583 & 2 & & III \\
\hline d503036 & 2.987 & 9.649 & 9.476 & 251.529 & 249.816 & 249.317 & 0.011 & -0.122 & 110.417 & 162.705 & 2 & & II \\
\hline d503037 & 2.987 & 10.824 & 10.576 & 258.227 & 257.049 & 256.505 & 0.011 & -0.232 & 108.849 & 160.847 & 2 & & II \\
\hline d503038 & 2.987 & 7.605 & 7.380 & 261.976 & 260.270 & 260.152 & 0.015 & 0.296 & 112.334 & 162.266 & 2,10 & & III \\
\hline $\mathrm{d} 5 \mathrm{pb} 012$ & 79.975 & 23.935 & 25.513 & 271.152 & 269.694 & 261.507 & 0.033 & 9.950 & 20.954 & 5078.881 & 7,9 & $\mathrm{D}, \mathrm{E}$ & II \\
\hline $\mathrm{d} 5 \mathrm{pb} 013$ & 79.936 & 26.341 & 29.645 & 272.510 & 270.978 & 252.637 & 0.025 & -9.181 & 60.284 & 5527.058 & 7 & $\mathrm{D}, \mathrm{E}$ & III, VI \\
\hline $\mathrm{d} 5 \mathrm{pb} 014$ & 60.107 & 24.786 & 27.134 & 271.073 & 269.822 & 256.584 & 0.027 & 3.880 & 69.921 & 3138.336 & 7,9 & $\mathrm{D}, \mathrm{E}$ & III, VI \\
\hline $\mathrm{d} 5 \mathrm{pb} 015$ & 90.003 & 20.349 & 25.648 & 278.896 & 277.807 & 248.308 & 0.028 & -21.526 & 73.616 & 3640.677 & 7,11 & $\mathrm{D}, \mathrm{E}$ & III, VI \\
\hline $\mathrm{d} 5 \mathrm{pb} 016$ & 44.899 & 22.863 & 24.015 & 272.603 & 271.130 & 264.708 & 0.026 & -3.128 & 75.542 & 1389.778 & 7,11 & & III, VI \\
\hline $\mathrm{d} 503039$ & 2.990 & 6.444 & 6.436 & 269.445 & 267.446 & 269.658 & -0.021 & 29.757 & 36.486 & -29.134 & 2,9 & $\mathrm{~F}$ & II \\
\hline
\end{tabular}


Table 26. Phase V Data Index (concluded)

\begin{tabular}{|c|c|c|c|c|c|c|c|c|c|c|c|c|c|}
\hline Campaign & $\begin{array}{c}\text { Mean } \\
\text { Blade 3 } \\
\text { Pitch } \\
\text { (deg) }\end{array}$ & $\begin{array}{c}\text { Mean } \\
\text { H.H. } \\
\text { Wind } \\
\text { Speed } \\
(\mathbf{m} / \mathbf{s})\end{array}$ & $\begin{array}{c}\text { Mean } \\
\text { Sonic } \\
\text { Wind } \\
\text { Speed } \\
(\mathrm{m} / \mathrm{s})\end{array}$ & $\begin{array}{c}\text { Mean } \\
\text { North } \\
\text { Wind } \\
\text { Direction } \\
\text { (deg) }\end{array}$ & $\begin{array}{c}\text { Mean } \\
\text { South } \\
\text { Wind } \\
\text { Direction } \\
\text { (deg) }\end{array}$ & $\begin{array}{l}\text { Mean Sonic } \\
\text { Wind } \\
\text { Direction } \\
\text { (deg) }\end{array}$ & $\begin{array}{c}\text { Mean } \\
\text { Richardson } \\
\text { Number }\end{array}$ & $\begin{array}{c}\text { Mean } \\
\text { Yaw } \\
\text { Error } \\
\text { Angle } \\
\text { (deg) }\end{array}$ & $\begin{array}{c}\text { Blade 1 } \\
\text { Max. Teeter } \\
\text { Damper } \\
\text { Force (N) }\end{array}$ & $\begin{array}{c}\text { Blade } 3 \\
\text { Max. } \\
\text { Teeter } \\
\text { Damper } \\
\text { Force (N) }\end{array}$ & Comments & Problems & $\begin{array}{c}\text { Calibration } \\
\text { History }\end{array}$ \\
\hline d503040 & 2.989 & 6.387 & 6.419 & 273.437 & 272.014 & 274.177 & -0.046 & -1.648 & 56.931 & -16.466 & 2 & & III \\
\hline $\mathrm{d} 5 \mathrm{~m} 3013$ & -2.995 & 7.129 & 7.182 & 272.251 & 270.478 & 272.874 & -0.003 & -4.878 & 62.005 & -5.890 & 1 & & III \\
\hline $\mathrm{d} 5 \mathrm{~m} 3014$ & -2.991 & 5.329 & 5.291 & 274.135 & 272.620 & 275.113 & 0.033 & -2.846 & 66.728 & -0.178 & 1 & & III \\
\hline d5pb017 & 90.064 & 21.970 & 24.263 & 275.585 & 274.121 & 264.394 & 0.003 & 2.803 & 46.793 & 3936.622 & 7,9 & & II \\
\hline $\mathrm{d} 5 \mathrm{pb} 018$ & 90.055 & 21.290 & 22.568 & 276.711 & 275.623 & 271.149 & 0.002 & 6.509 & 79.914 & 3743.562 & & & III \\
\hline d5pb019 & 90.046 & 20.871 & 21.102 & 273.161 & 271.497 & 272.313 & 0.000 & 10.031 & 107.947 & 3610.395 & & & III \\
\hline d5pb020 & 79.992 & 19.676 & 21.024 & 278.376 & 277.298 & 273.543 & -0.003 & -6.812 & 129.270 & 3223.492 & 9 & & III \\
\hline d5pb021 & 80.001 & 19.312 & 20.438 & 280.924 & 278.818 & 276.096 & -0.006 & -0.696 & 140.547 & 2968.051 & 7 & & III \\
\hline $\mathrm{d} 5 \mathrm{pb} 022$ & 75.060 & 20.284 & 21.587 & 278.243 & 276.771 & 272.548 & -0.007 & -4.721 & 148.815 & 2999.910 & 7 & G & III \\
\hline
\end{tabular}

Suite of problems:
A. Low-speed shaft $Y-Y$ bending not in operation
B. Pitch system failure (stuck at 3 degrees)
C. Cup Anemometer $17 \mathrm{~m}$ on north tower replaced.
D. Blowing snow caused sonic glitches
E. P2330.5L may have been blocked
F. $95 \%$ span transducer may not have gone into cal.
G. North anemometer possibly broken

Suite of comments:
1. $-3^{\circ}$ pitch
2. $3^{\circ}$ pitch
3. $8^{\circ}$ pitch
4. $-9^{\circ}$ pitch
5. $12^{\circ}$ pitch
6. Pitch angle switched from manual to automatic during run
7. No video
8. Manual pitch mode throughout
9. Yaw locked
10. Turned upwind during run
11. Yaw brake slipped

Calibration history:

I. Full system calibration (all non-pressure channels)

II. Pressure channel pre-calibration performed

III. Pre-cal. obtained from post-cal. of previous campaign

IV. Meteorological channels signal conditioners calibration verified

$V$. Teeter damper contact angle re-confirmed.

VI. Transducer at $47 \%$ span reading 1 count when should be zero. This was fixed prior to post-processing

Night Video

Collected during fall 1998 
Appendix E

Additional Figures 


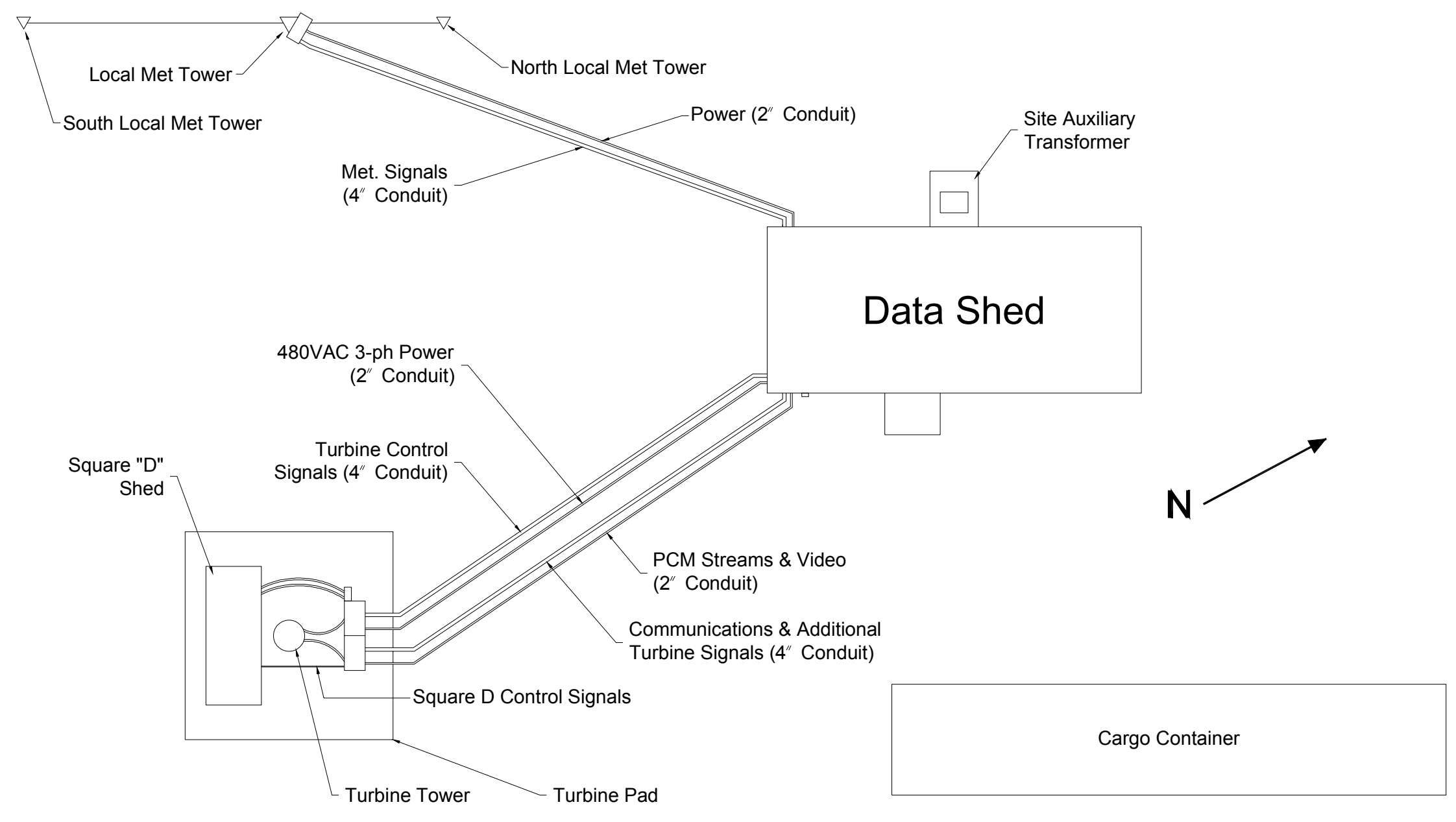

Figure 54. Aerial view of site layout 


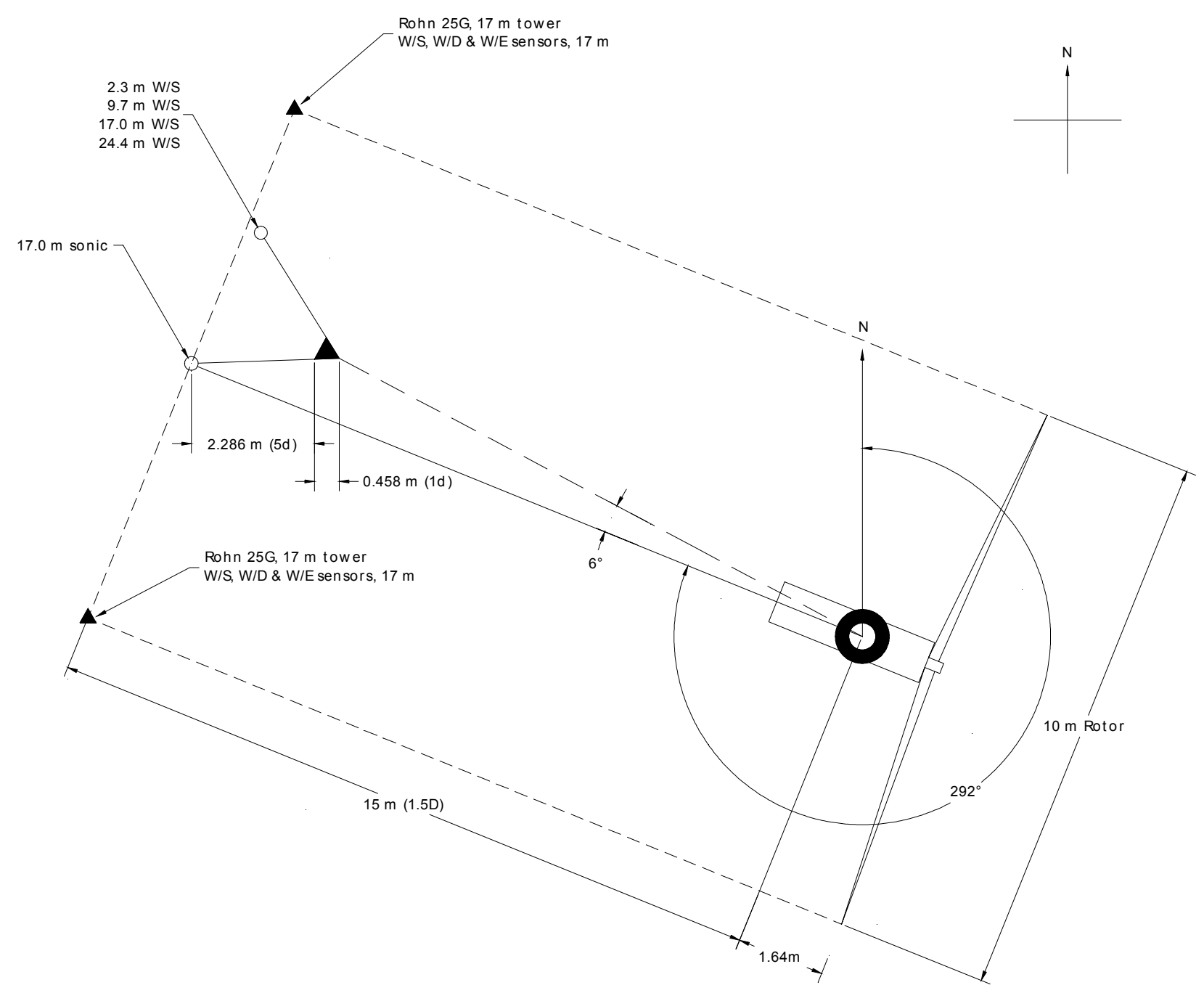

Figure 55. Plan view of site showing location of meteorological instruments relative to turbine 


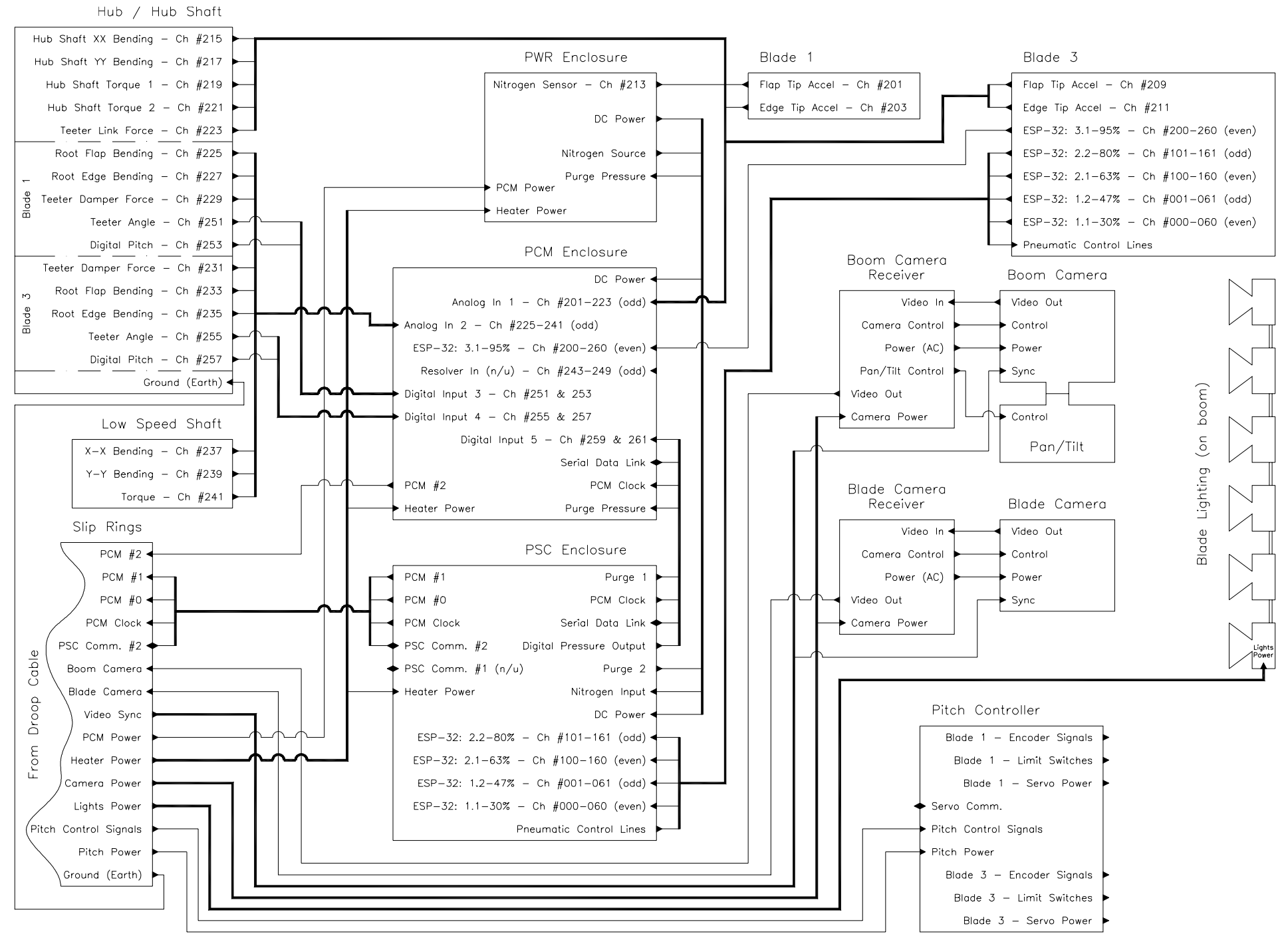

Figure 56. Rotor instrumentation block diagram 


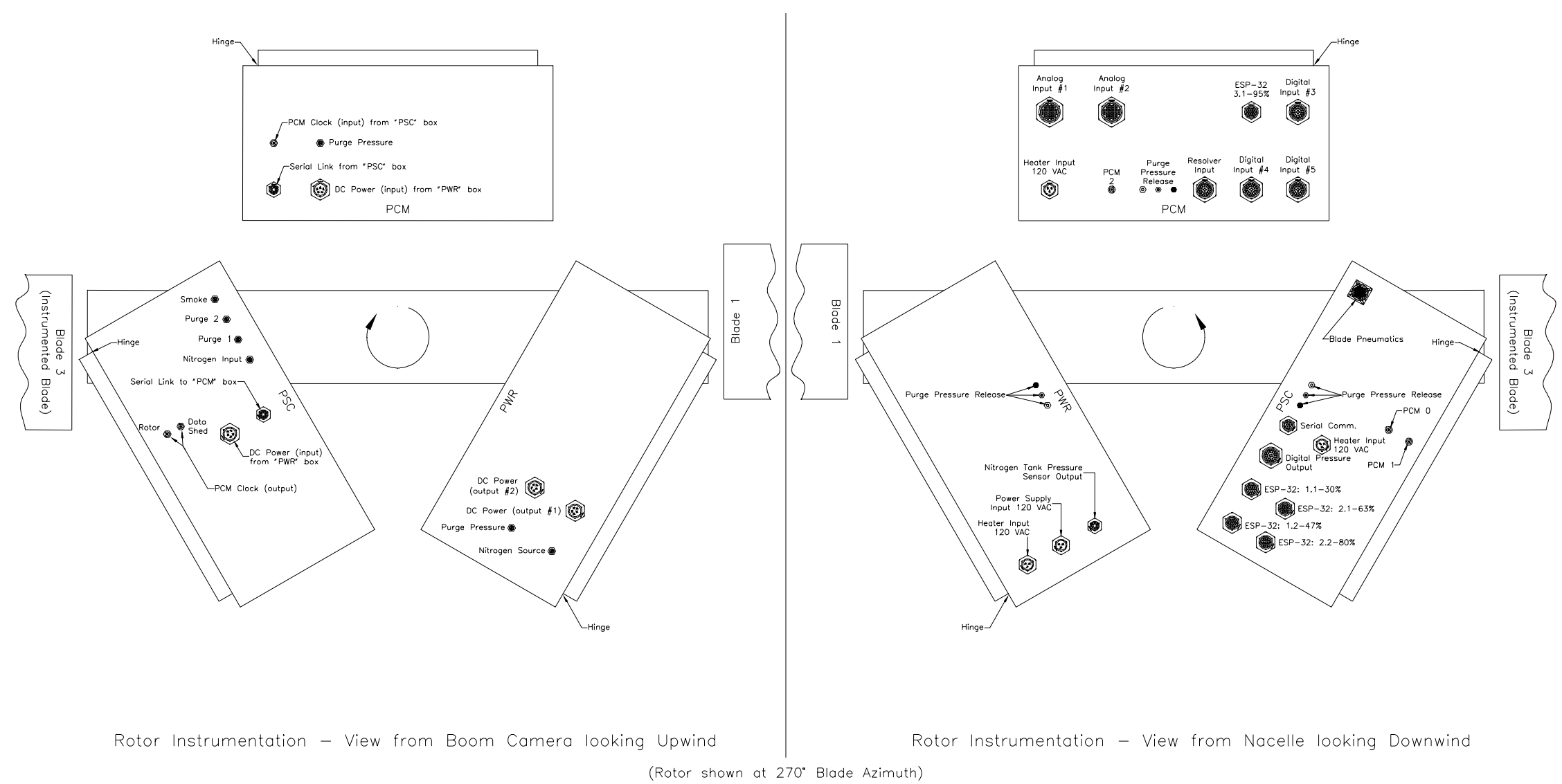

Figure 57. Rotor instrumentation enclosure and connector layout 


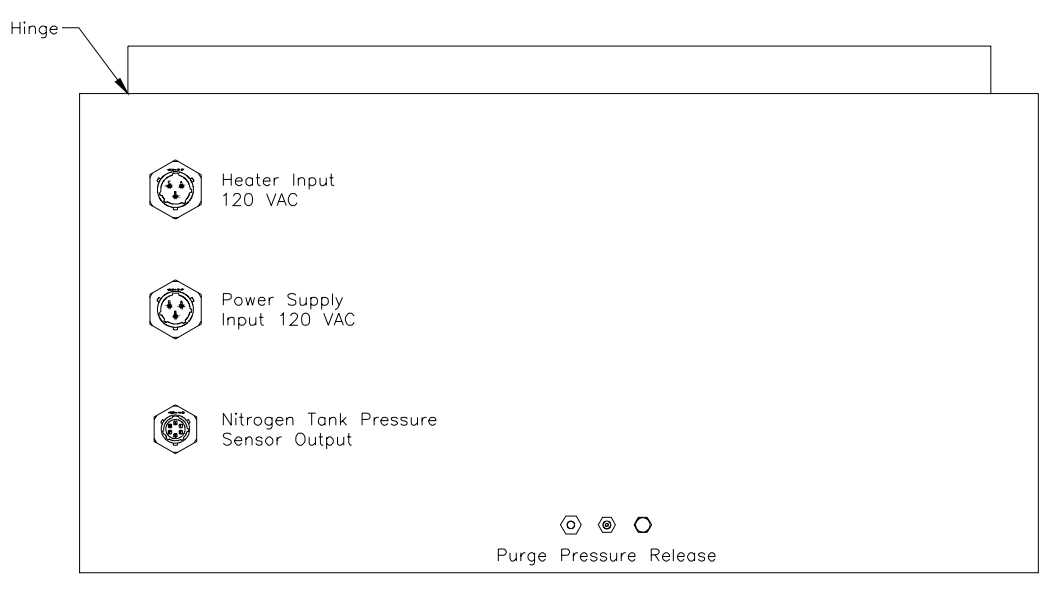

PWR Enclosure - View from Nacelle looking Downwind

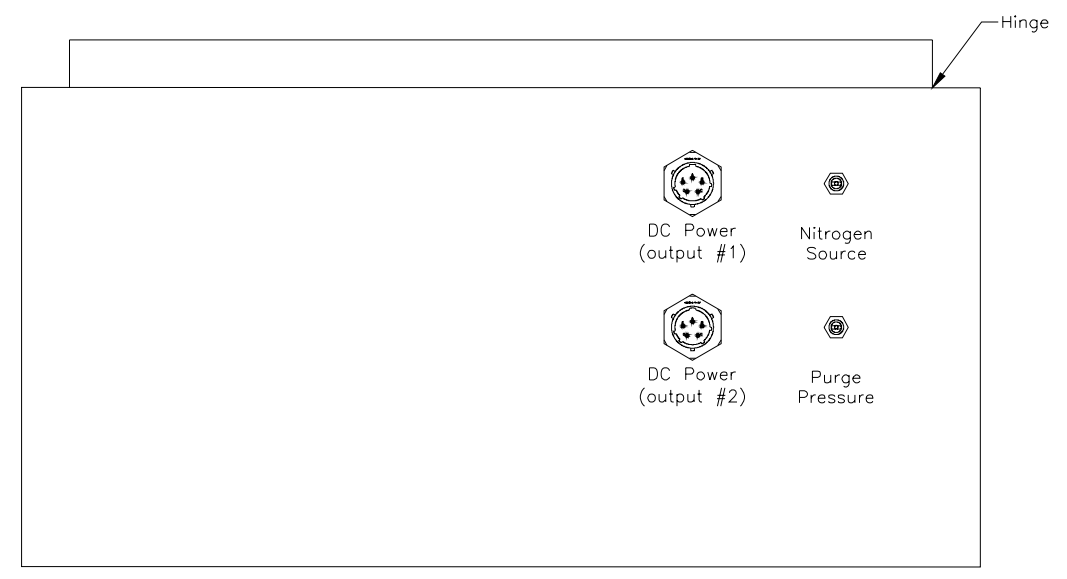

PWR Enclosure - View from Boom Comero looking Upwind

Figure 58. Rotor-based PWR enclosure (side view) 


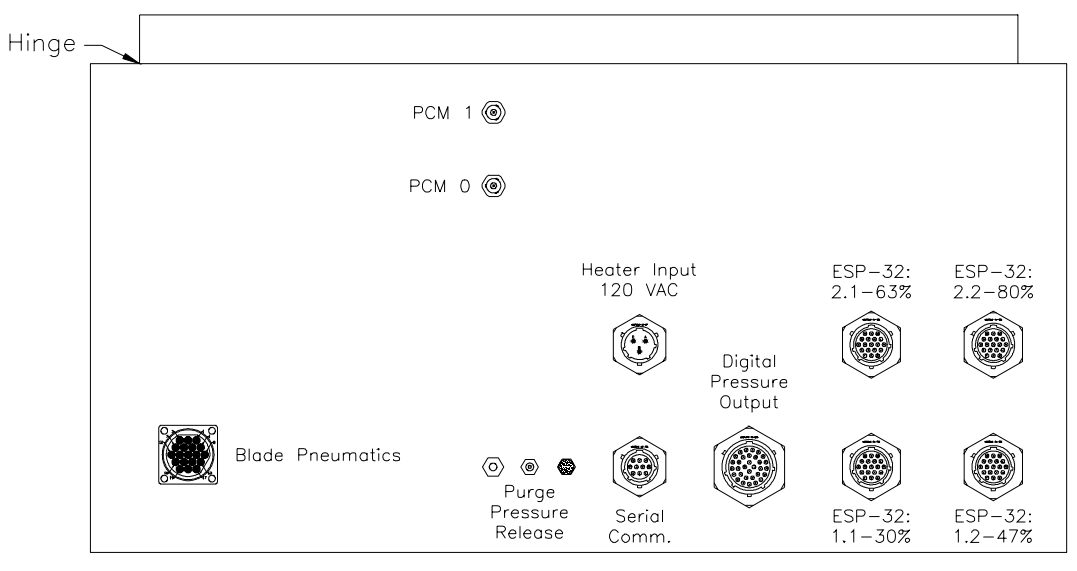

PSC Enclosure - View from Nacelle looking Downwind

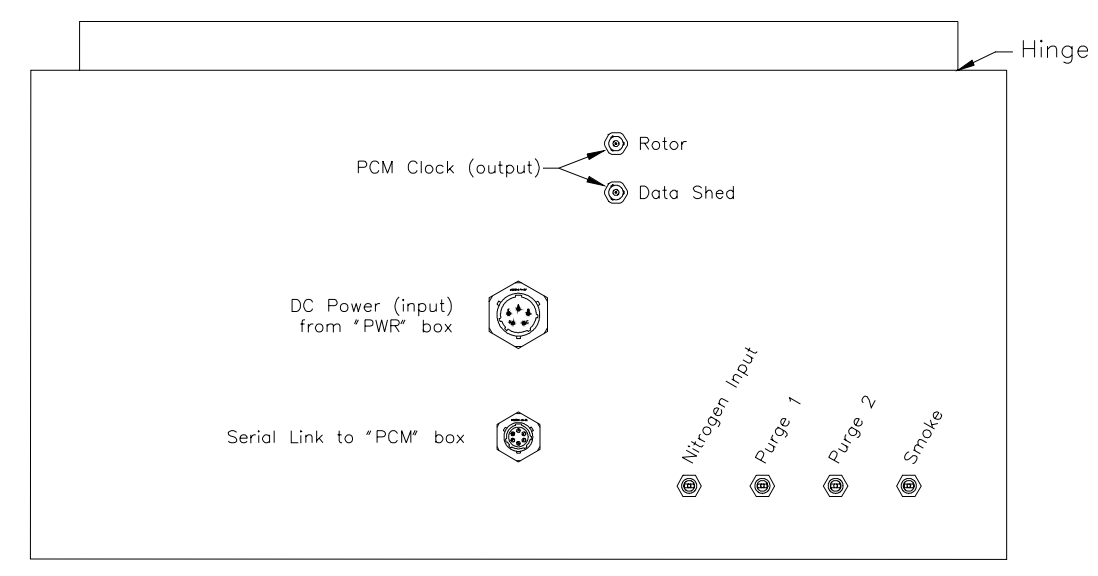

PSC Enclosure - View from Boom Comera looking Upwind

Figure 59. Rotor-based PSC enclosure (side view) 


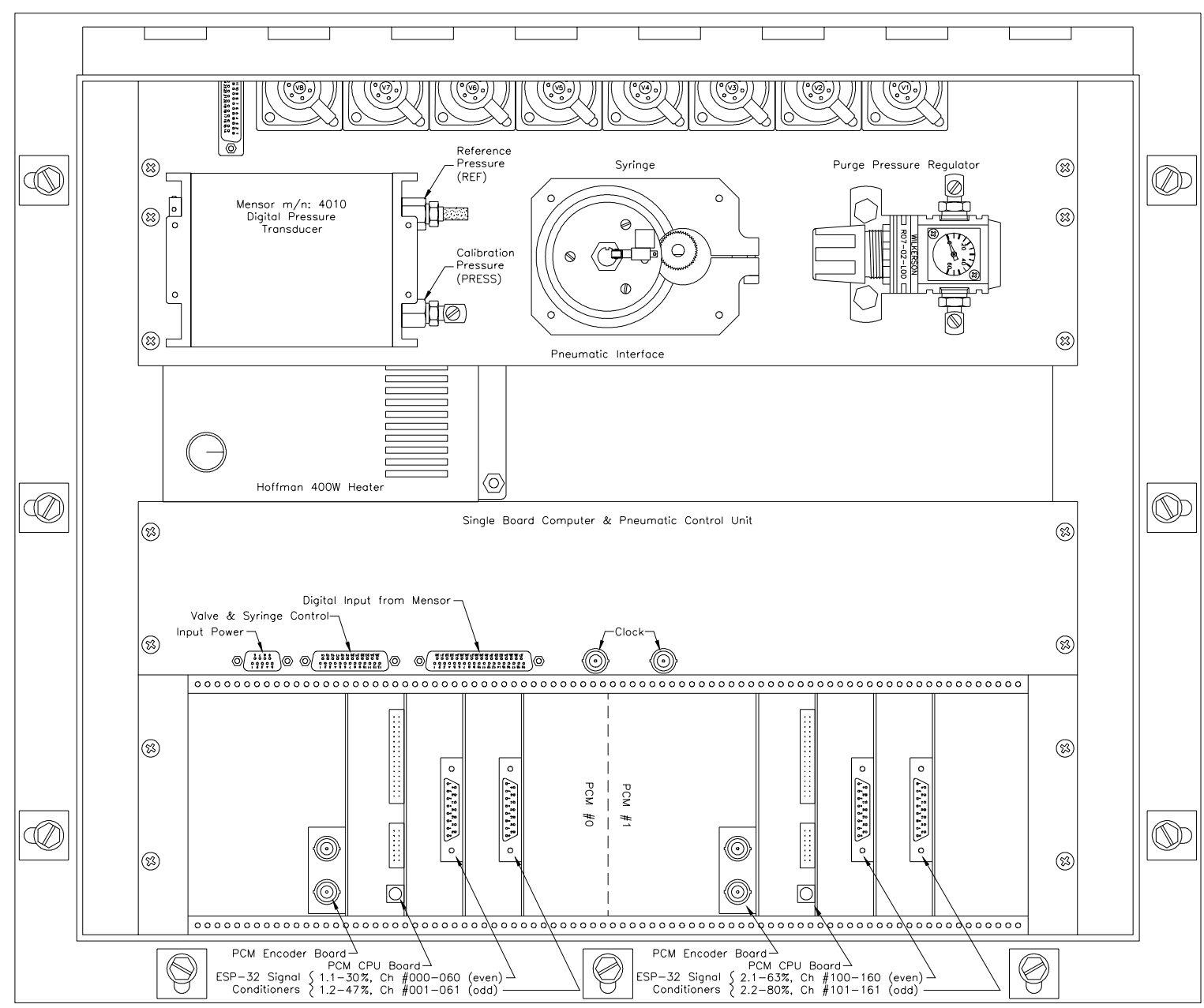

Figure 60. Rotor-based PSC enclosure (top view) 


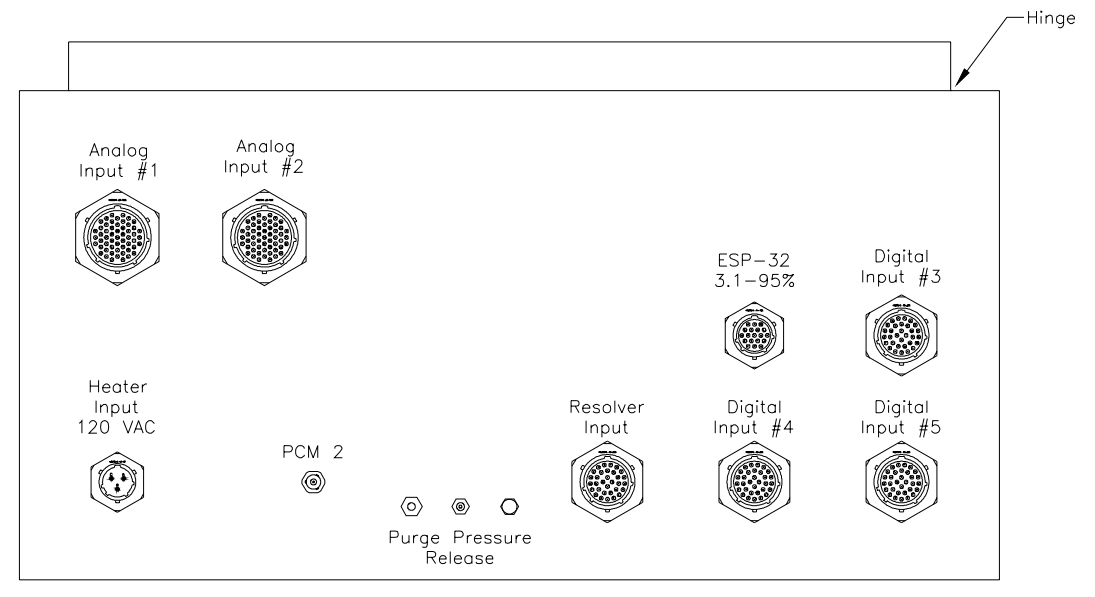

PCM Enclosure - View from Nacele looking Downwind

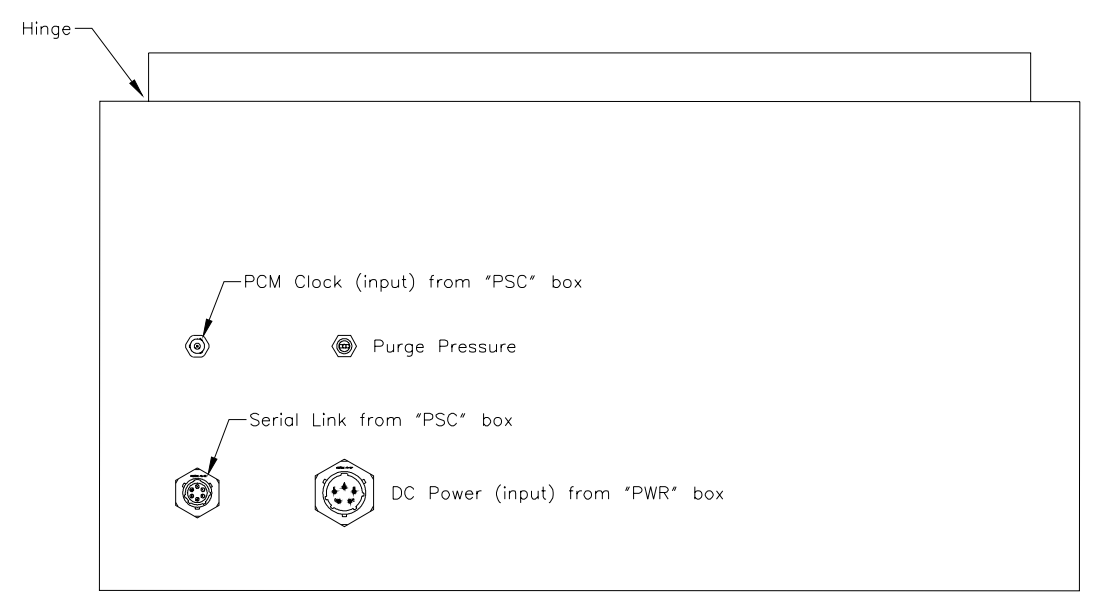

PCM Enclosure - View from Boom Comera looking Upwind

Figure 61. Rotor-based PCM enclosure (side view) 


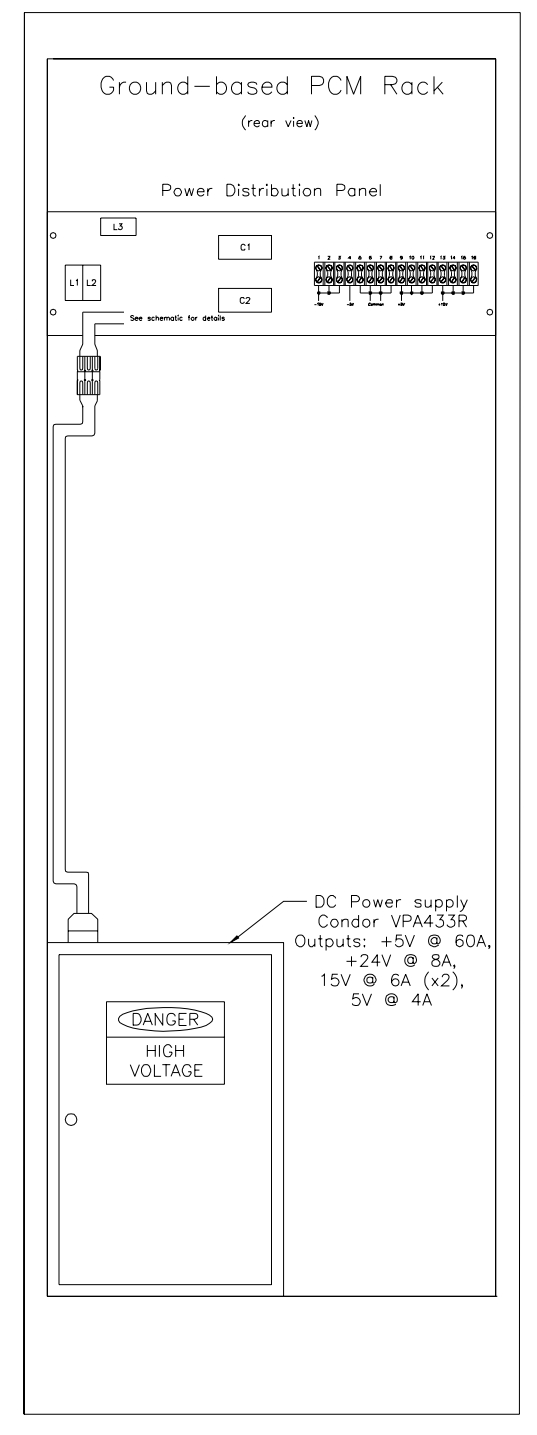

Power Distribution Panel

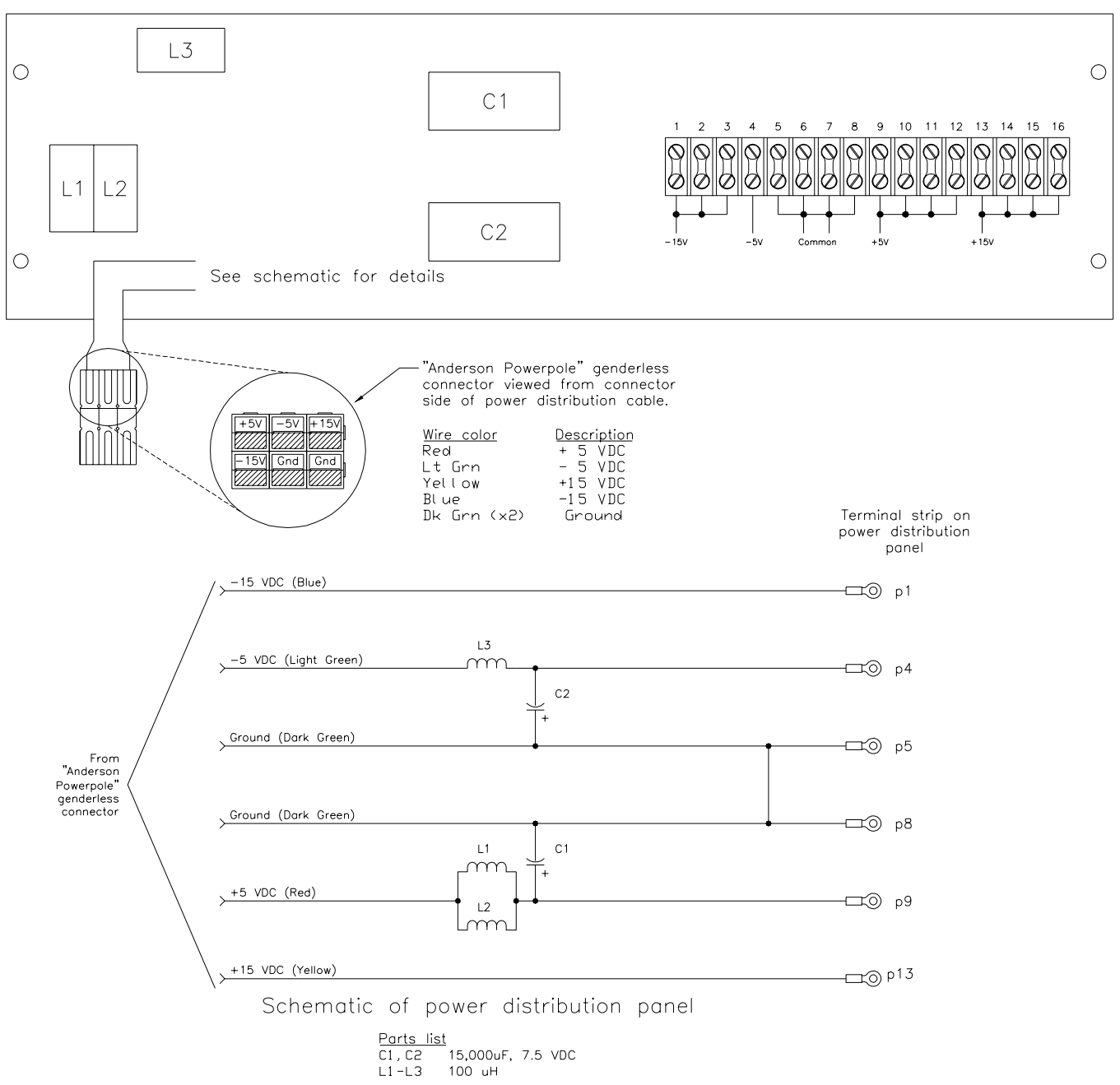

Figure 62. Ground-based PCM rack power 


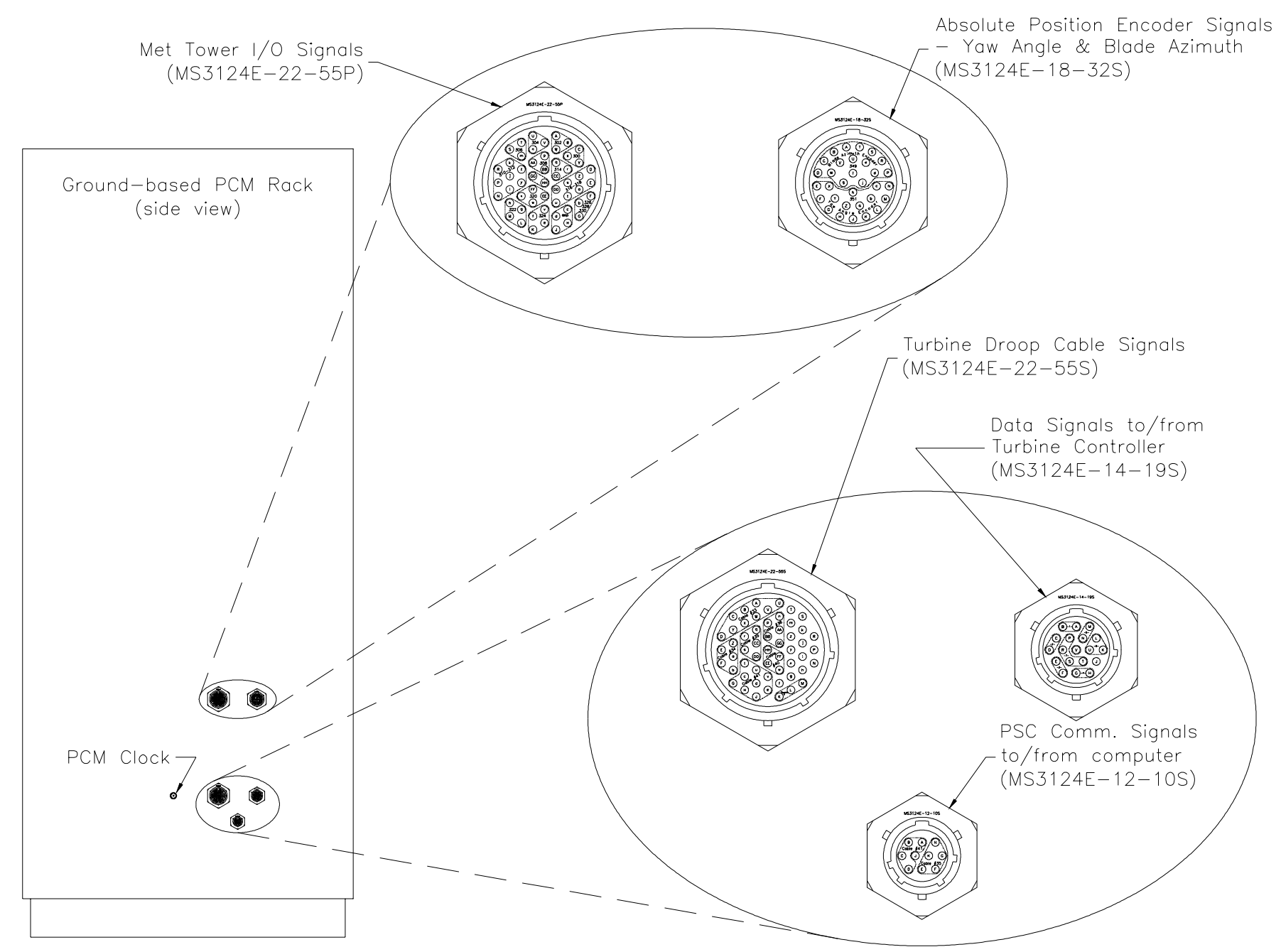

Figure 63. Ground-based PCM rack I/O 


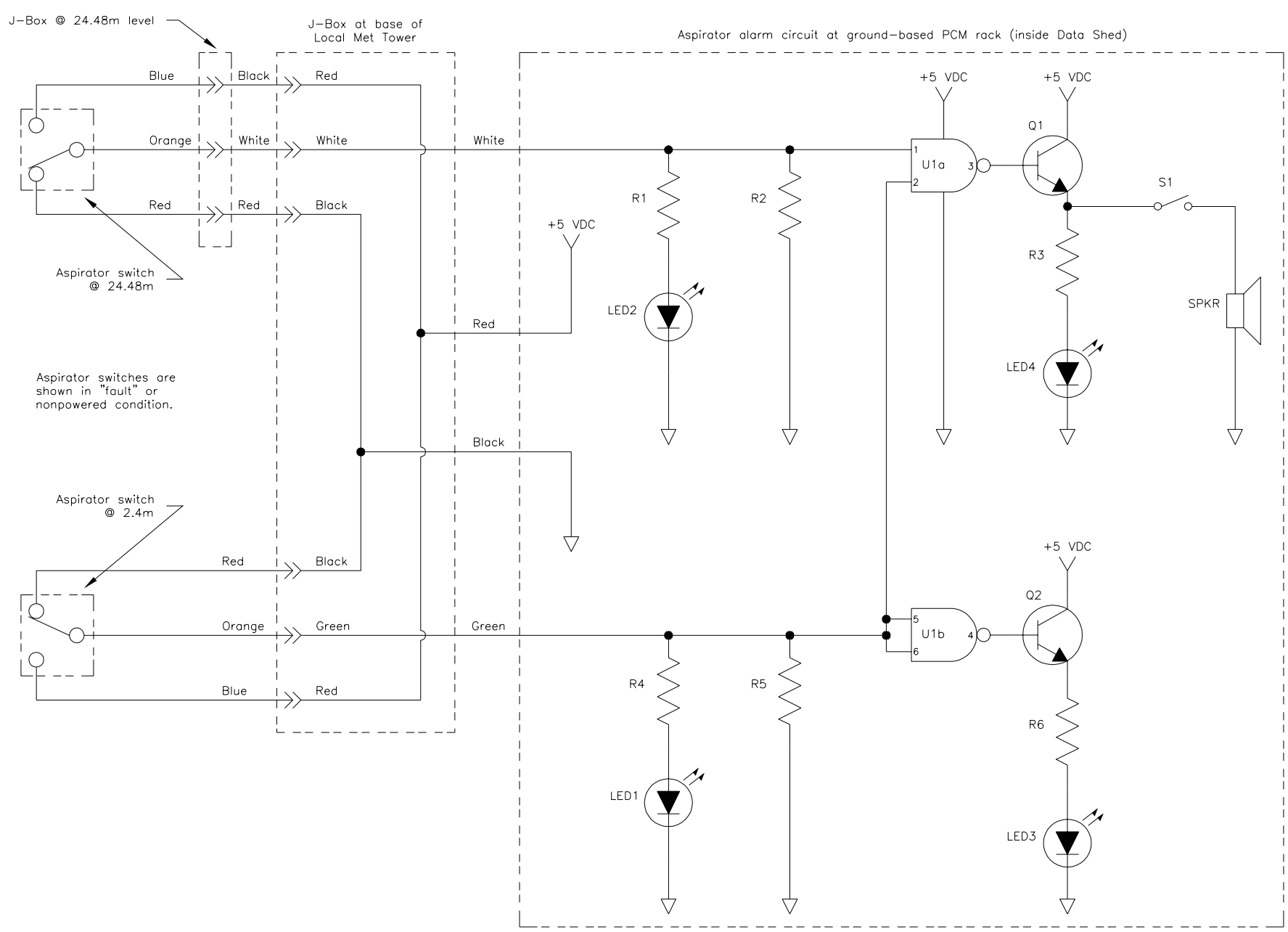

Figure 64. Aspirator alarm panel schematic 


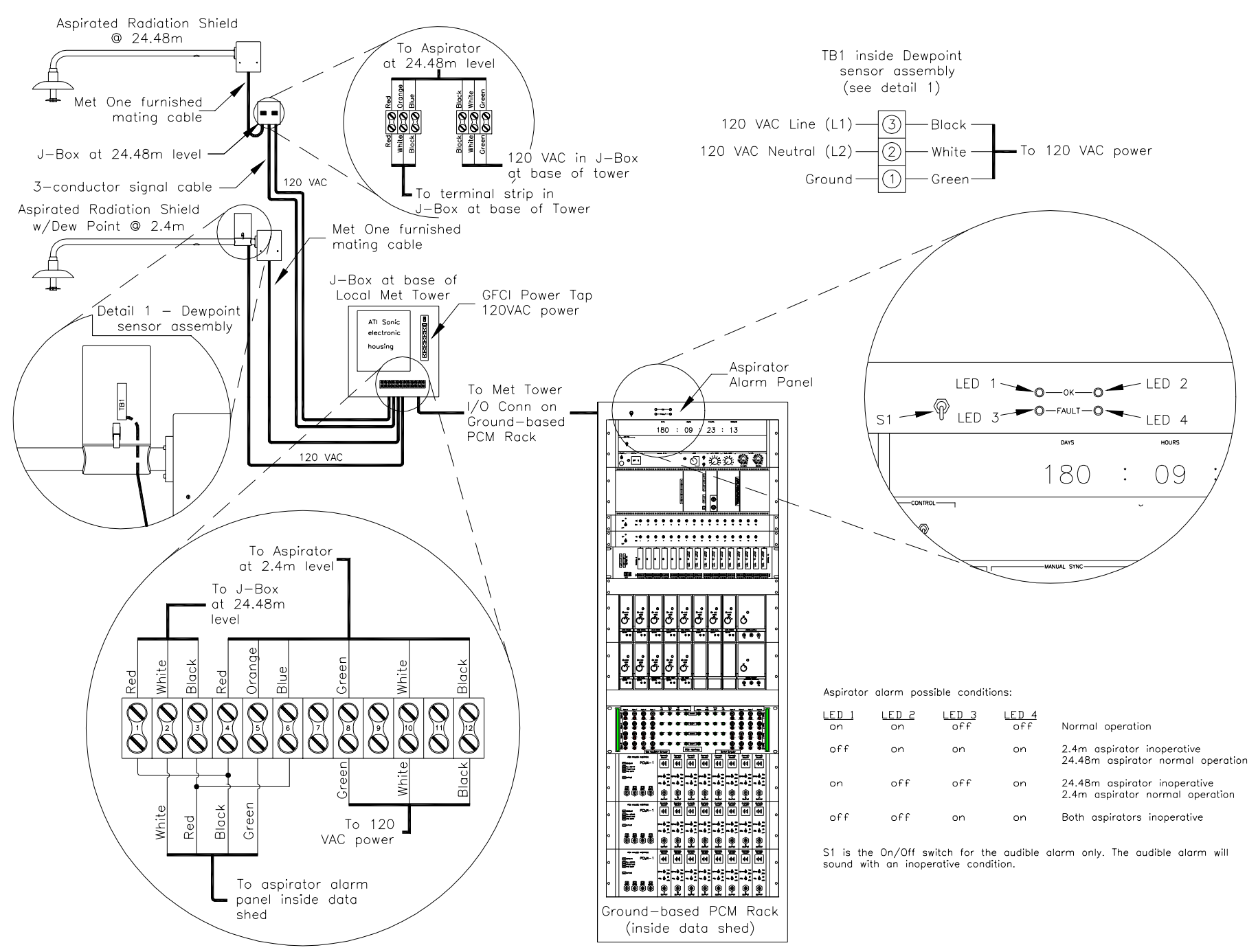

Figure 65. Aspirator alarm panel wiring 


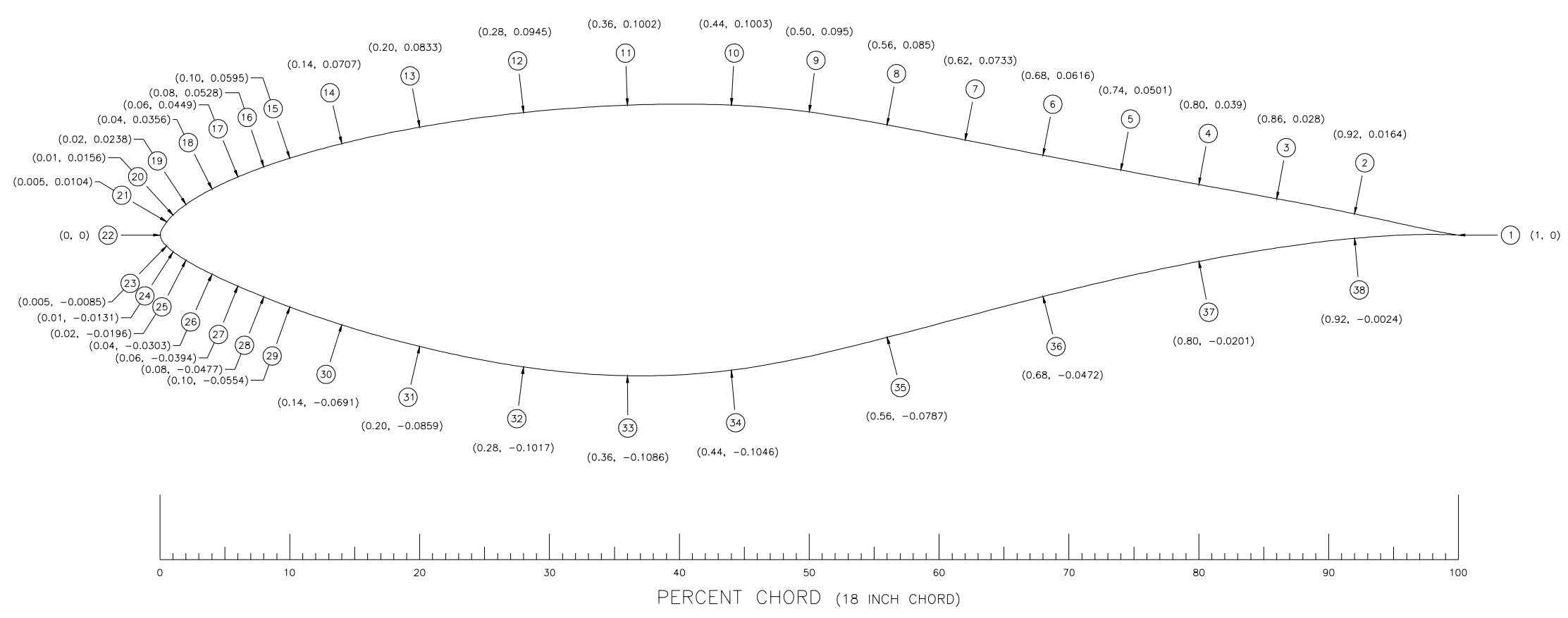

Figure 66. Pressure tap layout 


\section{References}

Butterfield, C.P.; Musial, W.P.; Simms, D.A. (1992). Combined Experiment Phase I Final Report. NREL/TP-257-4655. Golden, CO: National Renewable Energy Laboratory.

Composite Engineering. (1994). "Final Design and Analysis Report.” Unpublished.

Corten, G.P. (1998). "The April 95 Procedure to Measure the Pressure Coefficient Cp on a Wind Turbine in the Field. " Aerodynamics of Wind Turbines, $12^{\text {th }}$ Symposium, December 3-4, Lyngby, Denmark. Lyngby, Denmark: Technical University of Denmark for International Energy Agency.

Cotrell, J.R. (1999). The Mechanical Design, Analysis, and Testing of a Two-Bladed Wind Turbine Hub. NREL/TP-500-26645. Golden, CO: National Renewable Energy Laboratory.

Fingersh, L.J; Robinson, M.C. (1997). "Wind Tunnel Calibration of 5-hole Pressure Probes for Application to Wind Turbines." Proceedings of $16^{\text {th }}$ ASME Wind Energy Symposium, January 69, Reno, NV. New York: American Institute for Aeronautics and Astronautics.

Freeman, J.B.; Robinson, M.C. (1998). "Algorithm Using Spherical Coordinates to Calculate Dynamic Pressure from 5-Hole Pressure Probe Data.” Proceedings of 1998 ASME Wind Energy Symposium, January 12-15, Reno, NV. New York: American Institute for Aeronautics and Astronautics.

McNiff, B.; Simms, D. (1992). "Error Analysis in Wind Turbine Field Testing." Windpower '92 Proceedings, October 22-23, Seattle, Washington. Washington, D.C.: American Wind Energy Association.

Rae and Pope. (1984). Low-Speed Wind Tunnel Testing. New York: Wiley \& Sons.

Scott, G.N. (1996). "PDIS Pressure Display Program Technical Description.” Unpublished.

Shipley, D.E.; Miller, M.S.; Robinson, M.C.; Luttges, M.W.; Simms, D.A. (1995). Techniques for the Determination of Local Dynamic Pressure and Angle of Attack on a Horizontal Axis Wind Turbine. NREL/TP-442-7393. Golden, CO: National Renewable Energy Laboratory.

Simms, D.A.; Hand, M.M.; Fingersh, L.J.; Jager, D.W.; (1999). Unsteady Aerodynamics Experiment Phases II-IV Test Configurations and Available Data Campaigns. NREL/TP-50025950. Golden, CO: National Renewable Energy Laboratory.

Simms, D.A.; Robinson, M.C.; Hand, M.M.; Fingersh, L.J. (1996). "Characterization and Comparison of Baseline Aerodynamic Performance of Optimally-Twisted Versus Non-Twisted HAWT Blades." Prepared for $15^{\text {th }}$ ASME Wind Energy Symposium, January, 1996. NREL/TP442-20281. Golden, CO: National Renewable Energy Laboratory.

Simms, D.A.; Fingersh, L.J.; Butterfield, C.P. (1995). "NREL Unsteady Aerodynamics Experiment Phase III Test Objectives and Preliminary Results." Proceedings of ASME/ETCE Conference, January 29-February 1, Houston, Texas. New York: ASME.

Simms, D.A.; Butterfield, C.P. (1991). A PC-Based Telemetry System for Acquiring and Reducing Data from Multiple PCM Streams. SERI/TP-257-4123. Golden, CO: Solar Energy Research Institute (now known as National Renewable Energy Laboratory).

Smithsonian Institution. (1949). Smithsonian Meteorological Tables. Smithsonian Publication 4014. Smithsonian Institution Press: Washington, D.C. Prepared by R.J. List. 
Somers, D.M. 1997. Design and Experimental Results for the S809 Airfoil. NREL/SR-4406918. Golden, Colorado: National Renewable Energy Laboratory. 


\section{Index}

The page number of indexed figures or tables is italicized.

5-hole probe calibration, 10 dynamic pressure, 10 location, 10 upwash corrected angle of attack, 31

accelerometers

blade tip, 17, 79

nacelle, 17, 79

aerodynamic force coefficients, 12

air density

calculation of, 25

analog / digital conversion, 107

anemometer

sonic, 8

anemometers

bi-vane, 8

cup, 8

anemometers

bi-vane, 48

cup, 45

sonic, 54

barometric pressure, 8,62

blade

bending moments, 17

geometry, 6,37

materials, 6

pressure instrumentation, 12,13

structural properties, 41

twist distribution, 7,38

S809 airfoil, 5

blade pitch control control system, 5

brake

rotor, 4

yaw, $3,4,17,18,70,77$

calibration procedures

5 -hole probe, 10

for creation of calibration coefficient database, 23

for electronic path calibration, $23,46,49,52$, $55,60,62,79,82,115$

for instruments used to calibrate measured channels, 116

for load cells, 23, 64, 66

for pressure transducers, 22, 91

for strain gauges, 23,68
Calibration procedures (continued)

full path calibration, $64,66,68,72,74,77,91$, 114

using manufacturer specifications, 23, 46, 49, $51,55,59,60,62,79,82,84,85,87,98$, 100,114

using single-point offset, 23, 49, 52, 66, 85, 87,115

cone angle equation, 19

configuration differences, 3

correction

centrifugal force correction, 16, 25

factors for reference pressure offset, 34

hydrostatic variation, 16

reference pressure offset, 16, 33

upwash, 30

data processing

cycle average database, 25

engineering-unit file creation, 24, 111

header file creation, $24,112,115$

real-time viewing, 24, 111

derived channels

aerodynamic force coefficients, 27, 30

angle of attack, 30

blocked pressure taps, 27

dynamic pressure, 26

Richardson number, 32

rotational speed, 32

surface pressure coefficients, 27

wind speed and direction, 33

yaw error, 31

digital input / output, 107

drive train, 42

components, 5

efficiency, 5

generator slip, 5

rotating system inertia, 5

dyanamic characteristics

blade, 6,42

tower, 43

dynamic pressure

5-hole probe, 10, 26

from blade stagnation pressure, 26

error byte, 25

errors

5-hole probe calibration, 10

transducer range, 25

file format, 122

file naming conventions, 3 
filter, 106

flow visualization

black blade, 6

cameras, 20

lights, 21

tufts, 21

generator power, 20,82

geographic location, 4

inflow measurements, 8

air temperature, 57

barometric pressure, 8,62

bi-vane anemometer, 8,48

cup anemometers, 8,45

dew-point temperature, 58

sonic anemometer, 8, 54

temperature, 8

load cells

teeter damper, 5, 17, 66

teeter link, 5, 17, 64

meteorological towers. See inflow conditions

PCM system

encoding/decoding, 22, 108

filters, 22

quantizing errors, 22

sample rates, 21

pitch shaft

deflection, 6

description, 6,18

position encoders, 18,84

azimuth angle, 19

blade flap angle, 87, 20

blade pitch, 19

yaw angle, 19

pressure system controller, 17

pressure transducers, 90, 92, 94

calibration of, 91 digital, for calibration, 16, 98

measurement range, 15

reference pressure, 16

purging

taps, 5-hole probes, 15, 97

reference pressure

correction factors, 34

measurement of, 16, 33

Richardson number, 32

root bending moments, 17

rotational speed

calculation of, 32

signal conditioning, 102, 103, 104, 105

strain gauges

blade root, 17,72

hub shaft, 17, 68

low-speed shaft, 17, 74

yaw moment, 17, 77

surface pressure

dynamic effects, 12,15

normalization of, coefficients, 27

taps and tubing, 12, 14, 15, 91

teeter angle equation, 19

temperature

air, 8,57

dew point, 8,58

time code generator, 20, 100

tower

description and characteristics, 43

turbine

description, 4-7, 37

uncertainty, Phase II measurements, 23

upwind probe, 11

yaw error, 31

yaw moment

detecting yaw brake status, 17 
Public reporting burden for this collection of information is estimated to average 1 hour per response, including the time for reviewing instructions, searching existing data sources,

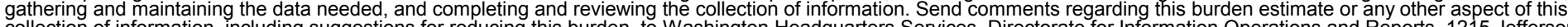
g this burden, to Washington Headquarters Services, Directorate for Information Operations and Reports, 1215 Jefferson Davis Highway, Suite 1204, Arlington, VA 22202-4302, and to the Office of Management and Budget, Paperwork Reduction Project (0704-0188), Washington, DC 20503.
1. AGENCY USE ONLY (Leave blank)
2. REPORT DATE
August 2001
3. REPORT TYPE AND DATES COVERED Technical Report

4. TITLE AND SUBTITLE

Unsteady Aerodynamics Experiment Phase V: Test Configuration and Available Data Campaigns

5. FUNDING NUMBERS

WER1.1110

\section{6. $\operatorname{AUTHOR}(\mathrm{S})$}

M.M. Hand, D.A. Simms, L.J. Fingersh, D.W. Jager, J.R. Cotrell

7. PERFORMING ORGANIZATION NAME(S) AND ADDRESS(ES)

8. PERFORMING ORGANIZATION REPORT NUMBER

9. SPONSORING/MONITORING AGENCY NAME(S) AND ADDRESS(ES) National Renewable Energy Laboratory

1617 Cole Blvd.

Golden, CO 80401-3393

10. SPONSORING/MONITORING AGENCY REPORT NUMBER

NREL/TP-500-29491

\section{SUPPLEMENTARY NOTES}

NREL Technical Monitor:

12a. DISTRIBUTION/AVAILABILITY STATEMENT

National Technical Information Service

12b. DISTRIBUTION CODE

U.S. Department of Commerce

5285 Port Royal Road

Springfield, VA 22161

13. ABSTRACT (Maximum 200 words) The main objective of the Unsteady Aerodynamics Experiment is to provide information needed to quantify the full-scale, three-dimensional, unsteady aerodynamic behavior of horizontal-axis wind turbines (HAWTs). To accomplish this, an experimental wind turbine configured to meet specific research objectives was assembled and operated at the National Renewable Energy Laboratory (NREL). The turbine was instrumented to characterize rotating-blade aerodynamic performance, machine structural responses, and atmospheric inflow conditions. Comprehensive tests were conducted with the turbine operating in an outdoor field environment under diverse conditions. Resulting data are used to validate aerodynamic and structural dynamics models, which are an important part of wind turbine design and engineering codes. Improvements in these models are needed to better characterize aerodynamic response in both the steady-state post-stall and dynamic- stall regimes._Much of the effort in the first phase of the Unsteady Aerodynamics Experiment focused on developing required data acquisition systems. Complex instrumentation and equipment was needed to meet stringent data requirements while operating under the harsh environmental conditions of a wind turbine rotor. Once the data systems were developed, subsequent phases of experiments were then conducted to collect data for use in answering specific research questions. A description of the experiment configuration used during Phase $\mathrm{V}$ of the experiment is contained in this report.

\begin{tabular}{|l|l}
15. NUMBER OF PAGES &
\end{tabular}

14. SUBJECT TERMS Wind Energy, unsteady aerodynamics experiment, wind turbine, research

16. PRICE CODE

17. SECURITY CLASSIFICATION OF REPORT

Unclassified

18. SECURITY CLASSIFICATION
OF THIS PAGE
Unclassified

18. SECURITY CLASSIFICATION Unclassified
19. SECURITY CLASSIFICATION OF ABSTRACT Unclassified
20. LIMITATION OF ABSTRACT

UL 